NIST NCSTAR 1-2A

Federal Building and Fire Safety Investigation of the World Trade Center Disaster

\title{
Reference Structural Models and Baseline Performance Analysis of the World Trade Center Towers
}

William J. Faschan

Richard B. Garlock 

Federal Building and Fire Safety Investigation of the World Trade Center Disaster

\section{Reference Structural Models and Baseline Performance Analysis of the World Trade Center Towers}

William J. Faschan

Richard B. Garlock

Leslie E. Robertson Associates, R.L.L.P.

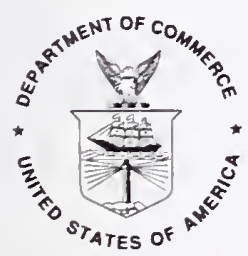

U.S. Department of Commerce

Carlos M. Gutierrez, Secretary

Technology Administration

Michelle O'Neill, Acting Under Secretary for Technology

National Institute of Standards and Technology

William Jeffrey, Director 
- Development of estimates of design gravity and wind loads on the towers for implementation into the reference structural models and use in the baseline performance analysis. Various wind load cases were considered in this study, including wind loads used in the original WTC design, wind loads based on two recent wind tunnel studies conducted in 2002 by Cermak Peterka Peterson, Inc. (CPP) and Rowan Williams Davies and Irwin, Inc. (RWDI) for insurance litigation concerning the towers, and refined wind load estimates developed by NIST from critical assessment of information obtained from the CPP and RWDI reports and state-of-the-art considerations. The following three loading cases were considered for the baseline performance analysis:

- Original WTC design loads case. Loads included dead and live loads as in original WTC design in conjunction with original WTC design wind loads.

- State-of-the-practice case. Loads included dead loads; current New York City Building Code (NYCBC 2001) live loads; and wind loads from the RWDI wind tunnel study, scaled in accordance with NYCBC 2001 wind speed.

- Refined NIST estimate case. Loads included dead loads; live loads from the current American Society of Civil Engineers Standard Minimum Design Loads for Buildings and Other Structures (ASCE 7-02); and the refined wind load estimates developed by NIST.

The global tower models were analyzed using the various gravity and wind loading cases, and the baseline performance results were obtained. The results included:

- Total and inter-story drift under wind loads

- Demand/capacity ratios for the primary structural components of the towers

- Axial forces in the exterior columns, including shear lag effects and presence of tensile forces

- Performance of splice connections at the exterior walls

- Towers' resistance to shear sliding and overturning under wind loads.

Similarly, the typical floor models were analyzed under gravity loading conditions, and the baseline performance results were obtained. The results included:

- Floor mid-span deflections

- Demand/capacity ratios for the primary structural components of the floors.

Keywords: Columns, floor system, gravity load, load, model, structural, truss, wind load, World Trade Center. 


\section{TABLE OF CONTENTS}

Abstract ..iii

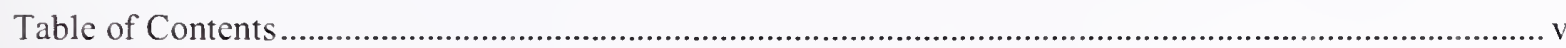

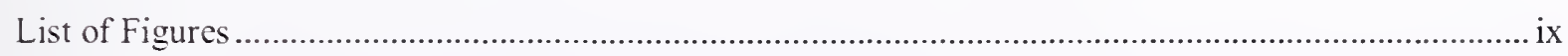

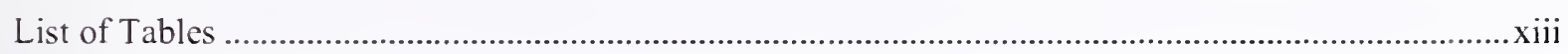

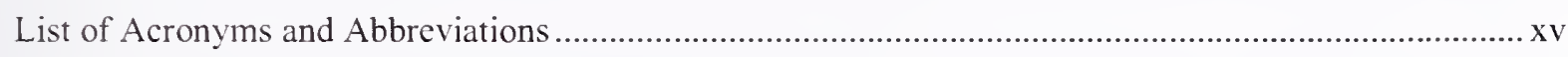

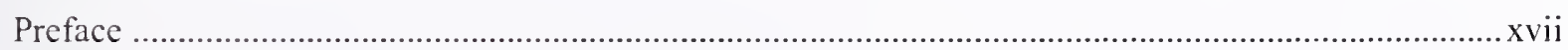

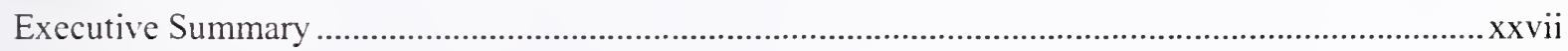

Chapter 1

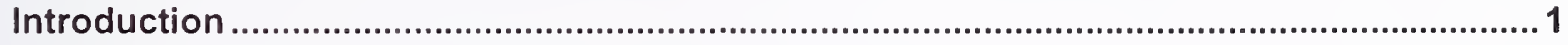

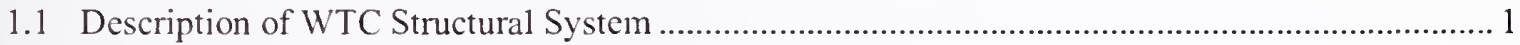

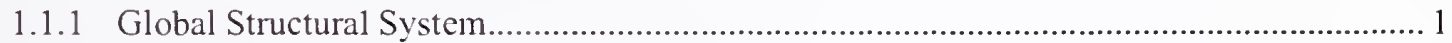

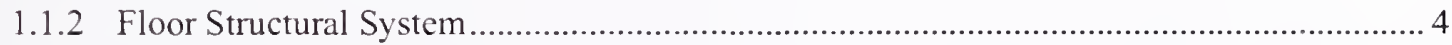

\section{Chapter 2}

Development of Structural Databases for the WTC Towers ............................................ 11

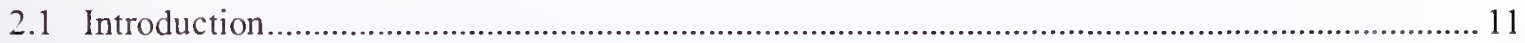

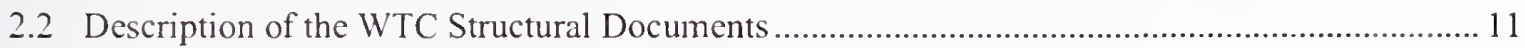

2.3 Overview of the WTC Structural Database (WTC-DB) .................................................. 13

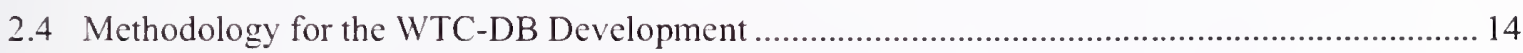

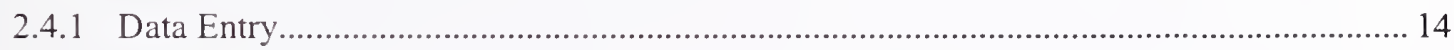

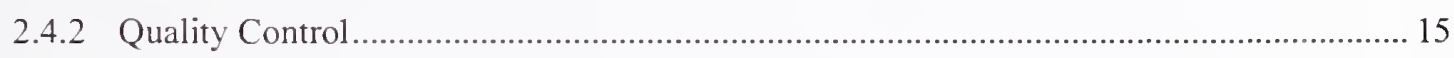

2.4.3 Cross Section Property Calculations ...................................................................... 15

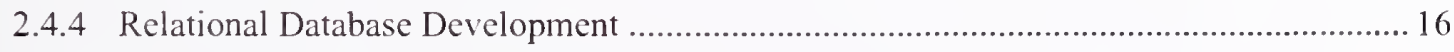

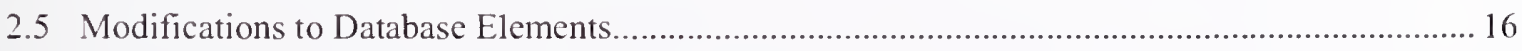

2.5.1 Core Column Reinforcing at Floors 98 to 106 .......................................................... 16

2.5.2 Core Column Reinforcing Due to Construction of Fiduciary Trust Vault ....................... 17

2.5.3 Repair Due to the Bombing of February 26, 1993 ................................................. 18

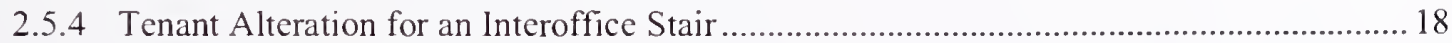

2.5.5 Drawing Book Data Discrepancies ........................................................................ 18

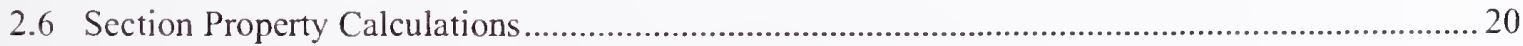

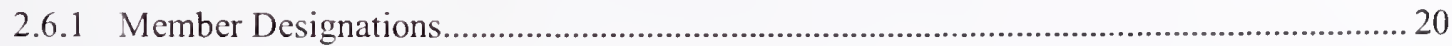

2.6.2 Column Member Multiple Section Property Calculation............................................... 21 
2.6.3 Spandrel Member Multiple Section Property Calculation ............................................. 23

2.6.4 Section Property Calculation Comparisons ............................................................. 24

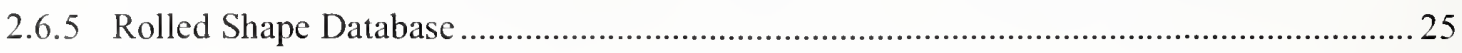

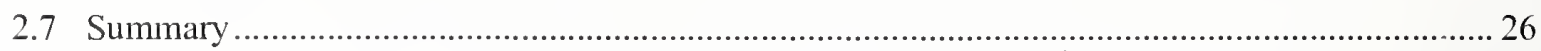

\section{Chapter 3}

Development of Reference Structural Models for the WTC Towers ................................227

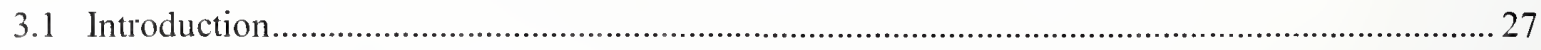

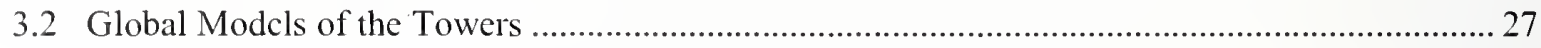

3.2.1 Components and Systems in the Towers' Global Models ............................................. 28

3.2.2 Coordinate System, Nomenclaturc, and Models Assembly Overview.............................28

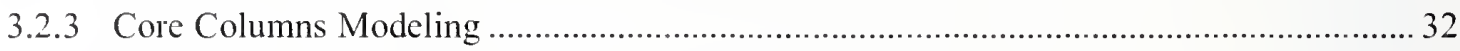

3.2.4 Exterior Wall, Foundation to Floor 4 Modeling ........................................................ 35

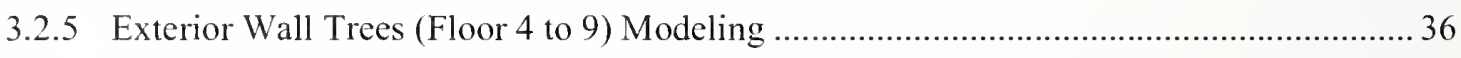

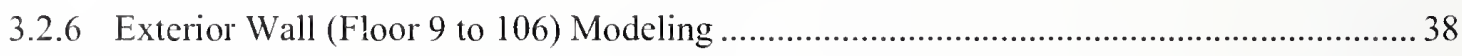

3.2.7 Exterior Wall (Floor 107 to 110 ) Modeling ................................................................. 41

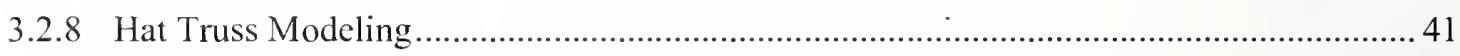

3.2.9 Flexible and Rigid Floor Diaphragm Modeling ................................................... 43

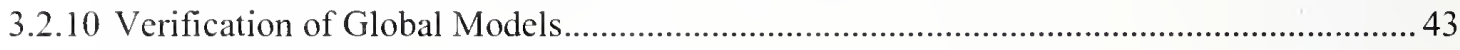

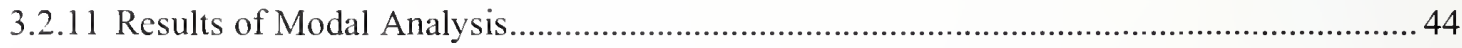

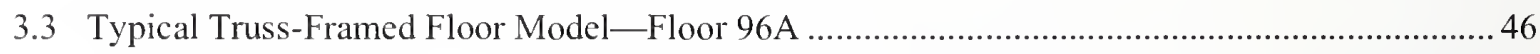

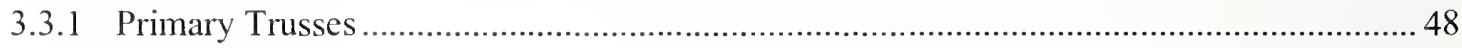

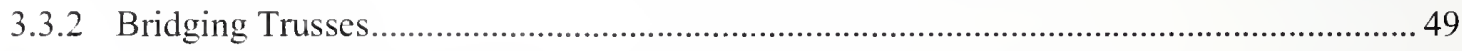

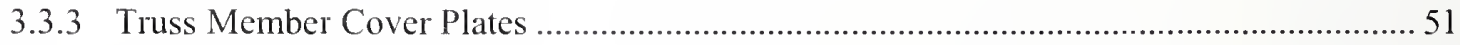

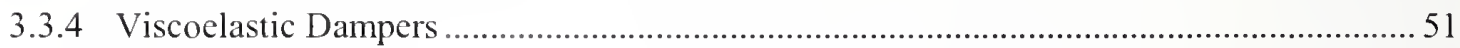

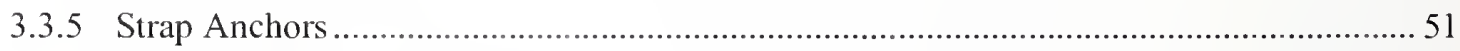

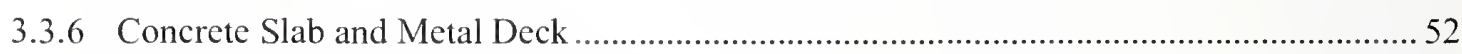

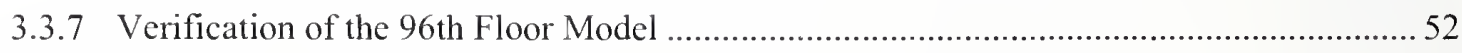

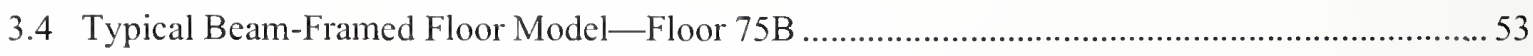

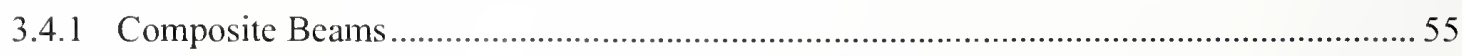

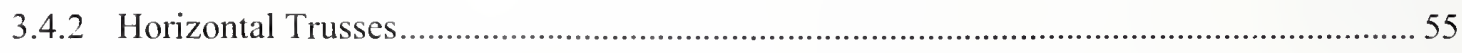

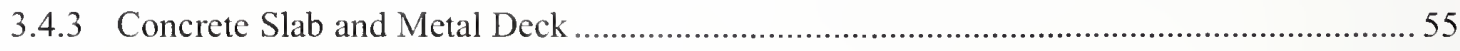

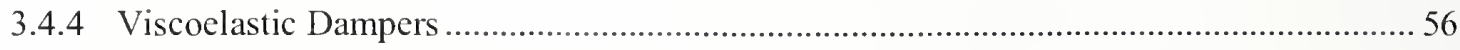

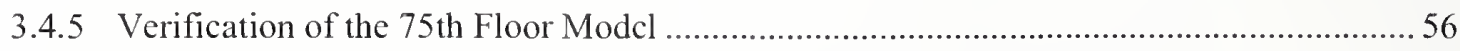

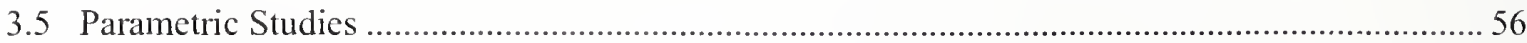


3.5.1 Exterior Wall Columns/Spandrel Typical Panels (Floors 9 to 106) ............................... 57

3.5.2 Exterior Wall Columns/Spandrel Corner Panels (Floors 9 to 106) .................................. 59

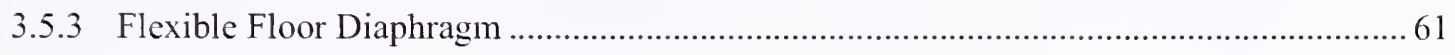

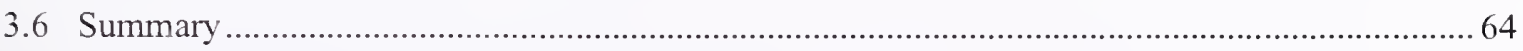

\section{Chapter 4}

Gravity and Wind Loads on the WTC Global Models ..................................................67

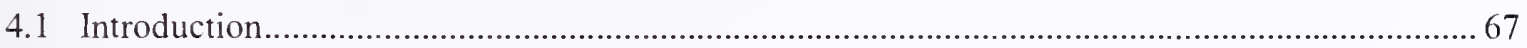

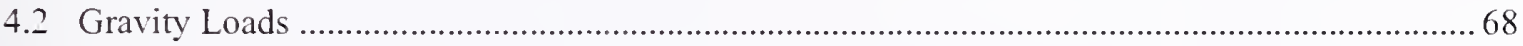

4.2.1 Gravity Loads from Areas Outside of Core ............................................................... 69

4.2.2 Gravity Loads from Areas Inside of Core …....................................................... 70

4.2.3 Construction Sequence Loading Effects ................................................................. 74

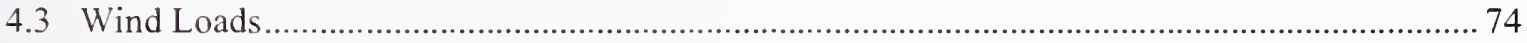

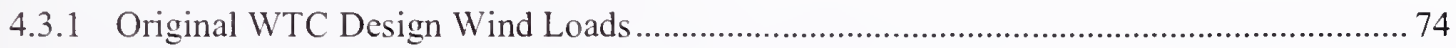

4.3.2 State-of-the-Practice Wind Loads ....................................................................... 78

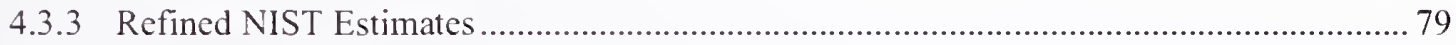

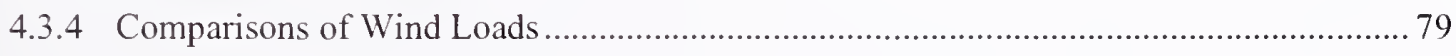

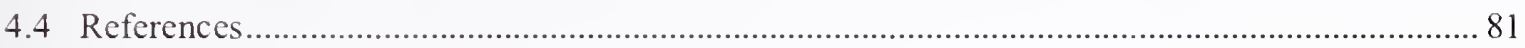

\section{Chapter 5}

Baseline Performance Analysis of the WTC Global Models ............................................83

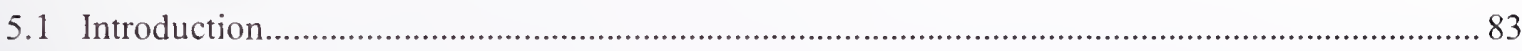

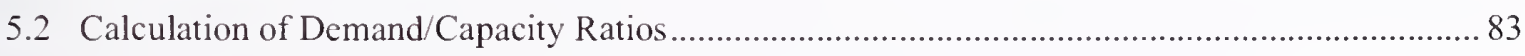

5.2.1 Selection of Global Models Design Parameters ........................................................ 85

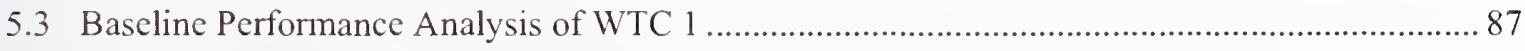

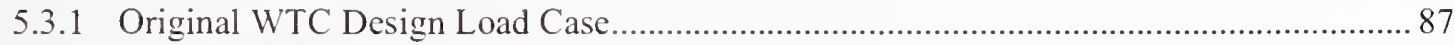

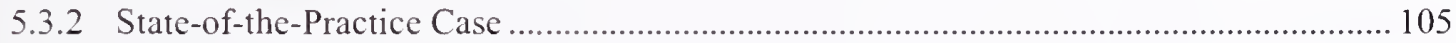

5.3.3 The Refined N1ST Estimate Case............................................................................. 107

5.4 Baseline Performance Analysis of WTC 2 ...................................................................... 109

5.4.1 Original WTC Design Load Case........................................................................... 110

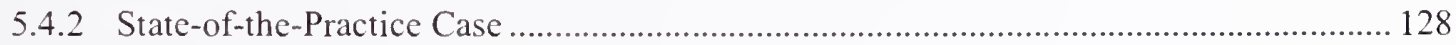

5.4.3 The Refined NIST Estimate Case ......................................................................... 130

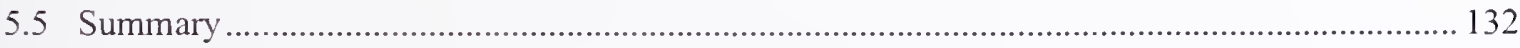

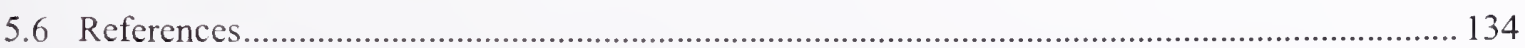




\section{Chapter 6}

Baseline Performance Analysis of Typical Floor Models 135

6.1 Introduction 135

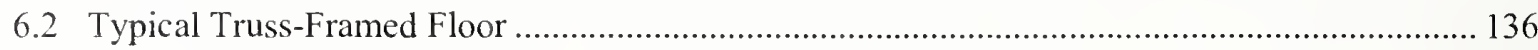

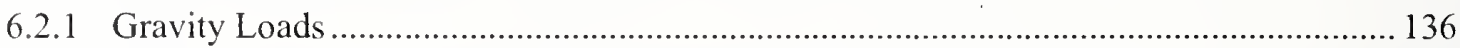

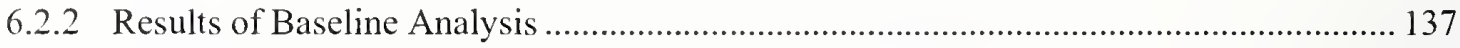

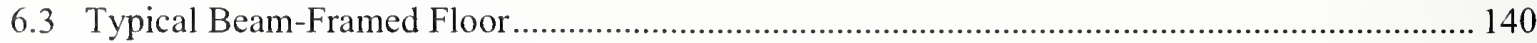

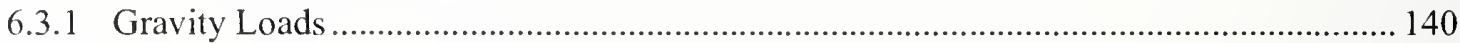

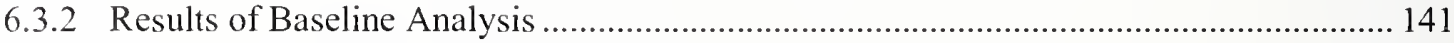

Chapter 7

Summary.

Appendix A

WTC Tower Structural Drawings Index for Large-Size Sheets

Appendix B

Drawing Book 19 Modifications for Structural Elements Not Included in the

Database

Appendix C

WTC Drawing Book Flowcharts.

Appendix D

Excel File List and Description.

Appendix $E$

Relational Database File List and Description

Appendix F

Relational Database Tutorial

Appendix G

Categorization of Floor Construction Types for Areas Outside of Core 


\section{LIST OF FIGURES}

Figure $\mathrm{P}-1$. The eight projects in the federal building and fire safety investigation of the WTC disaster. xix

Figure 1-1. Typical WTC tower architectural floor plan (floor 26, WTC 2) .................................... 2

Figure 1-2. Typical WTC exterior wall, foundation to floor 9 . ....................................................... 3

Figure 1-3. Typical WTC tower hat truss elevation (Drawing SA 401) ......................................... 4

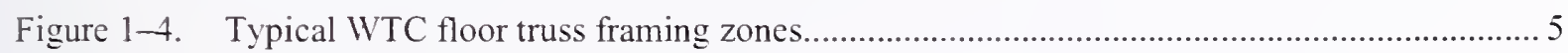

Figure 1-5. Part plan of floor 96 of WTC 1 (Drawing SA-104), components of typical truss framing system. 6

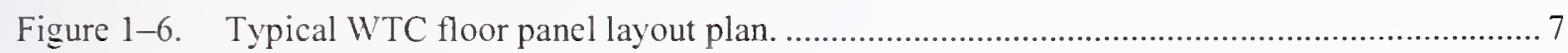

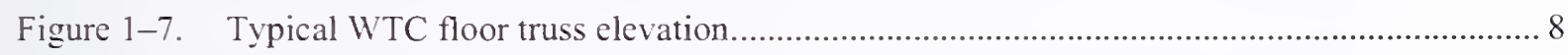

Figure 1-8. Part section typical truss floor panel. ..................................................................... 8

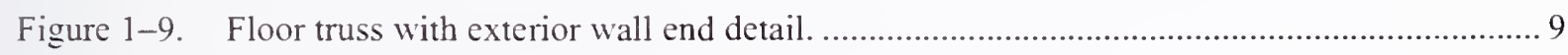

Figure 1-10. Details of the damping unit used in the truss-framed floors. ........................................ 9

Figure 1-11. Damping unit used in the beam-framed floors .................................................... 10

Figure 2-1. Drawing Book 3 flowchart: WTC 1 and WTC 2 core columns, foundation to floor

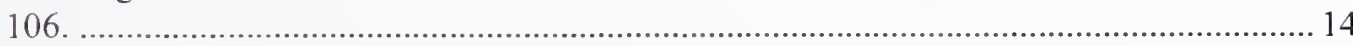

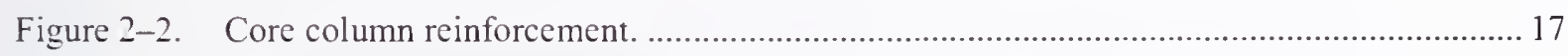

Figure 2-3. Column section at original column strap detail (taken from drawing book 18, page 18-AB2-12).

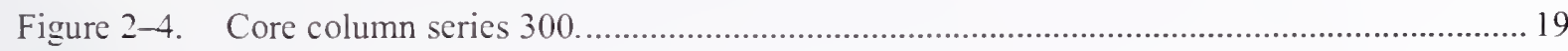

Figure 2-5. Exterior column type 300, floor 9 to floor 106 (taken from drawing book 4, page 4-AB2-18).

Figure 2-6. Column type 6000 with tapered spandrel (taken from drawing book 1, pages $1-\mathrm{A} 2-27$ and 28).

Figure 2-7. Box section and a built-up column.

Figure 3-1. Global model coordinate axis location...............................................................29

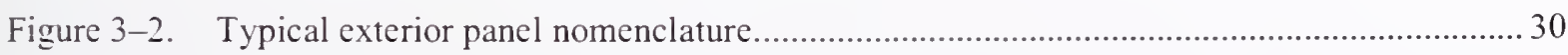

Figure $3-3$. Rendered isometric views of the WTC 1 model ..................................................... 33

Figure 3-4. Frame view of the WTC 2 model: exterior wall elevation and interior section illustrating the core columns, core bracing, and hat truss................................................. 34

Figure 3-5. Frame view and rendered view of the WTC 1 model (foundation to floor 9)................... 36 
Figure 3-6. Exterior wall tree panel (taken from Drawing Book 2, page 2-AB2-2)..........................37

Figure 3-7. Exterior wall tree: as-built cross sections for level E (taken from Drawing Book 2,

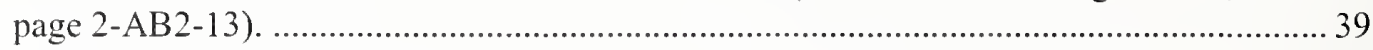

Figure 3-8. Frame view and rendered view of an exterior wall tree.............................................. 39

Figure 3-9. Typical WTC tower exterior wall panel............................................................. 40

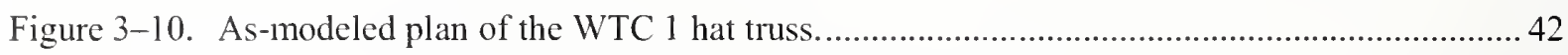

Figure 3-11. Rendered 3-D model of the WTC 1 hat truss (prior to assembly in the unified global

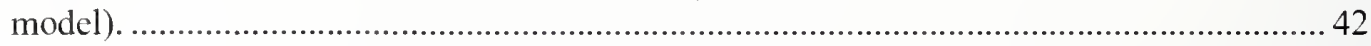

Figure 3-12. Mode shapes of WTC 1 (cxaggerated): (a) first mode shape (E-W), (b) second mode shape (N-S), (c) Third mode shape (torsion). ........................................................ 45

Figure 3-13. Typical truss-framed floor panels arrangement. …...................................................... 47

Figure 3-14. Typical truss-framed floor model (floor 96A), slab not shown. .................................... 48

Figure 3-15. Typical primary truss cross-section, as-built and as-modeled transformed truss work points.

Figure 3-16. Typical bridging truss cross-section, as-built and as-modeled transformed truss work

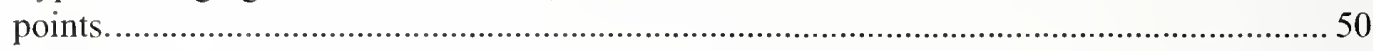

Figure 3-17. Connection between bottom chords of primary and bridging trusses............................. 51

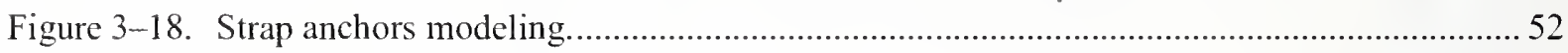

Figure 3-19. Typical beam-framed floor arrangement. .................................................................5

Figure 3-20. Typical beam-framed floor model (floor 75B). ...................................................... 54

Figure 3-21. Horizontal truss modeling, slab not shown................................................................55

Figure 3-22. Shell element and frame models of typical exterior wall panel..................................... 57

Figure 3-23. Selection of column and spandrel rigidity of typical exterior wall panel. ........................55

Figure 3-24. Shell element and frame models of typical exterior wall corner panel............................ 60

Figure 3-25. Selection of column and spandrel rigidity of typical exterior wall corner panel. ...............60

Figure 3-26. Detailed and simplified model of the exterior wall corner panel................................... 61

Figure 3-27. Deflection of typical beam-framed floor model due to lateral loading........................... 63

Figure 3-28. Deflection of equivalent floor model due to lateral loading. ........................................63

Figure 3-29. Deflections of the north and south faces of the floor for the detailed and equivalent

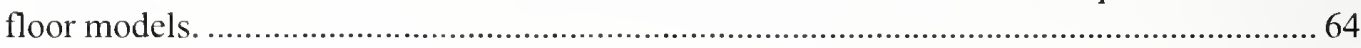

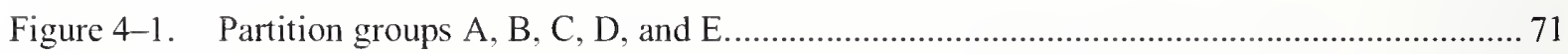

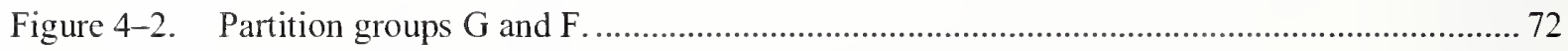

Figure 4-3. Windward and leeward distribution for (a) orthogonal and (b) diagonal wind directions. 
Figure 5-1. Drift diagrams of WTC 1 due to original WTC wind loads, (a) A0N-E- and (b) $\mathrm{A} 75 \mathrm{~N}+\mathrm{E}-$.

Figure 5-2. Demand/capacity ratios for WTC 1 under original design loads, (a) north elevation and (b) east elevation.

Figure 5-3. Demand/capacity ratios for WTC 1 under original design loads, (a) north elevation below floor 9

Figure 5-4. Demand/capacity ratios for WTC 1 core columns under original design loads, (a) 500 line and (b) 600 line.

Figure 5-5. Shear lag diagrams of WTC 1 due to original WTC wind loads at (a) floor B6,

(b) floor 39. and (c) floor 73.

Figure 5-6. Tension force distribution (kip) in the exterior wall columns of WTC 1 under original design dead and wind loads, (a) 100 face (north) and (b) 200 facc (east).

Figure 5-7. Drift diagrams of WTC 1 due to the lower estimate, state-of-the-practice loads,

(a) 1R14PDN and (b) 1R8PDN.

Figure 5-8. Drift diagrams of WTC 1 due to refined NIST estimate wind loads, (a) 1R14PD and

(b) $1 \mathrm{R} 8 \mathrm{PD}$.

Figure 5-9. Drift diagrams of WTC 2 due to original WTC wind loads, (a) B180N+E- and

(b) $\mathrm{B} 90 \mathrm{~N}-\mathrm{E}+$.

Figure 5-10. Demand/capacity ratios for WTC 2 under original design loads, (a) west elevation and (b) north elevation.

Figure 5-11. Demand/capacity ratios for WTC 2 under original design load case, (a) west elevation below floor 9 .

Figure 5-12. Demand/capacity ratios for WTC 2 core columns under original design loads, (a) 500 line and (b) 600 line.

Figure 5-13. Shear lag diagrams of WTC 2 due to original WTC wind loads at (a) floor B6,

(b) floor 39, and (c) floor 73 .

Figure 5-14. Tension force distribution (kip) in the exterior wall columns of WTC 2 under original design dead and wind loads. (a) 100 face (west) and (b) 200 face (north).

Figure 5-15. Drift diagrams of WTC 2 due to the lower estimate, state-of-the-practice case,

(a) 2R4PDN and (b) 2R11PDN.

Figure 5-16. Drift diagrams of WTC 2 due to refined NIST estimate wind loads, (a) 2R4PD and (b) 2R11PD.

Figure 6-1. Summary of WTC-design criteria reduced live loads for floor design: design load of $100 \mathrm{psf}$ - partition load is included in LL allowance.

Figure 6-2. Unbraced length of truss diagonal. 138

Figure 6-3. Connection detail for bcam 30WF116, floor 75 of WTC 2.

Figure 6-4. Demand/capacity ratios for floor 75, WTC 2: original WTC design criteria loading. 143

Figure 6-5. Beam-framed floor member groups. 
This page intentionally left blank. 


\section{LIST OF TABLES}

Table P-1. Federal building and fire safety investigation of the WTC disaster.............................xviii

Table P-2. Public meetings and briefings of the WTC Investigation. ...........................................xxi

Table 2-1. Modifications to members of the WTC database (WTC-DB).................................... 13

Table 3-1. Approximate size of the reference structural models (rounded)................................... 35

Table 3-2. Calculated first six periods and frequencies without P- $\Delta$ effects for the WTC towers....... 44

Table 3-3. Calculated first six periods and frequencies with P- $\Delta$ effects for the WTC towcrs........... 44

Table 3-4. Comparison of measured and calculated first two natural frequencies and periods for WTC 1

Table 3-5. Lateral displacement (in.) for the shell and frame models of typical exterior wall panel with varied column and spandrel rigidities.

Table 3-6. Lateral displacement (in.) for the shell and frame models of typical exterior wall corner panel with varied column and spandrel rigidities.

Table 4-1. Original WTC design criteria loads for floor 96A model for the design of columns

(typical truss floor). ${ }^{\mathrm{a}}$

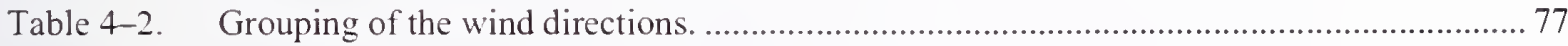

Table 4-3. A comparison of wind load estimates for WTC 1 from various sources.......................... 80

Table 4-4. Comparison of wind load estimates for WTC 2 from various sources............................8 80

Table 4-5. Base shears and base moments due to wind loads from different building codes.............. 81

Table 5-1. Statistics of demand/capacity ratios for WTC 1 under original design load case.

Table 5-2. Maximum calculated demand/capacity ratios (DCRs) for exterior wall column splices for WTC 1 under original design dead and wind load case.

Table 5-3. Statistics of demand/capacity ratios (DCRs) for WTC 1 under the lower estimate, state-of-the practice case.

Table 5-4. Statistics of demand/capacity ratios (DCRs) for WTC 1 under the refined NIST estimate case.

Table 5-5. Statistics of demand/capacity ratios (DCRs) for WTC 2 under original design load case.

Table 5-6. Maximum calculated demand/capacity ratios (DCRs) for exterior wall column splices for WTC 2 under original design dead and wind load case. 
Table 5-7. Statistics of demand/capacity ratios (DCRs) for WTC 2 under the lower estimate, state-of-the practice case.

Table 5-8. Statistics of demand/capacity ratios (DCRs) for WTC 2 under the refined NIST estimate case.

Table 6-1. Summary of typical truss-framed floor live loads and (reduced live loads) for areas outside of core.

Table 6-2. Area inside core: loading floor 96, WTC 1

Table 6-3. Summary of maximum deflections for typical truss-framed floor under DL + LL for areas outside of core

Table 6-4. Statistics of demand/capacity ratios for floor 96 under original design load case.

Table 6-5. Statistics of demand/capacity ratios (DCRs) for floor 96 under the ASCE 7-02 loading case

Table 6-6. Beam-framed core area: loading floor 75, WTC 2.

Table 6-7. Statistics of demand/capacity ratios for floor 75 under the original design loading case. 


\section{LIST OF ACRONYMS AND ABBREVIATIONS}

\section{Acronyms}

AISC American Institute of Steel Construction

AISI American Iron and Steel Institute

ASCE American Society of Civil Engineers

ASD Allowable Stress Design

BOCA/BBC Building Officials and Code Administrators Basic Building Code

CDL construction dead load

CPP Cermak Peterka Peterson, Inc.

DB database

DCR demand/capacity ratio

DL dead load

E-W $\quad$ East - West direction

GFI Government Furnished Information

LERA Leslie E. Robertson Associates, R.L.L.P.

LL live load

LRFD Load and Resistance Factor Design

MEP mechanical, electrical, and plumbing

MER mechanical equipment room

NIST National Institute of Standards and Technology

N-S North - South direction

NYCBC New York City Building Code

OCR Optical Character Recognition

PANYNJ Port Authority of New York and New Jersey

RWDI Rowan Williams Davies and Irwin, Inc.

SDL superimposed dead load

SQL Structured Query Language

WL wind load

WSHJ Worthington, Skilling, Helle \& Jackson

WTC World Trade Center 


$\begin{array}{ll}\text { WTC } 1 & \text { World Trade Center } 1 \text { (North Tower) } \\ \text { WTC } 2 & \text { World Trade Center } 2 \text { (South Tower) } \\ \text { WTC } 7 & \text { World Trade Center } 7\end{array}$

\section{Abbreviations}

2D

two dimensional

3D

three dimensional

$\mathrm{ft} \quad$ foot

$\mathrm{ft}^{2} \quad$ square foot

$F_{y} \quad$ yield strength

h hour

in. inch

kip a force unit equal to 1,000 pounds

ksi 1,000 pounds per square inch

lb pound

$\min \quad$ minute

pcf pounds per cubic foot

psf pounds per square foot

psi pounds per square inch 


\section{PREFACE}

\section{Genesis of This Investigation}

Immediately following the terrorist attack on the World Trade Center (WTC) on September 11, 2001, the Federal Emergency Management Agency (FEMA) and the American Society of Civil Engineers began planning a building performance study of the disaster. The week of October 7, as soon as the rescue and search efforts ceased, the Building Performance Study Team went to the site and began its assessment. This was to be a brief effort, as the study team consisted of experts who largely volunteered their time away from their other professional commitments. The Building Performance Study Team issued its report in May 2002. fulfilling its goal "to determine probable failure mechanisms and to identify areas of future investigation that could lead to practical measures for improving the damage resistance of buildings against such unforeseen events."

On August 21, 2002, with funding from the U.S. Congress through FEMA, the National Institute of Standards and Technology (NIST) announced its building and fire safety investigation of the WTC disaster. On October 1, 2002, the National Construction Safety Team Act (Public Law 107-23I), was signed into law. The NIST WTC Investigation was conducted under the authority of the National Construction Safety Team Act.

The goals of the investigation of the IVTC disaster were:

- To investigate the building construction, the materials used, and the technical conditions that contributed to the outcome of the WTC disaster.

- To serve as the basis for:

- Improvements in the way buildings are designed, constructed. maintained, and used;

- Improved tools and guidance for industry and safety officials;

- Recommended revisions to current codes, standards, and practices; and

- Improved public safety.

The specific objectives were:

1. Determine why and how WTC 1 and WTC 2 collapsed following the initial impacts of the aircraft and why and how WTC 7 collapsed;

2. Determine why the injuries and fatalities were so high or low depending on location, including all technical aspects of fire protection, occupant behavior, evacuation, and emergency response:

3. Determine what procedures and practices were used in the design, construction, operation, and maintenance of WTC 1,2, and 7; and

4. Identify, as specifically as possible, areas in current building and fire codes, standards, and practices that warrant revision. 
NIST is a nonregulatory agency of the U.S. Department of Commerce's Technology Administration. The purpose of NIST investigations is to improve the safety and structural integrity of buildings in the United States, and the focus is on fact finding. NIST investigative teams are authorized to assess building performance and emergency response and evacuation procedures in the wake of any building failure that has resulted in substantial loss of life or that posed significant potential of substantial loss of life. NIST does not have the statutory authority to make findings of fault nor negligence by individuals or organizations. Further, no part of any report resulting from a NIST investigation into a building failure or from an investigation under the National Construction Safety Team Act may be used in any suit or action for damages arising out of any matter mentioned in such report (15 USC 281 a, as amended by Public Law 107-231).

\section{Organization of the Investigation}

The National Construction Safety Team for this Investigation, appointed by the then NIST Director, Dr. Arden L. Bement, Jr., was led by Dr. S. Shyam Sunder. Dr. William L. Grosshandler served as Associate Lead Investigator, Mr. Stephen A. Cauffman served as Program Manager for Administration, and Mr. Harold E. Nelson served on the team as a private sector expert. The Investigation included eight interdependent projects whose leaders comprised the remainder of the team. A detailed description of each of these eight projects is available at http://wtc.nist.gov. The purpose of each project is summarized in Table $\mathrm{P}-1$, and the key interdependencies among the projects are illustrated in Fig. $\mathrm{P}-1$.

\section{Table P-1. Federal building and fire safety investigation of the WTC disaster.}

\section{Technical Area and Project Leader}

Analysis of Building and Fire Codes and Practices; Project Leaders: Dr. H. S. Lew and Mr. Richard W. Bukowski

Baseline Structural Performance and Aircraft lmpact Damage Analysis; Project Leader: Dr. Fahim H. Sadek

Mechanical and Metallurgical Analysis of Structural Steel; Project Leader: Dr. Frank W. Gayle

lnvestigation of Active Fire Protection Systems; Project Leader: Dr. David D. Evans; Dr. William Grosshandler

Reconstruction of Thermal and Tenability Environment; Project Leader: Dr. Richard G. Gann

Structural Fire Response and Collapse Analysis; Project Leaders: Dr. John L. Gross and Dr. Therese P. McAllister

Occupant Behavior, Egress, and Emergency Communications; Project Leader: Mr. Jason D. Averill

Emergency Response Technologies and Guidelines; Project Leader: Mr. J. Randall Lawson

\section{Project Purpose}

Document and analyze the code provisions, procedures, and practices used in the design, construction, operation, and maintenance of the structural, passive fire protection, and emergency access and evacuation systems of WTC 1,2 , and 7. Analyze the baseline performance of WTC 1 and WTC 2 under design, service, and abnormal loads, and aircraft impact damage on the structural, fire protection, and egress systems.

Determine and analyze the mechanical and metallurgical properties and quality of steel, weldments, and connections from steel recovered from WTC 1,2 , and 7.

lnvestigate the performance of the active fire protection systems in WTC 1,2, and 7 and their role in fire control, emergency response, and fate of occupants and responders.

Reconstruct the time-evolving temperature, thermal environment, and smoke movement in WTC 1,2, and 7 for use in evaluating the structural performance of the buildings and behavior and fate of occupants and responders.

Analyze the response of the WTC towers to fires with and without aircraft damage, the response of WTC 7 in fires, the performance of composite steel-trussed floor systems, and determine the most probable structural collapse sequence for WTC 1,2, and 7 .

Analyze the behavior and fate of occupants and responders, both those who survived and those who did not, and the performance of the evacuation system.

Document the activities of the emergency responders from the time of the terrorist attacks on WTC 1 and WTC 2 until the collapse of WTC 7, including practices followed and technologies used. 


\section{NIST WTC Investigation Projects}

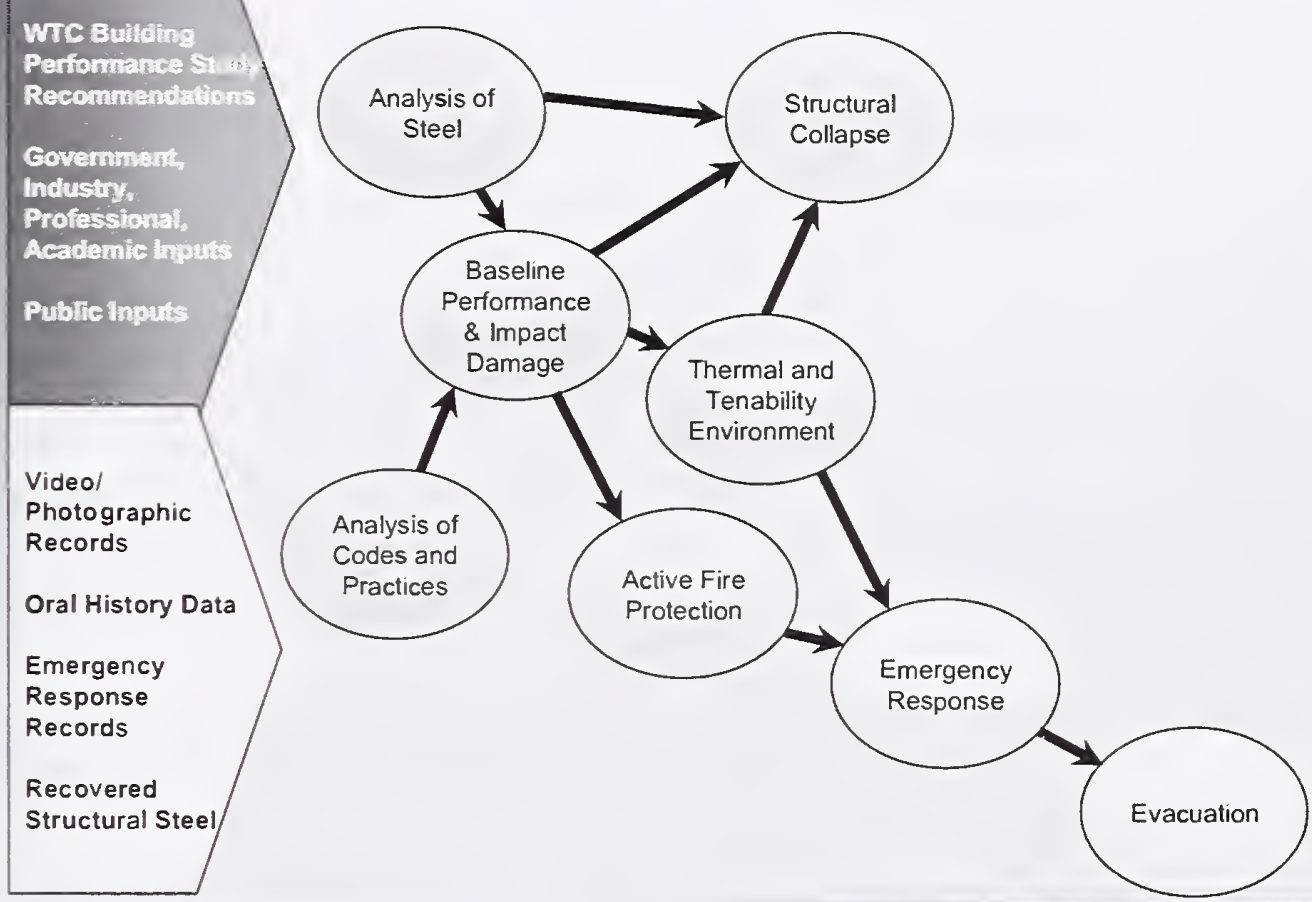

NLIT

Figure P-1. The eight projects in the federal building and fire safety investigation of the WTC disaster.

\section{National Construction Safety Team Advisory Committee}

The NIST Director also established an advisory committee as mandated under the National Construction Safety Team Act. The initial members of the committee were appointed following a public solicitation. These were:

- Paul Fitzgerald, Executive Vice President (retired) FM Global, National Construction Safety Team Advisory Committee Chair

- John Barsom, President, Barsom Consulting, Ltd.

- John Bryan, Professor Emeritus, University of Maryland

- David Collins, President, The Preview Group, Inc.

- Glenn Corbett, Professor, John Jay College of Criminal Justice

- Philip DiNenno, President, Hughes Associates, Inc. 
- Robert Hanson, Professor Emeritus, University of Michigan

- Charles Thornton, Co-Chairman and Managing Principal, The Thornton-Tomasetti Group, lnc.

- Kathleen Tierney, Director, Natural Hazards Research and Applications Information Center, University of Colorado at Boulder

- Forman Williams, Director, Center for Energy Research, University of California at San Diego

This National Construction Safety Team Advisory Committee provided technical advice during the Investigation and commentary on drafts of the Investigation reports prior to their public release. NIST has benefited from the work of many people in the preparation of these reports, including the National Construction Safety Team Advisory Committee. The content of the reports and recommendations, however, are solely the responsibility of NIST.

\section{Public Outreach}

During the course of this Investigation, NIST held public briefings and meetings (listed in Table P-2) to solicit input from the public, present preliminary findings, and obtain comments on the direction and progress of the Investigation from the public and the Advisory Committee.

NIST maintained a publicly accessible Web site during this Investigation at http://wtc.nist.gov. The site contained extensive information on the background and progress of the Investigation.

\section{NIST's WTC Public-Private Response Plan}

The collapse of the WTC buildings has led to broad reexamination of how tall buildings are designed, constructed, maintained, and used, especially with regard to major events such as fires, natural disasters, and terrorist attacks. Reflecting the enhanced interest in effecting necessary change, NIST, with support from Congress and the Administration, has put in place a program, the goal of which is to develop and implement the standards, technology, and practices needed for cost-effective improvements to the safety and security of buildings and building occupants, including evacuation, emergency response procedures, and threat mitigation.

The strategy to meet this goal is a three-part NIST-led public-private response program that includes:

- A federal building and fire safety investigation to study the most probable factors that contributed to post-aircraft impact collapse of the WTC towers and the 47-story WTC 7 building, and the associated evacuation and emergency response experience.

- A research and development (R\&D) program to (a) facilitate the implementation of recommendations resulting from the WTC Investigation, and (b) provide the technical basis for cost-effective improvements to national building and fire codes, standards, and practices that enhance the safety of buildings, their occupants, and emergency responders. 
Table P-2. Public meetings and briefings of the WTC Investigation.

\begin{tabular}{|c|c|c|}
\hline Date & Location & Principal Agenda \\
\hline June 24,2002 & New York City, NY & $\begin{array}{l}\text { Public meeting: Public comments on the Draft Plan for the } \\
\text { pending WTC Investigation. }\end{array}$ \\
\hline August 21. 2002 & Gaithersburg. MD & Media briefing announcing the formal start of the Investigation. \\
\hline December 9,2002 & Washington, DC & $\begin{array}{l}\text { Media briefing on release of the Public Update and NIST request } \\
\text { for photographs and videos. }\end{array}$ \\
\hline April 8. 2003 & New York City, NY & $\begin{array}{l}\text { Joint public forum with Columbia University on first-person } \\
\text { interviews. }\end{array}$ \\
\hline April 29-30.2003 & Gaithersburg. MD & $\begin{array}{l}\text { NCST Advisory Committee meeting on plan for and progress on } \\
\text { WTC Investigation with a public comment session. }\end{array}$ \\
\hline May 7.2003 & New York City. NY & Media briefing on release of May 2003 Progress Report. \\
\hline August 26-27.2003 & Gaithersburg. MD & $\begin{array}{l}\text { NCST Advisory Committee meeting on status of the WTC } \\
\text { investigation with a public comment session. }\end{array}$ \\
\hline September 17,2003 & New York City, NY & $\begin{array}{l}\text { Media and public briefing on initiation of first-person data } \\
\text { collection projects. }\end{array}$ \\
\hline December 2-3, 2003 & Gaithersburg, MD & $\begin{array}{l}\text { NCST Advisory Committee meeting on status and initial results } \\
\text { and release of the Public Update with a public comment session. }\end{array}$ \\
\hline February 12.2004 & New York City. NY & $\begin{array}{l}\text { Public meeting on progress and preliminary findings with public } \\
\text { comments on issues to be considered in formulating final } \\
\text { recommendations. }\end{array}$ \\
\hline June 18.2004 & New York City, NY & Media/public briefing on release of June 2004 Progress Report. \\
\hline June $22-23,2004$ & Gaithersburg, MD & $\begin{array}{l}\text { NCST Advisory Committee meeting on the status of and } \\
\text { preliminary findings from the WTC Investigation with a public } \\
\text { comment session. }\end{array}$ \\
\hline August 24.2004 & Northbrook, IL & $\begin{array}{l}\text { Public viewing of standard fire resistance test of WTC floor } \\
\text { system at Underwriters Laboratories, lnc. }\end{array}$ \\
\hline October 19-20, 2004 & Gaithersburg, MD & $\begin{array}{l}\text { NCST Advisory Committee meeting on status and near complete } \\
\text { set of preliminary findings with a public comment session. }\end{array}$ \\
\hline November 22,2004 & Gaithersburg, MD & $\begin{array}{l}\text { NCST Advisory Committee discussion on draft annual report to } \\
\text { Congress, a public comment session, and a closed session to } \\
\text { discuss pre-draft recommendations for WTC Investigation. }\end{array}$ \\
\hline April 5, 2005 & New York City, NY & $\begin{array}{l}\text { Media and public briefing on release of the probable collapse } \\
\text { sequence for the WTC towers and draft reports for the projects on } \\
\text { codes and practices, evacuation, and emergency response. }\end{array}$ \\
\hline June 23,2005 & New York City, NY & $\begin{array}{l}\text { Media and public briefing on release of all draft reports for the } \\
\text { WTC towers and draft recommendations for public comment. }\end{array}$ \\
\hline $\begin{array}{l}\text { September 12-13, } \\
2005\end{array}$ & Gaithersburg, MD & $\begin{array}{l}\text { NCST Advisory Committee meeting on disposition of public } \\
\text { comments and update to draft reports for the WTC towers. }\end{array}$ \\
\hline $\begin{array}{l}\text { September } 13-15 \\
2005\end{array}$ & Gaithersburg, MD & $\begin{array}{l}\text { WTC Technical Conference for stakeholders and technical } \\
\text { community for dissemination of findings and recommendations } \\
\text { and opportunity for public to make technical comments. }\end{array}$ \\
\hline
\end{tabular}

- A dissemination and technical assistance program (DTAP) to (a) engage leaders of the construction and building community in ensuring timely adoption and widespread use of proposed changes to practices, standards, and codes resulting from the WTC Investigation and the R\&D program, and (b) provide practical guidance and tools to better prepare facility owners, contractors, architects, engineers, emergency responders, and regulatory authorities to respond to future disasters.

The desired outcomes are to make buildings, occupants, and first responders safer in future disaster events. 


\section{National Construction Safety Team Reports on the WTC Investigation}

A final report on the collapse of the WTC towers is being issued as NIST NCSTAR 1. A companion report on the collapse of WTC 7 is being issued as NIST NCSTAR 1A. The present report is one of a set that provides more detailed documentation of the Investigation findings and the means by which these technical results were achieved. As such, it is part of the archival record of this Investigation. The titles of the full set of Investigation publications are:

NIST (National Institute of Standards and Technology). 2005. Federal Building and Fire Safety Investigation of the World Trade Center Disaster: Final Report on the Collapse of the World Trade Center Towers. NIST NCSTAR 1. Gaithersburg, MD, September.

NIST (National Institute of Standards and Technology). 2006. Federal Building and Fire Safety Investigation of the World Trade Center Disaster: Final Report on the Collapse of World Trade Center 7. NIST NCSTAR 1A. Gaithersburg, MD.

Lew, H. S., R. W. Bukowski, and N. J. Carino. 2005. Federal Building and Fire Safety Investigation of the World Trade Center Disaster: Design, Construction, and Maintenance of Structural and Life Safety Systens. NIST NCSTAR 1-1. National Institute of Standards and Technology. Gaithersburg, MD, September.

Fanella, D. A., A. T. Derecho, and S. K. Ghosh. 2005. Federal Building and Fire Safety Investigation of the World Trade Center Disaster: Design and Construction of Structural Systems. NIST NCSTAR 1-1A. National Institute of Standards and Technology. Gaithersburg, MD, September.

Ghosh, S. K., and X. Liang. 2005. Federal Building and Fire Safety Investigation of the World Trade Center Disaster: Comparison of Building Code Structural Requirements. NIST

NCSTAR 1-1B. National Institute of Standards and Technology. Gaithersburg, MD, September.

Fanella, D. A., A. T. Derecho, and S. K. Ghosh. 2005. Federal Building and Fire Safety Investigation of the World Trade Center Disaster: Maintenance and Modifications to Structural Systems. NIST NCSTAR 1-1C. National Institute of Standards and Technology. Gaithersburg, MD, September.

Grill, R. A., and D. A. Johnson. 2005. Federal Building and Fire Safety Investigation of the World Trade Center Disaster: Fire Protection and Life Safety Provisions Applied to the Design and Construction of World Trade Center 1, 2, and 7 and Post-Construction Provisions Applied after Occupancy. NIST NCSTAR 1-1D. National Institute of Standards and Technology. Gaithersburg, MD, September.

Razza, J. C., and R. A. Grill. 2005. Federal Building and Fire Safety Investigation of the World Trade Center Disaster: Comparison of Codes, Standards, and Practices in Use at the Tine of the Design and Construction of World Trade Center 1, 2, and 7. NIST NCSTAR 1-1E. National Institute of Standards and Technology. Gaithersburg, MD, September.

Grill, R. A., D. A. Johnson, and D. A. Fanella. 2005. Federal Building and Fire Safety Investigation of the World Trade Center Disaster: Comparison of the 1968 and Current (2003) New 
York City Building Code Provisions. NIST NCSTAR 1-1F. National Institute of Standards and Technology. Gaithersburg, MD, September.

Grill, R. A.. and D. A. Johnson. 2005. Federal Building and Fire Safety Investigation of the World Trade Center Disaster: Amendments to the Fire Protection and Life Safety Provisions of the New York City Building Code by Local Laws Adopted While World Trade Center 1, 2, and 7 Were in Use. NIST NCSTAR 1-1G. National Institute of Standards and Technology. Gaithersburg, MD, September.

Grill. R. A., and D. A. Johnson. 2005. Federal Building and Fire Safety Investigation of the World Trade Center-Disaster: Post-Construction Modifications to Fire Protection and Life Safety Systems of World Trade Center 1 and 2. NIST NCSTAR 1-1H. National Institute of Standards and Technology. Gaithersburg, MD, September.

Grill, R. A., D. A. Johnson, and D. A. Fanella. 2005. Federal Building and Fire Safety Investigation of the World Trade Center Disaster: Post-Construction Modifications to Fire Protection, Life Safety; and Stmictural Systents of World Trade Center 7. NIST NCSTAR 1-11. National Institute of Standards and Technology. Gaithersburg, MD, September.

Grill. R. A., and D. A. Johnson. 2005. Federal Building and Fire Safety Investigation of the World Trade Center Disaster: Design, Installation, and Operation of Fuel System for Energency Power in World Trade Center T. NIST NCSTAR 1-1J. National Institute of Standards and Technology. Gaithersburg, MD. September.

Sadek, F. 2005. Federal Building and Fire Safety Investigation of the World Trade Center Disaster: Baseline Structural Performance and Aircraft Impact Damage Analysis of the World Trade Center Towers. NIST NCSTAR 1-2. National Institute of Standards and Technology. Gaithersburg, MD, September.

Faschan, W. J., and R. B. Garlock. 2005. Federal Building and Fire Safety Investigation of the World Trade Center Disaster: Reference Structural Models and Baseline Performance Analysis of the World Trade Center Towers. NIST NCSTAR 1-2A. National Institute of Standards and Technology. Gaithersburg, MD, September.

Kirkpatrick, S. W., R. T. Bocchieri, F. Sadek, R. A. MacNeill, S. Holmes, B. D. Peterson, R. W. Cilke, C. Navarro. 2005. Federal Building and Fire Safety Investigation of the World Trade Center Disaster: Analysis of Aircraft Impacts into the World Trade Center Towers, NIST

NCSTAR 1-2B. National Institute of Standards and Technology. Gaithersburg, MD, September.

Gayle, F. W., R. J. Fields, W. E. Luecke, S. W. Banovic, T. Foecke, C. N. McCowan, T. A. Siewert, and J. D. McColskey. 2005. Federal Building and Fire Safety Investigation of the World Trade Center Disaster: Mechanical and Metallurgical Analy'sis of Structural Steel. NIST NCSTAR 1-3. National Institute of Standards and Technology. Gaithersburg, MD, September.

Luecke, W. E., T. A. Siewert, and F. W. Gayle. 2005. Federal Building and Fire Safety Investigation of the World Trade Center Disaster: Contemporaneous Structural Steel Specifications. NIST Special Publication 1-3A. National Institute of Standards and Technology. Gaithersburg, MD, September. 
Banovic, S. W. 2005. Federal Building and Fire Safety Investigation of the World Trade Center Disaster: Steel Inventory and Identification. NIST NCSTAR 1-3B. National Institute of Standards and Technology. Gaithersburg, MD, September.

Banovic, S. W., and T. Foecke. 2005. Federal Building and Fire Safety Investigation of the World Trade Center Disaster: Damage and Failhre Modes of Structural Steel Components. NIST NCSTAR 1-3C. National Institute of Standards and Technology. Gaithersburg, MD, September.

Luecke, W. E., J. D. McColskey, C. N. McCowan, S. W. Banovic, R. J. Fields, T. Foecke, T. A. Siewert, and F. W. Gayle. 2005. Federal Building and Fire Safety Investigation of the World Trade Center Disaster: Mechanical Properties of Structural Steels. NIST NCSTAR 1-3D. National Institute of Standards and Technology. Gaithersburg, MD, September.

Banovic, S. W., C. N. McCowan, and W. E. Luecke. 2005. Federal Building and Fire Safety Investigation of the World Trade Center Disaster: Physical Properties of Structural Steels. NIST NCSTAR 1-3E. National lnstitute of Standards and Technology. Gaithersburg, MD, September.

Evans, D. D., R. D. Peacock, E. D. Kuligowski, W. S. Dols, and W. L. Grosshandler. 2005. Federal Building and Fire Safety Investigation of the World Trade Center Disaster: Active Fire Protection Systems. NIST NCSTAR 1-4. National Institute of Standards and Technology. Gaithersburg, MD, September.

Kuligowski, E. D., D. D. Evans, and R. D. Peacock. 2005. Federal Building and Fire Safety Investigation of the World Trade Center Disaster: Post-Construction Fires Prior to September 11, 2001. NIST NCSTAR 1-4A. National Institute of Standards and Technology. Gaithersburg, MD, September.

Hopkins, M., J. Schoenrock, and E. Budnick. 2005. Federal Building and Fire Safety Investigation of the World Trade Center Disaster: Fire Suppression Systems. NIST NCSTAR 1-4B. National Institute of Standards and Technology. Gaithersburg, MD, September.

Keough, R. J., and R. A. Grill. 2005. Federal Building and Fire Safety Investigation of the World Trade Center Disaster: Fire Alarm Systems. NIST NCSTAR 1-4C. National Institute of Standards and Technology. Gaithersburg, MD, September.

Ferreira, M. J., and S. M. Strege. 2005. Federal Building and Fire Safety Investigation of the World Trade Center Disaster: Smoke Management Systems. NIST NCSTAR 1-4D. National Institute of Standards and Technology. Gaithersburg, MD, September.

Gann, R. G., A. Hamins, K. B. McGrattan, G. W. Mulholland, H. E. Nelson, T. J. Ohlemiller, W. M. Pitts, and K. R. Prasad. 2005. Federal Building and Fire Safety Investigation of the World Trade Center Disaster: Reconstruction of the Fires in the World Trade Center Towers. NIST NCSTAR 1-5. National Institute of Standards and Technology. Gaithersburg, MD, September.

Pitts, W. M., K. M. Butler, and V. Junker. 2005. Federal Building and Fire Safety Investigation of the World Trade Center Disaster: Visual Evidence, Damage Estimates, and Timeline Analysis. NIST NCSTAR 1-5A. National Institute of Standards and Technology. Gaithersburg, MD, September. 
Hamins, A.. A. Maranghides, K. B. McGrattan, E. Johnsson, T. J. Ohlemiller, M. Donnelly, J. Yang, G. Mulholland, K. R. Prasad. S. Kukuck, R. Anleitner and T. McAllister. 2005. Federal Building and Fire Safety Investigation of the World Trade Center Disaster: Experiments and Modeling of Structural Steel Elements Exposed to Fire. NIST NCSTAR 1-5B. National Institute of Standards and Technology. Gaithersburg, MD, September.

Ohlemiller, T. J.. G. W. Mulholland. A. Maranghides, J. J. Filliben, and R. G. Gann. 2005. Federal Building and Fire Safety Investigation of the World Trade Center Disaster: Fire Tests of Single Office Workstations. NIST NCSTAR 1-5C. National Institute of Standards and Technology. Gaithersburg, MD, September.

Gann, R. G., M. A. Riley, J. M. Repp, A. S. Whittaker, A. M. Reinhorn, and P. A. Hough. 2005. Federal Building and Fire Safety Imestigation of the World Trade Center Disaster: Reaction of Ceiling Tile Systenis to Shocks. NIST NCSTAR 1-5D. National Institute of Standards and Technology. Gaithersburg. MD, September.

Hamins, A., A. Maranghides, K. B. McGrattan, T. J. Ohlemiller, and R. Anleitner. 2005. Federal Building and Fire Safety Investigation of the World Trade Center Disaster: Experiments and Modeling of Multiple Workstations Burning in a Compartment. NIST NCSTAR 1-5E. National Institute of Standards and Technology. Gaithersburg, MD, September.

McGrattan. K. B.. C. Bouldin. and G. Forney. 2005. Federal Building and Fire Safety Investigation of the World Trade Center Disaster: Computer Simnlation of the Fires in the World Trade Center Towers. NIST NCSTAR 1-5F. National Institute of Standards and Technology. Gaithersburg. MD, September.

Prasad, K. R., and H. R. Baum. 2005. Federal Building and Fire Safety Investigation of the World Trade Center Disaster: Fire Structure Interface and Thermal Response of the World Trade Center Towers. NIST NCSTAR 1-5G. National Institute of Standards and Technology. Gaithersburg, $\mathrm{MD}$, September.

Gross, J. L., and T. McAllister. 2005. Federal Building and Fire Safety Investigation of the World Trade Center Disaster: Structural Fire Response and Probable Collapse Sequence of the World Trade Center Towers. NIST NCSTAR 1-6. National Institute of Standards and Technology. Gaithersburg, MD, September.

Carino, N. J., M. A. Starnes, J. L. Gross, J. C. Yang, S. Kukuck, K. R. Prasad, and R. W. Bukowski. 2005. Federal Building and Fire Safety Investigation of the World Trade Center Disaster: Passive Fire Protection. NIST NCSTAR 1-6A. National Institute of Standards and Technology. Gaithersburg, MD, September.

Gross, J., F. Hervey, M. Izydorek, J. Mammoser, and J. Treadway. 2005. Federal Building and Fire Safety Investigation of the World Trade Center Disaster: Fire Resistance Tests of Floor Truss Systems. NIST NCSTAR 1-6B. National Institute of Standards and Technology. Gaithersburg, $\mathrm{MD}$, September.

Zarghamee, M. S., S. Bolourchi, D. W. Eggers, Ö. O. Erbay, F. W. Kan, Y. Kitane, A. A. Liepins, M. Mudlock, W. I. Naguib, R. P. Ojdrovic, A. T. Sarawit, P. R Barrett, J. L. Gross, and 
T. P. McAllister. 2005. Federal Building and Fire Safety Investigation of the World Trade Center Disaster: Component, Connection, and Subsystem Structural Analysis. NIST NCSTAR 1-6C. National Institute of Standards and Technology. Gaithersburg, MD, September.

Zarghamee, M. S., Y. Kitane, Ö. O. Erbay, T. P. McAllister, and J. L. Gross. 2005. Federal Building and Fire Safety Investigation of the World Trade Center Disaster: Global Structural Analysis of the Response of the World Trade Center Towers to Impact Damage and Fire. NIST NCSTAR 1-6D. National Institute of Standards and Technology. Gaithersburg, MD, September.

McAllister, T., R. W. Bukowski, R. G. Gann, J. L. Gross, K. B. McGrattan, H. E. Nelson, L. Phan, W. M. Pitts, K. R. Prasad, F. Sadek. 2006. Federal Building and Fire Safety Investigation of the World Trade Center Disaster: Structural Fire Response and Probable Collapse Sequence of World Trade Center 7. (Provisional). NIST NCSTAR 1-6E. National Institute of Standards and Technology. Gaithersburg, MD.

Gilsanz, R., V. Arbitrio, C. Anders, D. Chlebus, K. Ezzeldin, W. Guo, P. Moloney, A. Montalva, J. Oh, K. Rubenacker. 2006. Federal Building and Fire Safety Investigation of the World Trade Center Disaster: Structural Analysis of the Response of World Trade Center 7 to Debris Damage and Fire. (Provisional). NIST NCSTAR 1-6F. National Institute of Standards and Technology. Gaithersburg, MD.

Kim, W. 2006. Federal Building and Fire Safety Investigation of the World Trade Center Disaster: Analysis of September 11, 2001, Seismogram Data. (Provisional). NIST NCSTAR 1-6G. National Institute of Standards and Technology. Gaithersburg, MD.

Nelson, K. 2006. Federal Building and Fire Safety Investigation of the World Trade Center Disaster: The Con Ed Substation in World Trade Center 7. (Provisional). NIST NCSTAR 1-6H. National Institute of Standards and Technology. Gaithersburg, MD.

Averill, J. D., D. S. Mileti, R. D. Peacock, E. D. Kuligowski, N. Groner, G. Proulx, P. A. Reneke, and H. E. Nelson. 2005. Federal Building and Fire Safety Investigation of the World Trade Center Disaster: Occupant Behavior, Egress, and Emergency Communication. NIST NCSTAR 1-7. National Institute of Standards and Technology. Gaithersburg, MD, September.

Fahy, R., and G. Proulx. 2005. Federal Building and Fire Safety Investigation of the World Trade Center Disaster: Analysis of Published Accounts of the World Trade Center Evacuation. NIST NCSTAR 1-7A. National Institute of Standards and Technology. Gaithersburg, MD, September.

Zmud, J. 2005. Federal Building and Fire Safety Investigation of the World Trade Center Disaster: Technical Documentation for Survey Administration. NIST NCSTAR 1-7B. National Institute of Standards and Technology. Gaithersburg, MD, September.

Lawson, J. R., and R. L. Vettori. 2005. Federal Building and Fire Safety Investigation of the World Trade Center Disaster: The Emergency Response Operations. NIST NCSTAR 1-8. National Institute of Standards and Technology. Gaithersburg, MD, September. 


\section{EXECUTIVE SUMMARY}

\section{E.1 INTRODUCTION}

This report presents the work conducted to establish the baseline performance of the North and South World Trade Center Towers (WTC 1 and WTC 2) under design gravity and wind loading conditions. Baseline performance results include basic information about the behavior of the towers, such as total and inter-story drift under wind loads, floor deflections under gravity loads, demand/capacity ratios for primary structural components, exterior columns response (shear lag effects and presence of tensile forces), performance of connections, and the towers' resistance to shear sliding and overturning.

The primary tasks that were undertaken to establish the baseline performance included the following:

- To develop structural databases for the primary structural components of the WTC 1 and WTC 2 towers from the original computer printouts of the structural documents.

- To develop reference structural analysis models that capture the intended behavior of each of the two towers using the generated databases. These reference models were used to establish the baseline performance of the towers and also served as a reference for more detailcd models for other phases of the National Institute of Standards and Technology (NIST) investigation.

- To develop estimates of design gravity (dead and live loads) and wind loads on each of the two towers for implementation into the reference structural models.

- To perform linear, static structural analyses to establish the baseline performance of each of the two towers under design gravity and wind loads.

\section{E.2 DEVELOPMENT OF STRUCTURAL DATABASES FOR THE WTC TOWERS}

This task included the development of structural databases of the primary components of the WTC 1 and WTC 2 towers. The electronic databases were developed from original computer printouts of the structural design documents, including modifications made after construction. The databases were generated for use in the development of the reference structural models of the towers.

The structural databases contained the computer and hand-tabulated data for the primary structural components of the towers from the original Drawing Books 1 through 5, including exterior walls, core columns, and beam schedule. In addition, some information from Drawing Book 6 (core bracing schedule) and Drawing Book 9 (beams in the hat truss region) were included in the database files as it was utilized in the modeling of the towers. Some modifications that were made to the towers were implemented in the databases, including strengthening of a number of core columns at floors 98 to 106 of both towers and reinforcing of two corner core column at floors 45 to 97 of WTC 2 due to the construction of a concrete vault at floor 97 . 
The task included the scanning and digitization of the original drawing books, a four-step quality control procedure, cross section property calculations, and development of the relational databases to link the generated database files into a format suitable for the development of the structural models.

\section{E.3 DEVELOPMENT OF REFERENCE STRUCTURAL MODELS FOR THE WTC TOWERS}

This task included the development of reference structural analysis models that capture the intended behavior of each of the two towers using the generated databases. These reference models were used to establish the baseline performance of the towers and also served as a reference for more detailed models for aircraft impact damage analysis and thermal-structural response and collapse initiation analysis. The main types of models developed were:

- Two global models of the major structural components and systems for the towers, one each for WTC 1 and WTC 2. The models included all primary structural components in the towers, including exterior walls (columns and spandrel beams), core columns, exterior wall bracing in the basement floors, core bracing at the mechanical floors, core bracing at the main lobby atrium levels, hat trusses, and rigid and flexible diaphragms representing the floor systems. To validate the global models, the calculated natural frequencies of WTC 1 were compared with those measured on the tower, and good agreement between the calculated and measured values was obtained.

- One model each of the typical truss-framed floor (floor 96 of WTC 1) and typical beamframed floor (floor 75 of WTC 2). The models included all major structural components in the floor system, including primary and bridging trusses, beams, strap anchors and horizontal trusses, concrete slabs, and viscoelastic dampers. To validate the floor models, several studies were carried out to compare stresses and deflections estimated from the model with hand calculations for representative composite sections. Good agreement was obtained between the model results and hand calculations.

Parametric studies were performed to evaluate the behavior of typical portions of the structure and to develop simplified models for implementation into the global models. These parametric studies included detailed and simplified models of typical exterior and comer wall panels and floor systems.

\section{E.4 GRAVITY AND WIND LOADS ON THE WTC GLOBAL MODELS}

This task included the development of estimates of design gravity and wind loads on the towers for implementation into the reference structural models and use in the baseline performance analysis. Various wind loads were considered in this study, including wind loads used in the original WTC design, wind loads based on two recent wind tunnel studies conducted in 2002 by Cermak Peterka Peterson, Inc. (CPP) and Rowan Williams Davis and Irwin, Inc. (RWDI) for insurance litigation concerning the towers, and wind load estimates developed by NIST from critical assessment of information obtained from the CPP and RWDI reports and state-of-the-art considerations. The following three loading cases were considered for the baseline performance analysis: 
- Original WTC design loads case. Loads included dead and live loads as in original WTC design in conjunction with original WTC design wind loads.

- State-of-the-practice case. Loads included dead loads; current New York City Building Code (NYCBC 2001) live loads; and wind loads from the RWDI wind tunnel study, scaled in accordance with NYCBC 2001 wind speed.

- Refined NIST estimate case. Loads included dead loads; live loads from the American Society of Civil Engineers (ASCE 7-02) Standard (a national standard); and wind loads developed by NIST.

The purpose of using the original WTC design loads was to evaluate the performance of the towers under original design loading conditions and ascertain whether those loads and the corresponding design were adequate given the knowledge available at the time of the design. The purpose of considering the stateof-the-practice and the refined NIST estimate cases was to better understand and assess the effects of successive changes in standards. codes, and practices on wind design practices for tall buildings.

The study indicated that the original WTC design wind load estimates exceeded those established by thc NYCBC prior to 1968. when the WTC towers were designed, and up to and including 2001. The dcsign values were also higher than those required by other prescriptive building codes of the time.

The two orthogonal base shear and base moment components used in the original design were in general smaller than the CPP, RWDI, and NIST estimates. However, the most unfavorable combined pcaks from the original design were larger than, or smaller by at most 15 percent than, estimates based on the CPP, RWDI, and NIST estimates. This is due to the conservative procedure used to combine the loads in the original design.

The estimated wind-induced loads on the towers vary by as much as 40 percent between the wind tunnel/elimatological studies conducted by CPP and RWDI in 2002, with CPP being the larger.

Considering the differences between RWDI and CPP rcsults, the RWDI loads may be viewcd as a "lowcrestimate, state-of-the-practice case."

\section{E.5 BASELINE PERFORMANCE ANALYSIS OF THE WTC GLOBAL MODELS}

The WTC 1 and WTC 2 global models were each analyzed under the three loading cases described above to establish their baseline performance. The following is a summary of the results:

- Under the original WTC design loads, the cumulative drifts at the top of the WTC 1 tower were about 56.6 in. $(\mathrm{H} / 304)$ and 55.7 in. $(\mathrm{H} / 309)$ in the $\mathrm{E}-\mathrm{W}$ and $\mathrm{N}-\mathrm{S}$ directions, respectively. These drifts were about 51.2 in. $(\mathrm{H} / 335)$ in the $\mathrm{E}-\mathrm{W}$ direction and $65.3 \mathrm{in}$. $(\mathrm{H} / 263)$ in the N-S direction for WTC 2. For the lower estimate, state-of-the-practice case, the drifts for WTC 1 were larger than those from the original design case by about 0.5 percent and 22 percent for the $\mathrm{E}-\mathrm{W}$ and $\mathrm{N}-\mathrm{S}$ directions, respectively. For the lower estimate, stateof-the-practice case for WTC 2, the E-W drift was larger than that of the original design case by about 16 percent, and the $\mathrm{N}-\mathrm{S}$ drift was smaller by about 15 percent. The drifts obtained from the refined NIST estimate ease were about 25 percent larger than those from the statc- 
of-the practice case. These differences are consistent with the differences between the base shears for the three loading cases.

- The demand/capacity ratios (DCR) were based on the allowable stress design procedure and were estimated using the AISC Specifications (1989). The results indicated that DCRs estimated from the original WTC design load case were, in general, close to those obtained for the lower estimate, state-of-the practice case. For both cases, a small fraction of structural components had DCRs larger than 1.0. These were mainly observed in both towers at (1) the exterior walls at the columns around the corners, where the hat truss connected to the exterior walls, and below floor 9; and (2) the core columns on the 600 line between floors 80 and 106 and at core perimeter columns 901 and 908 for much of their height.

- The refined NIST case estimated DCRs were higher than those of the original WTC design estimates and the lower state-of-the-practice estimates for the following reasons: The NIST estimated wind loads were about 25 percent higher than those used in the lower state-of-thepractice estimate, and mixed, some higher and others lower than the original WTC design wind loads. It is noted that the NIST estimated wind loads are about 20 percent smaller than those estimated by CPP (an upper estimate, state-of-the practice case). In addition, the original WTC design and the state-of-the-practice cases used NYCBC load combinations, which result in lower DCRs than the ASCE 7-02 load combinations used for the refined NIST case.

- Under a combination of the original WTC design dead and wind loads, tension forces were observed in the exterior walls of both towers. The forces were largest at the base of the building and at the corners. These tensile column loads were transferred from one panel to another through the column splices. The DCR ratios for the exterior wall splice connections under the effect of the tensile forces for the two towers were shown to be less than 1.0.

- For the towers' resistance to shear sliding and overturning due to wind, the dead loads that acted on the perimeter walls of the towers provided resistance to shear sliding and overturning at the foundation level. Considering the resistance to shear sliding under wind load, the factor of safety was calculated to be between 10 and 11.5 , while the factor of safety against overturning ranged from 1.9 to 2.7 for both towers.

\section{E.6 BASELINE PERFORMANCE ANALYSIS OF THE TYPICAL FLOOR MODELS}

The typical floor models were both analyzed under gravity loads. The following is a summary of the results:

- For the typical truss-framed floor (floor 96 of WTC 1), the DCRs for all floor trusses were less than 1.14 for the original WTC Design Criteria loads and less than 0.86 for the ASCE 7-02 loading. Under the original WTC Design Criteria loading, the DCR was less than 1.00 for 99.4 percent of the floor truss components. For the area outside the core, the average ratio of the DCRs under the ASCE 7-02 loading to the DCRs under the original WTC Design Criteria loading for all floor trusses was about 0.80 . For the core area, the DCRs for all floor beams inside the core were less than 1.08, and more than 99 percent had a DCR of less than 
1.0. Under the original WTC Design Criteria loading, the maximum floor deflections were $1.79 \mathrm{in} ., 0.57 \mathrm{in}$., and $1.44 \mathrm{in}$. for the long span one-way trusses, short span one-way trusses, and the two-way zone, respectively.

- For the typical beam-framed floor (floor 75 of WTC 2) under the original WTC Design Criteria loading, the DCRs for all floor beams were less than 1.0 except for two core beams where the shear DCRs were 1.125 and 1.09. The maximum mid-span deflections of the long span and short span zones under the original WTC Design Criteria loads were about 1.55 in. and $0.70 \mathrm{in}$, respectively. 
This page intentionally left blank. 


\section{Chapter 1 \\ INTRODUCTION}

The objective of this analysis was to establish the baseline performance of the North and South World Trade Center Towers (WTC 1 and WTC 2) under design gravity and wind loading conditions. Baseline performance results provide basic information about the towers' behavior under design loading conditions, including total and inter-story drift under wind loads, floor deflections under gravity loads, demand/capacity ratios for the primary structural components of the towers, exterior columns response (shear lag effects and presence of tensile forces), performance of connections, and the towers ${ }^{\star}$ resistance to shear sliding and overturning. The primary tasks that were undertaken to establish the baseline performance include the following:

- To develop structural databases for the primary structural components of the WTC 1 and WTC 2 towers from the original computer printouts of the structural documents.

- To develop reference structural analysis models that capture the intended behavior of each of the two towers using the generated databases. These reference models were used to establish the baseline performance of the towers and also served as a reference for more detailed models for aircraft impact damage analysis and thermal-structural response and collapse initiation analysis.

- To develop estimates of design gravity (dead and live loads) and wind loads on each of the two towers for implementation into the reference structural models.

- To perform linear, static structural analyses to establish the baseline performance of each of the two towers under design gravity and wind loads.

Chapter 1 of this report presents an introduction and a brief description of the structural system of the towers. Chapter 2 presents an outline and description of the methodology used for the development of the structural databases for both towers, along with the relational databases that are used to link the generated databases for use in the development of the reference structural models. Chapter 3 presents the development of the reference structural analysis models for WTC 1 and WTC 2, including global tower models, typical floor models, and parametric studies conducted for the development of the global modcls. Chapter 4 provides a discussion on the loading cases used in the baseline performance analysis and outlines the development of the gravity and wind loads on the global tower models. Chapters 5 and 6 outline the results of the baseline performance analysis for the global tower models and floors models, respectively. A summary of the report is presented in Chapter 7.

\section{$1.1 \quad$ DESCRIPTION OF WTC STRUCTURAL SYSTEM}

\subsubsection{Global Structural System}

WTC 1 and WTC 2 each consisted of a 110-story above grade structure and a 6-story below grade structure. The buildings, which were each approximately $207 \mathrm{ft}$ by $207 \mathrm{ft}$ square in plan and with story 
heights of typically $12 \mathrm{ft}$, rose to heights of 1,368 ft (WTC 1) and 1,362 ft (WTC 2) above ground. The exterior walls of the towers supported part of the gravity loads and all lateral loads, and were constructed of steel, closely spaced built-up columns and deep spandrels. The core contained columns that supported the remainder of the gravity loads of the towers. The core area was approximately $135 \mathrm{ft}$ by $87 \mathrm{ft}$ in plan (Fig. 1-1). The distances between the rectangular core and the square exterior wall were approximately $36 \mathrm{ft}$ and $60 \mathrm{ft}$. The areas outside of the core were free of columns, and the floors were supported by truss-framing in the tenant areas and beam-framing in the mechanical rooms and other areas.

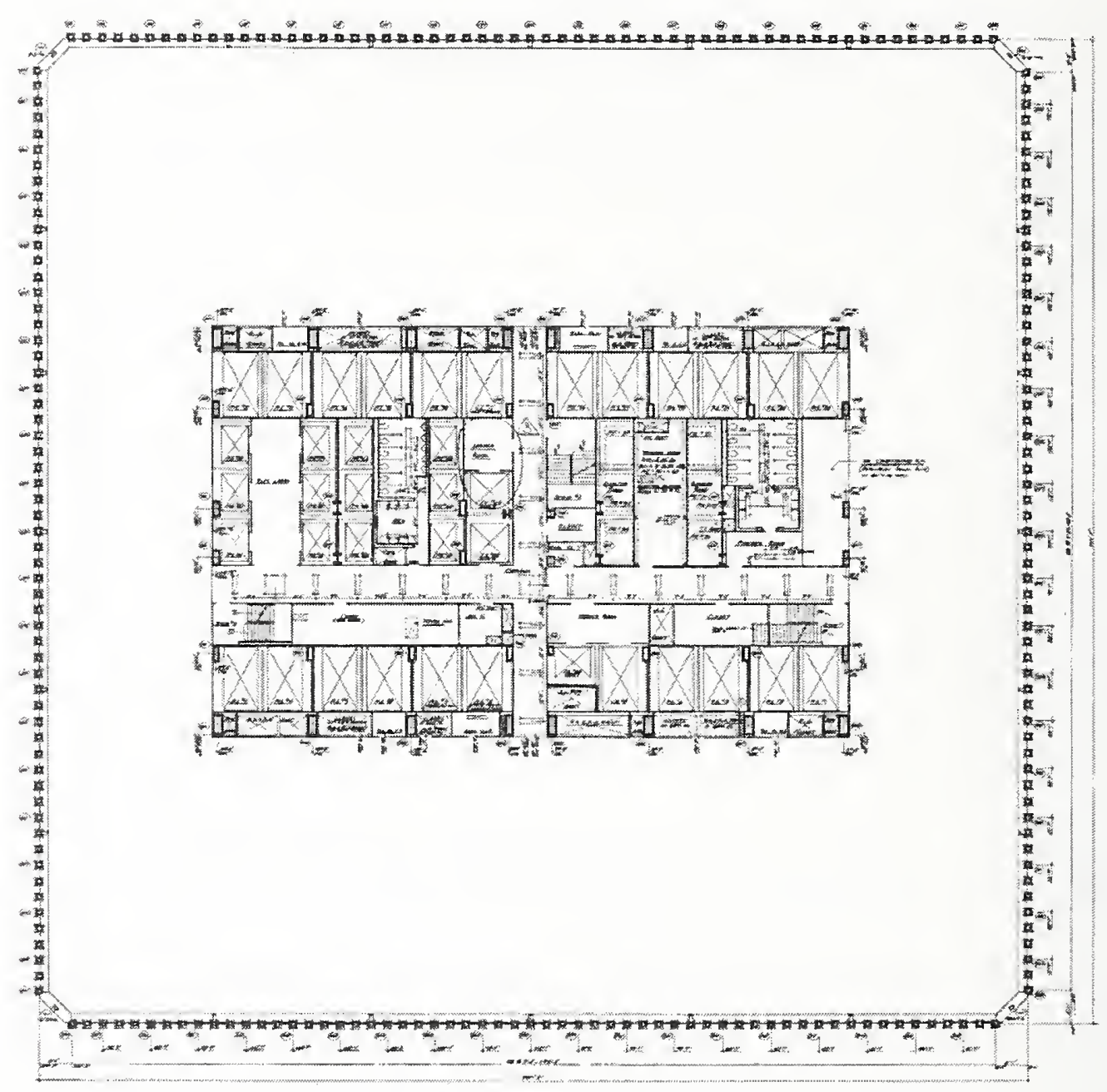

Source: Reproduced with permission of The Port Authority of New York and New Jersey.

\section{Figure 1-1. Typical WTC tower architectural floor plan (floor 26, WTC 2).}

The primary structural systems for the towers included exterior columns, spandrel beams, and bracing in the basement floors, core columns, core bracing at the mechanical floors, core bracing at the main lobby atrium levels, hat trusses, and the floor systems.

The exterior wall columns from the foundation level up to elevation $363 \mathrm{ft}$ were spaced $10 \mathrm{ft} 0 \mathrm{in}$. on center. They were built-up of steel plates and connected by deep spandrels. Bracings existed in the plane of the exterior wall between the Concourse level and the foundation (Fig. 1-2). Between elevation $363 \mathrm{ft}$ 
and floor 7 , the single exterior wall columns spaced $10 \mathrm{ft} 0 \mathrm{in}$. on center transitioned to three columns spaced at $3 \mathrm{ft} 4$ in. on center as shown in Fig. 1-2 (see also Fig. 3-6).

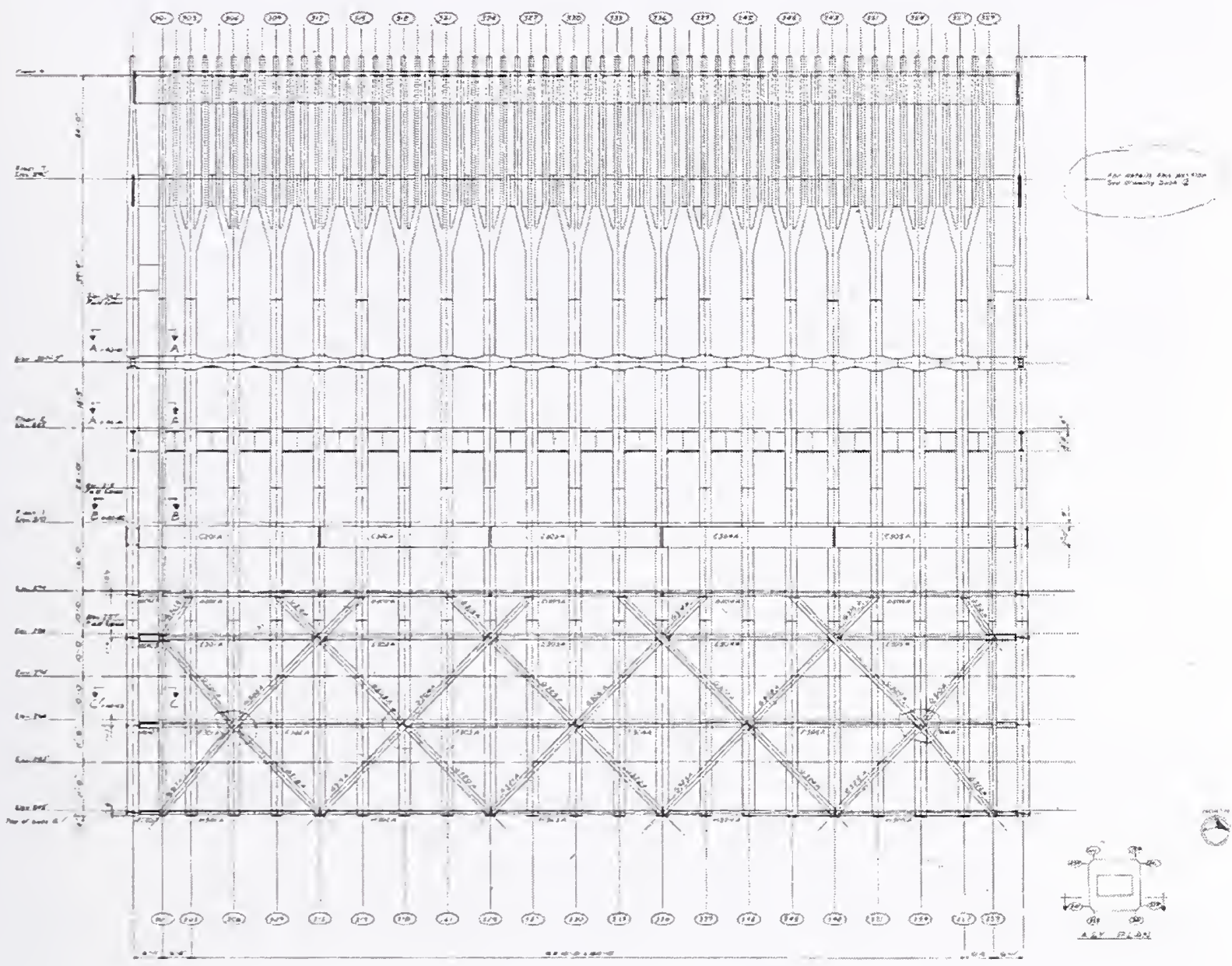

Source: Reproduced with permission of The Port Authority of New York and New Jersey

Figure 1-2. Typical WTC exterior wall, foundation to floor 9.

The exterior wall columns above floor 7 that were spaced $3 \mathrm{ft} 4 \mathrm{in}$. on center, were built-up of steel plates, and were connected to each other by spandrel plates, typically $52 \mathrm{in}$. deep. The exterior columns and spandrels were pre-assembled into exterior wall panels, typically 3-columns wide by 3 -stories tall (refer to Fig. 3-9).

The core columns were typically built-up box members at the lower floors and transitioned into rolled structural steel shapes at the upper floors. The core columns were typically spliced at three-story intervals at $3 \mathrm{ft}$ above floor level. Diagonal bracing of the core columns existed at the lobby atrium levels, the mechanical levels, and in the area of the hat truss.

At the top of each tower, hat trusses interconnected the core columns with the exterior wall panels and provided a base for the antennae. The vertical members of the hat trusses were wide flange core columns. 
The diagonals were primarily wide flange rolled sections, with the exception of the end diagonals connecting the core to the exterior walls, which consisted of built-up box sections. The majority of the horizontal membcrs in the hat truss system were wide flange and built-up box section floor beams. The members of the hat trusses were shown in the structural drawings SA/B-400 series elevations (see Fig. 1-3).

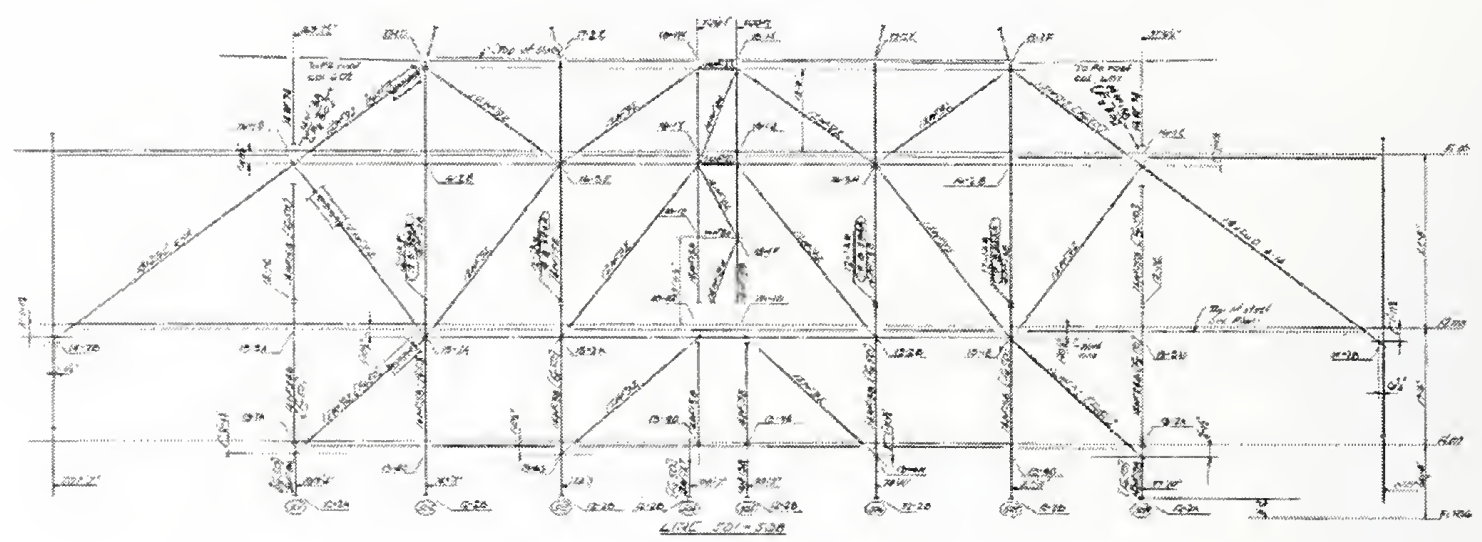

Source: Reproduced with permission of The Port Authority of New York and New Jersey.

Figure 1-3. Typical WTC tower hat truss elevation (Drawing SA 401).

\subsubsection{Floor Structural System}

In the typical WTC tower floor plan, the area inside the core was framed with rolled structural steel shapes acting in a composite fashion with formed concrete slabs. The area outside the core was framed either in trusses (typical on tenant floors) or in rolled structural steel shapes (typical on mechanical floors).

Truss-Framed Floors - The majority of the floors of the WTC towers were tenant floors where the areas outside of the core were constructed of steel trusses acting in a composite fashion with concrete slabs cast over metal deck. The trusses consisted of double angle top and bottom chords with round bar webs and were designed to act in a composite fashion with the concrete slab. Composite action was achieved by the shear connection provided by the web bar extending above the top chord and into the slab. Two trusses were placed at every other exterior column line, resulting in a $6 \mathrm{ft} 8 \mathrm{in}$. spacing between truss pairs. The typical floor consisted of three truss zones: a long span zone, a short span zone, and a two-way zone (see Fig. 1-4).

The floor trusses were pre-assembled into floor panels as defined in the contract drawings. The span of the primary trusses was about $36 \mathrm{ft}$ in the short direction and $60 \mathrm{ft}$ in the long direction. The floor panels included primary trusses, bridging trusses, deck support angles, metal deck, and strap anchors, all of which were defined by the contract drawings and specifications. The two-way zone included trusses in the long-span direction (primary trusses) as well the bridging trusses (secondary trusses). The secondary trusses had additional strength and connectivity to enable them to act in tandem with the long spanning trusses to form a two-way spanning truss grid as shown in zones labeled two-way area in Fig. 1-4. Also; the short span truss at the corner of the core was heavier than the typical ones because it did support the long span trusses that framed to it. 
Since the relative stiffness of the bridging trusses was significant in the two-way zone compared to that of the short span trusses, and since the corner of the floor was supported on two sides and the corner of the core, two directional structural behavior was developed. In the one-way zones, the bridging trusses were lighter and the floor was supported on only two sides (exterior wall spandrels and core perimeter beams), so only one-way behavior was dominant.

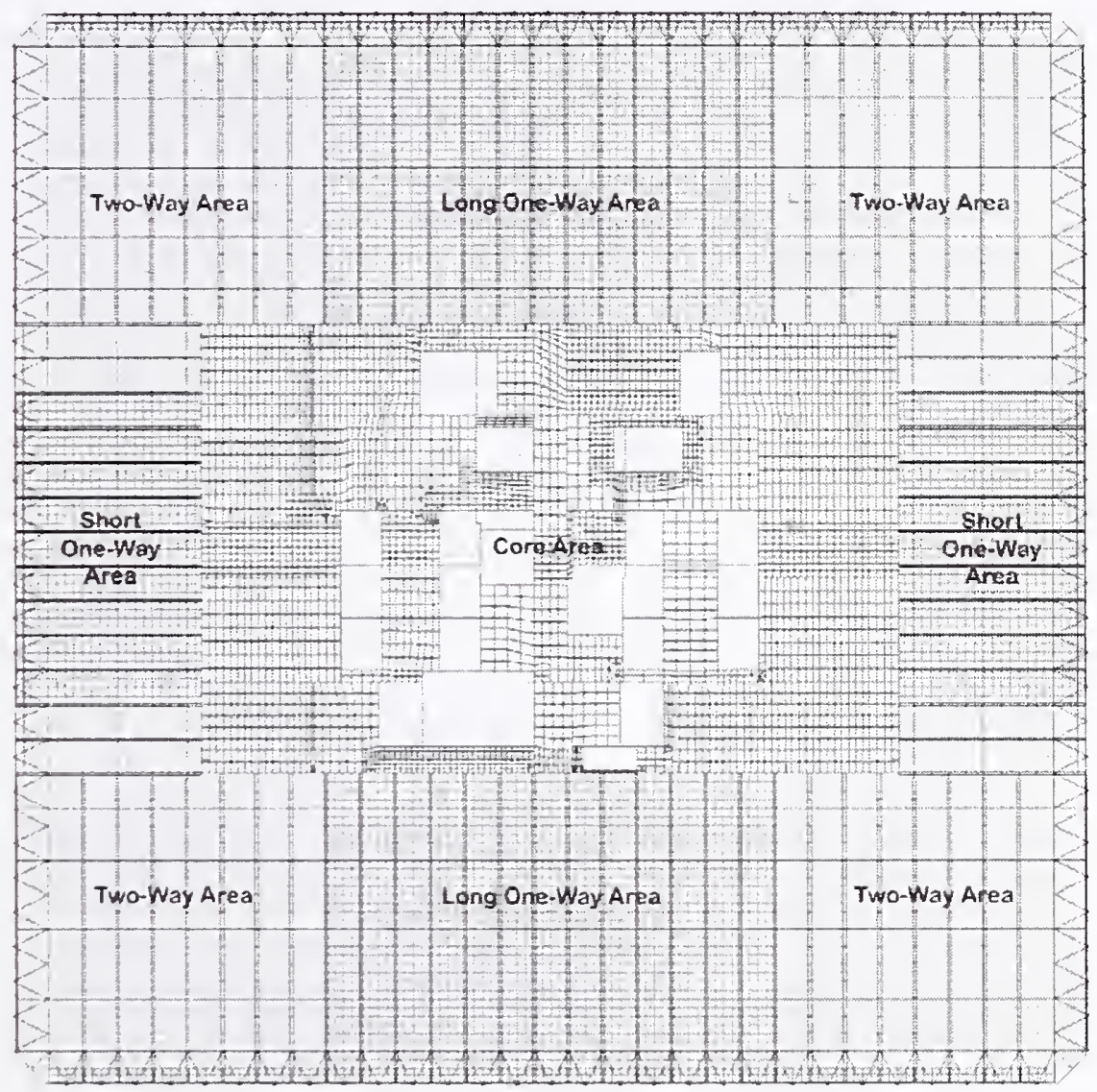

Figure 1-4. Typical WTC floor truss framing zones.

The floor truss panel types were indicated in the structural plans (Fig. 1-5). The plans refer in turn to Drawing Book 7 for information regarding the components of the floor truss panels, and to Drawing Book D for damper information (see Chapter 2 for more details). Drawing Book 7 provided panel by panel layout plans (Fig. 1-6) and elevations (Fig. 1-7) of each referenced truss. The section through a floor panel after the concrete was placed is illustrated in Fig. 1-8. Note that the dashed lines in Fig. 1-5 indicate power and telephone cells within the metal deck construction. 


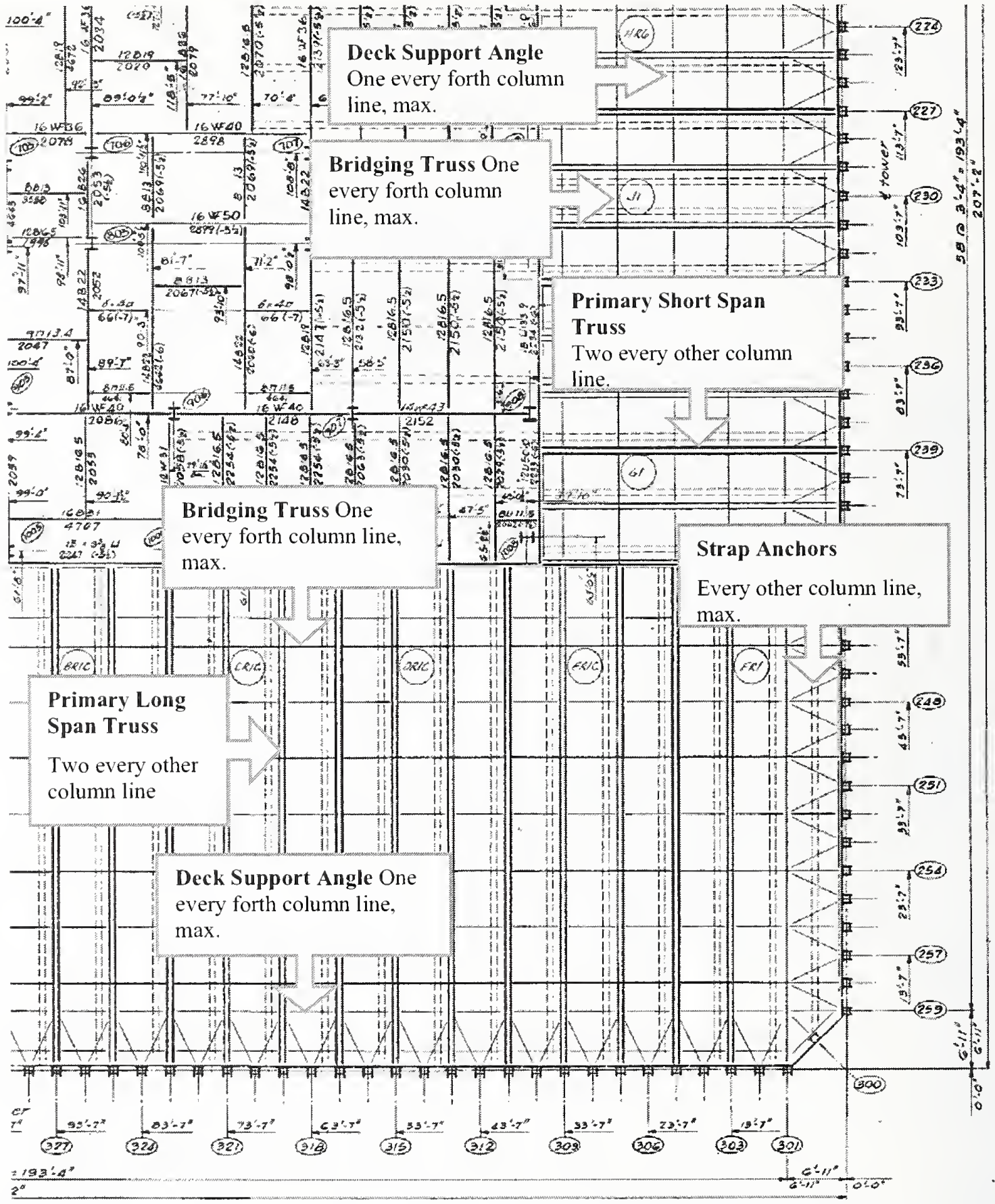

Source: Reproduced with permission of The Port Authority of New York and New Jersey. Enhanced by NIST.

Figure 1-5. Part plan of floor 96 of WTC 1 (Drawing SA-104), components of typical truss framing system. 


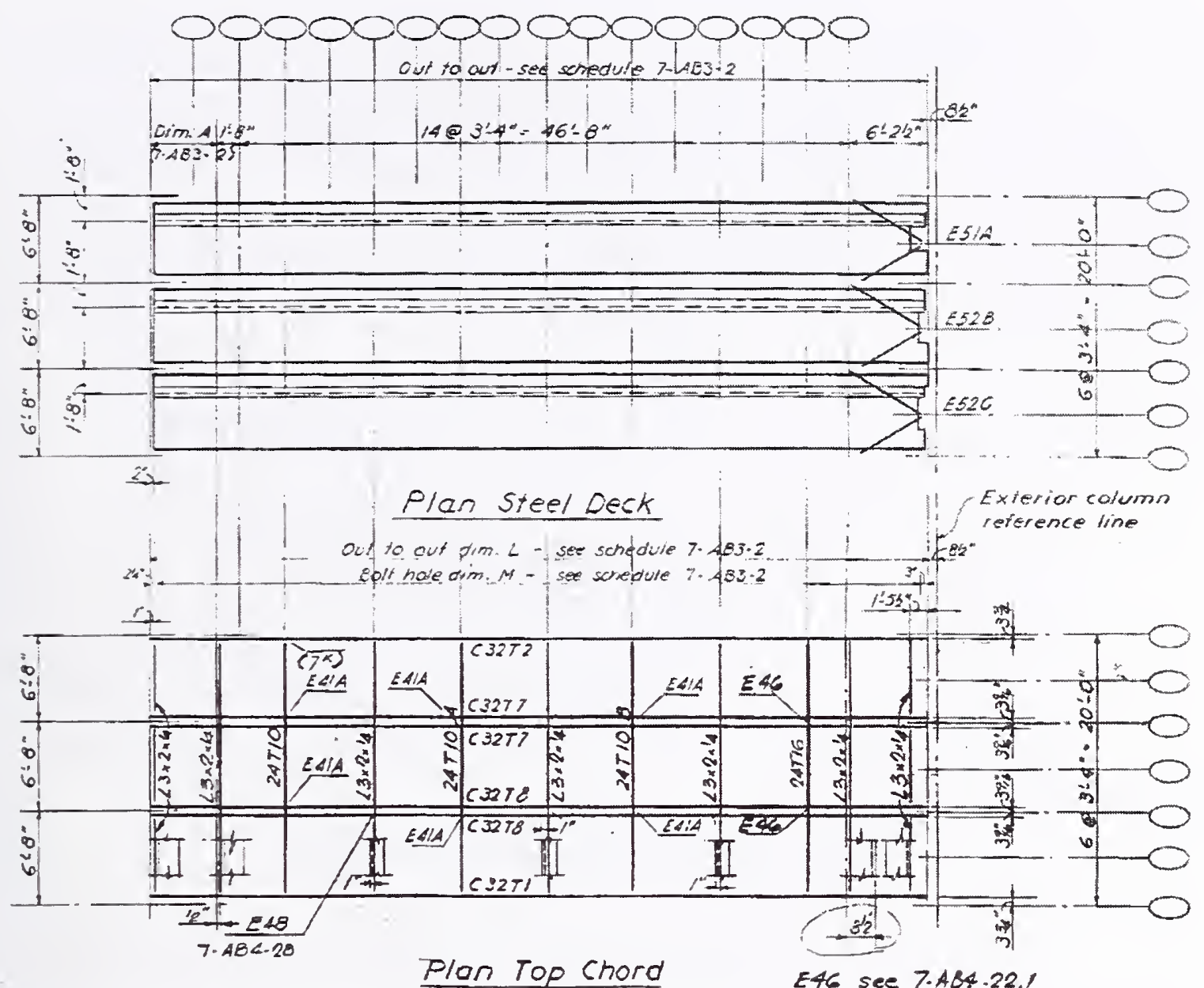

Source: Reproduced with permission of The Port Authority of New York and New Jersey.

Figure 1-6. Typical WTC floor panel layout plan. 


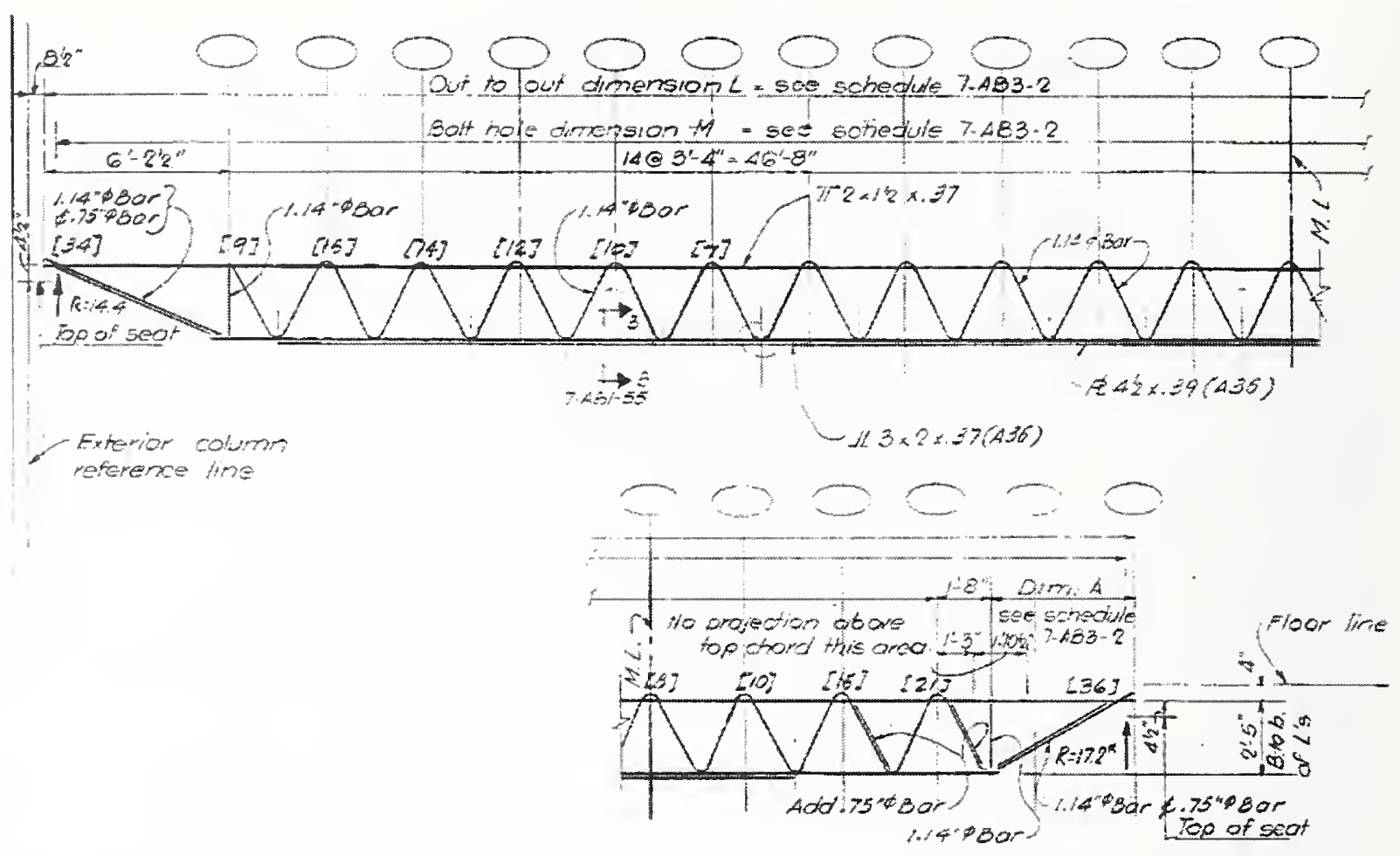

Source: Reproduced with permission of The Port Authority of New York and New Jersey.

Figure 1-7. Typical WTC floor truss elevation.

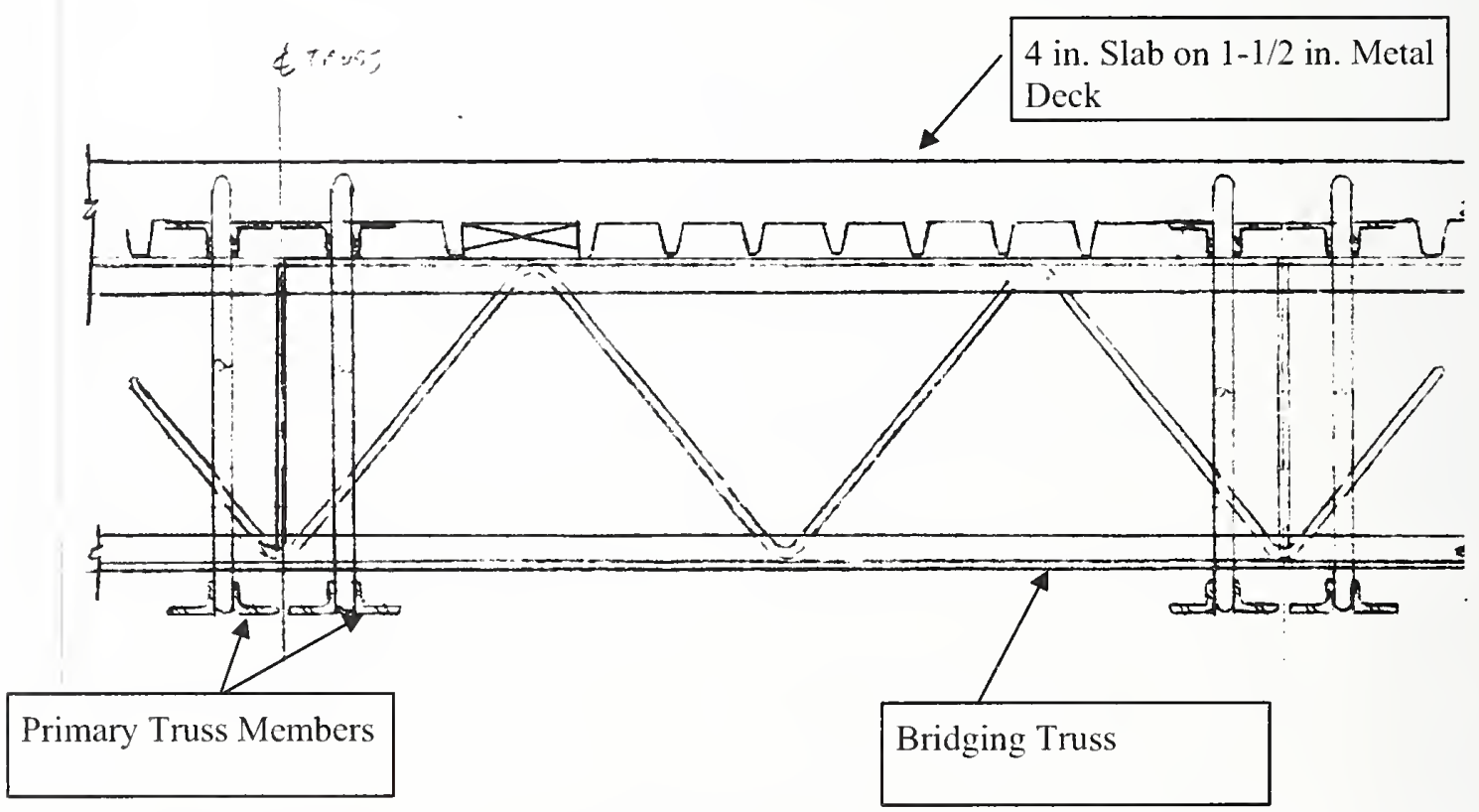

Source: Reproduced with permission of The Port Authority of New York and New Jersey. Enhanced by NIST.

Figure 1-8. Part section typical truss floor panel. 
Viscoelastic damping units were used in the floor system to reduce the wind-induced vibrations of the towers. As the towers oscillated during wind excitations, part of the energy of oscillation was dissipated through shear deformations in the viscoelastic part of the damping unit. The dampers were located between the bottom chords of the floor trusses and the exterior wall columns as shown in Fig. 1-9 and the associated detail in Fig. 1-10. The figures show the construction of the dampers along with the plates, bolts, and viscoelastic material dimensions. The dampers were defined in Drawing Book D. For further details on the dampers design. construction, and testing, refer to NIST NCSTAR 1-1.'

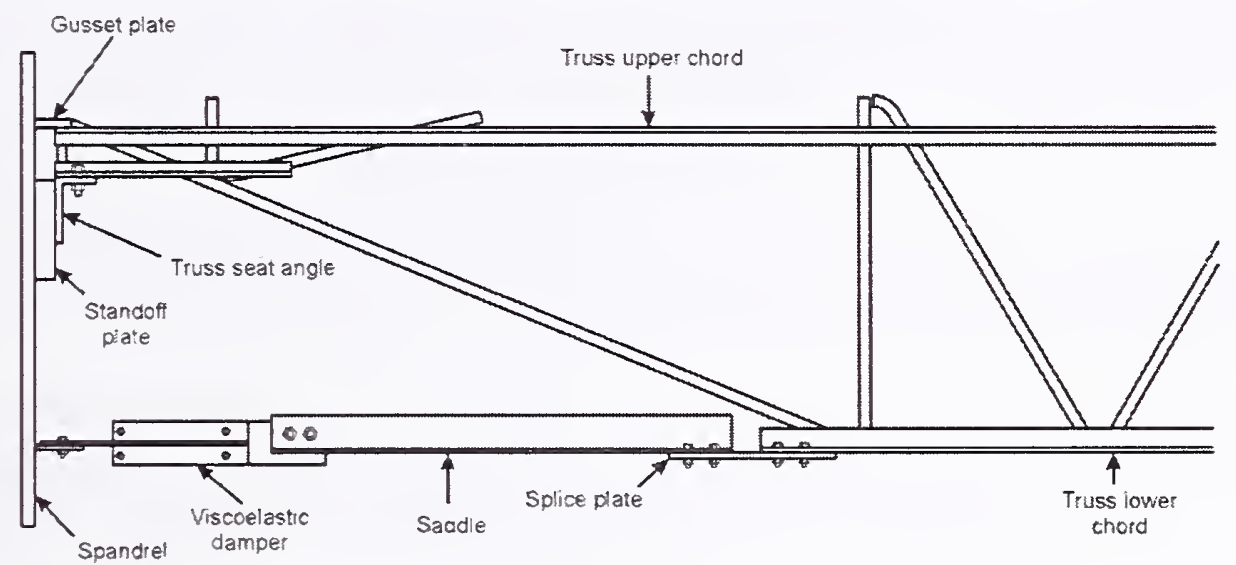

Source: Reproduced with permission of The Port Authority of New York and New Jersey. Enhanced by NIST.

Figure 1-9. Floor truss with exterior wall end detail.

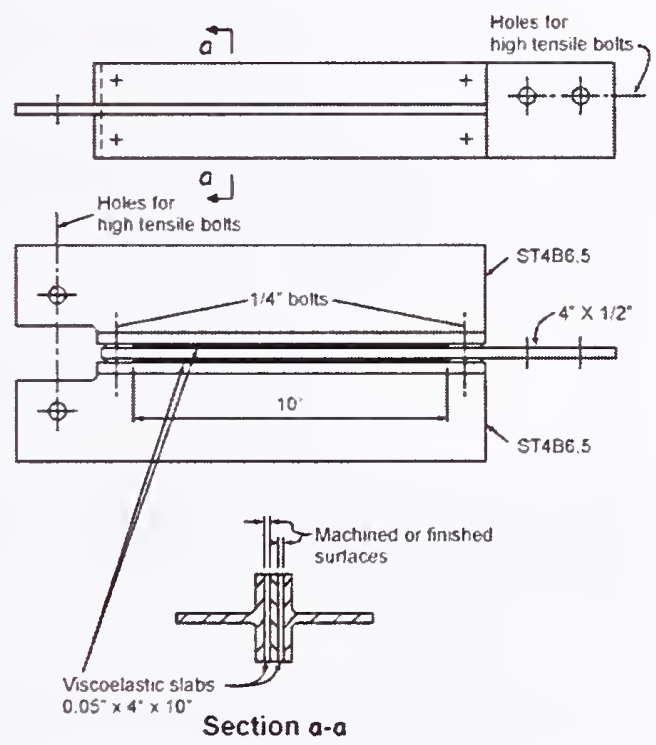

Source: Reproduced with permission of The Port Authority of New York and New Jersey. Enhanced by NIST.

Figure 1-10. Details of the damping unit used in the truss-framed floors.

I This reference is to one of the companion documents from this Investigation. A list of these documents appears in the Preface to this report. 
Beam-Framed Floors-The typical locations of the beam-framed floors were the meehanical floors, the mechanical mezzanines, and the floors above the mezzanines (e.g., floors 41, 42, and 43). These floors were constructed using rolled structural steel shapes. The beam framing for the typical floor system consisted of W27 beams in the long span region and W16 beams in the short span region. Typical beam spacing was $6 \mathrm{ft} 8 \mathrm{in}$. The steel beams acted in composite fashion with the normal weight concrete slab on metal deck.

The mechanical floors were $53 / 4$ in. concrete slabs on $1 \frac{1}{2}$ in. metal deck outside the core. The deck spanned in the direction of the primary beams and was supported typically at $6 \mathrm{ft} 8 \mathrm{in}$. intervals by a 4C5.4 deck support channel. A 2 in. concrete topping slab was placed on top of the structural slab. The core area was framed similarly to the core of the truss-framed floors, but the steel beams were typically larger, and the concrete slab was 6 in. deep. The beam-framed floors above the mechanical mezzanine had a $73 / 4$ in. normal weight concrete slab on $11 / 2$ in. metal deck, while the core slab was 8 in. normal weight concrete. The floor slabs were omitted from much of the mechanical mezzanines outside the core to provide double height space for the mechanical equipment.

Similar to the truss-framed floors, viscoelastic damping units were used in the beam-framed floors to reduce wind-induced vibrations. The dampers were located between the bottom flanges of the floor beams and the exterior wall columns as shown in Fig. 1-11. The dampers that were used in the beamframed floors were slightly longer than those used in the truss-frames floors. Also the connections between the damping units and the floor trusses were different than those between the damping units and floor beams as can be seen from Fig. 1-9 and Fig. 1-11.

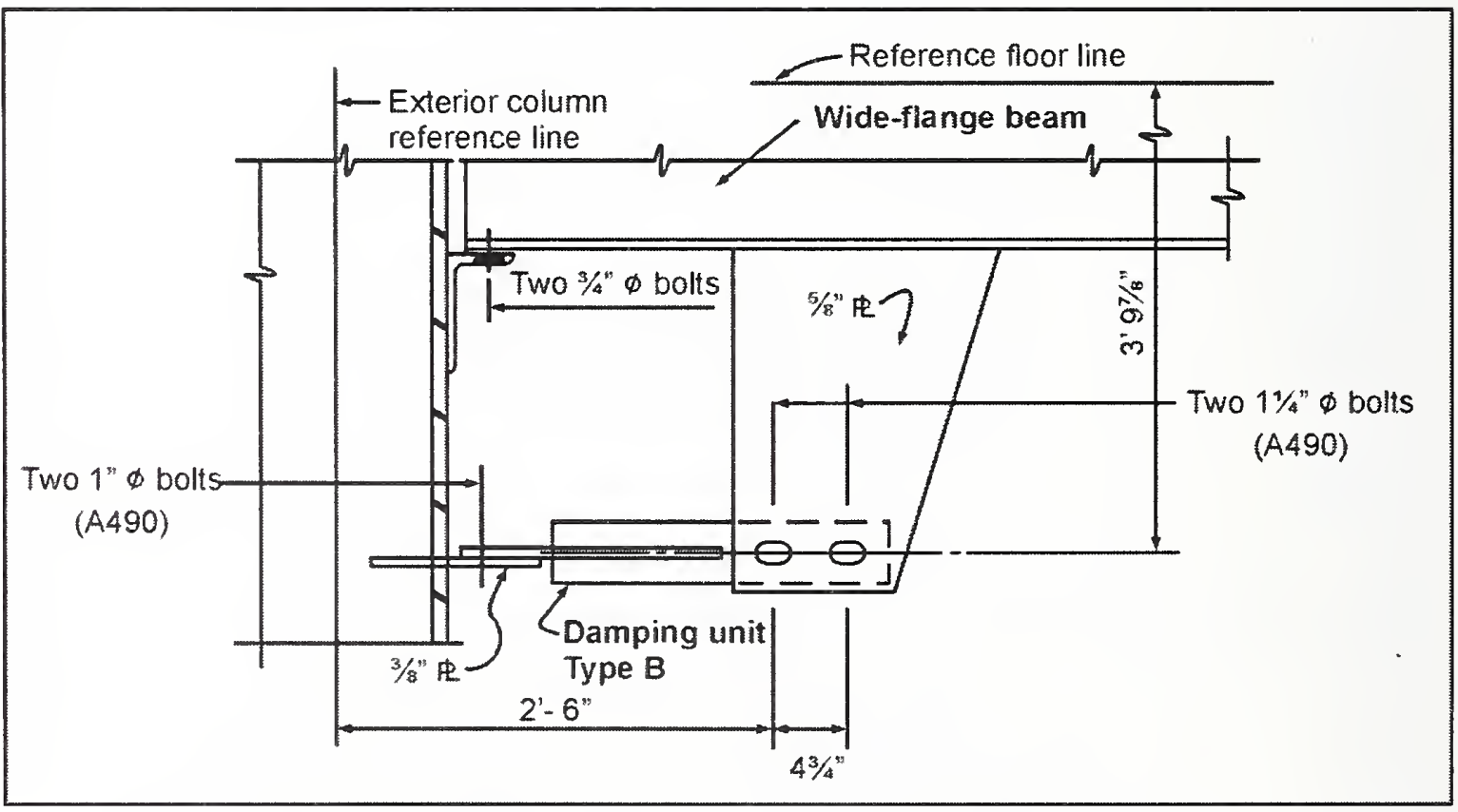

Figure 1-11. Damping unit used in the beam-framed floors.

Beam-framing was added to truss-framed floors at levels which supported escalators or stairs in the areas outside of the core. The escalator floors occurred typically in the two levels directly above the mechanieal rooms. 


\section{Chapter 2 \\ DeVELOPMENT OF StRuctural DATABASES For THE WTC TOWERS}

\section{$2.1 \quad$ INTRODUCTION}

The objective of this chapter is to describe the development of electronic structural databases for the primary structural components of the World Trade Center towers (WTC 1 and WTC 2) from the original computer printouts of the structural documents. These databases were generated for use in the development of the reference structural models of the towers (see Chapter 3 ).

Section 2.2 briefly describes the structural design documents of the towers. Section 2.3 presents an overview of the database development and contents, while Sec. 2.4 outlines the methodology used to develop the structural databases from the original computer printouts, and the relational databases used for the subsequent development of the reference structural analysis models of the towers (see Chapter 3 ). Section 2.5 describes the modifications made to elements of the database based on changes made to the primary structural components of the towers after construction. The calculation of cross section properties is presented in Sec. 2.6. Section 2.7 provides a summary of the chapter.

\subsection{DESCRIPTION OF THE WTC STRUCTURAL DOCUMENTS}

The WTC structural drawings were issued in two main formats: large-sized sheets containing plan and elevation information and smaller book-sized drawings containing details and tabulated information. Throughout the WTC drawings, Tower A or WTCA denotes WTC 1 (North Tower) and Tower B or WTCB denotes WTC 2 (South Tower). For WTC 1 and WTC 2, the large-size sheets are listed in Appendix A. These large-sized drawings always make reference to the structural drawing books in their notes, sections, and details. The structural drawing books for WTC 1 and WTC 2 contain the following materials:

- Book 1 contains exterior wall information to elevation $363 \mathrm{ft}$. (Dates: 02/1967 to 12/1968, Approx. 213 pages.)

- Book 2 contains exterior wall information elevation $363 \mathrm{ft}$ to floor 9. (Dates: 04/1967 to 12/1967, Approx. 62 pages.)

- Book 3 contains core column information. (Dates: 03/1967 to 09/1969, Approx. 137 pages.)

- Book 4 contains exterior wall information floor 9 to floor 110. (Dates: 04/1967 to 10/1972, Approx. 1,080 pages.)

- Book 5 contains the beam schedule. (Dates: 05/1967 to 08/1969, Approx. 292 pages.)

- Book 6 contains connection details and core bracing. (Dates: 08/1967 to 05/1969, Approx. 1,060 pages.) 
- Book 7 contains truss floor panel information. (Dates: 10/1967 to 07/1969, Approx. 345 pages.)

- Book 8 contains concrete notes and details. (Dates: 03/1968 to 07/1974, Approx. 926 pages.)

- Book 9 contains roof area column splice details. (Dates: 05/1970 to 04/1971, Approx. 440 pages.)

- Book 18 contains strap anchor and core truss seat information. (Dates: 10/1968 to 11/1969, Approx. 219 pages.)

- Book 19 contains revisions after fabrication. (Dates: 08/1968 to 05/1975, Approx. 374 pages.)

- Book 20 contains structural steel details. (Datcs: 07/1968 to 03/1971, Approx. 41 pages.)

- Book D contains damper details. (Dates: 03/1969 to 09/1971, Approx. 43 pages.)

Books 10,11, 12, and 13 contain information on the sub-grade structure. Books 14, 15, 16, and 17 were never used in the original design documents.

Until fabrication was begun, the drawings and drawing books listed above (with the exception of Book 19) were modified in keeping with requests for changes by contractor(s) and early tenant modifications. The drawings were modified up until such time as the fabrication of elements commenced. At that time, Book 19 was introduced. It contained the information regarding 'revisions after fabrication'.

Leslie E. Robertson Associates, R.L.L.P. (LERA) believes that the original structural drawings represent significantly accurate 'as-built' drawings for the towers. As tenant modification requests became large in scope, they becamc separate projects (e.g., the Fiduciary Trust Vault Project, see Sec. 2.5.2). Tenant structural modifications designed by LERA werc then documented in a single book of quarter-size plans, referred to as the 'WTC Tenant Structural Modifications Book.' Later tenant modifications were mostly archived on a job-by-job basis without a central accounting for all the changes. In some instances (e.g., additions to the mechanical levels) modifications were made by The Port Authority of New York and New Jersey (PANYNJ) Engineering. In other instances, tenant modifications, such as adding floor openings, were made by other engineers. In these instances, LERA does not have record of the work completed. These modifications were considered to not significantly affect the member propertics pertaining to the reference structural models and were not included in the WTC structural databases.

The few modifications made by LERA to the components compiled in the WTC structural databases that have an effect on the global behavior of the towers are listed in Table 2-1.

Drawing Book 19 has records of other modifications to structural elements of the WTC towers that were viewed as non-essential for the development of the reference models of the towers and as such were not included in the structural databases. These modifications are outlined in Appendix B. 
Table 2-1. Modifications to members of the WTC database (WTC-DB).

\begin{tabular}{|c|l|c|c|c|c|c|c|}
\hline Item & Description & Tower & Element & Floor & Element Effected & $\begin{array}{c}\text { WTC-IDB } \\
\text { Modified }\end{array}$ & Archived \\
\hline 1 & $\begin{array}{l}\text { Core column } \\
\text { reinforcing }\end{array}$ & $\begin{array}{l}\text { WTC 1 } \\
\text { and } \\
\text { WTC 2 }\end{array}$ & Numerous & $98-106$ & Core columns & Book 3 & Book 19 \\
\hline 2 & $\begin{array}{l}\text { Fiduciary Bank } \\
\text { Vault }\end{array}$ & WTC 2 & $\begin{array}{l}\text { Col. 508B and } \\
\text { Col. 1008B }\end{array}$ & $45-97$ & Core columns & Book 3 & LERA P209 \\
\hline 3 & $\begin{array}{l}\text { Bombing of 26 } \\
\text { February 1993 } \\
\text { repair }\end{array}$ & WTC 1 & $\begin{array}{l}\text { Col. 324, } \\
\text { bracing } \\
\text { G313A and } \\
\text { G304A }\end{array}$ & B-2 level & $\begin{array}{l}\text { Perimeter } \\
\text { column and } \\
\text { bracing }\end{array}$ & NA & $\begin{array}{l}\text { LERA } \\
\text { P1003118 }\end{array}$ \\
\hline 4 & EXCO stair & WTC 1 & $\begin{array}{l}\text { Col. 901A } \\
\text { Core column }\end{array}$ & NA & $\begin{array}{l}\text { LERA } \\
\text { P1003249 }\end{array}$ \\
\hline
\end{tabular}

\subsection{OVERVIEW OF THE WTC STRUCTURAL DATABASE (WTC-DB)}

The original WTC design documents were devised to limit the need for repetition in documenting the data shared between different elements with similar characteristics. The drawing book schedules refer to subsequent tables for information common to several lines of the same schedule. In an effort to minimize the amount of repeated information, and thereby, the data checking of the digital WTC-DB, the drawing book data within the databases were linked in a similar manner. In order to accurately follow the original flow of the drawing book links, flowcharts of the drawing books to be digitized were developed. These flowcharts were used to organize the links of the digitized data within the relational database. The flowcharts are illustrated in Appendix C. An example of such flowcharts for Drawing Book 3 (core columns) is shown in Fig. 2-1.

The WTC-DB contained the computer and hand-tabulated data for the major structural components from original Drawing Books 1 through 5, including exterior walls, core columns, and beam schedule for the towers. Where information from Drawing Books 1 through 5 was modified by Drawing Book 19 and would affect the towers' modeling, the information was included in the database. In addition, some information from Drawing Book 6 (core bracing schedule) and Drawing Book 9 (beams in the hat truss region) was included in the database files as it was utilized in the finite element modeling of the towers.

The drawing book tables were first digitized and stored in Microsoft Exccl format files. The Excel files included several worksheets that described the evolution of the data from the drawing book to the final database format, as well as additional information and notes for interpreting the data. Refer to Appendix D for the list of Excel format files.

The WTC relational database linked the Excel files and allowed users to view and select data through query commands. The primary benefit of the relational database format was the ability to programmatically query the database for data required in assembling the structural models of the towers. The query routine allowed multiple users the ability to review, extract, and export the basic data in any required form. The data can be manipulated using Structured Query Language (SQL) according to the desired output, for example the structure of the uscr's finite element model input file. 

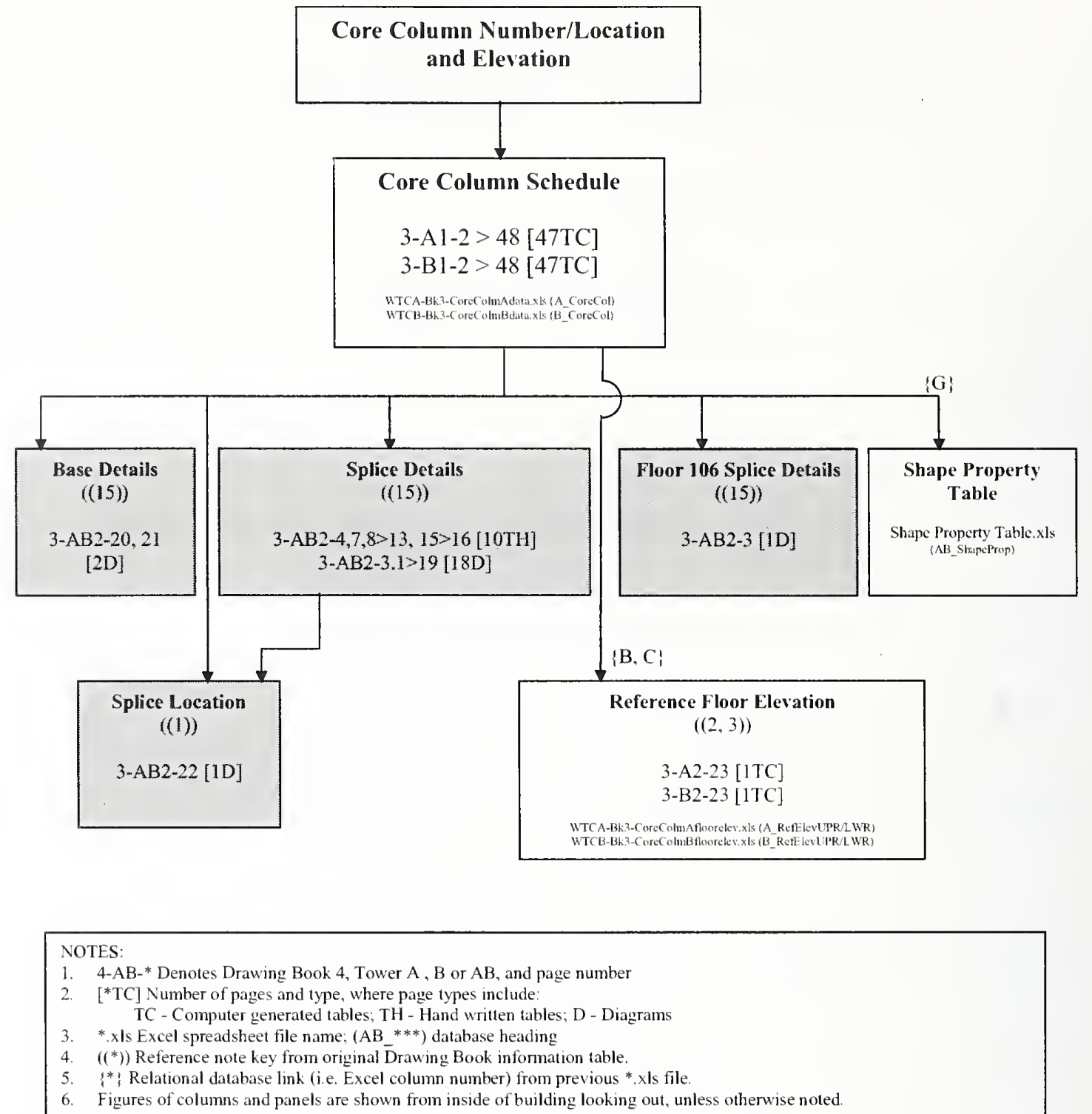

Figure 2-1. Drawing Book 3 flowchart: WTC 1 and WTC 2 core columns, foundation to floor 106.

\subsection{METHODOLOGY FOR THE WTC-DB DEVELOPMENT}

\subsubsection{Data Entry}

The tabulated portions of WTC Drawing Books 1, 2, 3, 4, 5, 6, and 9 were first scanned and stored in Tagged Image File Format (TIFF) image files. The image files containing the tabulated information were then opened in an Optical Character Recognition (OCR) program that converted the information into a text file. The OCR program was modified to allow for the filtration of unnecessary characters during the document conversion process. In other words, the user could direct the program to block specific characters that were not on the actual page. As an example, if after reviewing a table, one recognizes that 
it uniformly contains numbers and only the characters "A, B, -," and "/" then the remaining characters can be frozen out by the software. This reduced the misinterpretation, as an example, of a ' $Z$ ' for a ' 2 ,' or an 'O' for a 'zero.'

The raw text file was then opened in a word processing program, where it was compared with the original hardcopy drawing books. As needed. data columns were adjusted, and obvious errors were individually corrected. The 'cleaned' text file was then imported into a Microsoft Excel spreadsheet with column headings and proper alignment. When importing into Excel, "text" was the cell format used for handling of the scanned information to avoid the misinterpretation of fractions as dates (e.g., 3/8 as March 8). An Excel macro was written at this stage to convert the text fractions into number fractions. The final product of this stage was an Excel file that contains the information from the drawing book table.

\subsubsection{Quality Control}

Checking began during the OCR data entry process, where the files being entered and the OCR software interpretation were viewed simultaneously. This was considered a first check. Once the Excel file was complete, the file entered the 'second check' process.

The 'Second Check'-An engineer not involved during the OCR process performed a second, sample checking of the database in a random but methodical manner. For approximately once in four pages, every cell of data in the page was compared with the original drawing books. Discrepancies of the files were then either re-entered using OCR or were individually corrected to agree with the original books.

The 'Cross-Check Rectifi' Check-After completing the 'second check,' the files were compared with the database provided by a consultant for the leaseholder of the WTC towers as part of insurance litigation concerning the towers (provided by NIST as Government Furnished Information [GFI]) using a cross-check macro formula worksheet. Once compared, conflicting information appeared in a yellow highlighted cell displaying both sets of compared information in the "Calculation" macro formula worksheet. The cell was then reviewed and confirmed with the WTC drawing books. If errors were from the developed worksheet, data were rectified, and the yellow highlight in the 'Calculation' worksheet was then removed by comparing the files again. If errors were from the GFI worksheet, raw GFI data were not modified, but the cell was highlighted in blue to note that it had been reviewed. The files were then compared again, and the cell color in the 'Calculation' worksheet changed to blue. The process was repeated to remove all the yellow cells so that only blue highlighted cells remained. The worksheet 'ComparisonORIGINAL' was retained for the record of the original comparison, and the updated worksheet 'ComparisonFINAL' was retained for the record of the final comparison.

Final Review-Finally, the files were reviewed for completeness, formatting, and data units. A final check was made to find any numbers that may have been input as text letters. Following this review, the worksheet was used to develop the member section properties.

\subsubsection{Cross Section Property Calculations}

The next step was to calculate the cross section properties for the members included in the database. The section properties calculated included cross sectional area $(A)$, moment of inertia $(I)$, section modulus $(S)$, plastic section modulus $(Z)$, radius of gyration $(r)$, and torsional constant $(J)$ for both the major and minor 
axes, where applicable. The Section Designer function of SAP2000 Version 8 (SAP2000 2002) was used to calculate the cross section propcrties since it streamlines the development of the models and enables the program to perform more precise code checks, as the dimensions of each plate element that was part of the section would be input into the finite element model.

The current rolled shape database in SAP2000 represents the modern day rolling practices. The rolled shapes used in the construction of the WTC towers were from a different era and, thus, had different properties in comparison to present day shapes. Therefore, a rolled shape database consistent with the time of construction was developed. Sec Sec. 2.6.5 for further discussion about the rolled shape database.

\subsubsection{Relational Database Development}

As discussed earlier, the original WTC drawing books were designed to avoid repeating identical information. The drawing book schedules, therefore, refer to other tables for information common to several lines of the same schedule. In keeping with the nature of the original drawing books and to minimize the data in the digital WTC-DB, the drawing book and section property data were linked using Microsoft Access.

The assembly of the relational database began with the mapping of the original WTC drawing book into flowcharts (see Fig. 2-1). The digitized drawing book data with the corresponding cross sectional member properties from the Excel-format files were then imported into the Microsoft Access database program and partitioned into tables. The tables were then joined using the links cataloged in the flowcharts. These tables were developed to provide the input files for the finite element modeling of the towers as illustrated in Chapter 3. The generated Microsoft Access database files are listed in Appendix E. The relational database is described in the tutorial included in Appendix F.

\subsection{MODIFICATIONS TO DATABASE ELEMENTS}

Most original members and elements defined within the WTC-DB could be fully defined by the original data in the drawing books. As outlined in Table 2-1, however, some modifications were made, and these are described in the following sections. Of the items outlined in Table 2-1, items 1 and 2 were included within the database.

\subsubsection{Core Column Reinforcing at Floors 98 to 106}

A number of core columns in both WTC 1 and WTC 2 were reinforced at floors 98 to 106 . Book 19, pages 19-AB-974.1 through 4, shows that core columns 501, 508, 703, 803, 904, 1002, 1006, and 1007 from floors 98 to 106 in both towers were reinforced with steel plates. Three methods were used to attach the reinforcing plates to the wide flange columns: (1) the plates were welded to the flanges; (2) the plates were welded to the webs; and (3) the plates, which were parallel to the web, were welded to the flange ends. The plate information (width, thickncss, length, and yield strength) was incorporated into the database tables of Book 3. Since the plates varied from floor to floor, the original column (defined over a three-story height) was split into typically three floor-by-floor sections, and the designation of the column was appended to include either U (upper), M (middle), or L (lower) designation (refer to Fig. 2-2). For floors 104 and 106, the columns were two-stories high. Hence, the columns at these floors had only $U$ and $\mathrm{L}$ designations. The section property calculations included the contributions of the reinforcing plate 
at each level. For the built-up section property data, the reinforcing plate was considered to be applied to the column for its floor-to-floor height.

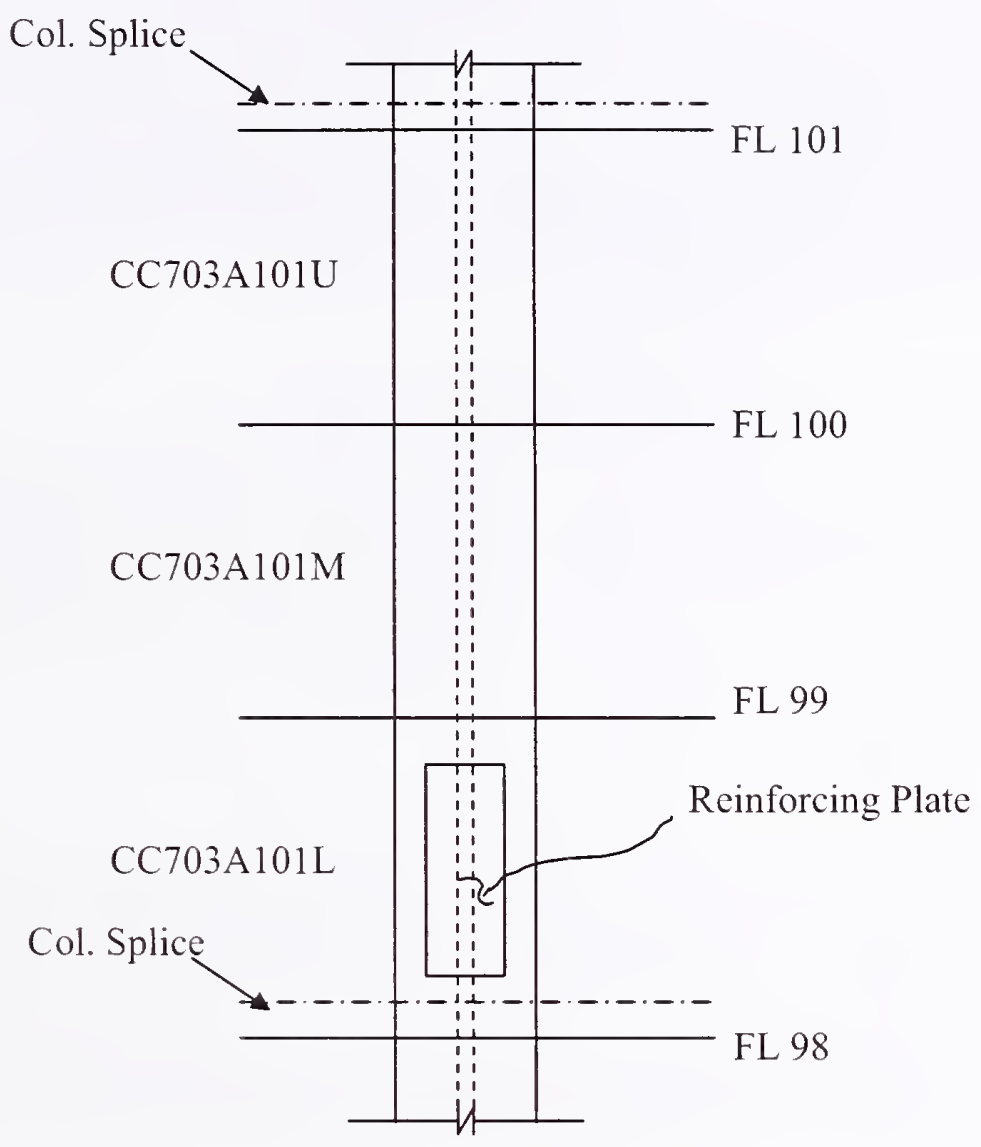

Figure 2-2. Core column reinforcement.

\subsubsection{Core Column Reinforcing Due to Construction of Fiduciary Trust Vault}

The Fiduciary Trust Company added a concrete vault at floor 97 of WTC 2, which required reinforcing two corner core columns at the north end of the core (columns 508 and 1008). This work was included in the WTC Towers A and B Structural Renovation Drawings Reference Manual. The Fiduciary Trust Structural Drawing 765-S-A-4 indicated that WTC 2 core columns 508 and 1008 were reinforced with steel plates from floors 45 to 97 . The reinforcement consisted of plates welded to the flanges of the builtup box columns (floors 45 to 83 ) and the flanges of the rolled shape columns (floors 83 to 97). These reinforcing plate modifications and the reinforcing plates' yield strength, $F_{y}$, were added to the original Book 3 data contained in the WTC-DB. The database included plates that were long enough to substantially affect the member properties of the column, that is, the added plates increased the capacity of the columns. Where the plates appeared to reinforce only the column splice, they were not included in the database. For the reinforced columns, no specific information is available about the fireproofing of these elements. It is presumed that these elements were fireproofed in the same way and using the same materials as other parts of the structure. 
The reinforcing plate data were tabulated and incorporated into the database in the same manner as the plates discussed in the previous section, except that a second length designation was added to differentiate the length of the plates on the north and south faces of the columns, i.e., the column designation "LN" refers to the length of the plates on the north face of the column. Again, when calculating the built-up column properties, the plate was assumed to be continuous along the floor-to-floor height of the column. When the length of the reinforcing plate shown in the drawing was greater than the floor height, the plate was attributed to the two column segments. Where the plate extended over the entire height of the segment, the length was tabulated as the height of the column segment. The remaining length of plate was attributed to the other column segment.

\subsubsection{Repair Due to the Bombing of February 26, 1993}

The 1993 bombing resulted in structural damage to WTC 1, centered at exterior column 324 (south wall), B-2 level. The face of the column toward the explosion was slightly bowed, and the splice in the column developed a hairline crack. The column was reinforced locally to account for the loss of steel area. The bracing on either side was replaced with equivalent sections and attached in a similar manner as the originals. No modification to the WTC-DB was made for this repair.

\subsubsection{Tenant Alteration for an Interoffice Stair}

A tenant alteration was provided for an interoffice stair between floors 25 and 26 in WTC 1. This work, adjacent to core column 901A, was performed by an engineering firm (other than LERA) and unknowingly resulted in the loss of a core column bracing strap (refer to Fig. 2-3), leaving the column unbraced about its minor axis for two stories. The PANYNJ alerted LERA to the issue, and asked LERA for a review. LERA found the column stability to be adequate. No modification to the WTC-DB has becn made for this modification. The effect of removing the strap is accounted for in the global model of WTC 1; see Sec. 3.2.3.

\subsubsection{Drawing Book Data Discrepancies}

In the original WTC drawing book data, the following discrepancies were discovered by LERA:

- Book 1, page 1-B-15. For member number G311A, the inch portion of the length is listed as $3-1 / 18$. Based on the comparison with similar bracing types in the area, this dimension was modified to be $3-1 / 8$ in. in the WTC-DB.

- Book 3, page 3-A1-10. For core column 601A between floors 86 to 89 and 89 to 92 , the column type is listed as 213 . Typc 213 is a column type which by definition has reinforcing plates, but for this location no plate data were provided in the schedule. This, in combination with comparisons with similar columns in plan, led to modifying the column type to 111 . This also applies to column $601 \mathrm{~B}$, page 3-B1-10 between floors 86 to 89 and 89 to 92 .

- Book 3, page 3-B1-48. For column 1008B between floors 63 to 66 , the yield strength, $F_{y}$, is listed as $6 \mathrm{ksi}$ in the table. Based on the yield strength of the columns above and below these floors, the yield strength was modified to be $36 \mathrm{ksi}$. For the same column number and floor segments, the lower splice detail number is listed as "01G." Based on the lower splice detail 
number of the columns above and below these floors, the number was modified to be "301G."
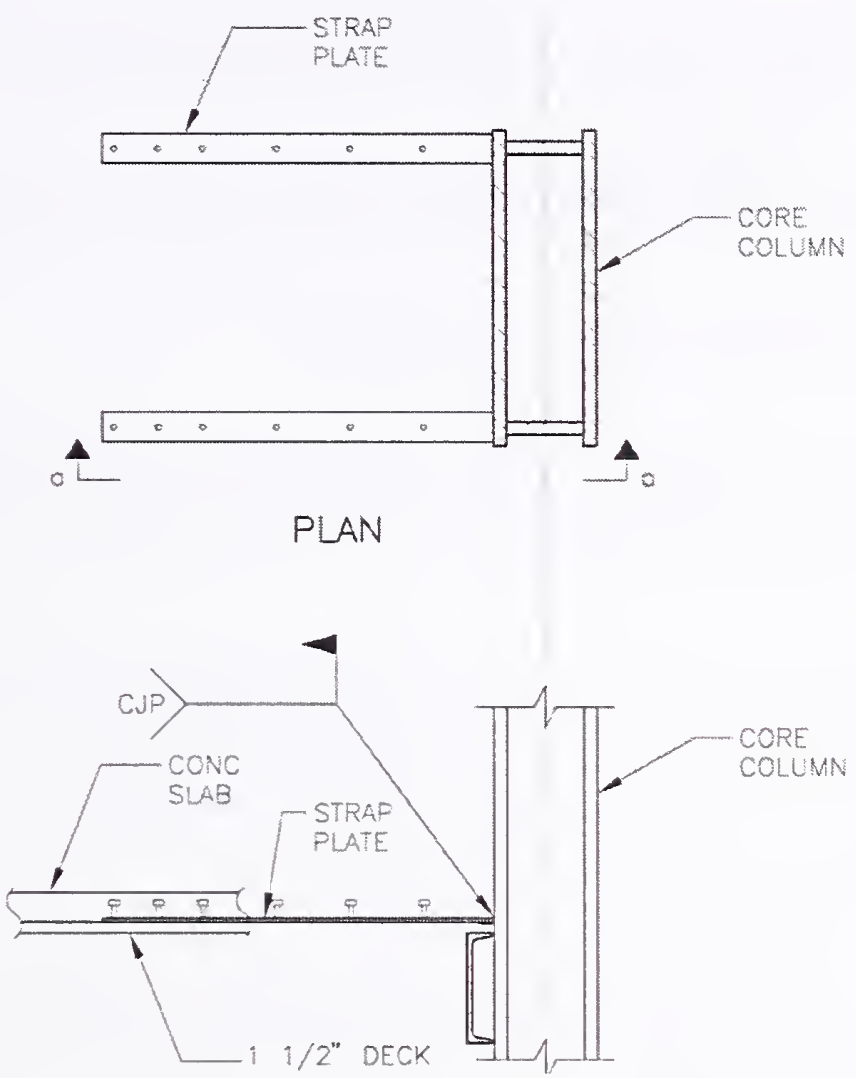

Source: Reproduced with permission of The Port Authority of New York and New Jersey. Enhanced by NIST.

Figure 2-3. Column section at original column strap detail (taken from drawing book 18, page 18-AB2-12).

- Book 3, page 3-B1-9. For core column 508B between floors 21 to 24 , the length of plate 1 , $W 1$, is tabulated as $11.25 \mathrm{in}$. However, length $B$ for this column is $22 \mathrm{in}$. and thickness $t 2$ is 5.5 in. $W 1$ equals $B$ minus two times $t 2$ (see Fig. 2-4). Hence, assuming $t 2$ was listed correctly in the table, $W 1$ was modified to be $11 \mathrm{in}$.

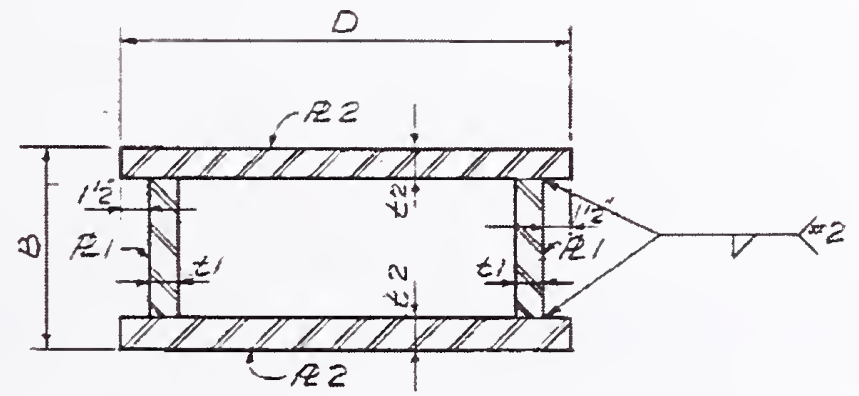

Source: Reproduced with permission of The Port Authority of New York and New Jersey. Enhanced by NIST.

Figure 2-4. Core column series 300 . 
- Book 1, page 1-B-23 and 1-B2-19. The details for column types 1024, 1025, 5024, and 6025 listed in the tables are not explicitly shown in the drawing book. For these members, column shapes were assumed to be as shown in the typical details in page 1-B-19 for the 1000 serics columns, $1-\mathrm{B}-24$ for the 5000 series column, and the $1-\mathrm{B}-27$ for the 6000 series column.

- Book 3, page 3-AB2-6. The column type 216 does not appear to be assigned to any member in the drawing book.

\subsection{SECTION PROPERTY CALCULATIONS}

SAP2000 Section Designer was typically used to calculate section propcrtics for built-up sections. The scctions were "built-up" within SAP2000 by defining plate dimensions and offsets from 0-0 location. Section orientations were defined with the $\mathrm{X}-\mathrm{X}$ axis horizontal to the bottom of the original drawing book page as the detail is shown in the drawing book.

During the process of calculating properties there was an exception to this orientation rule. Core column members CC1007A104L, CC1002A 104L, CC703A106L, CC1007B104L, CC1002B104L, and CC703B 106L consist of a wide flange shape and web reinforcing plates. These members were input into SAP2000 rotated 90 degrees from the orientation shown in the details to utilize the default orientation of the wide flange section in Section Designer. Once the properties were calculated, the sections were placed in the WTC-DB following the orientation of the detail (i.e., the axis was shifted back 90 degrees).

When rolled shapes were used to create built-up sections, the rolled shapes database developed for this analysis was used to build the sections in SAP2000 Section Designer as explained in Section 2.6.5. The 200 series core columns (wide flange rolled columns reinforced with plates) are examples of members whose properties were calculated in this manner.

\subsubsection{Member Designations}

For member section property calculations and assembly of the finite element models, the members were named using the following general member designations. The member designations are listed in the Microsoft Excel fïles.

First character:

- Book 1-below tree-B

- Book 2-exterior wall tree-T

- Book 3-core columns-C

- Book 4-exterior columns and spandrels-E 
Second character:

- C-column

- S-spandrel and below grade exterior wall spandrel, strut, or bracing

Third to fifth character: (third to sixth character for 4 digit column e.g., 1004)

- Column number

Sixth character:

- A-WTC 1

- B-WTC 2

Seventh character and above:

- Upper splice level—for core columns

- U (upper), M (middle), or L (lower)—column segment where reinforcing plates are added

- $\mathrm{T}$ or B-top or bottom of nonprismatic columns

- Detail letter (lowercase) - (where more than one section is calculated)

- $\mathrm{F}$ or $\mathrm{C}$ - face or center of nonprismatic spandrel

- Elevation-below tree spandrel elevations

\subsubsection{Column Member Multiple Section Property Calculation}

In the database, the following three types of column members had different cross sections along the length of the members:

- Exterior wall tree at level C in Drawing Book 2 (two different cross sections)

- Exterior wall tree at level E in Drawing Book 2 (three different cross sections)

- Exterior column type 300 (floor 9 to 106) in Drawing Book 4 (two different cross sections)

For these three member types, the section properties of the different cross sections were calculated and listed in the database tables. In an effort to minimize repeated information, the raw input data for all sections were only shown in the rows that corresponded to the first cross section. For the second and third (if any) cross sections, the calculated data followed in the rows below. The constant raw data such as the column number were not repeated in these rows of the table, and thus, the corresponding cells were left blank. Since the column number was used as a link for the development of the relational database, only the row containing the raw input data and the first cross section properties were returned in a query, 
and thus, the user must refer back to the Microsoft Access 'Tables' for the remaining section property information. The section names of the different cross sections along the member length were distinguished by the last one to two characters, which identified the cross sections where the section properties were calculated.

For example, exterior column EC339 (mechanical floors) tapers over a portion of the length of the member (refer to Fig. 2-5). The section properties above and below the spandrel were calculated. The column section above the spandrel was called EC339, while the column section below the spandrel was called EC339cc. The suffix 'cc' denoted the section below the spandrel. Note that the raw dimensional data for EC339cc were not shown in the table, as the information was the same as for EC339.

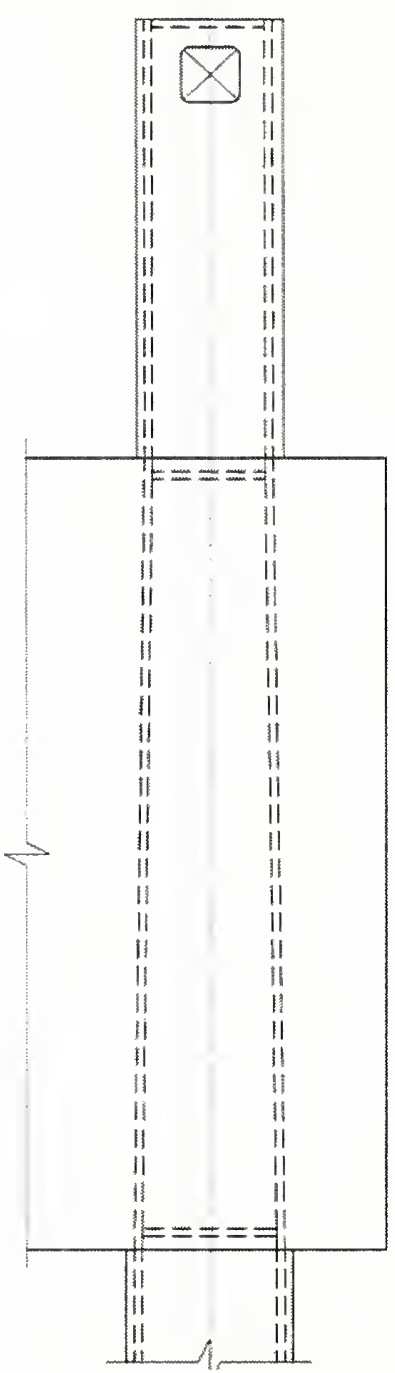

Source: Reproduced with permission of The Port Authority of New York and New Jersey. Enhanced by NIST.

Figure 2-5. Exterior column type 300, floor 9 to floor 106 (taken from drawing book 4, page 4-AB2-18). 


\subsubsection{Spandrel Member Multiple Section Property Calculation}

In the database, the exterior columns below elevation $363 \mathrm{ft}$ in column series 5000,6000 , and 7000 in Drawing Book 1 had corresponding spandrels shown in the details in Book 1. There were two types of spandrels for these members, tapered built-up box shapes and built-up I shapes. For the tapered built-up box shapes, the section properties of the different cross sections were calculated and listed in the database tables. The data were listed in the database files as described for columns with multiple cross sections. The section names of the different spandrel cross sections along the member length were distinguished by the last three to four characters, which identified the cross sections where the section properties were calculated.

For these exterior columns, there were spandrels at two elevations, $332 \mathrm{ft}$ and $350 \mathrm{ft}$ (see Fig. 2-6). At elevation $350 \mathrm{ft}$, the spandrels tapered, and as a result two cross section properties were calculated. The first section was at the face of the exterior column, and the corresponding section name had a Suffix F (face). The second section was at the center of the spandrel between two exterior columns, and the corresponding section name had a Suffix C (center). The elevations and locations of the cross sections of the spandrels were shown in the figures in the "Cross Section" worksheets in the database Excel files.

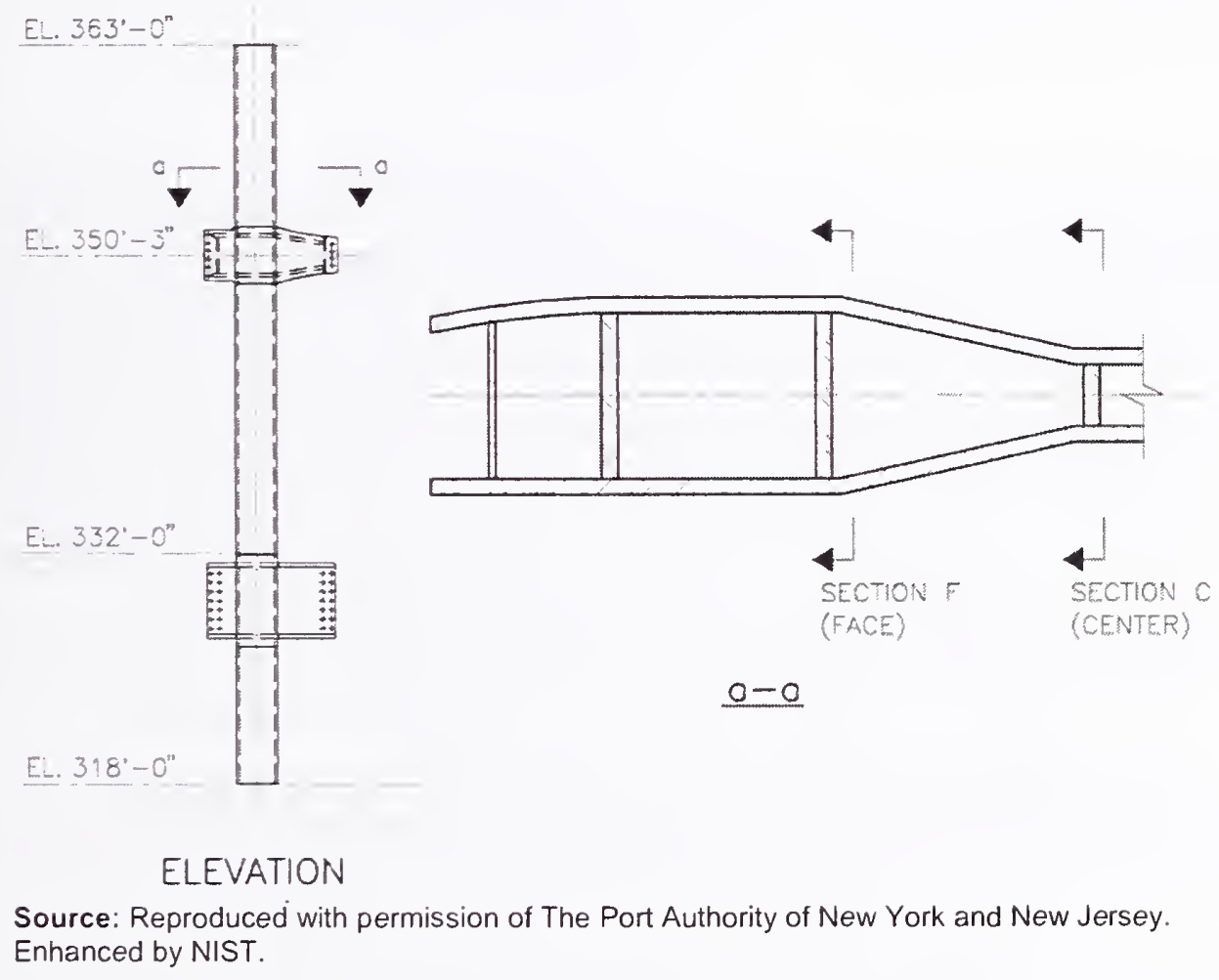

Figure 2-6. Column type 6000 with tapered spandrel (taken from drawing book 1, pages $1-\mathrm{A} 2-27$ and 28 ).

For example, four different section properties were calculated for exterior column 6009 in WTC 1. The first section was the exterior column itself, and the section name was BC6009A. The other three sections, BS6009AB332, BS6009AT350C, and BS6009AT350F were for the spandrel sections. The suffix B332 in BS6009AB332 denoted the bottom spandrel at elevation $332 \mathrm{ft}$. Suffixes T350C and T350F in 
BS6009AT350C and BS6009AT350F, respectively, denoted the top spandrel at elevation $350 \mathrm{ft}$, and the "C" or "F" identified the location whcrc the section properties were caleulated, see Fig. 2-6.

\subsubsection{Section Property Calculation Comparisons}

For all the members whose section properties were included in the GFI database, the cross sectional properties in the GFI data were comparcd with the data contained within the WTC-DB. Most section property results differed between the GFI and the WTC-DB by no more than 1 percent. It was found that results from the calculations of the torsional constant, $J$, however, did vary. LERA in-house programs wcre then used to confirm the accuracy of the $J$ calculation. For core columns in WTC 1, SAP2000 generated values used in the WTC-DB were on average 8 percent larger than $J$ values calculated using the LERA in-house program, while the results provided by the GFI database were on average 13 percent greater than LERA in-house program $J$ calculations.

The approximate equation used to calculate $J$ values by the LERA in-house program for a built-up column or box section as shown in Fig. $2-7$ is as follows:

$$
J=\frac{2(b h)^{2}}{\frac{b}{t_{f}}+\frac{h}{t_{w}}}
$$

It was found that for box sections, $J$ values calculated by the above equation matched the $J$ values given by SAP2000 Tube Section. However, for the same tube section, the $J$ values given by SAP2000 Section Designer were greater than $J$ given by SAP2000 Tube Section, even while all other properties were equivalent. According to Computers and Structures, Inc., the developer of SAP2000; the $J$ values given by SAP2000 Section Designer are more accurate as SAP2000 Section Designer uses a finite element method to calculate the $J$ values, while an approximate equation is used in SAP2000 Tube Section.

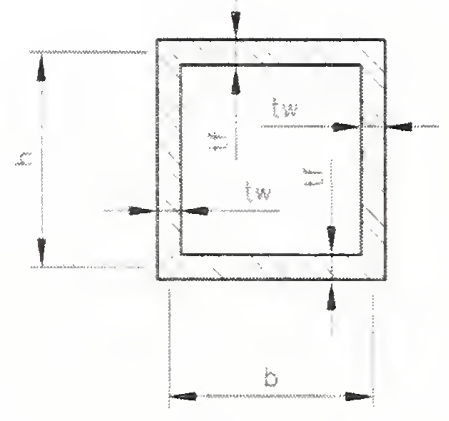

(a)

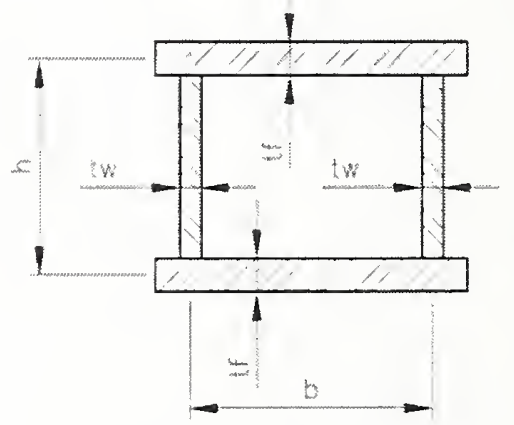

(b)

Figure 2-7. Box section and a built-up column.

In order to minimize the complexity of the model, where the member cross-section was of the type illustrated in Fig. 2-7 (a), box column members were defined in SAP2000 Tube Section. The remaining built-up box columns (similar to Fig. 2-7 b) were defined in SAP2000 Section Designer. 
For members whose properties were not given in the GFI database, hand calculations or calculations by LERA in-house program were carried out to verify the results from SAP2000 Section Designer for at least one section for each member type.

In summary, it was found that SAP2000 Section Designer provided section properties in close agreement with calculated properties. In most cases these properties also closely matched with the properties listed in the GFI database. In the cases where SAP2000 results disagreed with the GFI database, the results were reviewed, and it was concluded that the SAP2000 calculation provided the correct properties. Therefore, the section property results calculated using SAP2000 were used in the WTC-DB and the development of the finite element models of the towers.

\subsubsection{Rolled Shape Database}

While the majority of the primary members of the WTC towers' super-structure were built-up members, rolled shapes were also used. The rolled shapes specified in the drawings in a number of cases are no longer produced and. consequently, are not included in the rolled shape database embedded within SAP2000. Therefore. a rolled shape database was developed using the old nomenclature and section properties. The result was a file named 'Shape Property Table.xls.' The file contains three worksheets: 'Database,' 'Excel Format,' and 'WF Shape Properties from SAP.' The following is a discussion of their contents.

Data contained in 'Database' and 'Excel Format'-Drawing Books 3, 4, and 5 include reference to specific rolled shapes. The referenced shape names were extracted from these books and assembled into a single reference database for rolled shapes. Most of the section properties were obtaincd from the Manual of Steel Construction, American Institute of Steel Construction (AISC), Sixth Edition, 1963 (AISC 6th Edition) with few exceptions where cross sections were not included in this edition. Examples of these exceptions include the following:

- Section properties of 14WF455 to 14WF730 were obtained from the Manual of Steel Construction-Load and Resistance Factor Design, American Institute of Steel Construction, Third Edition, 2001 (AISC-LRFD 3rd Edition).

- Section properties of $6 \mathrm{CH} 12,6 \mathrm{CH} 15.1,12 \mathrm{CH} 40,12 \mathrm{CH} 45$, and $12 \mathrm{CH} 50$ wcre obtained from the MC-shapes table in the AISC-LRFD 3rd Edition.

- Section properties of 18WF69 were obtained from the Iron and Steel Beams 1873 to 1952, the American Institute of Steel Construction, 1968. 16WF342 was assumed to havc the same section properties of $16 \mathrm{H} 342$ tabulated in Iron and Steel Beams 1873 to 1952, the American Institute of Steel Construction, 1968.

- For $7 \times 5$ tube, $Z_{x}, Z_{y}$, and $J$ were obtained from the AISC-Allowablc Stress Design (ASD), 1989, 9th Edition.

- For $2 \mathrm{~L} 3 \mathrm{I} / 2$ in. $\times 3$ in. $\times 1 / 2$ in. long leg back to back, the combined properties were taken from SAP's embedded rolled shape database. 
Data contained in 'WF Shape Properties from $S A P$ '-For the rolled wide flange shapes, an additional database was created in SAP2000 based on the tabulated shape dimensions from the AISC Manuals as discussed above. Computers and Structures, Inc. provided an Microsoft Excel file named 'Proper.xls' with a macro that allowed the accurate calculation of the section properties for use within SAP2000. This information was then used by SAP2000 Section Designer to calculate section properties for built-up members comprised of wide flange sections and added plates.

For calculation of the properties with 'Proper.xls,' dimensions of the webs and flanges, as well as the size of the fillet, were input into the spreadsheet. The macro then calculated the section properties based on the input information. The results were shown to be in good agreement with the original tabulated properties.

\section{$2.7 \quad$ SUMMARY}

This chapter described the development of the electronic structural databases for the primary structural components of the WTC towers. These databases were developed from original computer printouts of the structural design documents, including modifications made after construction. The databases were generated for use in the development of the reference structural models of the towers.

The structural databases contained the computer and hand-tabulated data for the primary structural components of the towers from the original Drawing Books 1 through 5, including exterior walls, core columns, and beam schedule. In addition, some information fiom Drawing Book 6 (core bracing schedule) and Drawing Book 9 (beams in the hat truss region) were included in the database files as they were utilized in the modeling of the towers. Modifications to the towers that were implemented in the databases included strengthening of a number of core columns at floors 98 to 106 of both towers and reinforcing of two corner core columns at floors 45 to 97 of WTC 2 due to the construction of a concrete vault at floor 97 .

The steps that were undertaken to develop the structural databases included: (1) the scanning and digitization of the original drawing books, (2) a four-step quality control procedure, (3) cross section property calculations, and (4) the development of the relational databases to link the generated database files into a format suitable for the development of the structural models. 


\section{Chapter 3 \\ DeVelopment of Reference Structural Models for the WTC TOWERS}

\section{$3.1 \quad$ INTRODUCTION}

The objective of this chapter is to outline the development of the reference structural analysis models that capture the intended behavior of each of the two towers. The models were used to establish the baseline performance of the towers under gravity and wind loads. They also served as a reference for more detailed models used for other phases of the National Institute of Standards and Technology (NIST) Investigation, including aircraft impact analysis and thermal-structural response and collapse initiation analysis.

Included in this chapter are descriptions of the reference structural models, the modeling techniques, the parametric studies utilized in the development of the models, and the methodology used to export to the models the requisite data from the relational database (see Chapter 2). The main types of models developed are as follows:

- Two global models of the major structural components and systems for the towers, one each for World Trade Center (WTC) 1 and WTC 2.

- One model each of the typical truss-framed floor and typical beam-framed floor (mechanical level) within the impact and fire regions.

All models are linearly elastic and three-dimensional, and were developed using the Computers and Structures, Inc. SAP2000 Software, Version 8 (SAP2000 2002).

Section 3.2 describes the development, contents, and verification of the global models of WTC 1 and WTC 2. Sections 3.3 and 3.4 present the models for the typical truss-framed floor and beam-framed floor, respectively. Section 3.5 describes the parametric studies that were undertaken to facilitate the development of the global models. Section 3.6 presents a summary of the chapter.

\subsection{GLOBAL MODELS OF THE TOWERS}

A three-dimensional structural analysis computer model of the 110-story above-grade structure and 6-story below-grade structure for each of the two towers was developed. The global models for the towers consisted of the major structural components and systems required to establish the baseline performance of the towers under gravity and wind loads. In establishing the modeling techniques for the global models, parametric studies were performed to evaluate the behavior of typical portions of the structure and develop simplified models that could be implemented in the global models (see Sec. 3.5). 


\subsubsection{Components and Systems in the Towers' Global Models}

The models included all primary structural elements in the towers, including extcrior columns, interior (core) columns, exterior wall bracing in the basement floors, core bracing at the mechanical floors, core bracing at the main lobby atrium levels, spandrel beams, hat trusses, and rigid and flexible diaphragms representing the floor systems, as developed in Sec. 3.5 of this report. While the global models did not include the structural dampers in floor systems (see Secs. 3.3 and 3.4), the effect of the dampers on the wind load strcsses is accounted for in the determination of equivalent static wind loads using a total damping ratio of 2.5 percent (see Chapter 4 ).

\subsubsection{Coordinate System, Nomenclature, and Models Assembly Overview}

The large amount of data required to assemble the tower models dictated that the relational database capability of the WTC-DB be used (see Sec. 2.4.4). The methodology for the development of the models using the relational database is described in this section.

Coordinate System - The coordinate system for the model geometry was based on the column layout from the original drawings. Figure 3-1 shows the location of the $\mathrm{X}$ and $\mathrm{Y}$ axes for the global models and the floor models. The $\mathrm{Z}$ coordinates were based on actual elevations of the towers. The original column numbers were used throughout the models for member identification.

Nomenclature-A standard nomenclature for joints, frame names, and section names for use in the models was established. The nomenclature enables the user to know quickly where in the building a section is located by viewing any given piece of the model. Joint names generally included the column number, tower letter, and floor level. Frame element names generally included the joint name at the ' $\mathrm{j}$ ' end (second node). Section names were based on the section as described in the drawing book, and were repeated for each steel yield strength assigned for that section. Alternatively, where the section was unique to a particular member in the building, sections were named based on the frame member.

As an example, most nodes (or joints) in the tower models were named according to the following format:

- Column number

- Tower letter (A for WTC 1 and B for WTC 2)

- Floor level

- S for column splice nodes only

- J for spandrel splice nodes only 


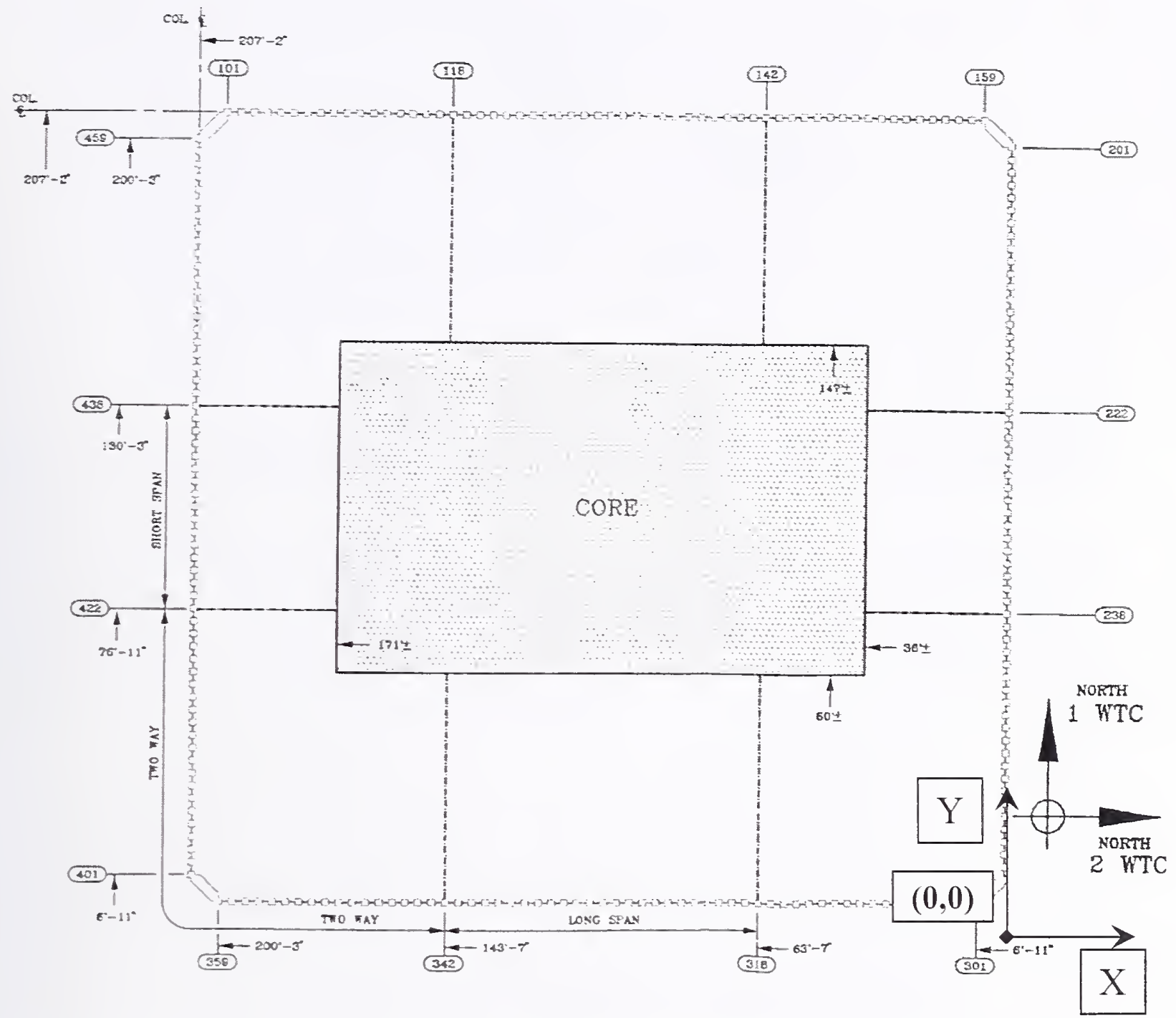

Source: Reproduced with permission from The Port Authority of New York and New Jersey. Enhanced by NIST.

Figure 3-1. Global model coordinate axis location.

Figure 3-2 illustrates the detailed frame and joint nomenclature for a typical exterior wall panel.

Model Assembly Overvien-An overview of the assembly of the data into the tower model is described herein along with an expanded section on the programmatic assembly of the models.

Following a basic study of modeling techniques and testing of SAP2000, Version 8 input format and capabilities, it was determined that the best approach was to divide the model into six main parts and then assemble them into a unified model. Manipulation of these individual parts was more efficient than attempting to build the whole model simultaneously. 


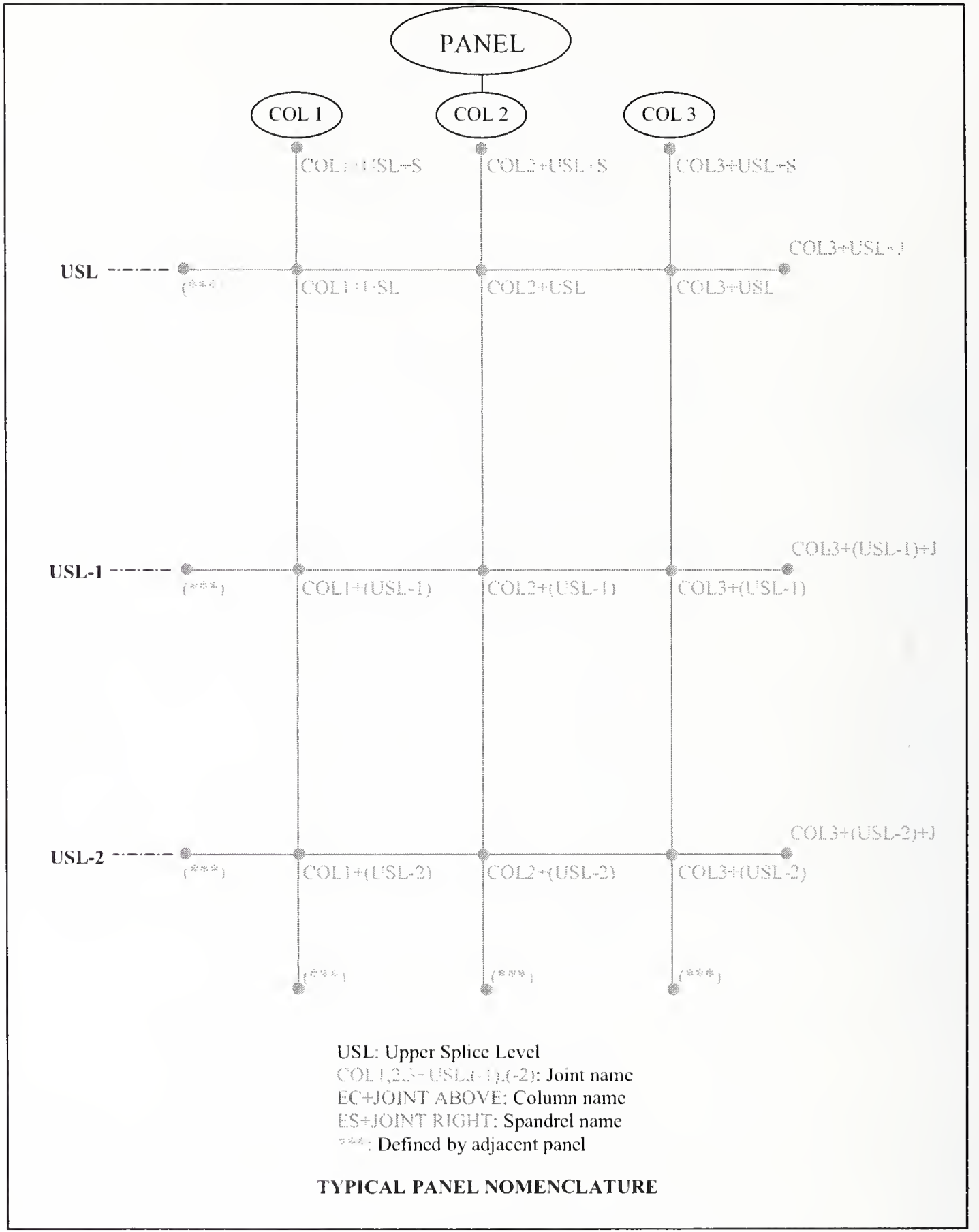

Figure 3-2. Typical exterior panel nomenclature. 
The six initial models were:

- Core columns

- Exterior wall, foundation to floor 4

- Exterior wall trees (floors 4 to 9)

- Exterior wall, floors 9 to 106

- Exterior wall, floors 107 to 110

- Hat truss

For the core columns and exterior walls at floors 9 to 106, most of the analysis input files were generated from queries of the WTC-DB. The other four parts of the model were assembled primarily in a more conventional manner.

Core columns and exterior wall panels (floors 9 to 106) were the greatest data-intensive challenges in the model development. Both parts included a large number of frame members and section and matcrial property variations. The query files were used to gather the necessary data, and then simple computer programming was used to convert the data into the SAP2000 input file format. Four main input tables for the SAP2000 input file were developed programmatically:

- Joint coordinates table

- Connectivity-frame/cable table

- Frame section properties tables

- Frame section properties 1-general

- Frame section properties 5-non-prismatic

- Section designer properties 04 - shape 1/wide flange

- Section designer properties 05-shape channel

- Section designer properties 11-shape plate

- Frame assignments table

- Gravity and wind load assignments

The remaining data were added directly in the SAP2000 model:

- Material properties

- Frame local axis 
- Joint restraint

- Insertion point

- Constraint

After the joint coordinates, connectivity, frame section properties, and frame assignments wcre complete for the six parts, the individual models were combined into a unified model. Rigid floor diaphragms, flexible floor diaphragms, core bracings, gravity loads, wind loads, and masses were then added to the unificd model. After assembly of the model, the assignment of properties for selected model elements was spot-checked, and the model was executed to verify its performance.

The development of the WTC 1 and WTC 2 models were separate and consecutive endeavors. The lessons learned in the assembly of the WTC 1 model were applied to the development of the WTC 2 model. While there were only minor differences in the basic structural systems of the two towers, there were significant differences in scction and material properties, and additional column transfers at the lower levels in WTC 2.

Isometric views of the complete WTC 1 model are shown in Fig. 3-3. Elevations of the complete WTC 2 model are shown in Fig. 3-4. A summary of the size of the global models of WTC 1 and WTC 2 is presented in Table 3-1. The following presents the details of each of the six parts used in the development of the unified global models for WTC 1 and WTC 2.

\subsubsection{Core Columns Modeling}

Core column coordinates were tabulated based on the structural drawings. Column locations were typically referenced at their centerlines. Columns on lines 500 and 1000, however, were located in plan drawings along most of their height according to the face of the column to which the floor trusses frame (i.e., WTC 1 north face for 500 columns and south face for 1000 columns). The centerline of these columns was based on their dimensions given in the drawing books. Where these column centerlines varied along the height of the towers (typically $11 / 2 \mathrm{in}$. between three-story pieces), a representative location was chosen to define the column node. Thus, the column coordinate at floor 106 was used as a constant along the tower height because at this level, these columns aligned with the hat truss above. Offsets were not used to shift the column locations because the floor framing needed to equilibrate such offsets was not included in the model.

The spandrel centerline elevation was selected as the representative floor elevation for exterior columns and used also for core columns. If there were no spandrels in exterior panels, reference elevations were used for the core columns. The reference elevations were defined in the original drawings and corresponded to the elevations of the top of the concrete floor.

There were over 5,000 nodes in the core column model. This amount of data required that the Interactive Database input table of SAP2000 be set up using a macro. These data were converted to text file format and later imported into SAP. Built-up sections were defined as Section Designer sections, and wide flange shapes were defined directly from "SectionWF1.pro" file (see Sec. 2.6.5). All section names were identical to those in the database. Around 1,280 Section Designer sections were defined in this model and imported through the Interactive Database function of SAP2000 to the model. 

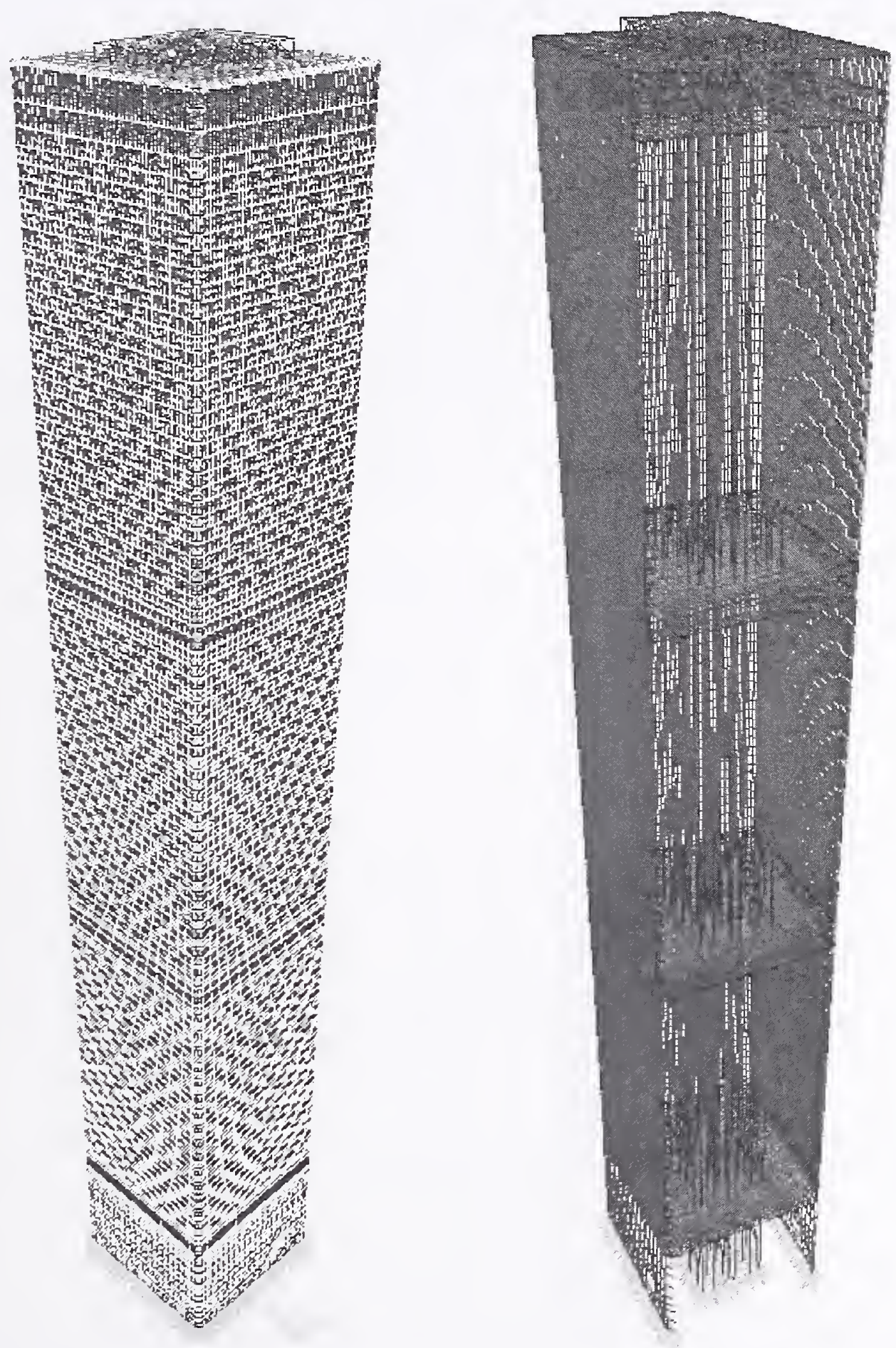

Figure 3-3. Rendered isometric views of the WTC 1 model. 

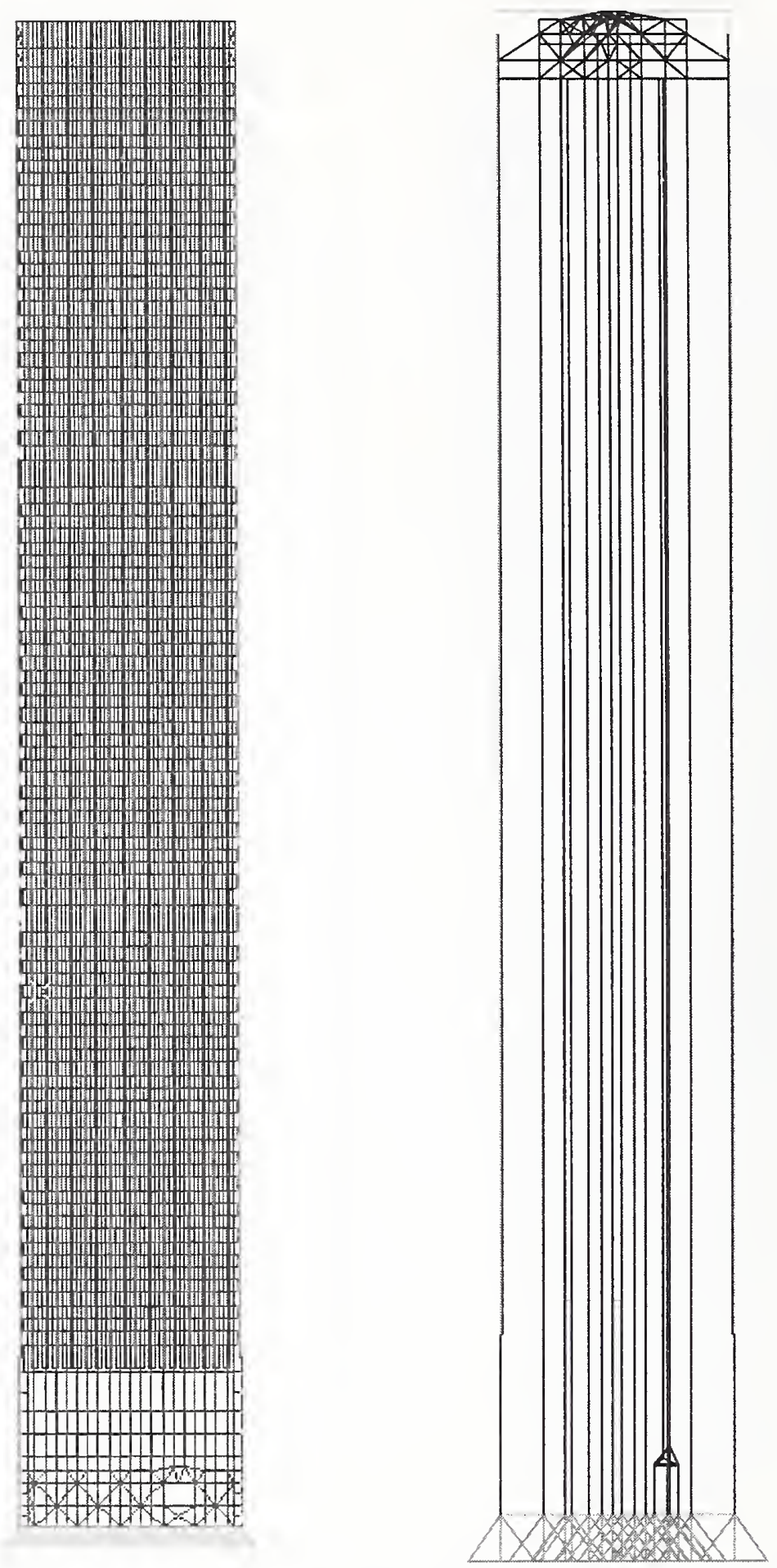

Figure 3-4. Frame view of the WTC 2 model: exterior wall elevation and interior section illustrating the core columns, core bracing, and hat truss. 
Table 3-1. Approximate size of the reference structural models (rounded).

\begin{tabular}{|l|c|c|c|c|c|}
\hline \multicolumn{1}{|c|}{ Model } & $\begin{array}{c}\text { Number of } \\
\text { Joints }\end{array}$ & $\begin{array}{c}\text { Degrees of } \\
\text { Freedom }\end{array}$ & $\begin{array}{c}\text { Number of } \\
\text { Frame Elements }\end{array}$ & $\begin{array}{c}\text { Number of } \\
\text { Shell Elements }\end{array}$ & $\begin{array}{c}\text { Total Number } \\
\text { of Elements }\end{array}$ \\
\hline WTC 1 global model $^{a}$ & 53,700 & 218,700 & 73,900 & 10,000 & 83,900 \\
\hline WTC 2 global model $^{\mathrm{a}}$ & 51,200 & 200,000 & 73,700 & 4,800 & 78,500 \\
\hline Typical truss-framed model & 28,100 & 166,000 & 27,700 & 14,800 & 42,500 \\
\hline Typical beam-framed model & 6,500 & 35,700 & 7,500 & 4,600 & 12,100 \\
\hline
\end{tabular}

a. Model does not include floors except for flexible diaphragms at 17 floors as explained later.

The core columns were defined as frame members spanning from node to node at the representative floor elevations. Splices in core columns occurred typically $3 \mathrm{ft}$ above the floor level. In the models, however, the splice was considered to occur at the floor level, and nodes were only defined at these levels (i.e., typically at spandrel centerlines). Most three-story column pieces were unique, as tabulated in the WTC-DB (Drawing Book 3). A section for each three-story piece was defined and then assigned to each of the three frame members that made up that column. Using the SAP2000 shading feature to graphically show the section on the model, each frame was rotated to its proper orientation based on the structural drawings.

In the as-designed drawings, there were strap anchors connecting the core columns to the concrcte floor slab to provide lateral bracing for the column. At floor 26 of WTC 1, the straps at column 901 were removed during a renovation project that was engineered by a firm other than Leslie E. Robertson Associates, R.L.L.P. (see Sec. 2.5.4). The loss of the straps at this location was included in the model by releasing the column from the diaphragm in the direction of the straps.

\subsubsection{Exterior Wall, Foundation to Floor 4 Modeling}

The models of the exterior wall up to elevation $363 \mathrm{ft}$ were developed manually, assigning joints and members connectivity as shown in the drawings. The elevation drawings show that below elevation $363 \mathrm{ft}$, columns were typically spaced at $10 \mathrm{ft}$ and braced with spandrels and diagonals. Joints wcre defined at all locations where diagonals braced the columns. However, when coordinates were not given in the drawings, joint coordinates were determined based on the geometry of the diagonal. Details in WTC Drawing Book 1 show that the column-diagonal intersections had continuity. Joints at elevation $253 \mathrm{ft}$ (level B-5) were defined only where the diagonals connect to the columns, since the tower floor did not frame into the exterior spandrels at that floor.

Where noted in elevation drawings, spandrel centerline elevations were used to define joint coordinates. Additionally, joints were defined at the spandrel splice midway betwecn two columns at elevation $350 \mathrm{ft}$ 3 in. (floor 3 ) and at elevation $329 \mathrm{ft} 3$ in. (floor 2) to allow for section type transitions.

The majority of the elements at these levels were defined as Section Designer sections, except for box shapes, which were defined as "Box/Tube." Channel shapes were defined directly from the "SectionWF1.pro" file (see Sec. 2.6.5). All section names were identical to those in the database. Around 200 sections were defined in this model using the Interactive Database function of SAP2000, which was used to import data into the model. 
Typical columns were connected from bottom to top, and typical spandrels were connected from left to right. The SAP2000 program allows assignment of rigid zone factors to frame end offsets to account for the overlap of cross sections. At the intersection of columns and spandrels, 100 percent rigidity for the column and the spandrels were assigned due to the large size of both columns and spandrels. Using the SAP2000 shading feature to graphically show the section on the model, each frame was rotated to its proper orientation based on the structural drawings.

Refer to Fig. 3-5 for a frame view and rendered view of the exterior wall (foundation to floor 9) of the WTC 1 model. The figure also shows the core columns and core bracings.
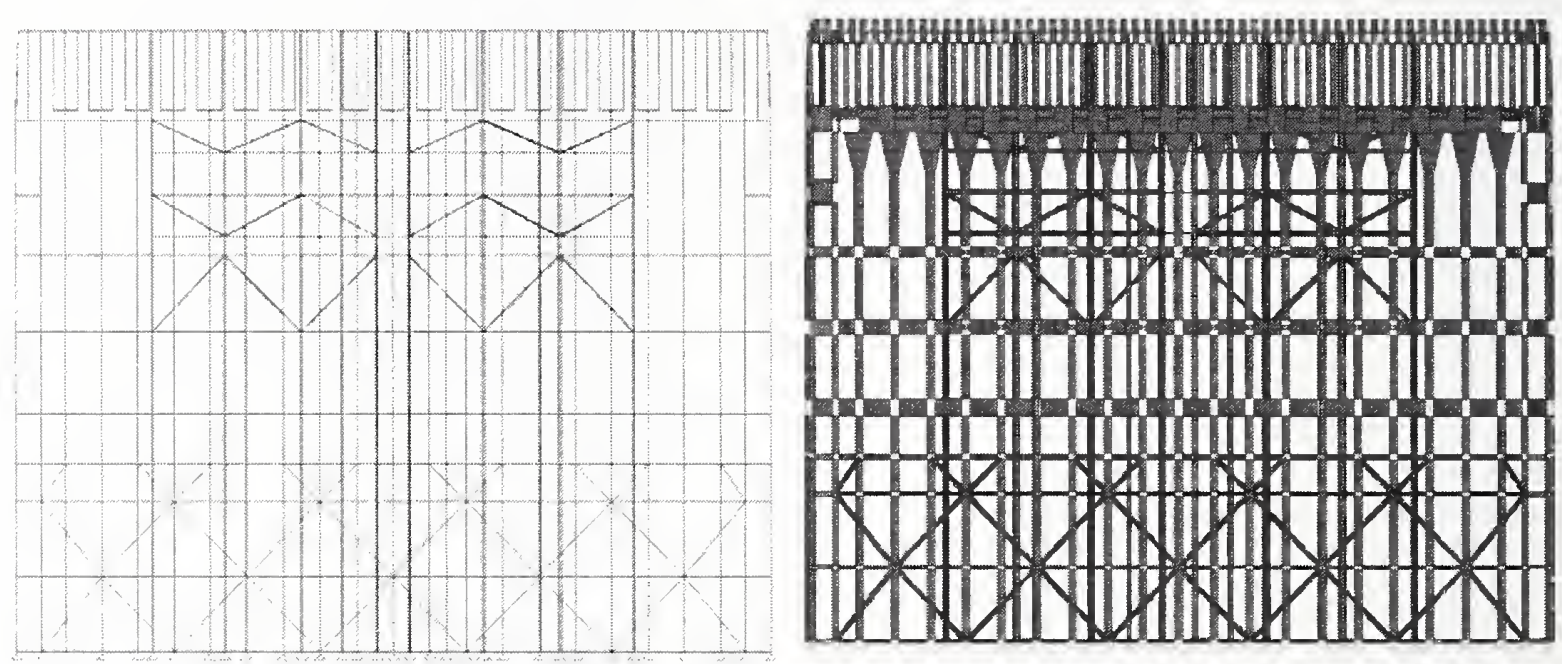

Figure 3-5. Frame view and rendered view of the WTC 1 model (foundation to floor 9).

\subsubsection{Exterior Wall Trees (Floor 4 to 9) Modeling}

The panels of the exterior wall between elevation $363 \mathrm{ft}$ and elevation $418 \mathrm{ft} 111 / 2 \mathrm{in}$. were called exterior wall trees. At the exterior wall trees, the typical exterior wall columns transitioned from a spacing of $10 \mathrm{ft}$ to a spacing of $3 \mathrm{ft} 4 \mathrm{in}$. A typical exterior wall tree panel is shown in Fig. 3-6, which indicates that each panel was divided into five different levels: B, C, D, E, and F. For each panel in the model, the three exterior columns from above elevation $418 \mathrm{ft} 11$ 1/2 in. continued down to level D. At that level, the three columns were connected by a horizontal rigid element to become one member, which extended down to elevation $363 \mathrm{ft}$.

In the model, the tree was also the location where the column insertion point transitioned from the inside face (at the spandrel) of the upper column to the centerline of the lower column. Between levels B and D (see Fig. 3-6), the location of the spandrel transitioned from $61 / 2$ in. offset from the exterior column reference line to the center of this reference line. Within the floor 9 spandrel, the exterior columns tapered; however, in the model, the tapering of the columns was not included because frame end length offsets were assigned to the columns to account for the rigidity of the spandrels.

Through the height of level C, the box-shaped columns tapered (Fig. 3-6). In the model, non-prismatic members were used to model the tapering columns. The columns started to taper at the bottom of the spandrel at level B, and ceased to taper at the top of the spandrel at level D. The dimensions of the 
columns at the spandrel edges were defined in the drawing book. In the model, the column extended from the centerline of the spandrel at level B to $1 \mathrm{ft}$ below the top of the spandrel at level D (see discussion for level D below). Therefore, in order to obtain the correct section properties along the length, the dimensions of the section at the joints were interpolated based on the dimensions of the section at the spandrel edges shown in the drawing book. The section properties of the tapering column were assumed to vary linearly between the two sections. Frame end length offsets were assigned to the columns to account for the rigidity of the spandrel at level B and the one foot dimension at level D.

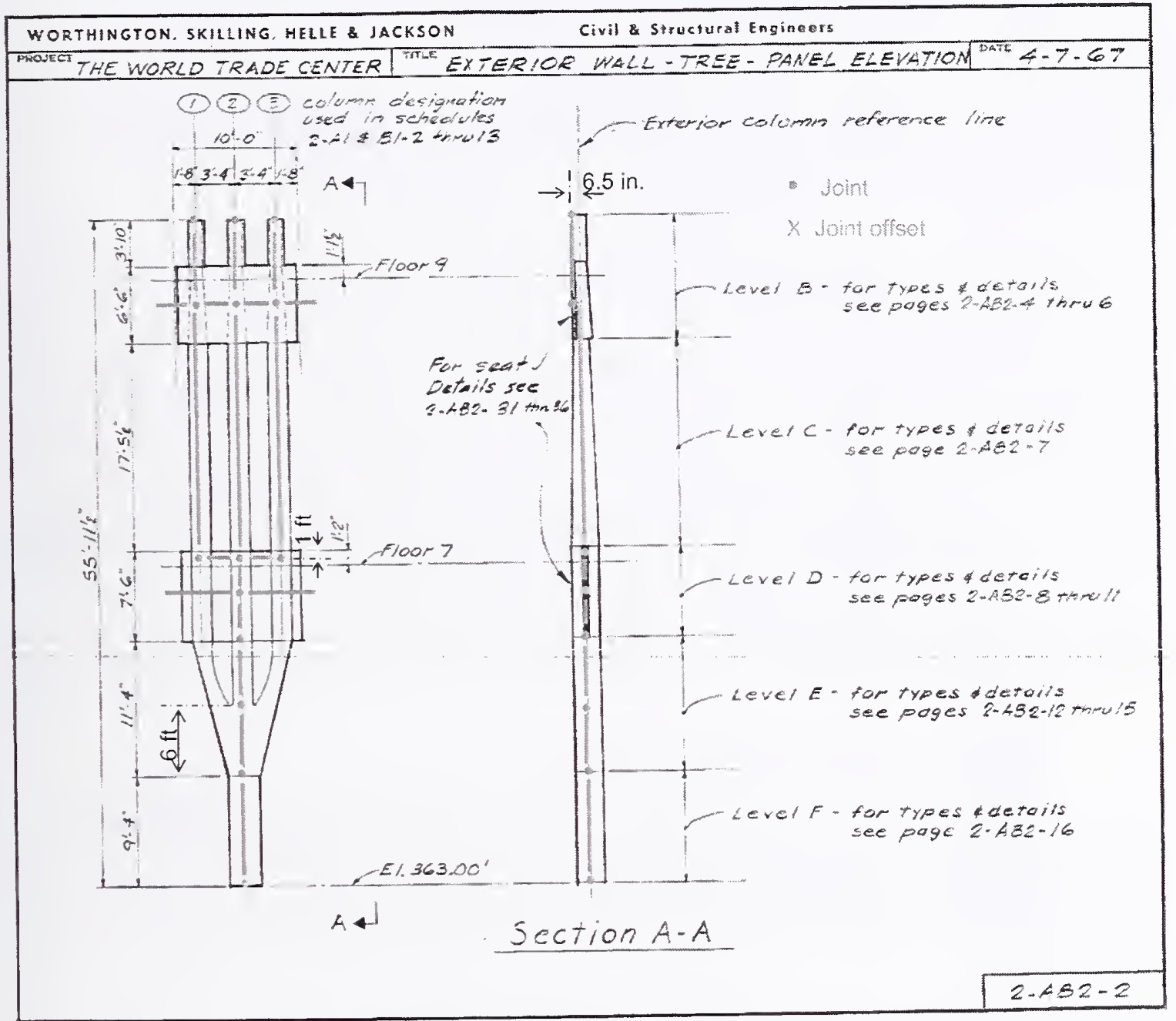

Source: Reproduced with permission of The Port Authority of New York and New Jersey. Enhanced by NIST.

Figure 3-6. Exterior wall tree panel (taken from Drawing Book 2, page 2-AB2-2).

At level D, two transitions occurred in the model. The first transition was for the exterior columns, where the three columns coming down from level $\mathrm{C}$ were connected by a horizontal rigid element to become one member at the bottom of the tree. This frame member consisted of the three exterior columns and the spandrel plate. Another horizontal member of the same section properties with the spandrel plate was also defined and connected between the neighboring exterior wall trees. This member connected the neighboring exterior wall trees and provided lateral bracing for the columns. Frame end length offsets 
were assigned to the spandrel to account for the overlap of the spandrel plate with the frame member, which also included the spandrel plate. The transition of the three members into one member was assumed to occur at one foot below the top of the spandrel at level D to account for the fact that the spandrel becomes engaged with the exterior columns after being connected to the exterior columns for a certain distance. Hence, the joints were defined at one foot below the top of the spandrel at level D.

There was a sccond transition at level D (Fig. 3-6). The nodes for the exterior wall columns were typically defined at $61 / 2 \mathrm{in}$. offset from the exterior column reference line, but for the joints at and below level $\mathrm{D}$ in the exterior wall tree, the joint coordinates were defined along the exterior column reference line. As a result, for the column member that framed between the nodes at levels B and D, a rigid joint offset of $61 / 2 \mathrm{in}$. was assigned at the top of the member using a rigid body constraint, while no offset was assigned at the bottom. Therefore, the column remained a vertically straight element while being connected to nodes that were not aligned vertically.

At level E, the cxterior columns tapered and had two different types of cross section (Fig. 3-7). For each panel, the exterior column transitioned from Section b-b in Fig. 3-7 into a box-shaped column (Sec. c-c in Fig. 3-7). The location of the transition betwecn the different types of cross section varied for different column types from $5 \mathrm{ft} 8$ in. to $6 \mathrm{ft} 4 \mathrm{in}$. measured from the bottom of level $\mathrm{E}$. In the model, the transition was assumed to be at $6 \mathrm{ft}$ measured from the bottom of level E. For each panel, the exterior column at level $\mathrm{E}$ was modeled as two non-prismatic members. The top section of the first non-prismatic member consisted of three box-shaped columns and a middle plate, while the bottom section was a box-shaped column (Sec. c-c in Fig. 3-7). The properties were assumed to vary linearly between the two sections. The second non-prismatic member was a tapering box shaped column (Sec. c-c in Fig. 3-7), and again, the properties were assumed to vary linearly between the two sections. At level F, the exterior wall tree columns wcre prismatic box-shaped columns.

The final modcl of a typical tree is illustrated in Fig. 3-8.

\subsubsection{Exterior Wall (Floor 9 to 106) Modeling}

In plan, column and spandrel members connected at nodes located at the outside face of the spandrel, $61 / 2$ in. from the exterior column reference line (see Fig. 3-9). The columns were offset horizontally, or 'inserted,' at this node using an insertion point located at the centerline of plate 3 . Insertion points were not adjusted for spandrel thickness. With this modeling, gravity and wind loads could be applied at the spandrel location.

In elevation, the columns and spandrel members connected at the spandrel centerline, typically $121 / 2 \mathrm{in}$. below the reference floor elevation (Fig. 3-9). The spandrels were then located correctly without the need for offsets to be defined. The effect of applying loads at both the spandrel centerlines and the reference floor elevations was studied, and it was found that it resulted in a negligible difference in spandrel stresses.

For typical exterior wall panels (i.e., three columns wide by three stories high), nodes at five elevations were defined. The models included nodes at the three representative floor levels (defined at the spandrel centerlines) as well as the upper and lower column splices. Diaphragms were assigned to all nodes at floor levels where concrete slabs existed to represent the high in-plane stiffness of the concrete floor slabs. 


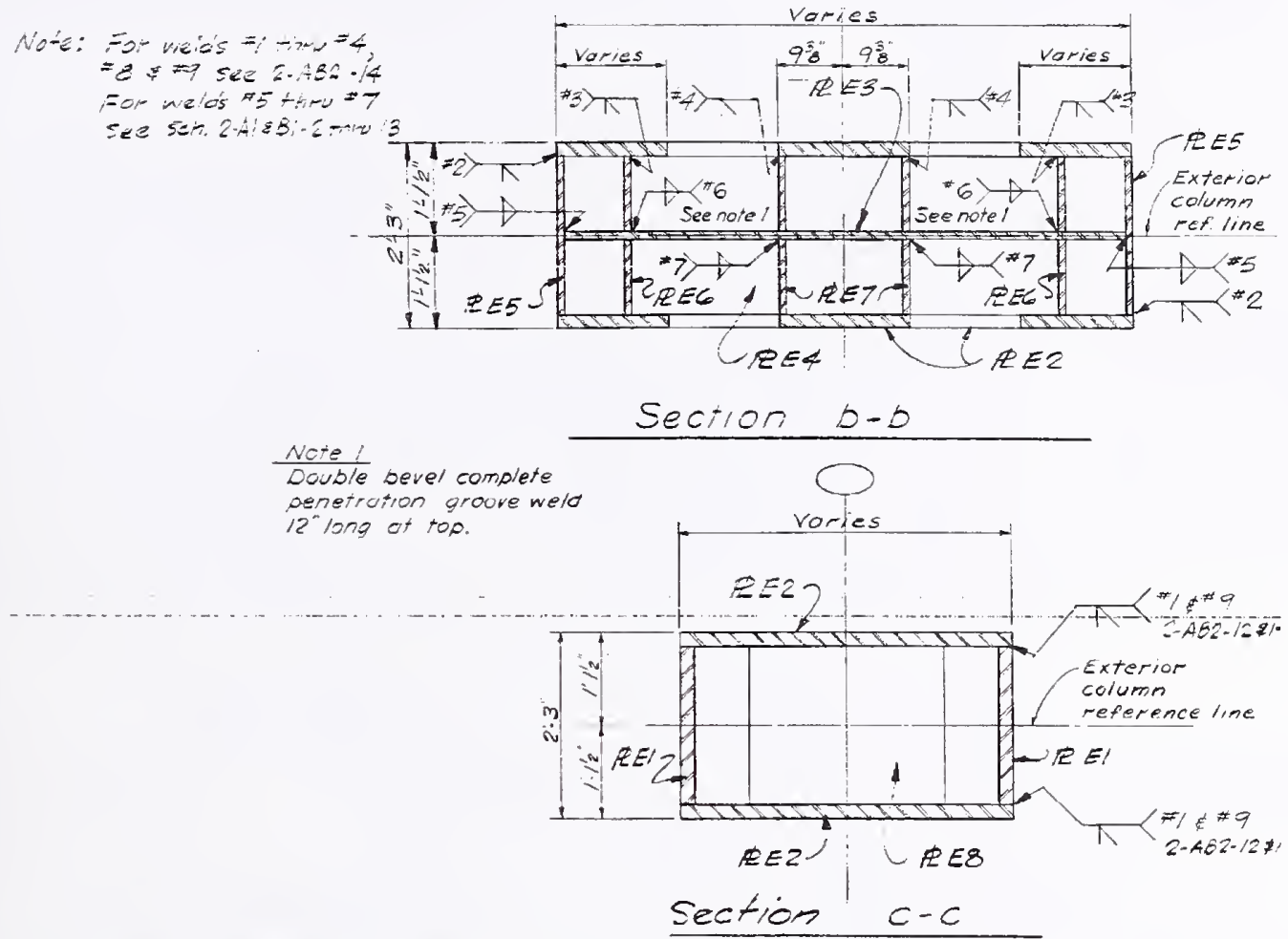

Source: Reproduced with permission of The Port Authority of New York and New Jersey.

Figure 3-7. Exterior wall tree: as-built cross sections for level $E$ (taken from Drawing Book 2, page 2-AB2-13).
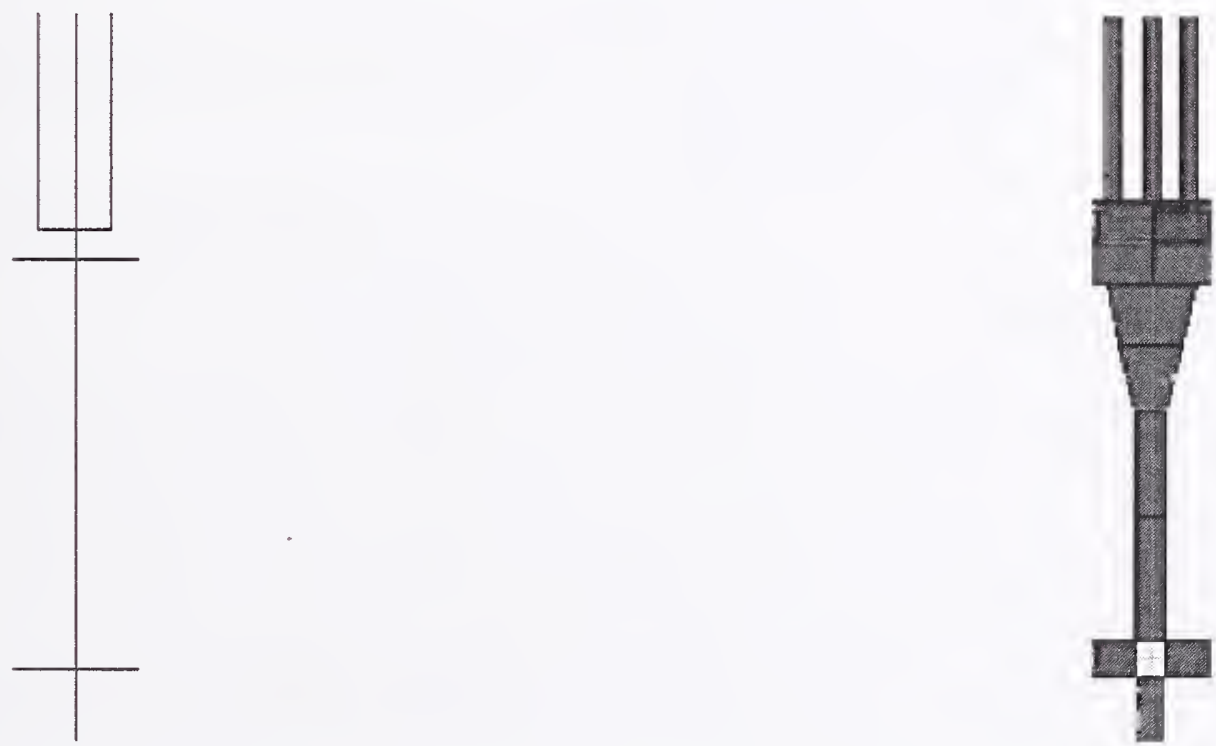

Figure 3-8. Frame view and rendered view of an exterior wall tree. 


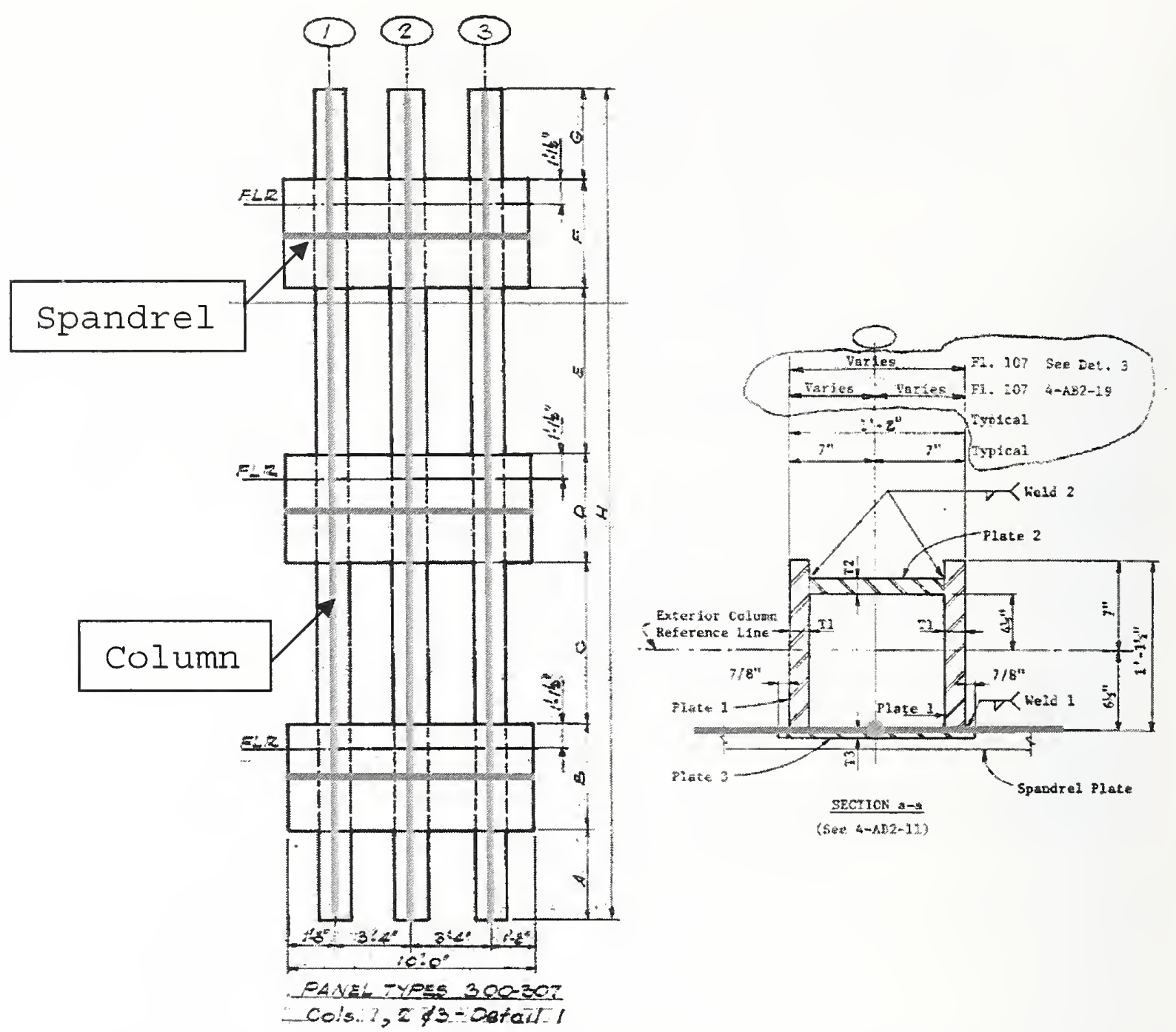

Source: Reproduced with permission of The Port Authority of New York and New Jersey. Enhanced by NIST.

Figure 3-9. Typical WTC tower exterior wall panel.

The SAP2000 program allows assignment of rigid zone factors to frame end offsets to account for the overlap of cross-sections. In the global model, 50 percent rigidity for the column and 100 percent rigidity for the spandrels were assigned for the typical exterior wall panels to match the lateral deflection of the detailed shell model of the panel based on the parametric study results (see Sec. 3.5.1). It was also found that, due to the relatively large depth of the spandrels and the close spacing bctween the columns, the spandrels contributed to the axial stiffness of the columns in the panels. This contribution was estimated to range from 20 percent to 28 percent increase in the vertical stiffness of the panels. Therefore, a frame property multiplier for the exterior wall column's cross-sectional area was used to provide a 25 percent increase in columns' axial stiffness (see Sec. 3.5.1).

For exterior wall corner panels, 25 percent rigidity for the columns and 50 pcrcent rigidity for the spandrels were assigned based on the parametric study results (see Sec. 3.5.2). Also, an area modifier 
was used to provide a 25 percent increase in the axial stiffness of the two continuous columns of the corner panels (Sec. 3.5.2). No modifier was used for the 100, 200, 300, and 400 series intermittent columns.

Exterior column types were defined in Drawing Book 4. A few types (100 series typical, 300 series at mechanical floors, and 400 to 500 series at corners) repeated extensively throughout the towers, with steel yield strengths that varied from $36 \mathrm{ksi}$ to $100 \mathrm{ksi}$. Since SAP2000 does not allow for the assignment of material properties at the member assignment stage, the number of different steel strengths was determined for each exterior column type, and sections were defined for each. The section name included the section number and the yield strength as tabulated in the drawing books.

Typical spandrels and corner panels were defined as rectangular shape and Section Designer section with stiffener, respectively. The top and bottom stiffener of each corner spandrel were included in both the parametric study and the global models. The detail shows that the stiffeners were 6 in. plates of thickness matching plate 2 in the corner column.

\subsubsection{Exterior Wall (Floor 107 to 110 ) Modeling}

Spandrel depths varied at floors 108 and 110. A weighted average of spandrel depth was determined in order to define the average centerline elevation of the spandrels and therefore, the node elevation for the entire floor.

For the $7 \times 5$ structural tube sections that were used in these floors, sections from the current American Institute of Steel Construction (AISC) Manual were assigned, and modification factors of 1.04 were applied to the section properties. The modifiers were used to match the section properties from the 6 th Edition AISC Manual.

The exterior wall members from floors 107 to 110 were typically rolled shapes with $F_{y}=42 \mathrm{ksi}$ or $F_{y}=50 \mathrm{ksi}$. Where not shown in the drawings as $F_{y}=50 \mathrm{ksi}, F_{y}=42 \mathrm{ksi}$ was used.

\subsubsection{Hat Truss Modeling}

In both WTC 1 and WTC 2, a truss system referred to as a 'hat truss' was constructed between floor 107 and the roof. The hat truss system was intended to support the load of the antenna on top of the tower and to interconnect the exterior walls to the core. The hat truss was made up of four trusses spanning perpendicularly to the long direction of the core and four trusses spanning perpendicularly to the shortdirection of the core (refer to Figs. 3-10 and 3-11).

Frame members between floors 107 and 110 were assigned to the model according to plan and elevation drawings of the hat truss. Node locations were set to coincide with the centerline of spandrels at the exterior wall. Columns, diagonals, and beams were included in the model. All columns and diagonals shown in drawings SA/B-400 through SA/B-404 were included in the model. Floor beams that did not participate in the hat truss system were not included in the model, unless they were used to transfer truss chords or core columns. Flexible floor diaphragms were used in this area. 
Coordinates were generally not given at floor 109, as this level did not contain a complete concrete floor slab. The geometry of the diagonals, columns, and beams was used to determine the location of the node where the diagonal would intersect floor 109. Unless otherwise noted in the drawings, diagonals and

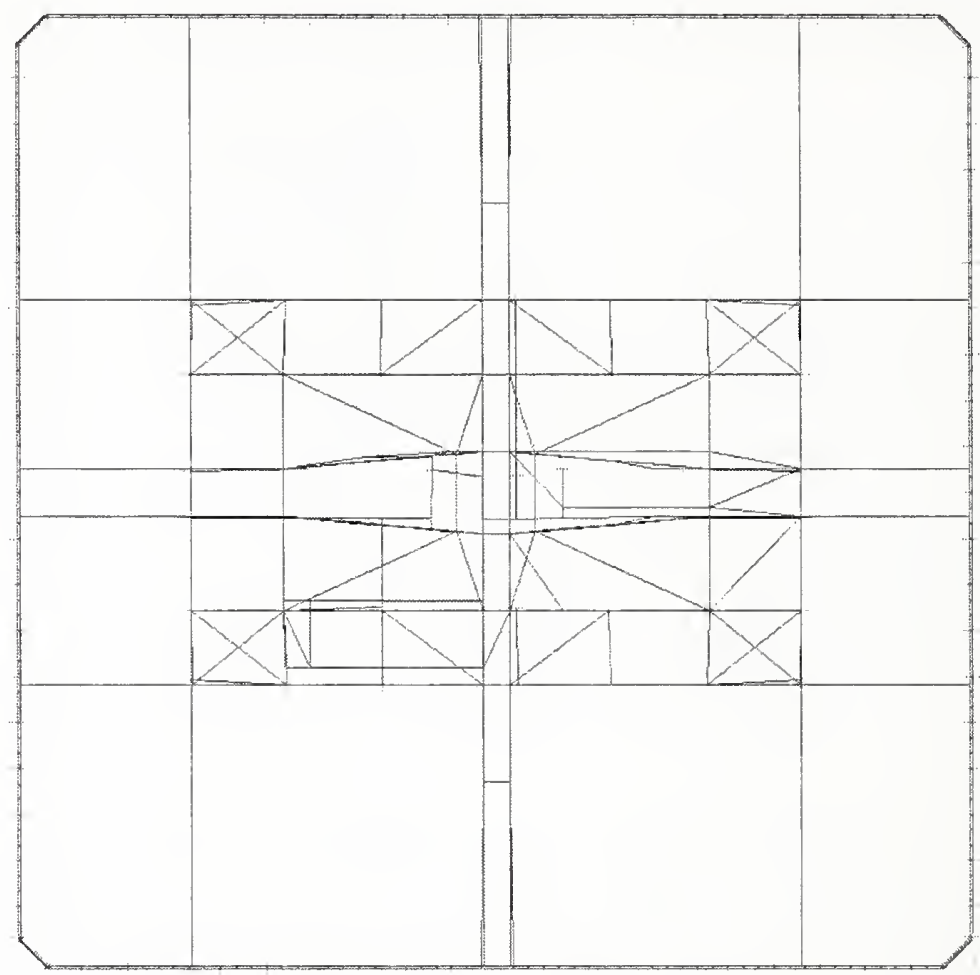

Figure 3-10. As-modeled plan of the WTC 1 hat truss.

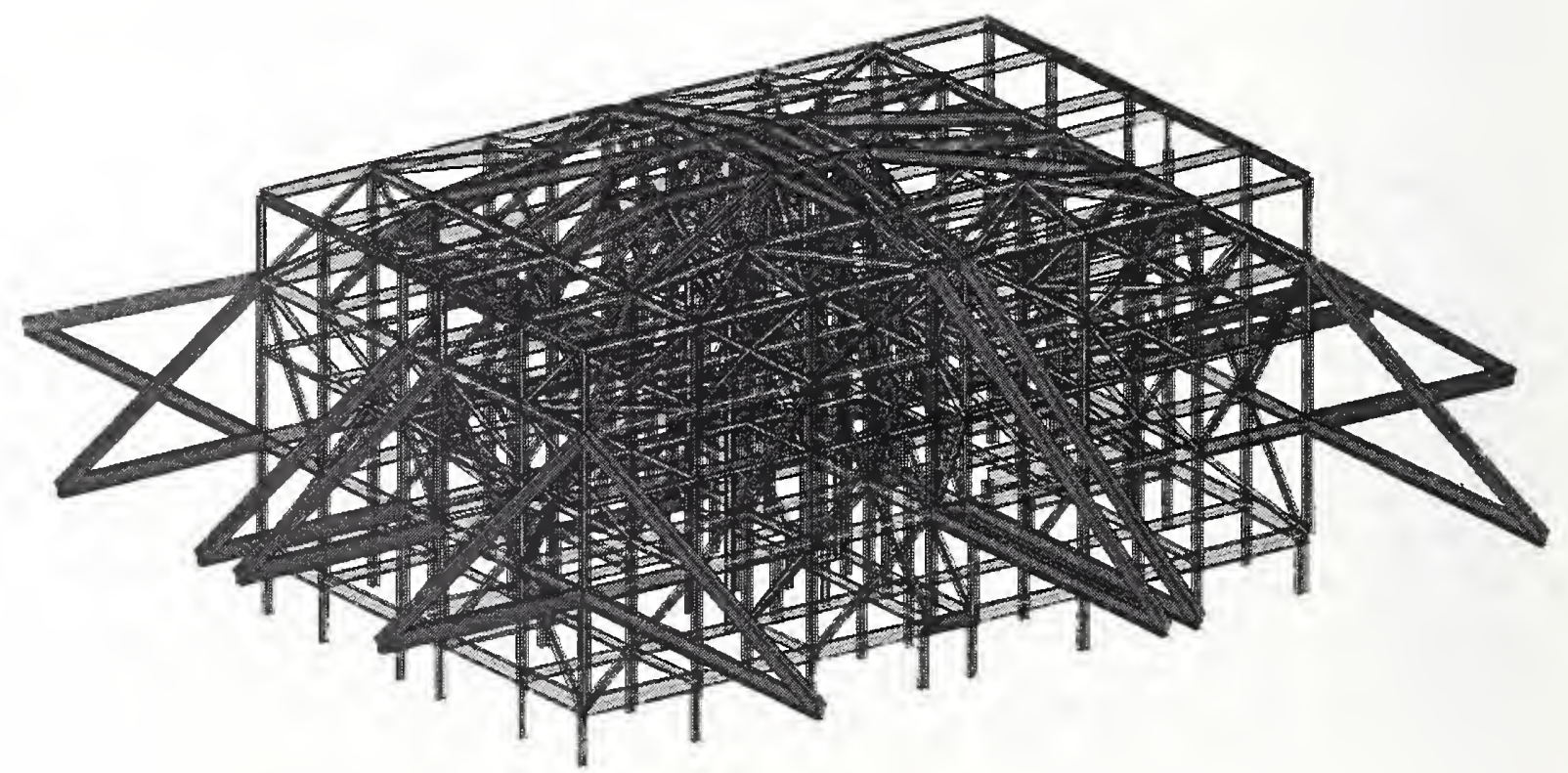

Figure 3-11. Rendered 3-D model of the WTC 1 hat truss (prior to assembly in the unified global model). 
columns were assumed to be non-composite, and floor beams were assumed to bc composite. Hat truss diagonals, main chords, and main columns were modeled with continuous joints. Hat truss beams, however, had pinned ends.

\subsubsection{Flexible and Rigid Floor Diaphragm Modeling}

For most floors, rigid diaphragms provide for a sufficiently accurate representation of the flow of forces and deformations for global structural response. This is a customary engineering practice for lateral force analyses. In cases where the flow of forces and deformations would be affected significantly by the use of rigid diaphragms, the floors were modeled as flexible diaphragms.

The floor models described in Secs. 3.3 and 3.4 were used to develop the flexible diaphragm stiffness utilized within the global models. Section 3.5.3 outlines the study for the determination of the in-plane diaphragm stiffness of the detailed floor models, using that in-plane stiffness to arrive at an equivalent shell element floor model. The equivalent shell element floor was used to represent the in-plane floor stiffness in the global model. The shell elements attached to all exterior wall columns and core columns.

Flexible diaphragms were used at the floors of the towers in the core of the atrium area, in the mechanical floors, and in the floors of the hat trusses. The floors modeled using flexible diaphragms were floors 3,4 , 5, 6, 7, 9 (atrium levels); 41, 42, 43, 75, 76, 77 (mechanical levels); 107, 108, 109, 110, and roof (hat truss region) of both towers. For the floors of the hat trusses, the stiffness of the flexible diaphragms was reduced by a factor of twenty, which resulted in diaphragm forces that were consistent with the diaphragm strength. This was done to achieve a reasonable agreement between the as-modeled stiffness of the floor diaphragm and the strength of the diaphragm to resist the forces it attracts. In the case of concrete floor slabs at the top and bottom chords of outrigger trusses or hat trusses, it has been found consistently that floor slabs modeled at nominal uncracked stiffness attract forces completely out of scale with the strength of the slabs. Based on parametric studies for a series of major high rise buildings, it became a customary engineering practice to reduce the stiffness of such floor slabs. This reduction factor was found, based on the parametric studies, to be about twenty. This reduction accounts for cracking and other factors that are consistent with the expected behavior of the floor diaphragms.

\subsubsection{Verification of Global Models}

Several steps were taken to verify the model input. SAP2000 Version 8 offers a 'shading' option once a model has been built with frame section assignments. This allows the user to view the members as the program interpreted their input. The shading option was helpful for using section-designed shapes, and for verifying the orientation (i.e., local axes) of members. Notc that shading is not correct when two Section Designer sections are used in non-prismatic members, so orientations for these sections were verified by reviewing their local axis member properties. The work was independently reviewed by engineers not associated with the initial model development.

Once the models were completed, checks for gravity and wind loads were performed. The overall performance of the tower models under these loads was found to be reasonable by checking deformations, stresses, reactions, etc. 


\subsubsection{Results of Modal Analysis}

Verification of the global models also included comparing the calculated natural frequencies with frequencies measured from accelerometers placed atop WTC 1 . The natural frequencies for WTC 1 and WTC 2 global models were estimated using modal analysis. The mass of the towers was estimated from the construction and superimposed dead loads only (see Chapter 4 for further details). No live loads were used in estimating the floor masses for the modal analysis. The calculated first six periods and frequencies for WTC 1 and WTC 2 are presented in Table 3-2 without P- $\Delta$ effects and in Table 3-3 with $\mathrm{P}-\Delta$ effects. The first three mode shapes are presented in Fig. 3-12.

Table 3-2. Calculated first six periods and frequencies without $P-\Delta$ effects for the WTC towers.

\begin{tabular}{|l|c|c|c|c|c|c|}
\hline \multirow{2}{*}{$\begin{array}{c}\text { Direction } \\
\text { of } \\
\text { Motion }\end{array}$} & Mode & $\begin{array}{c}\text { Frequency } \\
(\mathbf{H z})\end{array}$ & Period (s) & Mode & $\begin{array}{c}\text { Wrequency } \\
\text { (Hz) }\end{array}$ & Period (s) \\
\cline { 2 - 7 } & 1 & 0.088 & 11.4 & 2 & 0.093 & 10.7 \\
\hline N-S & 2 & 0.093 & 10.7 & 1 & 0.088 & 11.4 \\
\hline E-W & 3 & 0.192 & 5.2 & 3 & 0.192 & 5.2 \\
\hline Torsion & 4 & 0.233 & 4.3 & 5 & 0.263 & 3.8 \\
\hline N-S & 5 & 0.263 & 3.8 & 4 & 0.238 & 4.2 \\
\hline E-W & 6 & 0.417 & 2.4 & 6 & 0.417 & 2.4 \\
\hline Torsion & & & & & & \\
\hline
\end{tabular}

Table 3-3. Calculated first six periods and frequencies with $P-\Delta$ effects for the WTC towers.

\begin{tabular}{|l|c|c|c|c|c|c|}
\hline \multirow{2}{*}{$\begin{array}{c}\text { Direction } \\
\text { of } \\
\text { Motion }\end{array}$} & \multicolumn{3}{|c|}{ WTC 1 } & \multicolumn{3}{c|}{ WTC 2 } \\
\cline { 2 - 7 } & Mode & $\begin{array}{c}\text { Frequency } \\
(\mathbf{H z})\end{array}$ & Period (s) & Mode & $\begin{array}{c}\text { Frequency } \\
\text { (Hz) }\end{array}$ & Period (s) \\
\hline N-S & 1 & 0.083 & 12.1 & 2 & 0.089 & 11.2 \\
\hline E-W & 2 & 0.088 & 11.3 & 1 & 0.083 & 12.1 \\
\hline Torsion & 3 & 0.189 & 5.3 & 3 & 0.192 & 5.2 \\
\hline N-S & 4 & 0.227 & 4.4 & 5 & 0.250 & 4 \\
\hline E-W & 5 & 0.250 & 4 & 4 & 0.227 & 4.4 \\
\hline Torsion & 8 & 0.455 & 2.2 & 8 & 0.455 & 2.2 \\
\hline
\end{tabular}




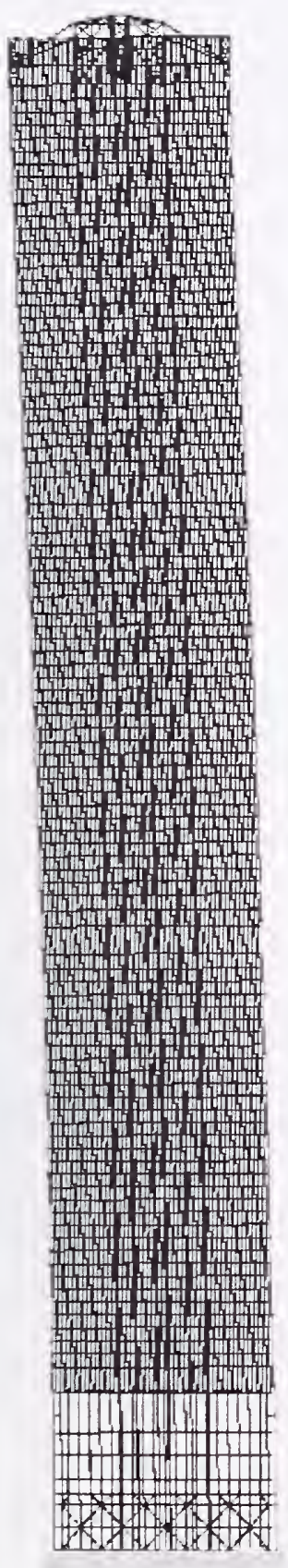

(a)

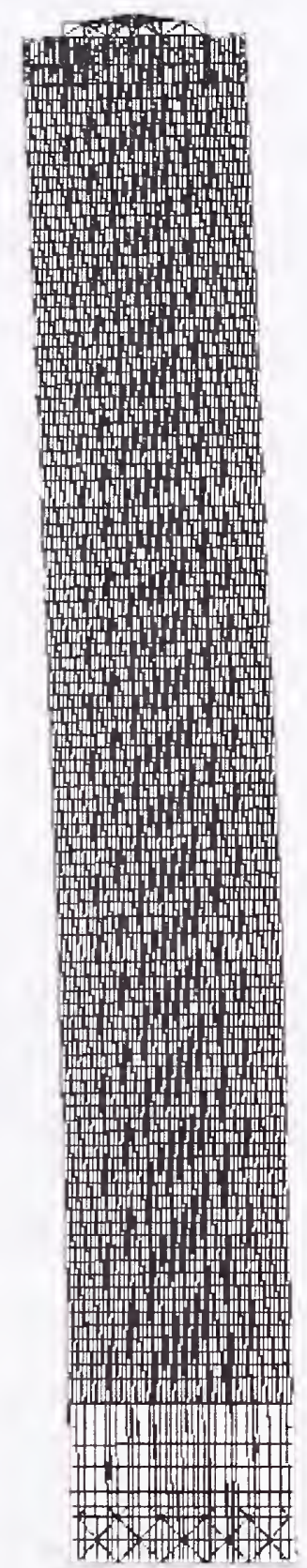

(b)

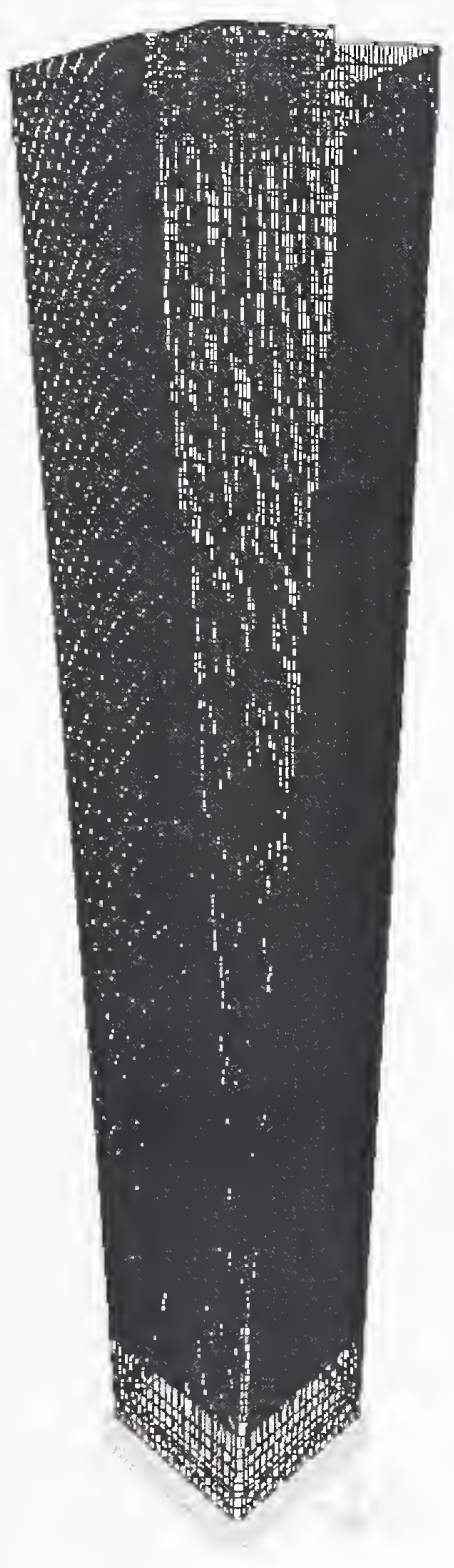

(c)

Figure 3-12. Mode shapes of WTC 1 (exaggerated): (a) first mode shape (E-W),

(b) second mode shape ( $\mathrm{N}-\mathrm{S}$ ), (c) Third mode shape (torsion). 
Table 3-4 presents a comparison of the calculated first three natural frequencies and periods ( $\mathrm{N}-\mathrm{S}$ direction, E-W direction, and torsion) against measured frequencies and periods obtained from WTC 1 based on analyzing acceleration records obtained from accelerometers installed on the top of WTC 1. The table also includes the values of the natural periods and frequencies predicted in the original design. The table shows good agreement between the calculated and measured periods, especially for the periods estimated without P- $\Delta$ effects, thus indicating that the reference global modcl is a reasonable representation of the actual structure. No measured periods or frequencies were available for WTC 2.

Table 3-4. Comparison of measured and calculated first two natural frequencies and periods for WTC 1.

\begin{tabular}{|c|c|c|c|c|c|c|c|}
\hline \multirow{3}{*}{$\begin{array}{c}\text { Data Sourcel } \\
\text { Event Date }\end{array}$} & \multirow{3}{*}{$\begin{array}{c}\text { Wind Speed \& } \\
\text { Direction }\end{array}$} & \multicolumn{3}{|c|}{ Frequency (HZ) } & \multicolumn{3}{|c|}{ Period (s) } \\
\hline & & \multicolumn{3}{|c|}{ Direction of Motion } & \multicolumn{3}{|c|}{ Direction of Motion } \\
\hline & & N-S & E-W & Torsion & N-S & E-W & Torsion \\
\hline \multicolumn{8}{|c|}{ Historical Data } \\
\hline October 11,1978 & $11.5 \mathrm{mph}, \mathrm{E} / \mathrm{SE}$ & 0.098 & 0.105 & 0.211 & 10.2 & 9.5 & 4.7 \\
\hline January 24, 1979 & $33 \mathrm{mph}, \mathrm{E} / \mathrm{SE}$ & 0.089 & 0.093 & 0.203 & 11.2 & 10.8 & 4.9 \\
\hline March 21, 1980 & $41 \mathrm{mph}, \mathrm{E} / \mathrm{SE}$ & 0.085 & 0.092 & 0.201 & 11.8 & 10.9 & 5.0 \\
\hline Decmber 11, 1992 & - & 0.087 & 0.092 & - & 11.5 & 10.9 & - \\
\hline February $2,1993^{1}$ & $20 \mathrm{mph}, \mathrm{NW}$ & 0.085 & 0.093 & 0.204 & 11.8 & 10.8 & 4.9 \\
\hline March $13,1993^{1}$ & $32 \mathrm{mph}, \mathrm{NW}$ & 0.085 & 0.094 & 0.199 & 11.8 & 10.6 & 5.0 \\
\hline March $10,1994^{1}$ & $14 \mathrm{mph}, \mathrm{W}$ & 0.094 & 0.094 & 0.196 & 10.6 & 10.6 & 5.1 \\
\hline December $25,1994^{2}$ & $\mathrm{~N}$ & 0.081 & 0.091 & - & 12.3 & 11.0 & - \\
\hline \multicolumn{8}{|c|}{ Average of Measured Data } \\
\hline Average & - & 0.088 & 0.094 & 0.202 & 11.4 & 10.6 & 4.9 \\
\hline \multicolumn{8}{|c|}{ Orginal Design - Predicted Values } \\
\hline Theoretical Value & - & 0.084 & 0.096 & - & 11.9 & 10.4 & - \\
\hline \multicolumn{8}{|c|}{ Reference Global Model } \\
\hline $\begin{array}{c}\text { LERA/NIST - WTC 1 } \\
\text { without P-Delta }\end{array}$ & & 0.088 & 0.093 & 0.192 & 11.4 & 10.7 & 5.2 \\
\hline $\begin{array}{c}\text { LERA/NIST - WTC } 1 \\
\text { with P-Delta }\end{array}$ & & 0.083 & 0.088 & 0.189 & 12.1 & 11.3 & 5.3 \\
\hline
\end{tabular}

Notes:

${ }^{1}$ Reported frequency value is the average of the SW corner, NE corner and center core frequency measurements. ${ }^{2}$ Reported frequency is based on center core data only.

\subsection{TYPICAL TRUSS-FRAMED FLOOR MODEL-FLOOR 96A}

In order to select the typical truss-framed floor within the expanded impact and fire zones of both towers, the drawings for floors 80 to 100 were reviewed to identify structural similarities. The summary of this review is provided in Appendix G, which shows a summary of the construction type and space usage for each floor, along with a categorization and description of floor types for both towers. It was found that floor 96 of WTC 1 (96A) represented the typical truss-framed floor in the expanded impact and fire 
region for WTC 1 (floors 89A to 103A). The only exception in this region of WTC 1 was floor 92, which had an increased dead load capacity required for the support of secondary water lines.

Floor 96A was also representative of the typical truss-framed floor in the expanded region for WTC 2 (floors 74B-88B). Specifically, floor 96A was similar to the truss framing at floor $74 \mathrm{~B}$ and floors $84 \mathrm{~B}$ through $88 \mathrm{~B}$. Floors $78 \mathrm{~B}$ and $79 \mathrm{~B}$ were sky lobby and upper escalator floors, respectively. Both contained long span trusses, which were similar to floor 96A, but also contained beam-framed floor construction in the entire short span area (where the escalators were located). Floors $80 \mathrm{~B}$ through $83 \mathrm{~B}$ had beam framing in place of a single truss panel in the short span area, while the remaining area contained trusses which were similar to floor $96 \mathrm{~A}$.

Based on the above analysis. floor 96 of WTC 1 was selected as the overall representative truss-framed floor for the majority of the expanded impact and fire zone in both towers and is described in the following sections (see Fig. 3-13). An isometric view of the typical truss-framed floor model is shown in Fig. 3-14. Table 3-1 includes a summary of the size of the $96 \mathrm{~A}$ floor model. The following presents the major structural systems and components of the truss-fiamed floor model.

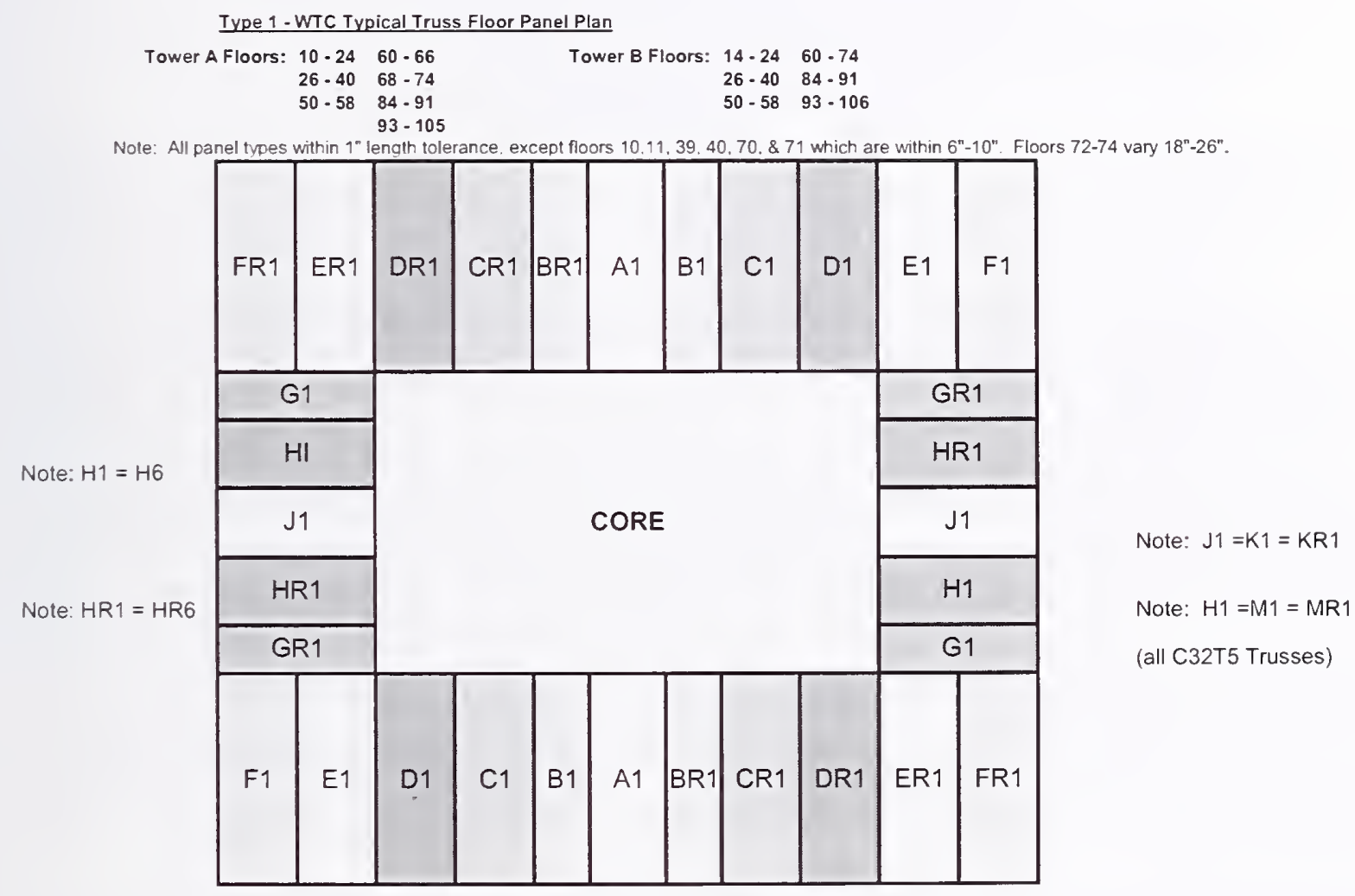

Figure 3-13. Typical truss-framed floor panels arrangement. 


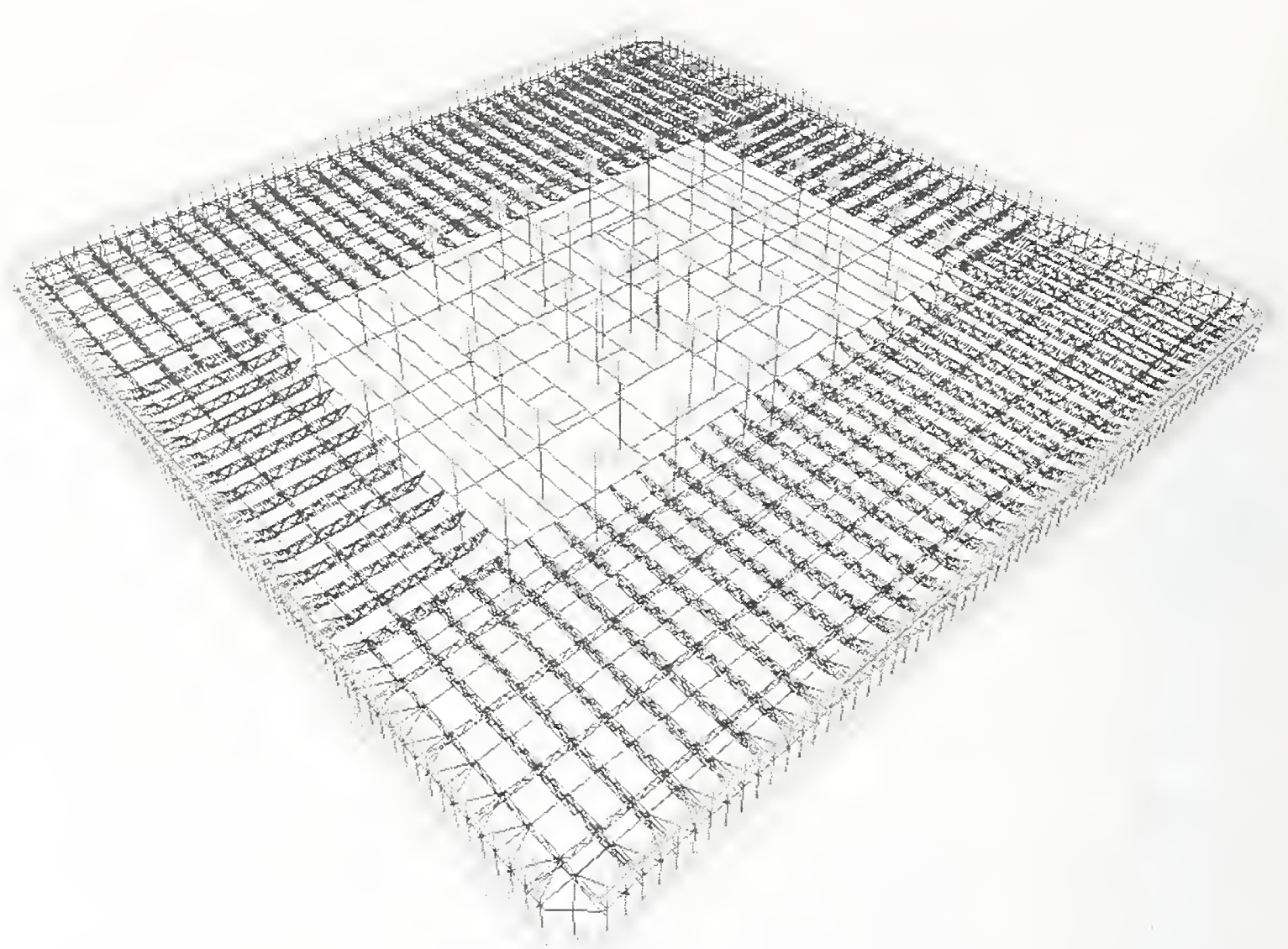

Figure 3-14. Typical truss-framed floor model (floor 96A), slab not shown.

\subsubsection{Primary Trusses}

The primary trusses consisted of double angle top and bottom chords, which were $29 \mathrm{in}$. out-to-out of the chords. The trusses acted compositely with a 4 in. concrete slab on $11 / 2$ in. metal deck. For a typical long-span truss, C32T1, the top chord consisted of two angles 2 in. by 1.5 in. by 0.25 in., short legs backto-back (SLB), and the bottom chord consisted of two angles 3 in. by 2 in. by 0.37 in., SLB. The distance between the centroid of the two chords was calculated to be 28.05 in. The distance from the centroid of the top chord to the neutral axis of the transformed composite slab with top chord was calculated to be 1.93 in. The sum of the distances, thus, was $28.05+1.93=29.98$ in. (Fig. 3-15). Dimensions for the short-span trusses were essentially identical to those for the long-span trusses. Therefore, in the model, 30.0 in. was taken as the typical distance between the top and bottom chords for both short- and long-span primary trusses.

In the long-span truss zone, the two individual primary trusses, which were part of the same floor panel and attached to the same column, were separated (typically) by a distance of $71 / 8 \mathrm{in}$. At the joint between panels, the distance between the abutting long-span trusses was $71 / 2 \mathrm{in}$. Therefore, in the model, $71 / 2$ in. was used as the spacing between all long-span primary trusses. In the short-span truss zone, two individual trusses which attached to the same column were separated by a distance that varied between $47 / 8 \mathrm{in}$., $5 \mathrm{in}$., and 5 1/4 in. In the model, the typical spacing between all short-span double 
trusses was $5 \mathrm{in.}$ The long span trusses in the two-way zone had an as-modeled length of $58 \mathrm{ft} 10 \mathrm{in}$., while the long span trusses in the one-way zone had an as-modeled length of $59 \mathrm{ft} 8 \mathrm{in}$.

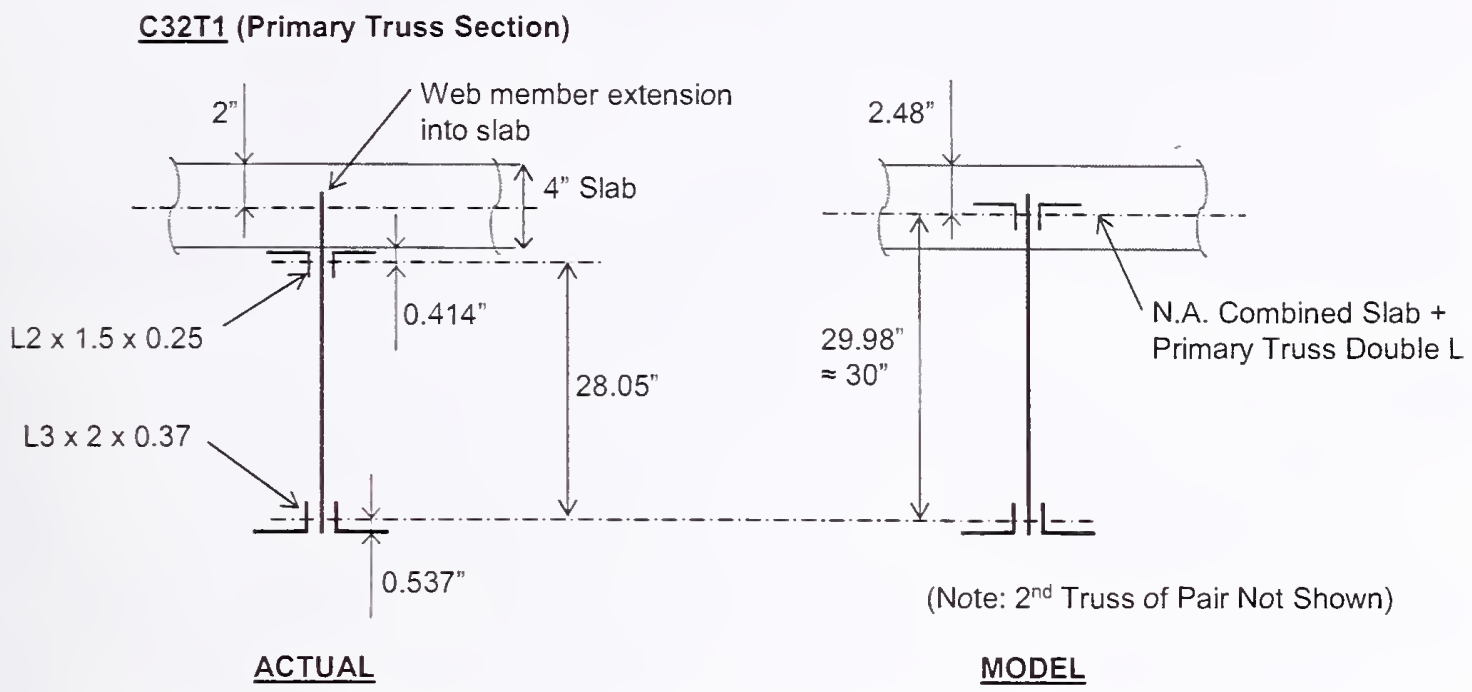

Figure 3-15. Typical primary truss cross-section, as-built and as-modeled transformed truss work points.

The diagonal web bars for the primary trusses were most often 1.09 in. diameter bars. Therefore, for double angle shapes in the primary trusses, 1.09 in. was taken as the distance between the two angles. This holds true for primary trusses where bar diameters varied between $0.92 \mathrm{in}$. and $1.14 \mathrm{in}$.

The as-built truss diagonals had end fixity, but were considered pinned for the analysis. Pinning the diagonals is conservative and provides an upper bound of the gravity load stresses. To mitigate the effect of the pinned member approach, end length offsets were used for the truss diagonals to compensate for the difference in the as-built diagonal unbraced length and the model unbraced length. The as-built unbraced length for a typical diagonal in a primary truss was $32.4 \mathrm{in}$., while the modeled member length was 36.05 in., and therefore, an end offset of 1.8 in. was used at both ends. Similarly, for the bridging trusses, the actual unbraced length for a typical diagonal of a bridging truss was $29 \mathrm{in}$., while the modeled length was $30.66 \mathrm{in.}$ Therefore, an end offset of 0.83 in. was used at both ends. A rigid zone factor of 100 percent was used for all offset zones.

In the model, the deck support angles, typically 3 in. by 2 in. by $0.75 \mathrm{in.}$ were located in the same plane as the combined truss top chord and composite slab centroid.

\subsubsection{Bridging Trusses}

The bridging trusses were 24 in. deep, edge-to-edge, with double angle chords. For a typical bridging truss, $24 \mathrm{~T} 11$, the top and bottom chords consisted of two angles $1.5 \mathrm{in}$. by $1.25 \mathrm{in}$. by $0.23 \mathrm{in}$., SLB. The distance between the centroid of the two chords was $23.26 \mathrm{in}$. The distance used as the offset between the top and bottom chords for all bridging trusses was taken as $23.25 \mathrm{in.}$ (Fig. 3-16). The distance between the work points of the top chord of the bridging truss and the top chord of the primary trusses and equivalent slab plate for truss $24 \mathrm{~T} 11$ was calculated to be $3.39 \mathrm{in}$. This distance was selected for all 
bridging trusses to be $3.375 \mathrm{in}$. As in the as-built structure, the bridging truss was not connected along its length to the slab shell elements in the model. At the intersection of the top chords of the primary and the bridging trusses, the intersection was modeled using vertical rigid links, connected in turn to the slab shell elements representing the concrete slab.

\section{$\underline{24111}$ (Bridging Truss Section)}

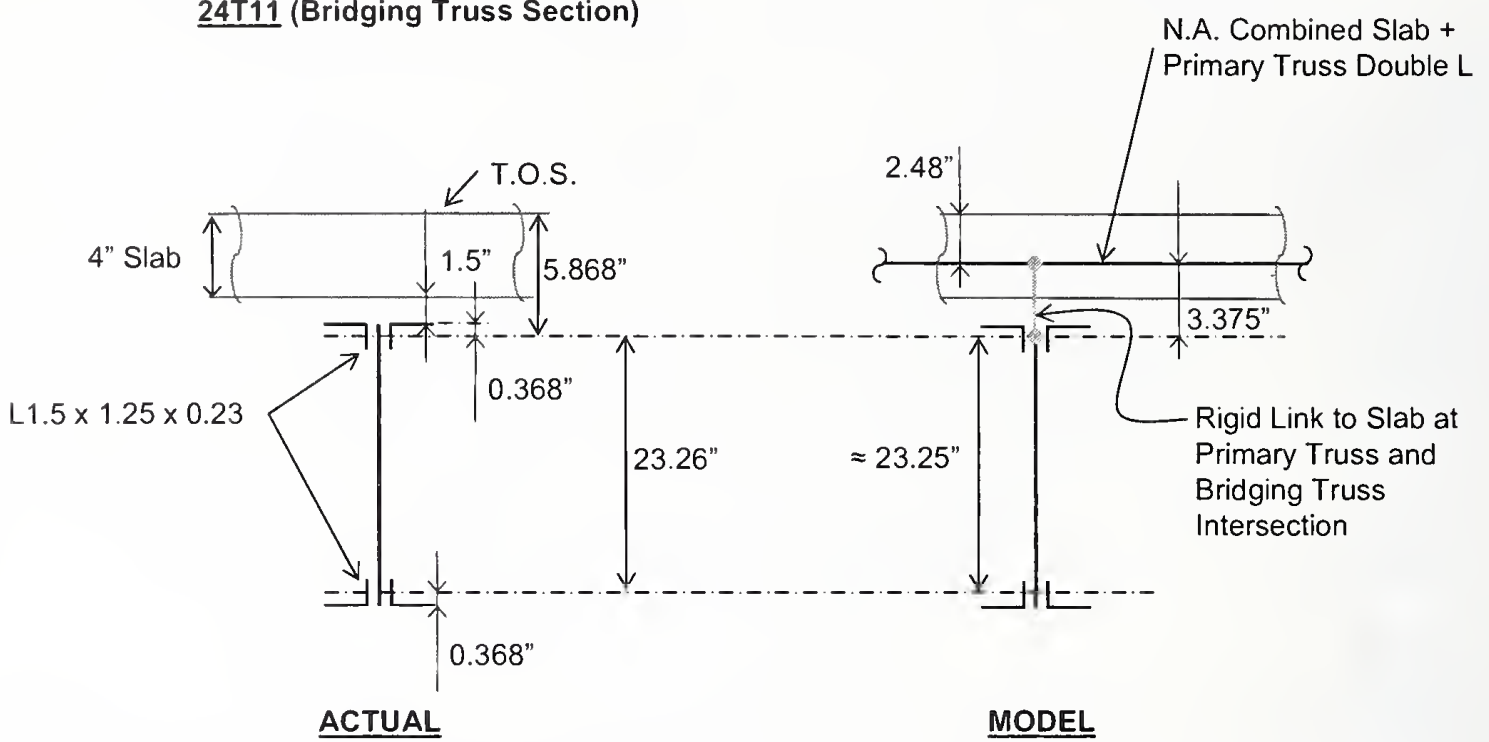

\section{Figure 3-16. Typical bridging truss cross-section, as-built and as-modeled transformed truss work points.}

The original contract drawings indicated that the bottom chord of the primary trusses was connected to the bottom chord of the bridging trusses along the length of the primary trusses only on column lines 111 , 149,311 , and 349 . The connection consisted of double angles 2 in. by $11 / 2 \mathrm{in.} \mathrm{by} 0.25 \mathrm{in}$. welded to both primary and bridging truss lower chord members as shown in Fig. 3-17. These connection angles were included in the model. The Laclede (the manufacturer of the floor truss panels) shop drawings indicated that the bottom chords of the primary trusses were similarly connected to the bottom chords of the bridging trusses at all their intersections for construction purposes. These were conservatively not included in the models. 


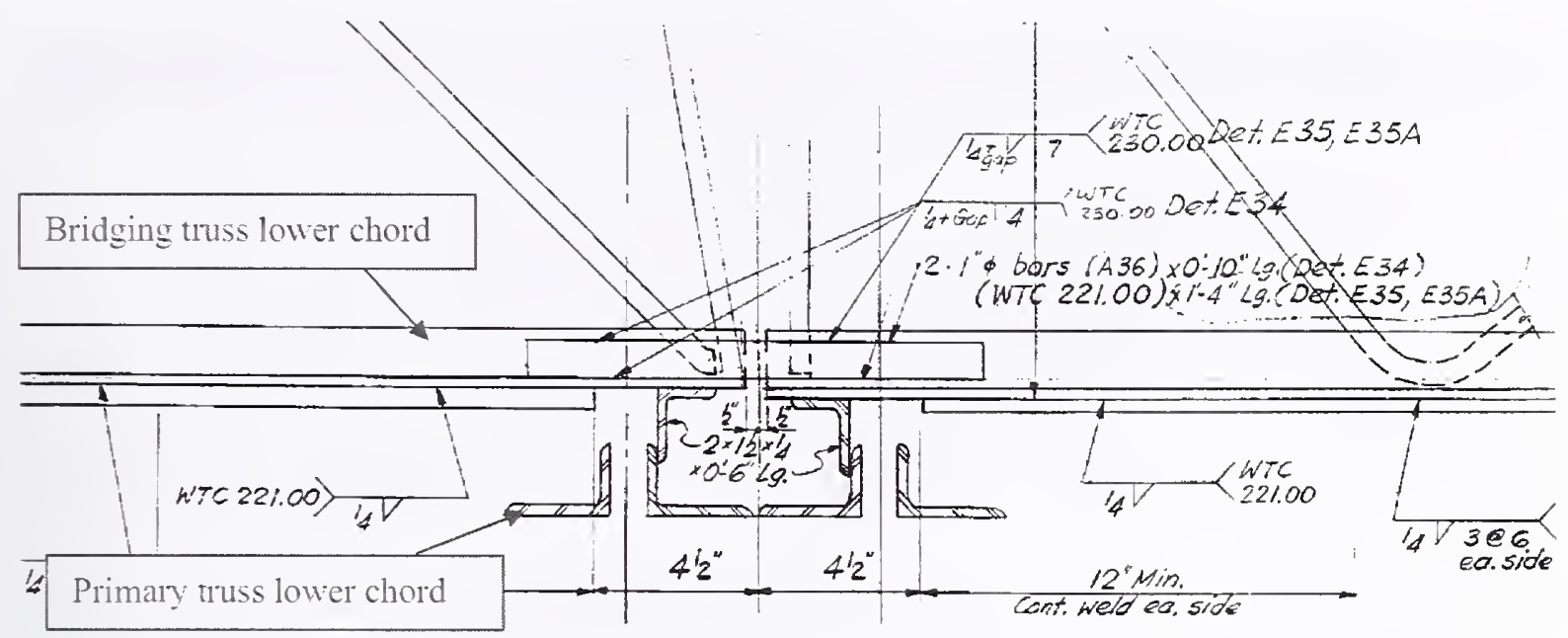

Source: Reproduced with permission of The Port Authority of New York and New Jersey. Enhanced by NIST.

\section{Figure 3-17. Connection between bottom chords of primary and bridging trusses.}

For bridging trusses in the model, a 0.75 in. angle gap was used for trusses with web bar diameters that varied between $0.75 \mathrm{in}$. and 0.98 in.

\subsubsection{Truss Member Cover Plates}

In 30 percent of the floor area, truss members were supplemented with cover plates. The members with additional plates included top chords, web members, and most typically bottom chords. Section properties were calculated with SAP2000 Section Designer. The primary truss top chords were reinforced with an additional set of double angles at truss end connections. At these locations, the work points for the section were located at the centroid of the composite double angle and concrete slab.

The Laclede shop drawings indicated plates $3 / 8$ in. by 3 in. connecting the bottom chord of the primary truss pairs together at each end and where intersected by a bridging truss. These plates were included in the model.

\subsubsection{Viscoelastic Dampers}

Viscoelastic dampers were located where the bottom chords of the long span, short span, and bridging trusses intersected the exterior columns (see Chapter 1 for description and details). The dampers resisted static and quasi-static loads (such as gravity loads) at the time of load application. Immediately following load application, the dampers shed load until the stress in the dampers was dissipated. A placeholder element was located in the model at the damper location.

\subsubsection{Strap Anchors}

Exterior columns not supporting a truss or truss pair were anchored to the floor diaphragm by strap anchors. These strap anchors were connected to the columns by complete penetration welds. The strap anchors were then connected to the slab with shear stud connectors and to the top chords of the trusses by fillct welds. The straps were included in the model and located in the plane of the centroid of the 
composite top chord. Also, in the model the work points intersected with the centerline of the column and used a rigid link to attach back to the spandrel (see Fig. 3-18).

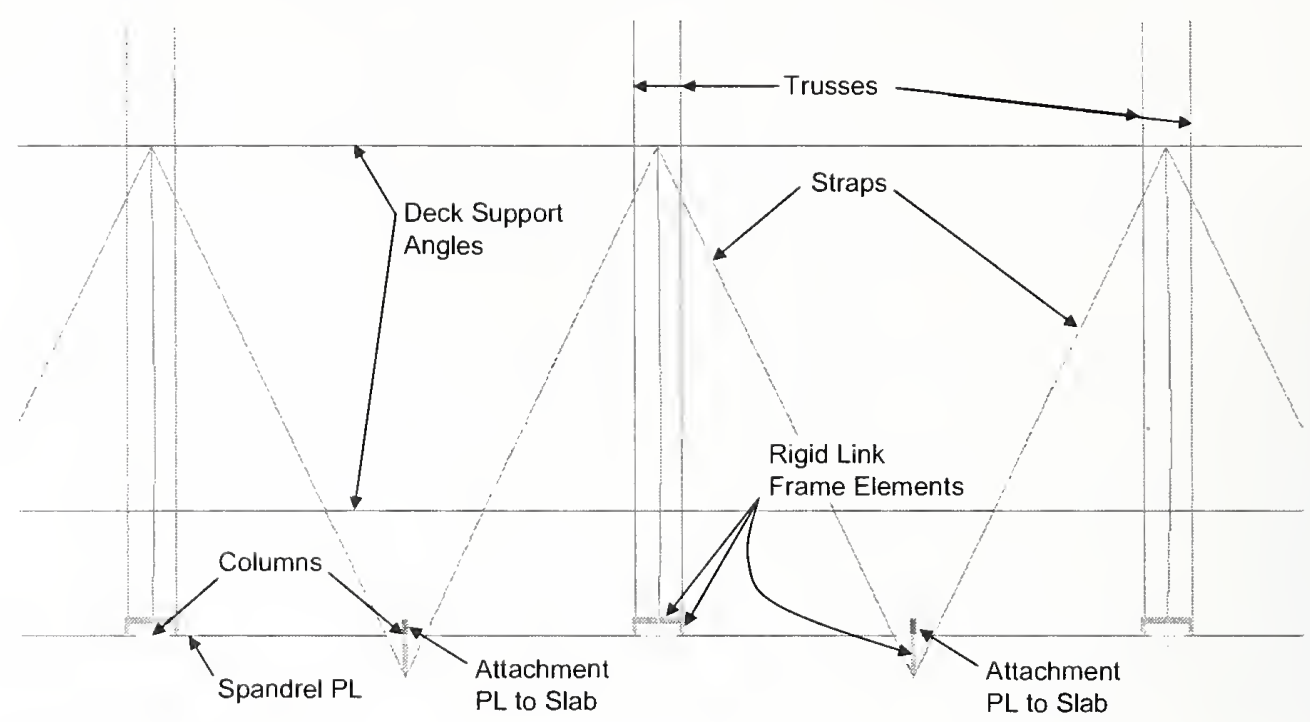

Key: PL, Plate.

Note: Slab not shown.

Figure 3-18. Strap anchors modeling.

\subsubsection{Concrete Slab and Metal Deck}

Outside the core, the primary trusses acted compositely with the 4 in. concrete slab on $11 / 2 \mathrm{in}$. metal deck. In the model, the average depth of the slab plus deck was modeled as $4.35 \mathrm{in}$. The concrete slab consisted of lightweight concrete with a self-weight of $100 \mathrm{pcf}$ and a design compressive strength, $f^{\prime}{ }_{c}=3,000 \mathrm{psi}$. The concrete modulus of elasticity, $E_{c}$, used for modeling was $1,810 \mathrm{ksi}$, and the calculated modular ratio, $n=E_{s} / E_{c}$, was taken as 16 , where $E_{s}$ is the steel modulus of elasticity. These values are consistent with those included in the WTC Structural Design Criteria Book.

Typically, inside the core, the beams acted compositely with a $41 / 2 \mathrm{in}$. formed concrete slab. The concrete slab consisted of normal weight concrete with a self-weight of $150 \mathrm{pcf}$ and a design compressive strength, $f_{c}^{\prime}=3000 \mathrm{psi}$. The concrete modulus of elasticity, $E_{c}$, used for modeling was $3,320 \mathrm{ksi}$, and the calculated $n$ ratio, $E_{s} / E_{c}$, was taken as 8.7 .

The floors of the WTC towers had an in-floor electrical distribution system of electrified metal deck and trench headers. The effects of the in-slab trench headers were accommodated in the model by reducing the slab shell element thickness. A $1 \mathrm{ft} 8$ in. wide shell panel (the typical truss-floor shell mesh size) was reduced in thickness from $4.35 \mathrm{in}$. to $2.35 \mathrm{in}$. or $1.35 \mathrm{in}$. at the trench header locations per drawing SCA-109 (Floor 96A Structural Concrete Floor Plan).

\subsubsection{Verification of the 96th Floor Model}

Several steps were taken to verify the model input. SAP2000 Version 8 offers a 'shading' option once a model has been built with frame section assignments. This allows the user to view the members as the program has interpreted their input. The shading option was helpful for using section designed shapes, 
and for verifying the orientation (i.e., local axes) of members. The work was independently revicwed by engineers not associated with the initial model development.

Once the model was completed, checks were performed for gravity loads. All superimposed dead loads and live loads included in the model were based on WTC Design Criteria; self weight was m accounted for by SAP2000. To justify the modeling assumptions, several studies were performed to compare stress results to hand calculations for representative composite sections. Hand calculations were uscd to estimate deflections and member stresses for a simply supported composite truss under gravity loading. For the composite truss sections, the steel stress results were within 4 percent of thosc calculated by SAP2000 for the long-span truss and 3 percent for the short-span truss. Deflections for the beams and trusses matched hand calculations within 5 percent to 15 percent.

\subsection{TYPICAL BEAM-FRAMED FLOOR MODEL-FLOOR 75B}

As described in Section 3.3 for truss-framed floors, the structural drawings were reviewed to identify structural similarities between the beam-framed floors within the expanded impact and fire zones of both towers (see Appendix G). It was found that floor 75 of WTC 2 (75B) represented the typical beamframed floor in the expanded impact zone for WTC 2 (floors 74B to 88B). There were no beam-framed floors within the expanded impact zone of WTC 1.

Floors 75 and 76 of WTC 2, lower and upper mechanical equipment room (MER) floors, rcspectively, were typical of the lower three MER floor pairs in both towers (floors 7 and 8, 41 and 42, and 75 and 76 for both WTC 1 and WTC 2). Floor 77 of WTC 2, a lower escalator floor, was a beam-framed floor similar to the lower floor of the MER floor pairs, i.e., floor 75B.

Based on the above analysis, floor 75 of WTC 2 was selected as the overall representative beam-framcd floor for the expanded impact and fire zone in both towers and is described in the following sections (see Fig. 3-19). An isometric view of the typical beam-framed floor model is illustrated in Fig. 3-20.

Table 3-1 includes a summary of the size of the 75B floor model. The following prescnts the major structural systems and components of the beam-framed floor model. 
Type 12 - WTC Beam Framed Floor Floor Plan

Towers A \& B MER Floors: $7,41,75,108$

Towers A \& B Near MER Floors: 9,43,77,107,110,Roof

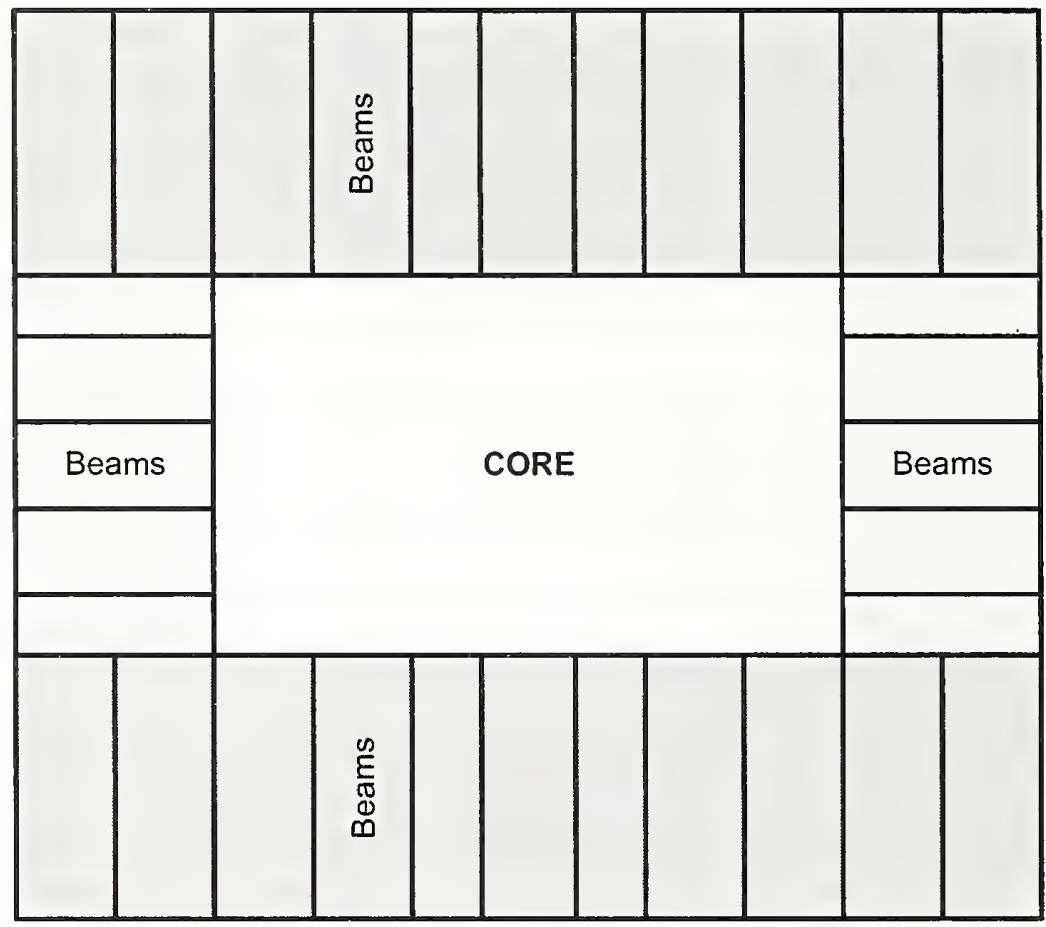

Figure 3-19. Typical beam-framed floor arrangement.

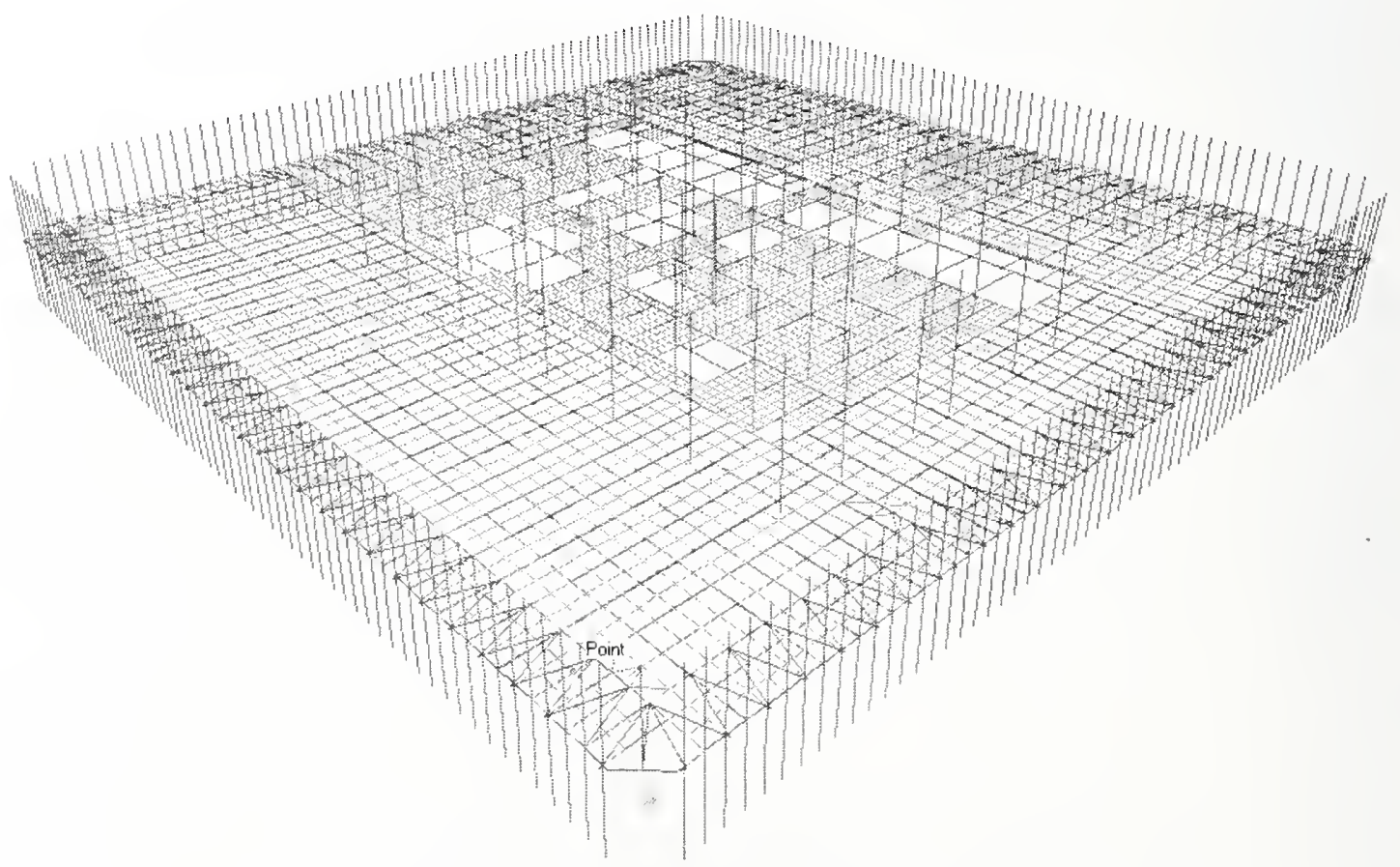

Figure 3-20. Typical beam-framed floor model (floor 75B). 


\subsubsection{Composite Beams}

The beams in the model were located at the elevation of the centerline of the concrete slab. The insertion point for the beams was set at the beam top flange, and then the beam was offset down by one-half the thickness of the slab. The beam was rigidly linked with the slab to simulate the composite action. This option provided for accurate estimation of the composite stiffness of the floor.

For beams with cover plates, the properties were calculated by SAP2000 Section Designer, and the slab, beam, and reinforcing plates were rigidly linked.

\subsubsection{Horizontal Trusses}

Exterior columns which did not support a beam were connected to the floor for bracing purposes by horizontal trusses. These exterior horizontal trusses were anchored to the columns with complete joint penetration welds. The horizontal trusses were then connected with shear stud connectors to the slab. The truss angles (typically 4 in. by $4 \mathrm{in}$. by $5 / 16$ in.) were then field welded to the top flange of the beams. In the model, the work points intersected with the centerline of the column and used a rigid link to attach back to the spandrel. The truss members were located in the plane of the centroid of the composite top chord (see Fig. 3-21).

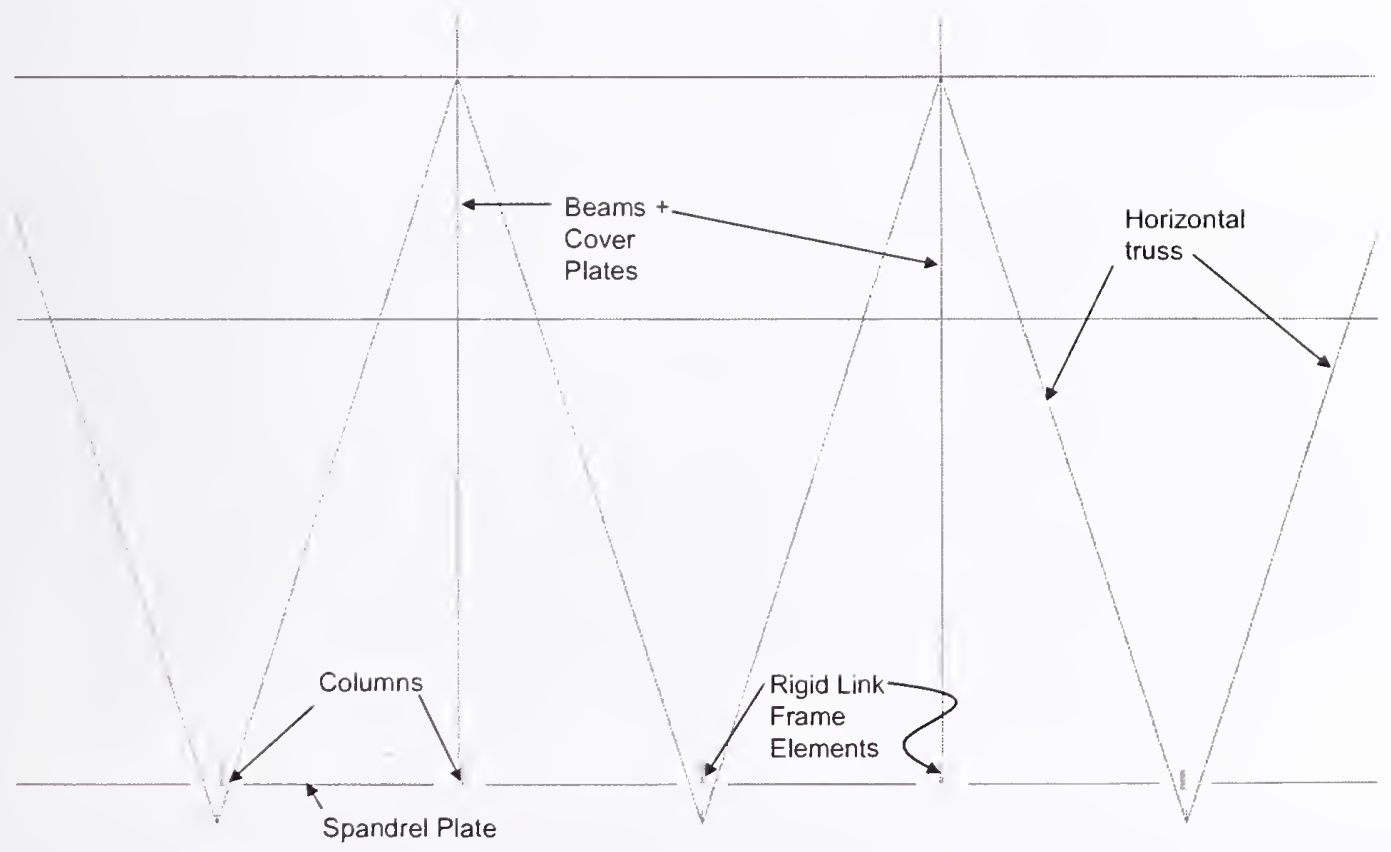

Figure 3-21. Horizontal truss modeling, slab not shown.

\subsubsection{Concrete Slab and Metal Deck}

Outside the core on the mechanical floors, the beams acted compositely with a $53 / 4$ in. concrete slab on $11 / 2$ in. metal deck. The average cross-sectional depth of the slab in the model was taken as 6.1 in. The 
deck spanned between channels that, in turn, spanned between the floor beams. The concrete slab consisted of normal weight concrete with a self-weight of $150 \mathrm{pcf}$ and a design compressive strength of typically $f_{c}^{\prime}=3,000 \mathrm{psi}$. The concrete modulus of elasticity, $E_{c}$, used for modeling was $3,320 \mathrm{ksi}$ and the calculated modular ratio, $n$, was taken as 8.7.

Typically, inside the core, the beams acted compositely with a 6 in. formed concrete slab. The concrete slab consisted of normal weight concrete with the same properties as concrete outside the core.

The mechanical floors had a 2 in. maximum depth topping slab both inside and outside the core. The topping slab stiffness was not included in the models, but the weight was accounted for in the baseline performance analysis.

\subsubsection{Viscoelastic Dampers}

Viscoelastic dampers were located below the bottom flange of the beams where the beams intersected the exterior columns (see Chapter 1 for description). Similar to floor 96A model, a placeholder element was located in the model at the damper location.

\subsubsection{Verification of the 75th Floor Model}

Similar to the 96th floor model, the 'shading' option in SAP2000 was used to view the members as the program interpreted their input. The shading option was helpful for using section designed shapes, and for verifying the orientation (i.e., local axes) of members. The work was independently reviewed by engineers not associated with the initial model development.

Once the model was completed, checks were performed for gravity loads. All superimposed dead loads and live loads included in the model were based on WTC Design Criteria; self-weight is accounted for by SAP2000. To justify the modeling assumptions, several studies were performed to compare stress results to hand calculations for representative composite sections. Hand calculations were used to estimate deflections and member stresses for a simply supported composite beam under gravity loading. The model yielded accurate steel stress results compared to hand calculations-around 1 percent for both short- and long-span beams. Where the beams were built-up with reinforcing plates, it was found that SAP2000 Section Designer shapes were not calculating the stresses correctly, so instead, separate beam and plate elements drawn over each other were inserted. This method yielded very accurate steel stress results-between 1 percent and 2 percent for both short- and long-span beams.

\subsection{PARAMETRIC STUDIES}

Modeling techniques employed in the development of the global models of WTC 1 and WTC 2 were consistent with, but often more advanced than, the techniques typically employed in the analysis and design of high-rise buildings. As such, building components were idealized so that overall performance was replicated while appropriately reducing the computational requirements. The following describes the studies undertaken to establish the idealizations used in the models, including typical exterior wall panels, exterior corner panels, and flexible floor diaphragms. 


\subsubsection{Exterior Wall Columns/Spandrel Typical Panels (Floors 9 to 106)}

A parametric study of typical three-column, three-spandrel exterior wall panels from the faces of the towers (floors 9 to 106) was performed using two modeling methods (see Fig. 3-22). The first model was a detailed shell model, where each plate of each column or spandrel was specifically modeled, and the second was a simplified frame model. Internal column stiffeners were included in the shell model. The parametric study assumed that the shell model best represented the as-built panel performance, and therefore, it was used to tune the performance of the frame model, which was used throughout the global model (see Sec. 3.2.6). The objectives of the study were to (1) match the axial stiffness of the frame model with the detailed shell model under gravity load and (2) match the inter-story drift of the two models by modifying the rigidity of the column/spandrel intersections in the frame model.
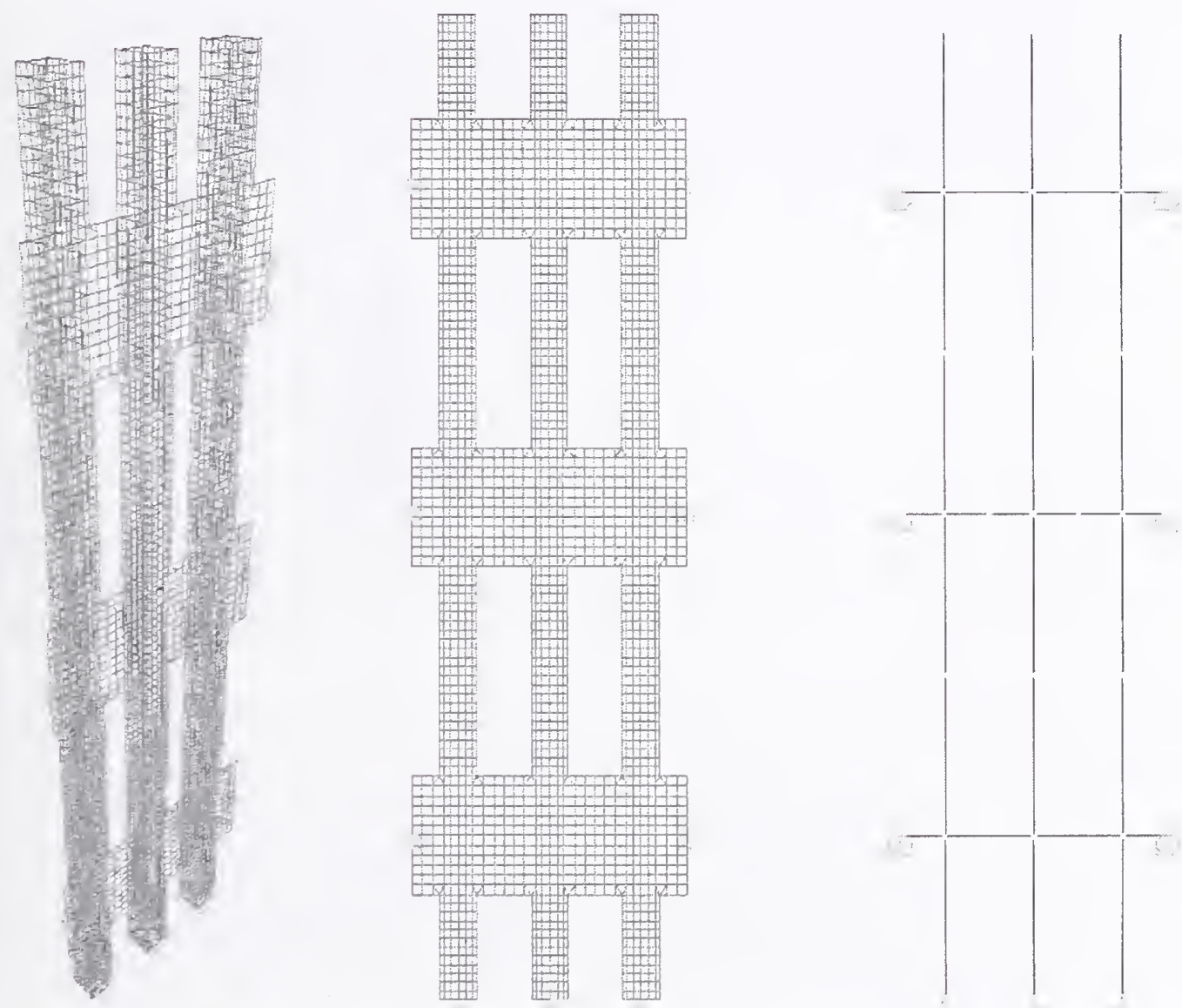

Figure 3-22. Shell element and frame models of typical exterior wall panel.

For comparing the axial stiffness of the simplified frame model of the panel with the detailed shell model, both models were loaded vertically while pin-supported at the bottom of the columns. The results indicated that the shell model was stiffer than the equivalent beam model due to the contribution of the spandrel beams to the columns' axial stiffness. This was due to the rigidity of the spandrel beams and the proximity between the columns. The parametric study on a wide range of panels over the height of the 
towers showed that the vertical stiffness of the columns in the bottom third of the towers should be increased by a factor in the range of 25 percent to 28 percent, and the columns in the middle and upper thirds of towers should be increascd by a factor in the range of 20 percent to 28 percent. Based on these results, 25 percent increase of the axial stiffness of exterior columns was selected as a reasonable representation for the panel vertical stiffness over the height of the towers between floors 9 and 106 (see Sec. 3.2.6).

For studying the lateral deformation of the exterior panels, panel properties were taken from three different areas of the building. These included floors 79 to 82,53 to 56 , and 23 to 26 . The deformations at points A, B, 1, and II (see Fig. 3-23) were studied for three different panel locations and their respective spandrel and column thickness. The topmost columns were connected via a rigid link and loaded in the plane of the panel and perpendicular to the column with a $100 \mathrm{kip}$-load. The boundary conditions were as shown in Fig. 3-22.

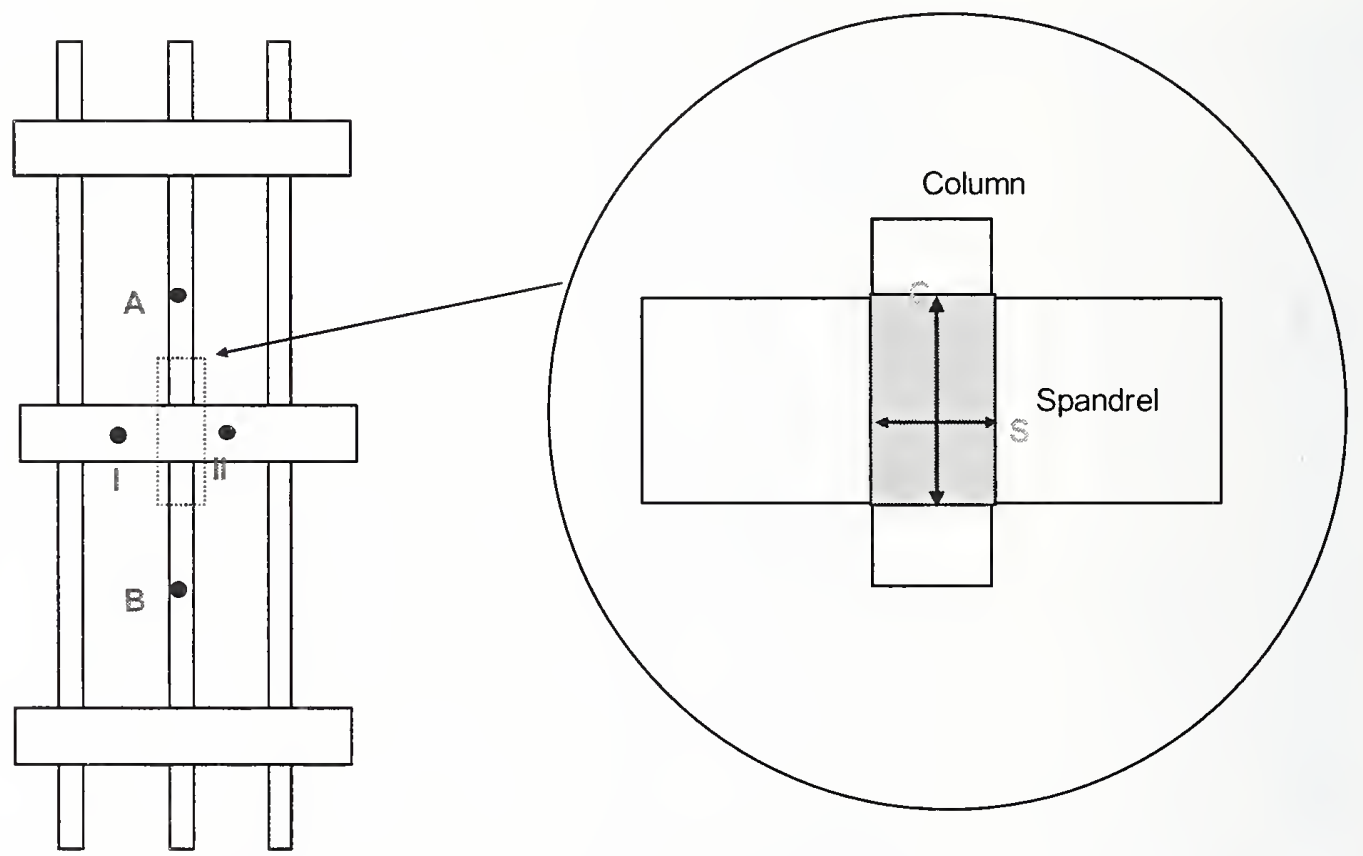

Figure 3-23. Selection of column and spandrel rigidity of typical exterior wall panel.

The lateral displacements found for the shell and frame models of typical exterior wall panels with varied column and spandrel intersection rigidities are reported in Table 3-5. The study found that 50 percent column rigidity and 100 percent spandrel rigidity in the frame model produced deflection results consistent with the shell model. 
Table 3-5. Lateral displacement (in.) for the shell and frame models of typical exterior wall panel with varied column and spandrel rigidities.

\begin{tabular}{|c|c|c|c|c|}
\hline & \multicolumn{4}{|c|}{ Lateral displacement (in) } \\
\hline & \multicolumn{4}{|c|}{ Floor 79-82 } \\
\hline & \multirow{2}{*}{ Shell model } & \multicolumn{3}{|c|}{ Frame model (Rigidity) } \\
\hline & & No rigidity & C: $50 \%, \mathrm{~S}: 100 \%$ & C: $100 \%$, S:100\% \\
\hline A & 0.60 & 1.04 & 0.59 & 0.35 \\
\hline $\mathrm{B}$ & 0.28 & 0.52 & 0.29 & 0.18 \\
\hline 1 & 0.45 & 0.78 & 0.44 & 0.26 \\
\hline \multirow[t]{4}{*}{ II } & 0.45 & 0.78 & 0.44 & 0.26 \\
\hline & \multicolumn{4}{|c|}{ Floor 53-56 } \\
\hline & \multirow{2}{*}{ Shell model } & \multicolumn{3}{|c|}{ Frame model (Rigidity) } \\
\hline & & No rigidity & C: $50 \%, \mathrm{~S}: 100 \%$ & C: $100 \%, \mathrm{~S}: 100 \%$ \\
\hline A & 0.26 & 0.43 & 0.27 & 0.18 \\
\hline$B$ & 0.12 & 0.22 & 0.14 & 0.11 \\
\hline 1 & 0.19 & 0.32 & 0.2 & 0.15 \\
\hline \multirow[t]{4}{*}{ II } & 0.19 & 0.32 & 0.2 & 0.15 \\
\hline & \multicolumn{4}{|c|}{ Floor 23-26 } \\
\hline & \multirow{2}{*}{ Shell model } & \multicolumn{3}{|c|}{ Frame model (Rigidity) } \\
\hline & & No rigidity & $\mathrm{C}: 50 \%, \mathrm{~S}: 100 \%$ & $\mathrm{C}: 100 \%, \mathrm{~S}: 100 \%$ \\
\hline A & 0.21 & 0.37 & 0.21 & 0.12 \\
\hline$B$ & 0.1 & 0.18 & 0.1 & 0.06 \\
\hline 1 & 0.16 & 0.28 & 0.16 & 0.09 \\
\hline 11 & 0.16 & 0.28 & 0.16 & 0.09 \\
\hline
\end{tabular}

\subsubsection{Exterior Wall Columns/Spandrel Corner Panels (Floors 9 to 106)}

A parametric study was performed of an exterior wall corner panel typical over each comer of the towers from floors 9 to 106. Similar to the exterior typical panels, to account for the contribution of the spandrels into the axial stiffness of the columns, it was found that an arca modificr to provide a 25 pcrcent increase in the axial stiffness of the two continuous columns of the corner panels was suitable for modeling the columns' axial stiffness. No modifiers wcre needed for the intermittcnt columns.

The panel from floor 53 to 56 was selected to be reprcsentative, with two additional columns attachcd on either side. The objective of the study was to match the inter-story drift of a dctailcd shcll model and a simplified frame model of the corner panel by modifying the rigidity of the column/spandrel interscctions in the frame model. For this parametric study, the panel was straightened to simplify the study and to isolate the behavior of interest (see Fig. 3-24). The deformations at points T1, T2, B1, B2, and M2 (Fig. 3-25) were studied for representative column and spandrel plate dimensions. The topmost columns were connected via a rigid link and loaded in the plane of the pancl and perpendicular to the column with a 100 kip load.

The lateral displacements calculated for the shell and frame modcls of the typical exterior wall corner panel with varied column and spandrel rigidities are reported in Table 3-6. The study indicated that 25 percent column rigidity and 50 percent spandrel rigidity in the frame model produced deflection results consistent with the shell model. 

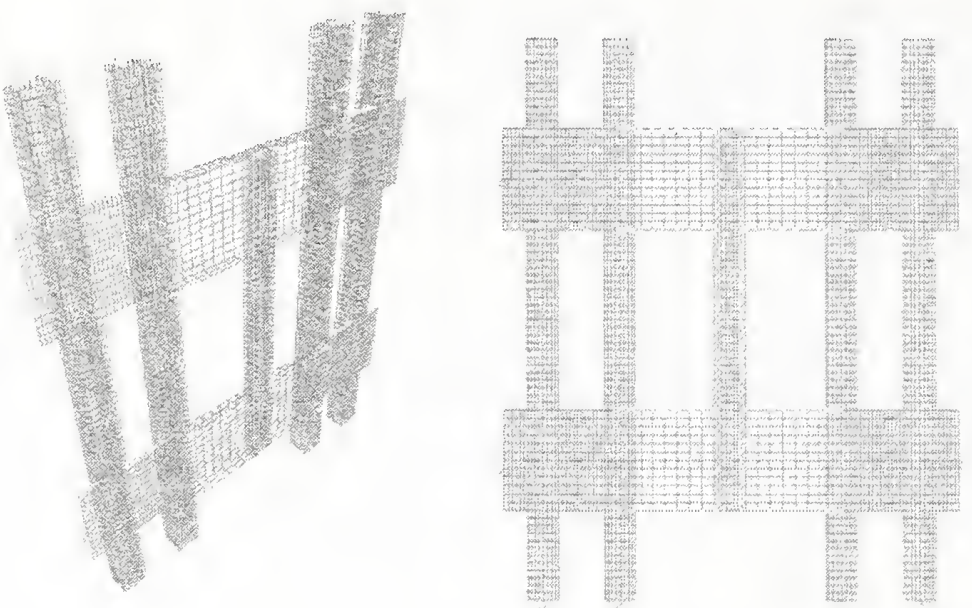

Figure 3-24. Shell element and frame models of typical exterior wall corner panel.

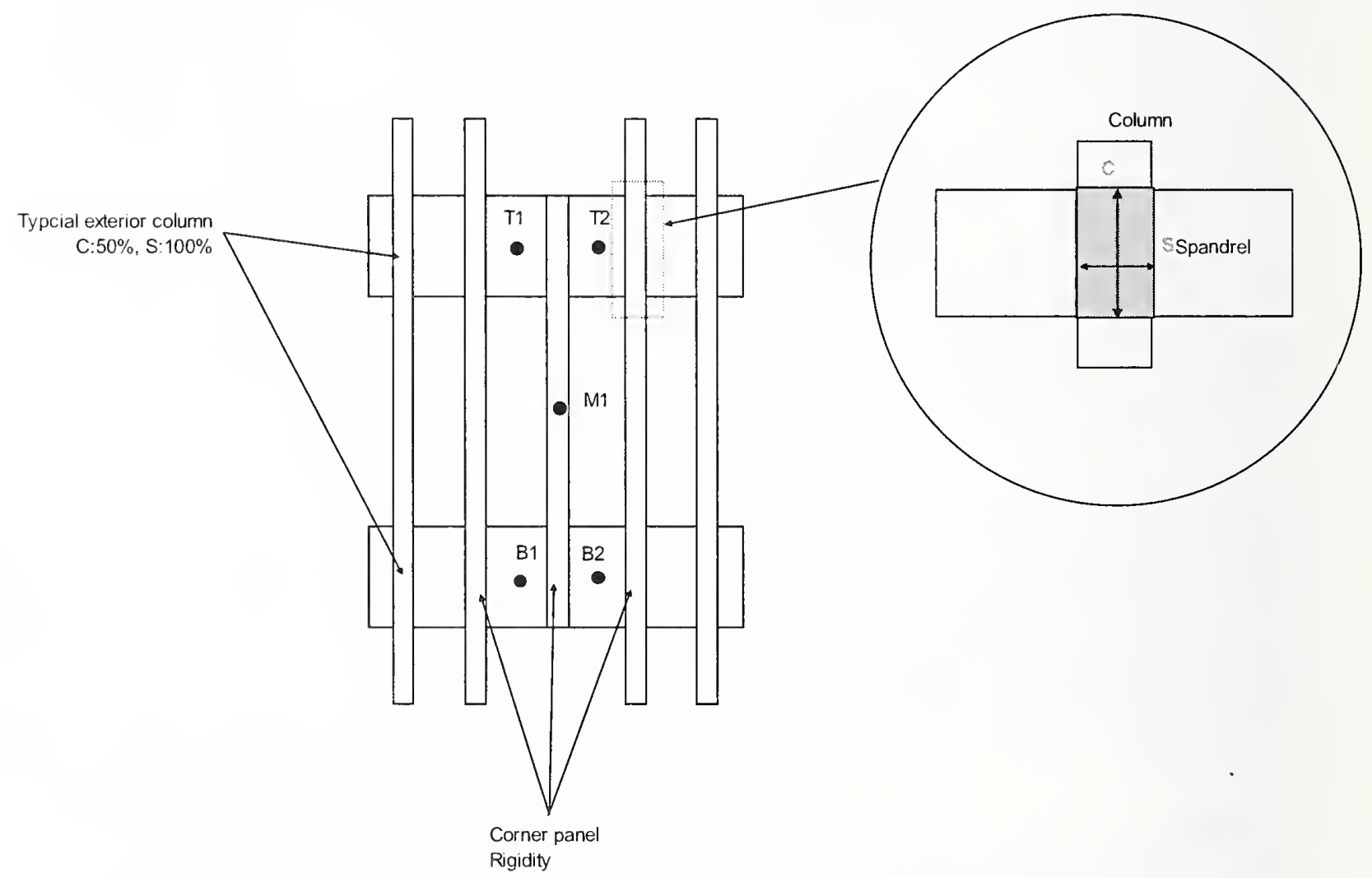

Figure 3-25. Selection of column and spandrel rigidity of typical exterior wall corner panel. 
Table 3-6. Lateral displacement (in.) for the shell and frame models of typical exterior wall corner panel with varied column and spandrel rigidities.

\begin{tabular}{|c|c|c|c|c|}
\hline \multirow{2}{*}{} & \multirow{4}{*}{ Shell model } & \multicolumn{3}{|c|}{ Corner panel rigidity } \\
\cline { 3 - 5 } & & No rigidity & $\mathrm{C}: 25 \%, \mathrm{~S}: 50 \%$ & $\mathrm{C}: 100 \%, \mathrm{~S}: 100 \%$ \\
\hline T1 & 0.227 & 0.236 & 0.222 & 0.152 \\
\hline T2 & 0.227 & 0.236 & 0.222 & 0.152 \\
\hline M1 & 0.149 & 0.154 & 0.149 & 0.102 \\
\hline B1 & 0.084 & 0.072 & 0.077 & 0.053 \\
\hline B2 & 0.084 & 0.072 & 0.077 & 0.053 \\
\hline
\end{tabular}

As part of the in-house NIST review of the reference structural models (see NIST NCSTAR 1-2), a detailed shell element model of original corner panel (not straightened) was analyzed under lateral loads to test the accuracy of the simplified frame model with 25 percent column rigidity and 50 percent spandrel rigidity calculated above. Both the detailed and simplified models were loaded as shown in Fig. 3-26. The deflections calculated from the frame model were consistent with those estimated from the shell model. indicating that the rigidities estimated using the straight model (Fig. 3-25) accurately represented the actual corner panel behavior.

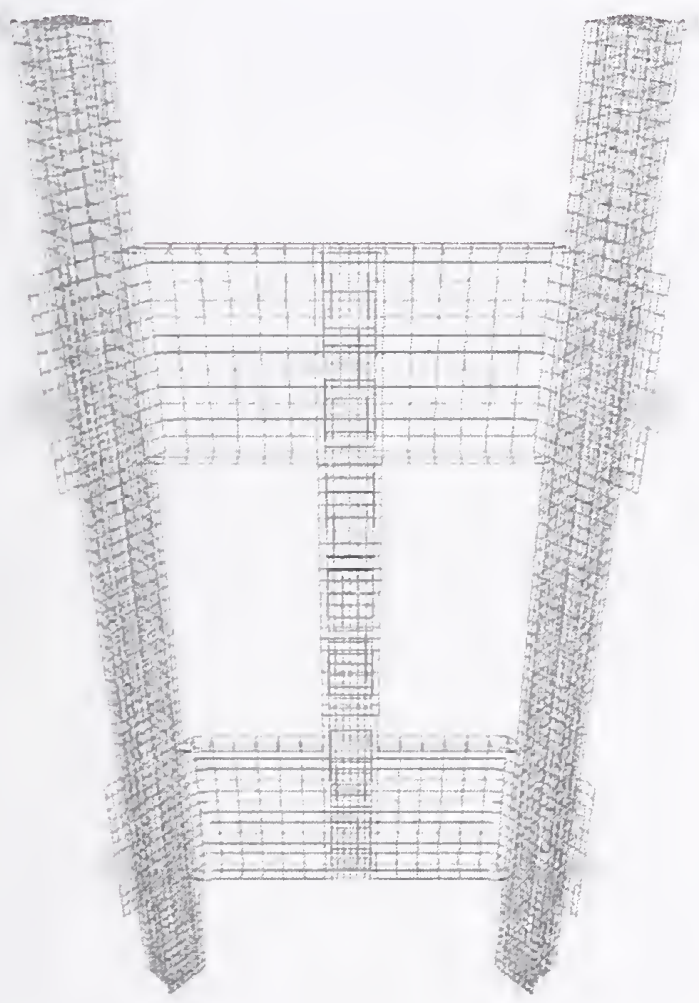

Figure 3-26. Detailed and simplified model of the exterior wall corner panel.

\subsubsection{Flexible Floor Diaphragm}

The floor models developed as described in Secs. 3.3 and 3.4 were used to develop the flexible diaphragm stiffness used within the WTC 1 and WTC 2 global models. The in-plane diaphragm stiffness of the 
detailed floor models was determined and used to arrive at an equivalent shell element floor model. This flexible shell element floor model was then inserted in the global models at specific floors to capture the in-plane flow of forces and deformations. These flexible diaphragms were not used throughout, as the rigid diaphragms in the majority of floors provided for a sufficiently accurate representation of the flow of forccs and deformations while keeping manageable the model's computational requirements. In the global models, flexible diaphragms were used at the beam-framed floors $3,4,5,6,7,9,41,42,43,75,76$, $77,107,108,109,110$, and roof of both towers. For floors 107, 108, 109, 110, and roof, the stiffness of the flexible diaphragms was reduced to prevent thcse diaphragms from attracting large forces incompatible with the strength of the slabs (see Sec. 3.2.9).

Parametric studies were performed to compare the diaphragm stiffness of two different floor models for both the typical truss-framed floor and the beam-framcd floor. The typical floor models were compared with simplified equivalent models that duplicated the representation of the exterior wall columns, exterior wall spandrels, core columns, and their boundary conditions. The floor framing, both inside and outside the core, was replaced by shcll elements. The matcrial properties of the shell model matched the properties of the concrete floor outsidc the core in the respective floor model.

The comparative floor models were loaded in the plane of the floors with a lateral load of $180 \mathrm{lb} / \mathrm{ft}$ (equivalent to $15 \mathrm{psf}$ over the $12 \mathrm{ft}$ story height) on both the windward and leeward faces. The column base supports were released for the exterior wall columns along the loaded faces and for all core columns to allow lateral translation only in the direction of loading.

The comparative models were executed to assess the horizontal deflection of the floor on both the windward and leeward sides of the model and for the case where the lateral loads were applied nonconcurrently along the 100 face and 200 face of the tower. Both the total horizontal deflection of the slab and the relative displacement between the windward and leeward sides were compared between the models. The shell thickness was modified to match the in-plane stiffness determined by the detailed floor models.

The deformations from the lateral load case using the 75th floor model of WTC 2 are illustrated in Fig. 3-27, while Fig. 3-28 shows the deformations of the simplified floor model. Fig. 3-29 shows the latcral deflection of the north and south sides of the floor model under lateral load applied in the north dircction using the detailed and equivalent floor models. 


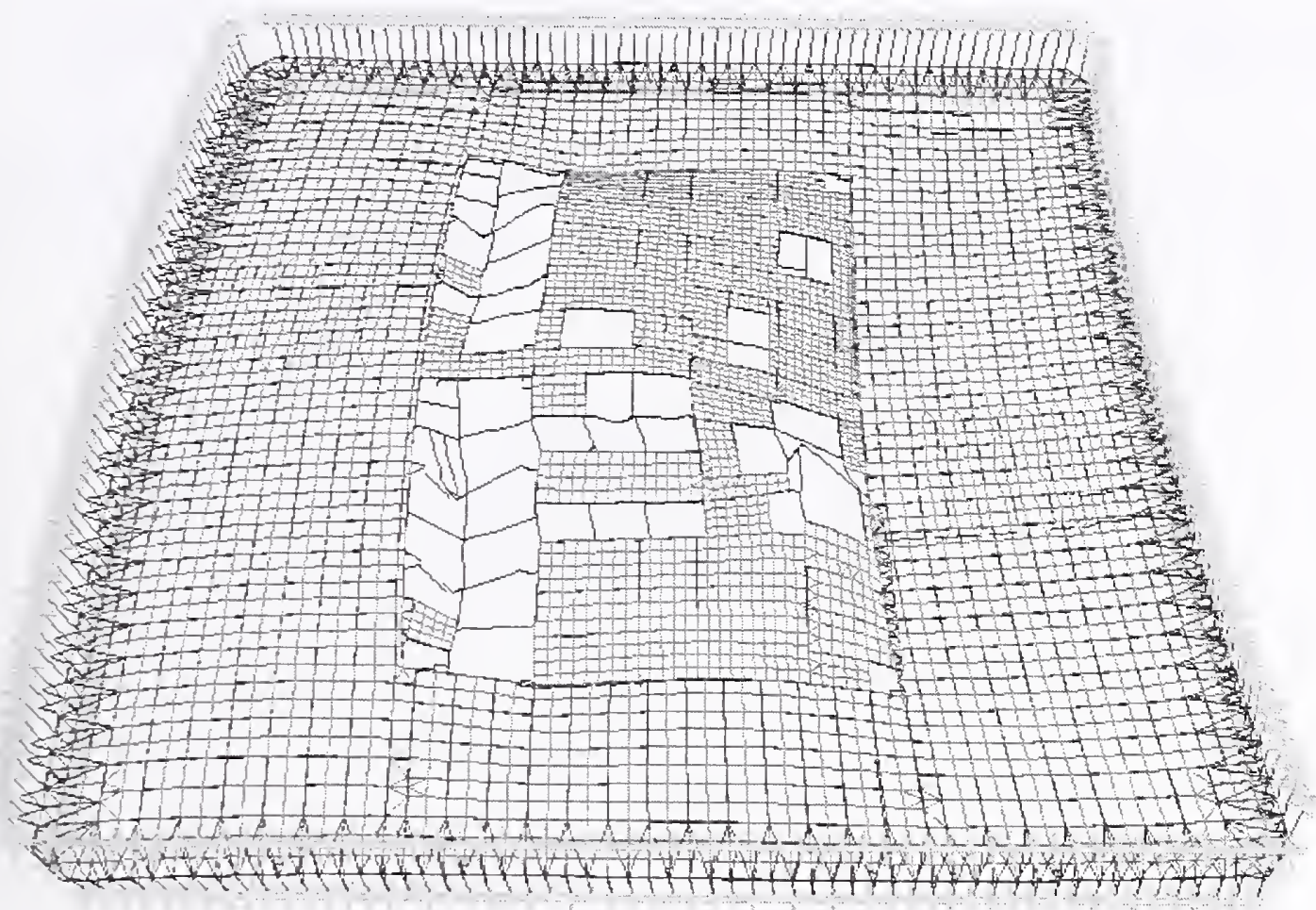

Note: Exaggerated scale.

Figure 3-27. Deflection of typical beam-framed floor model due to lateral loading.

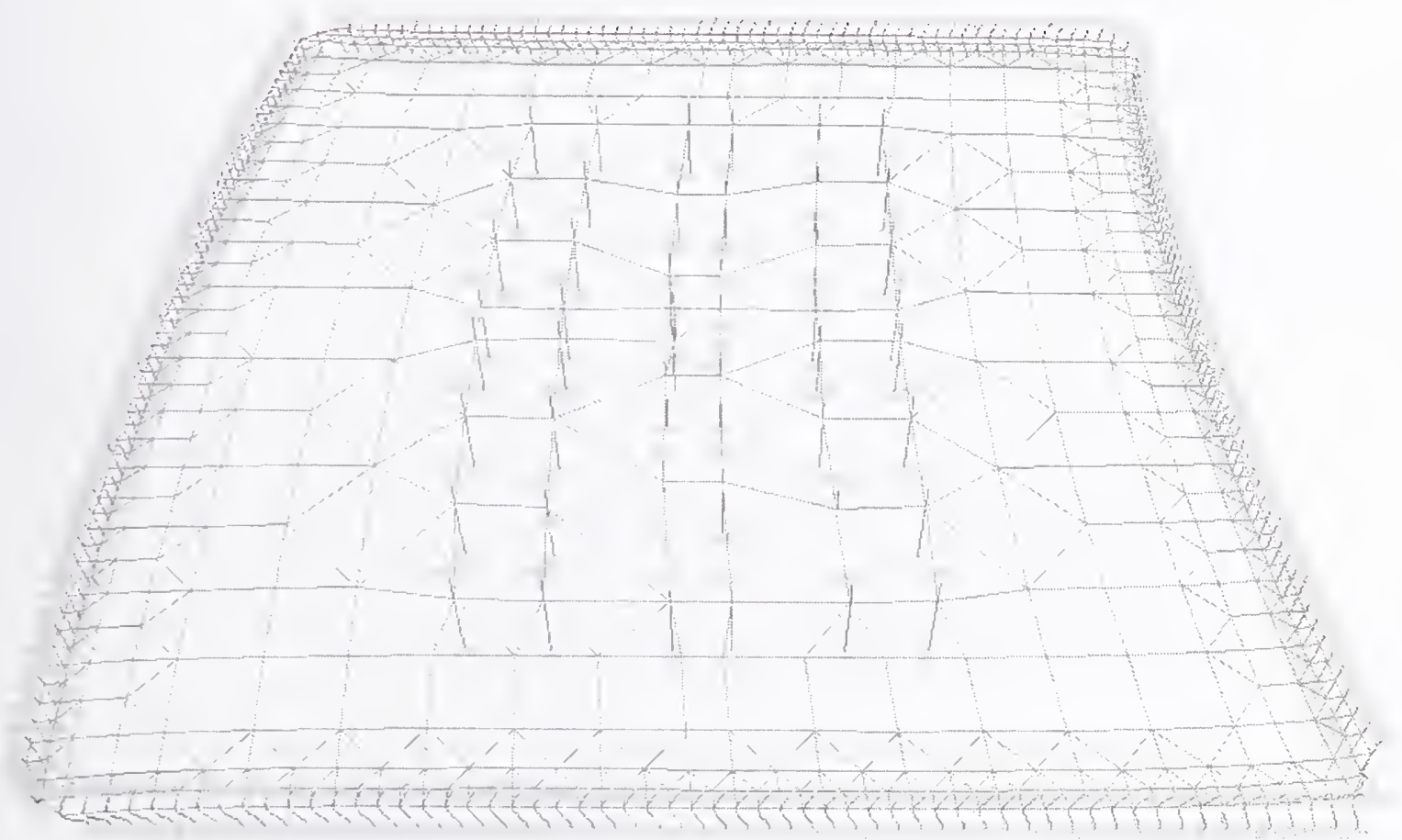

Note: Exaggerated scale.

Figure 3-28. Deflection of equivalent floor model due to lateral loading. 


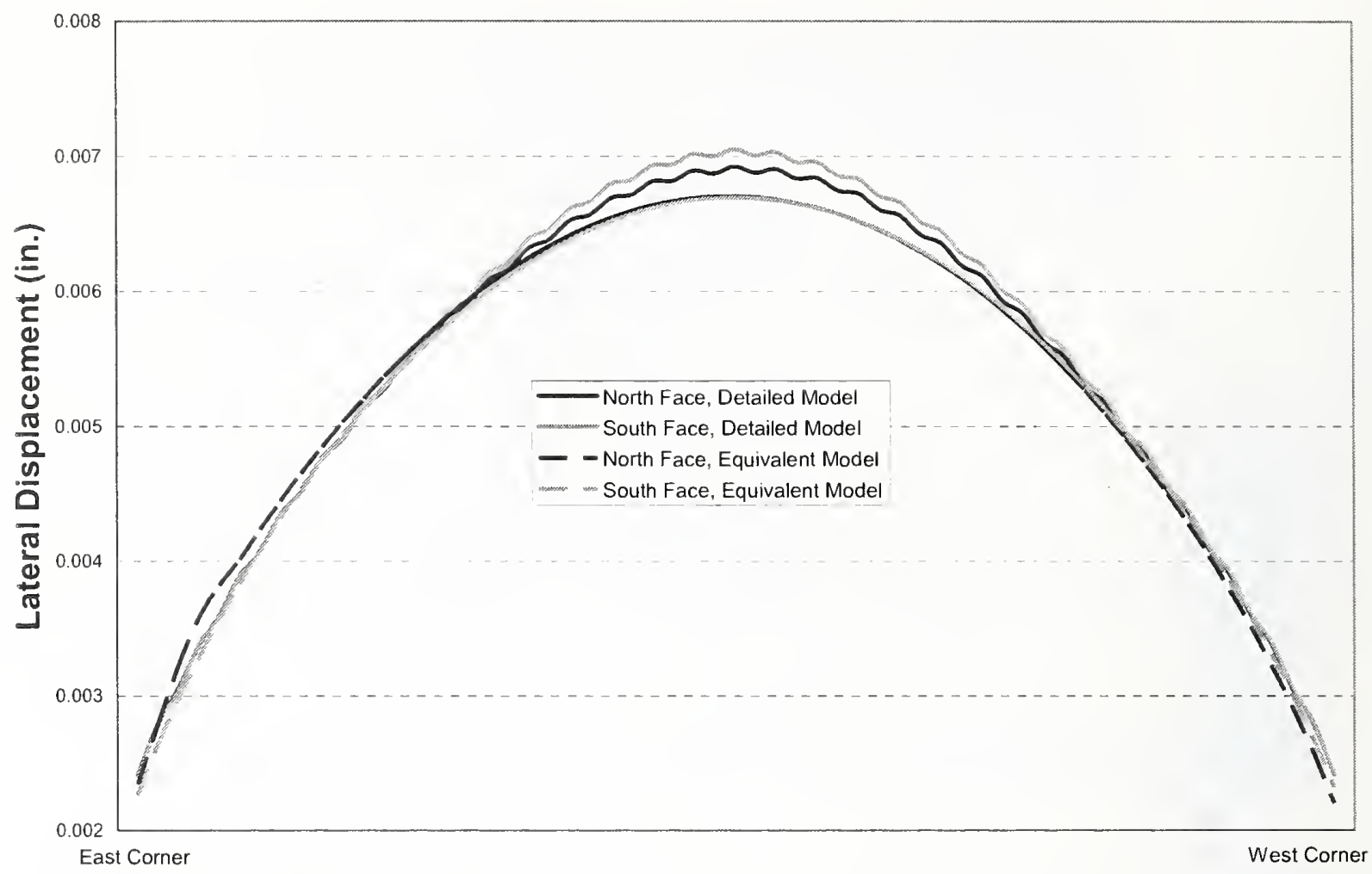

Figure 3-29. Deflections of the north and south faces of the floor for the detailed and equivalent floor models.

\subsection{SUMMARY}

This chapter described the development of the reference structural models for the WTC towers. These reference models were used to establish the baseline performance of the towers and also served as a reference for more detailed models for aircraft impact damage analysis and thermal-structural response and collapse initiation analysis. The main types of models developed were:

- Two global models of the towers, one each for WTC 1 and WTC 2. The models included all primary structural components in the towers, including exterior walls (columns and spandrel beams), core columns, exterior wall bracing in the basement floors, core bracing at the mechanical floors, core bracing at the main lobby atrium levels, hat trusses, and rigid and flexible diaphragms representing the floor systems. The models were developed using the electronic databases described in Chapter 2. To validate the global models, the calculated natural frequencies of WTC 1 were compared with those measured on the tower and good agreement between the calculated and measured values was obtained.

- One model each of a typical truss-framed floor (floor 96 of WTC 1) and a typical beamframed floor (floor 75 of WTC 2) in the impact and fire zones in the two towers. The models included all primary structural components in the floor system, including primary and bridging trusses, beams, strap anchors and horizontal trusses, concrete slabs, and viscoelastic dampers. To validate the floor models, several studies were carried out to compare stresses 
and deflections estimated from the model with hand calculations for representative composite sections. Good agreement was obtained between the model results and hand calculations.

Parametric studies were performed to evaluate the behavior of typical portions of the structure and to develop simplified models that could be implemented in the global models. These parametric studies included detailed and simplified models of typical exterior and corner wall panels, and floor systems. 
This page intentionally left blank. 


\section{Chapter 4 \\ GRAVITY AND WIND LOADS ON THE WTC GLOBAL MODELS}

\section{$4.1 \quad$ INTRODUCTION}

This chapter outlines the estimation of the gravity and wind loads applied to the global models of the World Trade Center (WTC) towers to establish their baseline performance. The following sources were used to develop the loads for the various loading cases considered in this study:

- Design Criteria document of the WTC towers, prepared by Worthington, Skilling, Helle \& Jackson (henceforth referred to as Design Criteria).

- WTC architectural and structural drawings (henceforth WTC Dwgs.).

- Wind reports prepared by Worthington, Skilling, Helle \& Jackson, describing the development of design wind loads for the WTC towers (henceforth WSHJ Wind Reports).

- Reports from two independent wind tunnel studies concerning the WTC towers, conducted in 2002 for insurance litigation by Cermak Peterka Peterson, Inc. (henceforth CPP) and Rowan Williams Davies and Irwin. Inc. (henceforth RWDI).

- Current New York City Building Code (henceforth NYCBC 2001).

- Current American Society of Civil Engineers (ASCE 7) Standard (henceforth ASCE 7-02).

Three loading cases were considered for the baseline performance analysis. They included:

- Original WTC design loads case. Loads were as follows: Dead and live loads as in original WTC design in accordance with Design Criteria, used in conjunction with original WTC design wind loads from WSHJ Wind Reports.

- State-of-the-practice case. Loads were as follows: Dead loads as in original design; NYCBC 2001 live loads; and wind loads from RWDl wind tunnel study, scaled in accordance with NYCBC 2001 wind speed. This wind load is considered as a lower estimate state of the practice since, as will be explained later, the CPP wind tunnel study produced larger wind loads on the towers and is considered as an upper estimatc state-of-the-practice case.

- Refined NIST estimate case. Loads were as follows: Dead loads as in original design; live loads from ASCE 7-02 (a national standard); and wind loads developed by National Institute Standards and Technology (NIST) from critical assessment of information obtained from the RWD1 and CPP reports and state-of-the-art considcrations.

The purpose of using the original WTC design loads was to evaluate the performance of the towers under original design loading conditions, and ascertain whether those loads and the corresponding design were adequate given the knowledge available at the time of the design. The purpose of considering the state- 
of-the-practice case and the refined NIST estimate case was to better understand and assess the effects of successive changes in standards, codes, and practices on wind design practices for tall buildings.

Section 4.2 of this chapter presents the gravity loads on the towers, including: dead loads and live loads used in the original design, and in accordance with NYCBC 2001 and ASCE 7-02. Section 4.3 presents and compares the wind loads used in the original design, state-of-the-practice wind loads, and wind load estimates developed by NIST.

\subsection{GRAVITY LOADS}

The gravity loads applied to the global WTC models consisted of dead loads (DL) and live loads (LL), appropriately combined as stipulated in the Design Criteria. Dead loads were applied to the global system computer models in two parts: construction dead loads (CDL) and superimposed dead loads (SDL), based on the WTC Dwgs and the Design Criteria.

- $\mathrm{CDL}$ is defined as the self-weight of the structural system, including floor slabs, beams, truss members, columns, spandrel beams, etc.

- SDL is defined as the added dead load associated with architectural, mechanical, electrical, and plumbing systems; such as curtain walls, ceilings, partitions, floor finishes, mechanical equipment and ducts, transformers, etc.

Three indcpendent sets of live loads were combined with the dead loads:

- The first set was taken from the Design Criteria and was used with the original WTC design loads case.

- The second set was taken from NYCBC 2001 and was used for the state-of-the-practice case.

- The third set was taken from ASCE 7-02 and was used for the refined NIST estimates case. The live loads given in ASCE 7-02 are essentially identical to the NYCBC 2001 live loads.

For each live load set, live load reductions for column design were taken from their respective source. The live load reductions in NYCBC 2001 are essentially identical to those of the Design Criteria.

Gravity loads were applied to the global system computer models using three methods:

- The self-weight of the structural steel frame for the exterior wall, core columns, and hat truss was applied using the SAP2000 self-weight feature.

- The loads from areas outside the core of the typical truss-framed and beam-framed floors were taken from the reactions of the typical floor computer models (see Sec. 4.2.1) and were applied to the global models as concentrated loads on the columns.

- Since the occupancy, opening layout, and floor framing in the core area varied among floors, the loads within the core area, from floor B5 to the roof, were calculated using a spreadsheet (see Sec. 4.2.2) and were applied to the global models as concentrated loads on the columns. 


\subsubsection{Gravity Loads from Areas Outside of Core}

The loads from areas outside the core area of the typical truss-framed floor were based on the reactions from the typical floor computer model (floor 96 of WTC 1). The Design Criteria live load for areas outside of core was 100 psf. The reduced applied loads for the typical truss-framed floor for use in the global system computer models are summarized in Table 4-1, which shows the original WTC design criteria for gravity loads. The partition allowance from the original WTC Design Criteria was also used as the partition allowance for the NYCBC 2001 and the ASCE 7-02. The live load of $50 \mathrm{psf}$ is the same for the original design criteria, the NYCBC 2001, and ASCE 7-02.

Table 4-1. Original WTC design criteria loads for floor 96A model for the design of columns (typical truss floor). ${ }^{a}$

\begin{tabular}{|l|c|c|c|c|}
\hline \multirow{2}{*}{ Floor Area } & CDL $^{\mathbf{b}}$ & SDL $^{\mathbf{c}}$ & Total DL & LL \\
\cline { 2 - 5 } & $(\mathbf{p s f )}$ & $(\mathbf{p s f )}$ & $(\mathbf{p s f})$ & (psf) $^{*}$ \\
\hline Long Span & 3.5 & 14 & 17.5 & 50 \\
\hline Short Span & 3.5 & 14 & 17.5 & 50 \\
\hline Two-Way Zone & 3.5 & 16 & 19.5 & 50 \\
\hline Core $^{\text {d }}$ & None & None & None & None \\
\hline
\end{tabular}

a. The self-weight of interior and exterior columns, exterior spandrels, core frame members, and core floor slabs is not included in the tabulated loads and is not applied to the floor computer model.

b. The self-weight of the concrete slab and of the structural steel members in the floor system, as computed by SAP2000, is added to these loads.

c. Includes a 6 psf allowance for partitions.

d. Since the loads inside the core are applied separately to the global system computer models, the live loads, superimposed dead loads on the core area, and core frame members are reduced to zero in the floor computer models.

Live load reductions for columns for the original WTC design live loads were taken from the Design Criteria and were identical to those specified in NYCBC 2001. Live load reductions for the ASCE 7-02 live loads follow the ASCE 7-02 tributary area provisions. For the ASCE 7-02 loads, at the exterior walls live load reductions were calculated using an influence factor coefficient of two as defined in ASCE 7-02. The influence area for exterior wall columns was calculated using a 45 degree spread for the distribution of loads among the columns located below the loading point.

In the floor model, the self-weights of the exterior columns and spandrels, the interior core columns, and interior core beams (not including those of the core perimeter) were not included in the analysis, since these weights were already accounted for in the global models. For this purpose, the zero self-weight frame property modifier in SAP2000 was used. Appropriate portions of the core slab section definition were also modified by using a zero self-weight property modifier. In addition, since the loads inside the core were applied separately to the global models, the live loads and superimposed dead loads on the core area elements and core frame members were reduced to zero in the floor computer models.

For calculating the loads outside the core, three typical floors (floor 96, 75, and 43) were selected to be representative of all of the floors in the tower except for the roof, the floors at and below floor 2 , and the mezzanine floors. Models of floors 75 and 96 were developed as discussed previously in Chapter 3, and floor 43 was used as a representative of the beam-framed floors that were not mechanical floors (floor 75 model with modified loads was used to simulate this floor). Based on the column reactions from the typical floor computer models, gravity loads on columns at other floors were generated by applying 
conversion factors to the results from these floor computer models. The conversion factors were based on unit area loading differences between floors. These calculations were performed in a spreadsheet.

The conversion factors were calculated for CDL, SDL, and LL. For CDL and SDL, the conversion factors were calculated for any given floor by dividing the overall floor CDL and SDL by their counterparts at the representative typical floor. For LL, the conversion factors were similarly calculated, except that the factors included also the appropriate live load reduction factor. The overall floor CDL and SDL were compiled using a weighted average based on the floor area for each of the floor zones: longspan, short-span, and two-way zone.

Loads on columns outside of the core at the roof, floors at and below floor 2, and the mezzanine floors were calculated by spreadsheet.

\subsubsection{Gravity Loads from Areas Inside of Core}

For the floor areas inside the core from floor B5 to the roof, gravity loads were calculated for individual columns on the basis of tributary areas using a spreadsheet. The calculations were based on the WTC Dwgs and the original Design Criteria.

The floor framing information was obtained from the structural drawings. Occupancies and opening layouts (elevator and shaft layout) for each floor inside the core were obtained from the architectural drawings. Floors with similar occupancy, opening layout, and floor framing were grouped together and were represented by a typical floor in the group. Floors with special occupancies, opening layouts, or floor framing were calculated individually.

The core column loads for each of the typical floors and special floors below floor 107 were calculated in spreadsheets. The NYCBC 2001 loads are essentially identical to, and were used for the ASCE 7-02 loads. In the worksheet, the tributary area of a core column was divided into four regions. For each region, the area was calculated from the coordinates of the core columns in the computer models, then modified for each type of floor according to the opening layout specific to that floor.

For each region, the dominant occupancy specified in the architectural plan was used. For the loads corresponding to each occupancy, the floor worksheet referenced the Load worksheet in the same Excel file. For each occupancy, the Load worksheet tabulated the CDL of the concrete slab, the SDL, and the LL.

\section{Dead loads}

In addition to the weight of the concrete slab (including reinforcing steel and metal deck), the CDL of the floor framing consisted of the weight of the structural steel beams. The floor computer models were used to calculate the weight of the steel floor framing averaged over the floor area. The weight of the steel floor framing was calculated to be 6 psf and 7 psf at floors 96 and 75, respectively.

The floor framing CDL calculated for floor 96 was applied to all floors except the mechanical floors, where the floor $75 \mathrm{CDL}$ was applied. For typical occupancies inside the core, such as corridors and elevator lobbies, the concrete slab CDL was based on the structural drawings and was listed in the Load worksheet. For special floors, the concrete slab CDL for these typical occupancies was overwritten in the Floor worksheet to reflect the actual thickness of the concrete slab specified in the structural drawings. 
Where a load was not listed in the Load worksheet, the concrete slab CDL was included in the Floor worksheet.

The SDL includes the weights of partitions, beam fireproofing, ductwork, electrical conduit and piping, floor finish, ceiling, and mechanical equipment. The types of floor finish and ceiling applied to each occupancy were obtained from the architectural plans and from the finish schedule in the architectural drawings. The weight of finishes was obtained from the Design Criteria (Sheet BC-1-7). In accordance with the original WTC Design Criteria. for equipment rooms on the mechanical floors an SDL of 75 psf was used.

Partition layouts and types were obtained from the architectural drawings, and the partition weights were taken from the Design Criteria (Sheets BC-1-7 and BC-1-8). As shown in Figs. 4-1 and 4-2, partition loads per gross area were calculated for seven typical opening/occupancy configurations. A partition weight of $20 \mathrm{psf}$ per gross area was assumed for the return plenums and for areas where the occupancy was not specified in the architectural drawings. A partition weight of $6 \mathrm{psf}$, taken over the gross area, was used for tenant space. For occupancies that included an additional $75 \mathrm{psf}$ in SDL for equipment weight, a partition weight was not added.

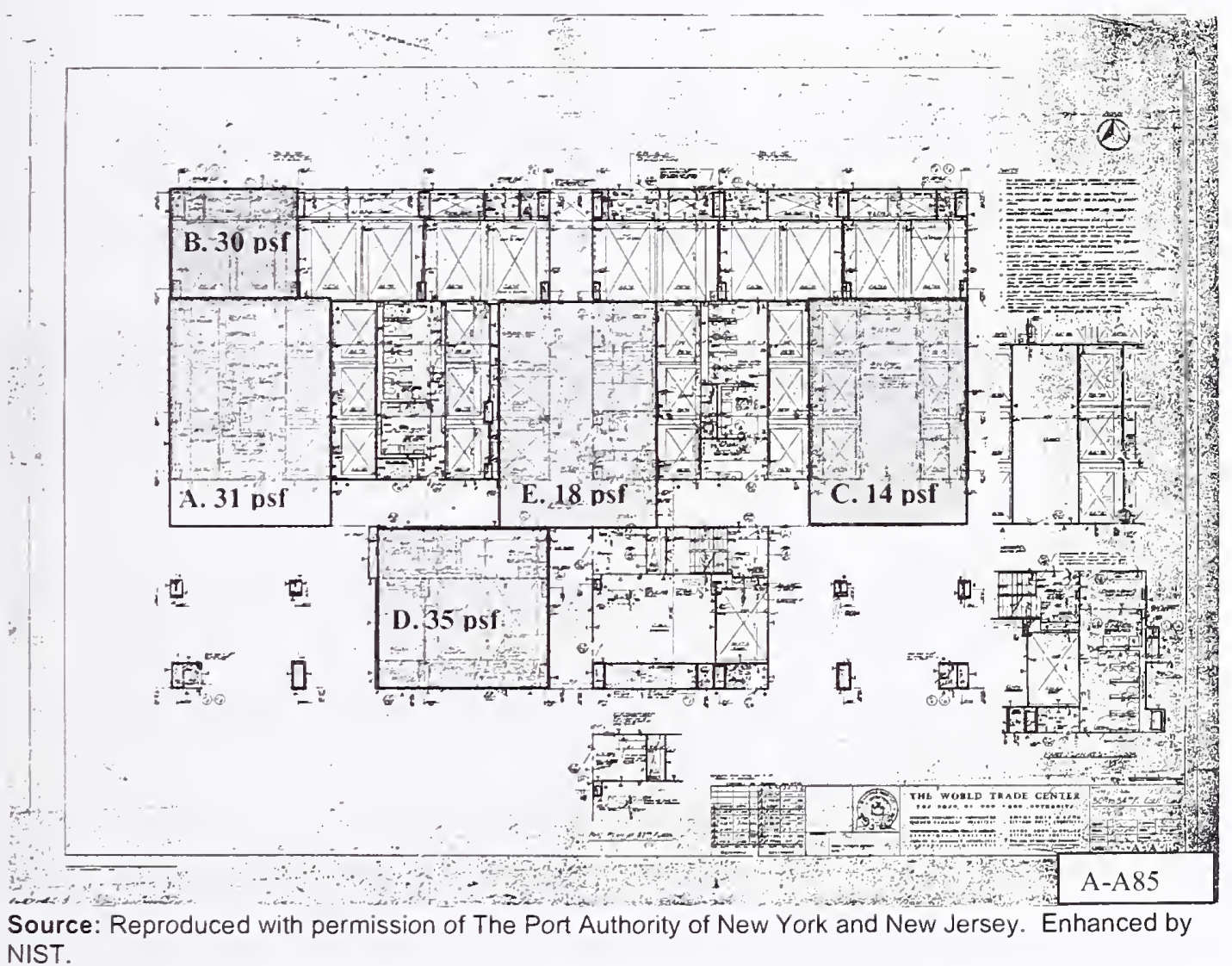

Figure 4-1. Partition groups $A, B, C, D$, and $E$. 

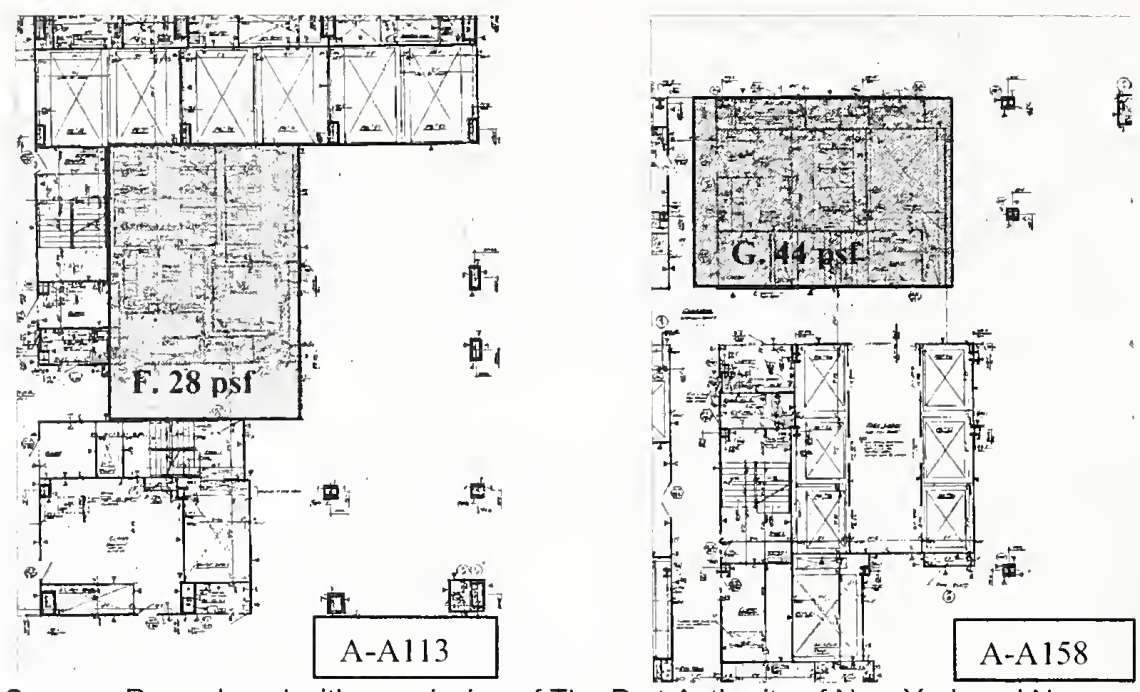

Source: Reproduced with permission of The Port Authority of New York and New Jersey. Enhanced by NIST.

Figure 4-2. Partition groups $\mathbf{G}$ and $\mathbf{F}$.

Weights of concrete beam encasements were taken from the structural drawings and the Design Criteria. At floors 77, 43, 9 to B3, and B5, most of the core beams were concrete-encased. For the entire core, a 20 psf uniformly distributed load taken on the gross tributary area was added to the dead load. See below for the concrete encasement weights assumed for floors in the hat truss region. For all other floors, the concrete beam encasement loads were applied directly to the columns to which concrete-encased beams werc connected.

The loads due to the construction of the Fiduciary Trust vault in WTC 2 (see Sec. 2.5.2) were added to the dead loads of the original construction.

\section{Live Loads}

The original WTC live loads for occupancies inside the core were taken from the Design Criteria (Sheets CC-1-2 and CC-1-3). For a few occupancies not explicitly listed in the Design Criteria, the live load listed for the most similar occupancy was used.

ASCE7-02 live loads were taken from Table 4-1 of the standard. Where a WTC occupancy was not listed in ASCE7-02, the Design Criteria live load was used. NYCBC 2001 live loads are essentially identical to the ASCE 7-02 live loads and were not tabulated separately.

\section{Live Load Reduction}

For use with the corresponding live loads, live load reductions for column design were based on the original WTC Design Criteria and on ASCE 7-02.

The live load reduction factors in the original WTC design were taken from sheets DC1-3 of the Design Criteria. NYCBC 2001 live load reductions are essentially identical to the original WTC Design Criteria and were not tabulated separately. 
For the core columns, the ASCE7-02 live load reductions were calculated in accordance with the tributary area provisions of ASCE7-02. Core columns were divided into three column groups based on their tributary areas:

- Columns 704, 705, 805, and 904

- Columns at the perimeter of the core

- All other core columns

A single set of live load reduction factors was applied to all the columns within the same column group.

\section{Hat Truss Floors}

Except for floor 107, for the floor areas tributary to the hat truss framing, gross tributary areas were calculated by hand. Openings were subtracted from gross tributary areas, and the resulting net areas were entered into an Excel spreadsheet. Except for columns 704B106Z, 704B107, 705B106Z, 803B107, 804AB107, and 804B106Z, where gross and net areas were calculated directly, for floor 107, the net areas were taken from floor 106.

CDL, SDL, and LL were based on the Design Criteria sheets BF1-11 A, BF1-12, BF1-13, and BF1-14. These sheets assign uniform loads throughout entire floors (both outside and inside the core). For floor 109 (mechanical floor), sheet BC1-3 indicates LL = 150 psf. However, for consistency with the design criteria for other mechanical floors, this live load was applied in two parts, as LL $=75$ psf and additional $\mathrm{SDL}=75 \mathrm{psf}$.

For some occupancies in the core for floors 107 to the roof, the occupancy-specific live load given elsewhere in the IVTC Design Criteria exceeded the uniform live load specified for the entire floor. For these occupancies, the higher live load was applied to the computer model. These occupancies are summarized below:

- Stair: $L L=100$ psf (instead of the uniform $L L=75$ psf)

- Corridors: LL= 100 psf per WTC Design Criteria or 80 psf per ASCE 7-02 (instead of the uniform $L L=75 \mathrm{psf}$ )

- Service room: $L L=100$ psf (instead of the uniform $L L=75$ psf)

- Window washer storage $L L=125$ psf (instead of 75 psf)

Note that beams, girders, and diagonals that were part of the hat truss system were included in the global models and that their self weights were calculated by SAP2000 and added to the CDL. In addition, a 20 psf uniform load at every level (floor 107 to roof) was used to account for the weight of structural steel that was not modeled and the weight of concrete encasement. The ASCE 7-02 loads were essentially identical to and were used for the NYCBC 2001 loads.

The antenna gravity loads were also considered in the WTC 1 global model. 


\subsubsection{Construction Sequence Loading Effects}

Located between floor 107 and the roof in both towers, the hat truss interconnected the core columns and the columns of the exterior walls. The hat truss system distributed both gravity loads and wind loads between the core and the exterior walls. However, the CDL and SDL put in place prior to the completion of the hat truss system were not distributed through the hat truss. In order reasonably to differentiate between those loads distributed through the hat truss system and those that were not, the construction sequence was considered in the computer models.

The effects of construction sequence on the distribution of gravity loads was modeled using the nonlinear staged construction analysis function in SAP2000. The primary purpose of this step in the analysis was to provide, at the top of the towers, a reasonably accurate distribution of construction and superimposed dead loads between the core columns and the exterior wall. Accordingly, the global system computer model was subdivided into two portions: floor 106 and below, and the area above floor 106. In the first stage, the lower portion of the full computer model was loaded with all of the CDL and SDL associated with floor 106 and below. In the second stage, the portion of the full model above floor 106 was activated, and the CDL and SDL associated with the upper floors were placed on the full computer model. Live loads on the whole model were applied to the full building with the hat truss engaged in the second stage. This methodology approximates well the way in which the towers were built.

\subsection{WIND LOADS}

The investigation of wind loads and wind effects presented in this report has two objectives. The first is to ascertain the adequacy of the original wind loads and the corresponding structural design given the knowledge available at the time of the design. The second objective is better to understand and assess the effects on design practices of successive changes in standards, codes, and practices, with a view to helping improve standard provisions for wind loads in the future. This case study provides an opportunity to achieve this objective with unique effectivencss.

To achieve these objectives, three independent sets of wind loads were applied to the global tower models as explained in Sec. 4.1. These sets are further described as follows:

\subsubsection{Original WTC Design Wind Loads}

Wind loads were determined for the original design of the WTC towers through the development and implementation of a boundary-layer wind-tunnel study which simulated the mean and fluctuating (turbulence) properties of the wind from ground to gradient height by using the knowledge and techniques available in the 1960s. The original WTC wind loads were taken from summaries given in Part IV of the WSHJ Wind Reports. From among the loading cases, the most severe were determined by comparisons of diagrams of wind-induced shcar and overturning moment.

In the original WTC wind tunnel studies, wind tunnel data were collected for each tower for wind approaching from 24 wind directions, $\alpha$, in 15 degree increments. Part IV of the WSHJ Wind Reports provides equations for the wind-induced shears and overturning moments in the towers at 21 elevations, $z$, along the building height, $H$, at increments of $0.05 \mathrm{H}$. For each wind direction, the reports provided sets of coefficients to be used in these equations to obtain the static and the dynamic components of shear and 
overturning moment in the N-S and E-W directions. Coefficients were also provided for calculating torsional moments. The torsional moments are associated with eccentricity of the global wind excitation of the building with respect to the building center of rigidity. Based on these equations, shears and torsions were calculated for each wind direction for the two orthogonal directions. The equivalent effective static shear forces, $S$, and overturning moments, $M$, at each level were comprised of static and dynamic components:

$$
\begin{aligned}
& S=\bar{S}+S^{\prime} \\
& M=\bar{M}+M^{\prime}
\end{aligned}
$$

where the first and second terms indicate, respectively, the mean or steady-state components and dynamic components. The static components of the shears and moments were calculated from the following equations:

$$
\begin{aligned}
& \bar{S}(z)=\frac{1}{2} \rho \bar{V}_{o}^{2} D H C_{S}(z) \\
& \bar{M}(z)=\frac{1}{2} \rho \bar{V}_{o}^{2} D H C_{M}(z)
\end{aligned}
$$

where:

$\rho=$ design air density $=0.0023 \mathrm{slug} / \mathrm{ft}^{3}$

$\bar{V}_{o}=$ mean (or equivalent) design wind speed, determined to be $98 \mathrm{mph}$ averaged over $20 \mathrm{~min}$ at a height of $1,500 \mathrm{ft}$ above ground.

$C_{S}$ and $C_{M}=$ shear force and overturning moment coefficients, respectively, obtained from wind tunnel tests and provided in tabular form

$D$ and $H=$ dimension in plan and height of the tower

The dynamic components of the shear forces and overturning moments at any height $z$ were obtained from the following equations:

$$
\begin{aligned}
& S^{\prime}(z)=4 \pi^{2} n_{o}^{2} A \int_{z}^{H} m(z) \mu(z) d z \\
& M^{\prime}(z)=\int_{z}^{H} S^{\prime}(z) d z
\end{aligned}
$$


where:

$n_{o}=$ natural frequency of oscillation of the tower

$A=$ amplitude of oscillation at the top of the tower corresponding to the mean design wind speed

$m(z)=$ mass per unit height of the tower

$\mu(z)=$ amplitude of fundamental vibration mode at height $z$ for unit amplitude at the top of the tower.

The wind loads werc calculated on the basis of 2.5 percent total damping. This value includes the intrinsic damping of the structural systems plus the supplemental damping provided by the dampers.

The differential static and dynamic shears between successive levels were calculated and distributed using two different methods:

- The static wind load to be applied to each floor was determined from the shear diagram.

- The dynamic wind load to be applied to each floor was based on the distribution of mass over the tower height, the fundamental mode shape, and the dynamic component of the lateral wind-induced sway at the roof.

Note that for $\alpha=90$ degrees, coefficients were not found in the microfilm of the WSHJ Wind Reports for calculating the static component of the wind forces for WTC 1. Accordingly, the static coefficients were deduced from data for the $\alpha=270$ degrees, for WTC 2. By observation of the static coefficient data, it was determined that the basic data for the two towers is shifted by 180 degrees.

Considering the 24 different wind directions and the four combinations of the static and dynamic components of the N-S and E-W components of the building forces listed below, there were 96 different wind load cases for each tower.

$$
\begin{aligned}
& \text { N-S (Static + Dynamic) and E-W (Static + Dynamic) } \\
& \text { N-S (Static + Dynamic) and E-W (Static - Dynamic) } \\
& \text { N-S (Static - Dynamic) and E-W (Static + Dynamic) } \\
& \text { N-S (Static - Dynamic) and E-W (Static - Dynamic) }
\end{aligned}
$$

The static and dynamic shears in the N-S and E-W directions were calculated for all 96 loading cases, and the overturning moments were calculated from the shears. In order to dctermine the most severe of the 96 loading cases for each tower, the wind-induced shears and overturning moments were compared, for each direction, at heights $z / H=0.75,0.50,0.25$ and 0 . The wind loading cases producing the maximum shears in either of the two orthogonal directions were identified for application to the global models.

To compare ovcrturning moments for each loading case, the moments in the two orthogonal directions were combined vectorially (i.e., the magnitude of the resultant is equal to the square root of the sum of the squares of the components, and the direction $\beta$ of the resultant moment is the arctangent of the ratio of the 
$y$ - and $x$-components). The load cases were grouped by the angle $\beta$ using an increment of 45 degrees, resulting in 8 groups of load cases. For each $\beta$ group, at $z / H=0.75,0.50,0.25$ and 0 , the wind load cases that generated the maximum resultant moment were identified for application to the computer global system models. Eight groups of maximum moment plus four directions of maximum shear at four heights in the towers would result in 48 different loading cases. However, some individual wind load cases produced a maximum resultant moment and/or a maximum shear at more than one elevation in the towers. As a result, for WTC 1, 16 loading cases were identified, and for WTC 2, 17 loading cases were identified.

For cases where an intermediate floor did not provide lateral support for the exterior wall, the wind load was distributed to the floors above and below, omitting the intermediate floor wind load.

For the floors modeled in the global model by rigid diaphragms, the wind forces in the N-S and E-W directions were applied as concentrated loads at the geometric center of the building. The torsional moments were also taken into account. For the floors with flexible diaphragms (see Chapter 3), the forces, based on tributary areas, were resolved into point loads at the perimeter columns. Both windward and leeward forces were applied. At these floors, the torsional moment was represented by four identical concentrated forces applied parallel to the four faces of the tower at the center columns of each face. The simplified method used for applying the torsional loads at floors with flexible diaphragms did not have any noticeable effects on the analysis results. For each loading case, the orthogonal wind forces were subdivided into windward and leeward forces based on the direction of the wind. For this purpose, the 24 wind directions $\alpha$ (discussed previously) were divided into 8 groups as given in Table 4-2. The wind direction for $\alpha=0$ is for wind blowing from north to south.

Table 4-2. Grouping of the wind directions.

\begin{tabular}{|c|c|}
\hline Group & $\alpha$ \\
\hline 1 & $337.5 \leq \alpha \leq 22.5$ \\
\hline 2 & $22.5<\alpha<67.5$ \\
\hline 3 & $67.5 \leq \alpha \leq 112.5$ \\
\hline 4 & $112.5<\alpha<157.5$ \\
\hline 5 & $157.5 \leq \alpha \leq 202.5$ \\
\hline 6 & $202.5<\alpha<247.5$ \\
\hline 7 & $247.5 \leq \alpha \leq 292.5$ \\
\hline 8 & $292.5<\alpha<337.5$ \\
\hline
\end{tabular}

For groups 1, 3,5, and 7 (orthogonal or near-orthogonal wind directions), the wind forces were distributed in accordance with Fig. 4-3a. For groups 2, 4, 6, and 8 (diagonal or near-diagonal wind directions), the wind forces were distributed in accordance with Fig. 4-3b. The factors shown in Fig. 4-3 were based on Figure 6-6 of ASCE 7-02 Standard. 


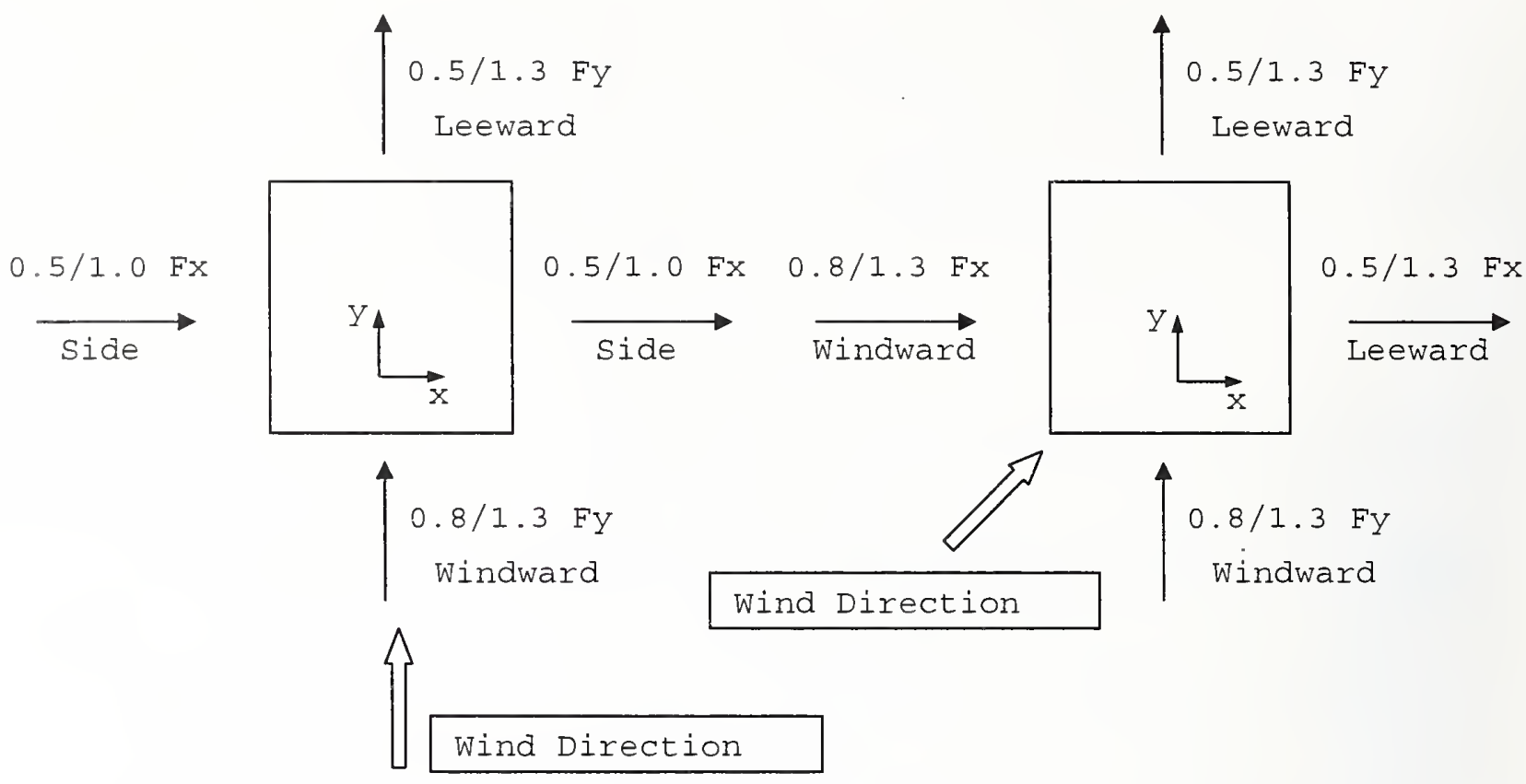

a)

(b)

\section{Figure 4-3. Windward and leeward distribution for (a) orthogonal and (b) diagonal wind directions.}

\subsubsection{State-of-the-Practice Wind Loads}

For the WTC towers, two wind tunnel tests and wind engineering studies based thereon were conducted in 2002 by independent laboratories as part of insurance litigation unrelated to the NIST investigation. The tests and studies were conducted by Cermak Peterka Peterson, Inc. (CPP) and by RWDI. The results of both studies were made available to NIST; see NIST NCSTAR 1-2 for more details.

For the purpose of the baseline analysis, the state-of-the-practice wind load case consisted of the wind load estimates provided by RWDI, scaled in accordance with a wind speed equivalent to the NYCBC 2001 wind speed (interpreted to be the $80 \mathrm{mph}$ fastest-mile wind speed at $30 \mathrm{ft}$ elevation over open terrain). These wind loads were applied to the global models using the directional and torsional load combination factors presented in the RWDI reports.

The wind loads from RWDI are smaller than those obtained from CPP for WTC 2 (see Sec. 4.3.4). Considering the differences between RWDI and CPP results, RWDI practice may be viewed as a "lowerestimate, state-of-the-practice case."

The state-of-the-practice wind loads were distributed in the global system computer models in a manner similar to that described in connection with the original design wind loads. 


\subsubsection{Refined NIST Estimates}

NIST completed an independent analysis to estimate the wind loads that would be appropriate for use in designing the towers based on state-of-the-art considerations. The analysis was based on results provided by CPP and RWDI, with modifications that draw on recently developed knowledge in wind engineering. The objective of this analysis was not to assess the adequacy of the original design wind loads, but rather to better understand and assess the effects of successive changes in standards, codes, and practices.

Wind loads based on recently developed knowledge and consistent with the design wind speed in ASCE 7-98 Standard (which is the same as in the ASCE 7-02 Standard) were estimated by NIST using the RWDI results scaled in accordance with a wind speed equivalent to the ASCE 7-02 Standard wind speed and then multiplied by a factor of 1.15. This number was recommended by NIST for the refined NIST baseline analysis. For details on how these wind loads were obtained see NIST NCSTAR 1-2.

The lateral wind loads on the towers, consistent with the ASCE 7-98 and ASCE 7-02 design wind speed requirements, were estimated by using the effective static floor-by-floor wind loads presented in Table 5 a (without P- $\Delta$ effects) or Table $5 b$ (with P- $\Delta$ effects) of the RWDI report (north tower) for WTC 1 and Table 3a (without P- $\Delta$ effects) or Table $3 b$ (with P- $\Delta$ effects) of the RWDI report (south tower) for WTC 2.2 These effective static floor-by-floor wind loads were multiplied by the factor 1.15 and by the factors indicated in note (3) provided at the bottom of Tables 3 and 5 in RWDI. The loads so obtained were applied to the global model of each tower using the load combinations presented in Table 6a of RWDI (north tower) and Table 4a of RWDI (south tower).

\subsubsection{Comparisons of Wind Loads}

Tables 4-3 and 4-4 provide a summary of the wind-induced base shears and base moments on WTC I and WTC 2, respectively. The values in Tables 4-3 and 4-4 are based on the I938 and 1968 versions of the NYCBC, the RIWDI study, the CPP study, the refined NIST estimates, and the original design. The wind loads are expressed in terms of two orthogonal components and of measures of the most unfavorable combined peaks obtained by various methods, as follows:

- RWDI: Most unfavorable peak is calculated as vector sum of weighted $x$ and $y$ peaks, with weighting factors approximately consistent with the "principle of companion loads," the approximations being based on engineering judgment and in-house experience.

- CPP: Most unfavorable peak is calculated as vector sum of $x$ peak and companion point-intime $y$-response, or $y$ peak and companion point-in-time $x$-response, whichever is larger.

- Original WTC design: Most unfavorable peak is calculated as vector sum of $x$ and $y$ peaks corresponding to most unfavorable wind direction. These $x$ and/or $y$ peaks may be smaller for that most unfavorable direction than the $x$ peaks and $y$ peaks corresponding to wind normal to a building face (see Sec. 4.3.1).

\footnotetext{
2 For the WTC 2 tower Tables $3 \mathrm{~b}$ and $3 \mathrm{c}$ in the RWDI report (South Tower) were inadvertently switched. The loads accounting for P- $\Delta$ effects are in fact given in Table $3 \mathrm{c}$ of the report.
} 
Table 4-3. A comparison of wind load estimates for WTC 1 from various sources.

\begin{tabular}{|c|c|c|c|c|c|c|c|}
\hline \multirow[b]{2}{*}{ Source } & \multirow[b]{2}{*}{ Year } & \multicolumn{3}{|c|}{ Base Shear 103 kip } & \multicolumn{3}{|c|}{ Base Moment $106 \mathrm{kip} \cdot \mathrm{ft}$} \\
\hline & & $\mathrm{N}-\mathrm{S}$ & $\mathrm{E}-\mathrm{W}$ & $\begin{array}{c}\text { Most } \\
\text { unfavorable } \\
\text { combined } \\
\text { peak }\end{array}$ & $\begin{array}{l}\text { About } \\
\text { N-S }\end{array}$ & $\begin{array}{l}\text { About } \\
\text { E-W }\end{array}$ & $\begin{array}{c}\text { Most } \\
\text { unfavorable } \\
\text { combined } \\
\text { peak }\end{array}$ \\
\hline NYC Building Code & 1938 & 5.3 & 5.3 & & 4.2 & 4.2 & \\
\hline NYC Building Code & $\begin{array}{l}1968 \text { to } \\
\text { date }\end{array}$ & 9.3 & 9.3 & & 7.7 & 7.7 & \\
\hline $\begin{array}{l}\text { RWD1 / NYC Building } \\
\text { Code }\end{array}$ & 2002 & 11.4 & 10.5 & 13.0 & 10.1 & 10.5 & 12.2 \\
\hline RWD1 / ASCE 7-98 & 2002 & 12.3 & 11.3 & 14.0 & 10.8 & 11.4 & 13.1 \\
\hline $\begin{array}{l}\text { CPP / NYC Building } \\
\text { Code }\end{array}$ & 2002 & NA & NA & NA & NA & NA & NA \\
\hline CPP / ASCE 7-98 & 2002 & NA & NA & NA & NA & NA & NA \\
\hline $\begin{array}{l}\text { N1ST / third-party SOM } \\
\text { review }\end{array}$ & 2004 & 14.1 & 13.0 & 16.1 & 12.4 & 13.1 & 15.1 \\
\hline Original WTC Design & 1960 s & 9.8 & 10.6 & 14.0 & 10.3 & 9.1 & 13.7 \\
\hline
\end{tabular}

Table 4-4. Comparison of wind load estimates for WTC 2 from various sources.

\begin{tabular}{|l|c|c|c|c|c|c|c|}
\hline \multirow{2}{*}{\multicolumn{1}{|c|}{ Source }} & & \multicolumn{3}{c|}{ Base Shear 103 kip } & \multicolumn{2}{c|}{ Base Moment 106 kip-ft } \\
\cline { 3 - 8 } & Year & N-S & E-W & $\begin{array}{c}\text { Most } \\
\text { unfavorable } \\
\text { combined } \\
\text { peak }\end{array}$ & $\begin{array}{c}\text { Most } \\
\text { About } \\
\text { N-S }\end{array}$ & $\begin{array}{c}\text { About } \\
\text { E-W }\end{array}$ & $\begin{array}{c}\text { unfarable } \\
\text { combined } \\
\text { peak }\end{array}$ \\
\hline NYC Building Code & 1938 & 5.3 & 5.3 & & 4.2 & 4.2 & \\
\hline NYC Building Code & $\begin{array}{c}1968 \text { to } \\
\text { date }\end{array}$ & 9.3 & 9.3 & & 7.6 & 7.6 & \\
\hline $\begin{array}{l}\text { RWD1/ NYC Building } \\
\text { Code }\end{array}$ & 2002 & 9.7 & 11.1 & 12.3 & 10.1 & 9.2 & 11.3 \\
\hline RWD1/ ASCE 7-98 & 2002 & 10.6 & 12.2 & 13.5 & 11.1 & 10.1 & 12.4 \\
\hline $\begin{array}{l}\text { CPP / NYC Building } \\
\text { Code }\end{array}$ & 2002 & NA & NA & NA & NA & NA & NA \\
\hline CPP / ASCE 7-98 & 2002 & 15.1 & 15.3 & 17.1 & 15.5 & 14.0 & 17.0 \\
\hline $\begin{array}{l}\text { N1ST / third-party SOM } \\
\text { review }\end{array}$ & 2004 & 12.2 & 14.0 & 15.5 & 12.8 & 11.6 & 14.3 \\
\hline Original WTC Design & 1960 `s & 13.1 & 10.1 & 16.5 & 8.8 & 12.6 & 15.2 \\
\hline
\end{tabular}

a. Using ASCE 7-98 Sections 6.5.4.1 and 6.6.

Table 4-5 presents a summary of design base shears and base moments based on various building codes at the time of the design. Note that the base moments presented in Tables 4-3 to 4-5 are calculated at the foundation level (rather than at the street level). 
Table 4-5. Base shears and base moments due to wind loads from different building codes.

\begin{tabular}{|l|c|c|c|c|c|}
\hline \multicolumn{1}{|c|}{ Building Code } & $\begin{array}{c}1938 \\
\text { NYC } \\
\text { Building Code }\end{array}$ & $\begin{array}{c}1968 \text { to Date } \\
\text { NYC } \\
\text { Building Code }\end{array}$ & $\begin{array}{c}1964 \\
\text { NY } \\
\text { State Code }\end{array}$ & $\begin{array}{c}1965 \\
\text { BOCA/BBC }\end{array}$ & $\begin{array}{c}1967 \\
\text { Chicago } \\
\text { Municipal Code }\end{array}$ \\
\hline $\begin{array}{l}\text { Base Shear } \\
\left(10^{3} \text { kip }\right)\end{array}$ & 5.3 & 9.3 & 9.5 & 9.8 & 8.7 \\
\hline $\begin{array}{l}\text { Base Moment } \\
\left(10^{6} \text { kip.ft }\right)\end{array}$ & 4.2 & 7.7 & 7.6 & 8.5 & 7.5 \\
\hline
\end{tabular}

Tables 4-3 and 4-4 indicate that the original design wind load estimates exceed in all cases those established by the NYCBC (a prescriptive minimum requirements code) prior to 1968 , when the WTC towers were designed, and up to and including 2001. Table 4-5 shows that the design values are also higher than those required by other prescriptive building codes of the time, including the $1964 \mathrm{New}$ York State Code, the 1965 Building Officials and Code Administrators Basic Building Code (BOCA/BBC), and the 1967 Chicago Municipal Code. It is noted also that wind effects obtained from various wind-tunnel-based studies are in all cases higher than wind effects based on prescriptive codes and standards.

The two orthogonal base shear and base moment components used in the original dcsign are in general smaller than the CPP, RWDI, and refined NIST estimates. However, the most unfavorable combined peaks from the original design are larger than, or smaller, by at most 15 percent than cstimates based on the CPP. RWDI, and NIST estimates. This is due to the conservative procedure used to combine the loads in the original design. (For example, NIST estimates are higher by about 15 percent than the most unfavorable original design wind loads for WTC 1 , and lower by about 5 percent than the most unfavorable original design loads for WTC 2.)

Tables 4-3 and 4-4 indicate that the estimated wind-induced loads on the towers vary by as much as 40 percent between the wind tunnel/climatological studies conducted in 2002 by CPP and RWDI, with CPP being the larger. Thus, CPP loads are considered as an upper estimate, state of the-practice, while RWDI loads are considered as a lower estimate, state of the-practice.

\subsection{REFERENCES}

ASCE 7-02: American Society of Civil Engineers, ASCE 7 Standard Minimum Design Loads for Buildings and Other Structures, Reston, VA, 2002.

CPP report: Data Report, Wind-Tunnel Tests - World Trade Center, Cermak Peterka Petersen, Inc. August 2002.

Design Criteria: Design Criteria document for the WTC towers developed by Worthington, Skilling, Helle \& Jackson.

NYCBC 2001: Building Code of the City of New York, 2001 Edition, Gould Publications, Binghamton, NY. 
RWDI report: (north tower) Final Report, Wind-Induced Structural Rcsponses, World Trade CenterTower 1, Rowan Williams Davies and Irwin, Inc., Octobcr 4, 2002.

(south tower) Final Report, Wind-Induced Structural Responses, World Trade Center - Tower 2, Rowan Williams Davies and Irwin, Inc., October 4, 2002.

SAP2000 (2002), Linear and Nonlinear Static and Dynamic Analysis and Design of Three-Dimensional Structures Basic Analysis Reference, Computers \& Structures Inc., Berkeley, CA.

WSHJ Wind Reports: A series of wind reports developed by Worthington, Skilling, Helle \& Jackson, outlining the development of design wind loads for the WTC towers (see NIST NCSTAR 1-1).

WTC Dwgs: WTC architectural and structural drawings. 


\section{Chapter 5 \\ Baseline Performance Analysis of the WTC Global Models}

\section{$5.1 \quad$ INTRODUCTION}

This chapter presents the results of the baseline performance analysis for the World Trade Center (WTC) 1 and WTC 2 global models under the three gravity and wind loading cases described in Chapter 4. These cases include the original WTC design load case, the lower-estimate state-of-thepractice case. and the refined National Institute of Standards and Technology (NIST) estimate case. Baseline performance results include basic information about the behavior of the towers under design loading conditions, pertaining to total and inter-story drift, demand/capacity ratios of primary structural components, exterior columns response (shear lag effects and presence of tensile forces). performance of connections, and the towers' resistance to shear sliding and overturning.

Section 5.2 describes the estimation of the demand/capacity ratios and the selection of the design parameters for their estimation. Section 5.3 presents the results of the baseline performance analysis for WTC 1 under the three loading cases. Similarly, Sec. 5.4 presents the results for WTC 2. Section 5.5 presents a summary of the results. For both towers. detailed baseline performance results are provided for the original WTC design loading case. while a brief summary of the results is provided for the state-ofthe-practice and refined NIST estimate cases.

\subsection{CALCULATION OF DEMAND/CAPACITY RATIOS}

For all analysis cases, the demand/capacity ratios (DCRs) for structural components were estimated using the Allowable Stress Design (ASD) procedure as specified in the American Institute of Steel Construction (AISC) Specification for Structural Steel Buildings - Allowable Stress Design and Plastic Design - $9^{\text {th }}$ Edition, 1989. The DCRs were calculated by dividing component demands by component capacities, taken at unfactored (working) loads and at working stresses. not at ultimate loads or yield stresses. These DCRs for the structural components were determined as follows:

1. The component demands were obtained from the results of the baseline performance analysis using the reference global models (see Sec. 3.2) and working loads based on the following load combinations:

- For the original WTC design loading case and for the state-of-the-practice case, the load combinations were those specified by the AlSC Specification (1989) and the New York City Building Code (NYCBC) 2001 :

Dead Load

Dead Load - Live Load

Dead Load - Live Load + Wind Load 
Dead Load + Wind Load

- For the refined NIST estimate case, the load combinations were those specified by the American Society of Civil Engineers (ASCE 7-02) Standard:
Dead Load
Dead Load + Live Load
Dead Load + Wind Load
Dead Load $+0.75 \times($ Live Load + Wind Load $)$
$0.6 \times$ Dead Load + Wind Load

2. The component capacities were based on the nominal steel strength as specified in the original design documents and using the AISC Specification (1989):

- For the original design loading case and for the state-of-the-practice case (consistent with NYCBC 2001), a one-third increase in the allowable stress was considered for load cases that included wind, as specified at the time of the design and as is currently specified in NYCBC 2001 and AISC Specification (1989).

- For the refined NIST estimate case, where loads were based on the ASCE 7-02 Standard, load combinations were taken from the ASCE 7-02 Standard, which does not allow the one-third increase in allowable stress.

The interaction equation in AISC Specifications (1989) estimates the DCR as the larger of the following two equations for members subjected to both axial compression and bending stresses:

$$
\begin{aligned}
& D C R=\frac{f_{a}}{F_{a}}+\frac{C_{m x} f_{b x}}{\left(1-\frac{f_{a}}{F_{c x}^{\prime}}\right) F_{b x}}+\frac{C_{m y} f_{b y}}{\left(1-\frac{f_{a}}{F_{c y}^{\prime}}\right) F_{b y}} \\
& D C R=\frac{f_{a}}{0.60 F_{y}}+\frac{f_{b x}}{F_{b x}}+\frac{f_{b y}}{F_{b y}}
\end{aligned}
$$

For the case when $f_{a} / F_{a} \leq 0.15$, the following equation is permitted in lieu of the previous two equations:

$$
D C R=\frac{f_{a}}{F_{a}}+\frac{f_{b x}}{F_{b x}}+\frac{f_{b y}}{F_{b y}}
$$

where the subscripts $x$ and $y$ indicate the axis of bending about which a particular stress or design property applies, and 
$F_{a}$ and $F_{b}$ are the axial compressive stress and compressive bending stress, respectively, that would be permitted if axial force alone or if bending moment alone existed.

$f_{a}$ and $f_{b}$ are the computed axial stress and compressive bending stress at a given point, respectively.

$F_{e}^{\prime}$ is the Euler buckling stress divided by a factor of safety.

$C_{m}$ is a coefficient that depends on column curvature caused by applied moment.

A review of the basic design equations and allowable stresses for combined axial load and bending for the 6th Edition of the AISC Specifications (1963), which was in effect at the time of the design, indicates that they are essentially identical to those of the 9th Edition (1989) design equations and allowable stresses. There are, however, some variations between the 6th and 9th Editions of the specification. The 1963 Specification did not specifically address biaxial bending in the combined stress equations. In addition, the allowable stress formulations for bending with lateral torsional buckling are somewhat different between the two design specifications.

For the original design loading case, the SAP2000 program was used directly to estimate the DCRs using the above equations. For the lower-estimate state-of-the-practice case and the refined NIST estimate case, a second order analysis that accounted for P- $\Delta$ effects was used to estimate member demands under thc applied gravity and wind loads. The P- $\Delta$ analysis results in a moment magnification in the components of the global models; as a result, the terms $C_{m}$ and $\left(1-f_{a} / F_{c}^{\prime}\right)$ were assigned a unit value in the above equations to estimate component DCRs. For these cases, DCRs were calculated in Excel spreadsheets, using results obtained by the SAP2000 computer program. The calculations were spot-checked for accuracy and to verify that the correct design information was being applied. For most of the component calculations that were checked, the SAP2000/Microsoft Excel spreadsheet calculations were found to be acceptable. When errors were detected, the design parameters were corrected to provide for an acceptable calculation.

\subsubsection{Selection of Global Models Design Parameters}

For estimating the DCRs of the structural components under the various loading conditions, the following design parameters were used in the global models of WTC 1 and WTC 2 to yield accurate results:

- The effective length factors, $\mathrm{K}$ factors, for ASD column design werc selected by comparing the actual column end conditions with the theoretical end conditions depicted in Table C-C2.1 in the Commentary of the 9th Edition of the AISC ASD Manual.

- Virtually all core columns were designed originally as axially loaded members without significant eccentric loads and without continuity of framing that would generate significant P- $\Delta$ moments. The details of construction are consistent with this design approach. Accordingly, in order to eliminate erroneous bending stresses in the interaction equations, allowable bending stresses for core columns were increased sufficiently to reduce the bending term in the interaction equation to less than 0.01 . 
- The cross-section of the intermittent corner columns of the tower included a web plate that extended beyond the flanges. The web plate extensions effectively, but inappropriately, reduced the section modulus of the cross-section by significantly limiting the allowable stress in the flange. To correct for this inappropriate reduction, the allowable bending stress for inplane bending was increased.

- For the floor 107, 108, and 110 spandrel beams, for bending in the plane of the slab, the slab would resist the tendency for the spandrels to bend preventing significant bending stresses from developing in the spandrels. To achieve this behavior in the model, the spandrels' allowablc bending stress was increased sufficiently to limit the bending term in the interaction equation to less than 0.01 , eliminating erroneous bending stresses.

- For the floor 7 spandrels, the actual span length was insignificant due to the actual geometry of the spandrel plate construction. Since the as-modeled spandrels had a significant span and would otherwise develop erroneous bending stresses, the allowable bending stress was increased sufficiently to limit the bending term in the interaction equation to less than 0.01 .

- At the exterior wall between floors 1 and 10 , the unbraced lengths and the properties of the extcrior columns varied significantly along the height. These variations, particularly pronounced in the out-of-plane direction, had a notable effect on the buckling strength of the columns. The effects of variation in unbraced lengths and non-prismatic columns are only obliquely addressed in the equations in the AISC specifications for column capacities. To study the influence of unequal unbraced lengths in consecutive floors on the buckling strength of the exterior columns, an elastic buckling (eigenvalue) analysis was carried out for a typical column tree using SAP2000. Since the columns buckle in the inelastic range, the elastic buckling capacities obtained from the SAP2000 buckling analysis were converted into allowable inelastic buckling capacities using the procedure in Appendix E3 of the AISC Load and Rcsistance Factor Design (LRFD) Specification (1986). The study showed that, in the out-of-plane direction, for the typical exterior column unsupported between floors 2 and 7 , consideration of the shorter unbraced lengths above and below increased the inelastic out-ofplane buckling capacity by about 25 percent. The default allowable buckling stress calculated by the SAP2000 computer program was, therefore, overwritten to reflect this increase.

Beyond the influence of unequal unbraced lengths in consecutive floors on the columns buckling capacity, the elastic buckling analysis was also uscd to study the buckling capacity of the non-prismatic columns located between floors 7 and 9. Again, the procedure in Appendix E3 of the AISC LRFD Specification (1986) was used to convert the elastic buckling capacities of the non-prismatic members into allowable inelastic buckling capacities. The average area along the non-prismatic member was used in the conversion equations. Based on the inelastic buckling capacities of the non-prismatic members, the allowable buckling stress at the minimum section of the non-prismatic members was used in the global systems computer models. The resulting modifications to the design parameters were as follows:

- Floors 9 to 10: upper columns - Modified $F_{a}=$ Calculated SAP2000 default $F_{a} \times 0.89$

- Floors 9 to 10: bottom columns - Modified $F_{a}=$ Calculated SAP2000 default $F_{a} \times 1.08$ 
- Floors 7 to 9: Modified $F_{a}=$ Calculated SAP2000 default $F_{a}$ (based on $\mathrm{K}=1.0$ about both axes) $\times 1.43$.

- Floors 2 to 7: Modified $F_{a}=$ Calculated SAP2000 default $F_{a} \times 1.26$

- Floors 2 to 10: $C_{m}=1.0$ for out of plane bending and $C_{m}=0.85$ for in plane bending

\subsection{BASELINE PERFORMANCE ANALYSIS OF WTC 1}

The baseline performance analysis of the global model of WTC 1 was performed on a Pentium 4 personal computer with a CPU speed of $3.06 \mathrm{GHz}$ and $1.0 \mathrm{~GB}$ of RAM. The duration of the analysis was about $15 \mathrm{~h}$. The following summarizes the results under the three loading cases.

\subsubsection{Original WTC Design Load Case}

The analysis reported in this section used the gravity and wind loads used in the original design of the towers, as explained in Chapter 4.

The results of the analysis indicated that for the dead and live loads used in the original WTC design, the core columns and the exterior walls carried approximately 53 percent and 47 pcrcent, respcctively, of the total gravity load at the basement (B6) level.

The calculated total maximum drift of WTC 1 induced by the original WTC design wind loads was

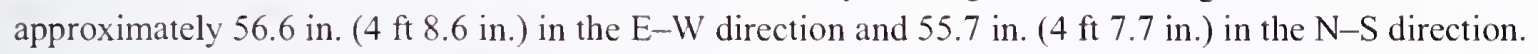
These drifts are equivalent to about $\mathrm{H} / 304$ and $\mathrm{H} / 309$ in the $\mathrm{E}-\mathrm{W}$ and $\mathrm{N}-\mathrm{S}$ directions, respcctively, where $\mathrm{H}$ is the height of the tower from the foundation level to the roof. Limitation of total building drift undcr wind loads was not part of the original WTC design criteria. Instead, inter-story drifts were determined and compared to the capability of the architectural building systems such as the partitions and the cxtcrior cladding, to accommodate these inter-story drifts. Accordingly, there is no historical project-specific data available to which the total drifts may be compared. Figure 5-1 presents the deflected shapc (cumulative drift) and the inter-story drifts normalized by the story height for WTC 1 under the original dcsign loads. The plots are presented for the E-W and N-S directions for the cases producing the maximum cumulativc drift (wind azimuth 0 and 75 degrees for the E-W and N-S directions, respectively, wherc azimuth 0 indicates tower north).

DCRs were calculated using the SAP2000 computer program. The calculations were spot-chccked for accuracy and to verify that the correct design information was bcing applied. For most of the componcnt calculations checked, the SAP2000 calculations were found to be acceptable. The DCR statistics for WTC 1 global systems components under the original WTC design loading are summarized in Table 5-1. The statistics include, for each member category, the number of members, the mean valuc of the DCR, their coefficient of variation (C.O.V.), the pcrcentage of components with DCR greatcr than 1.0 and greater than 1.05, the number of members with DCR greater than 1.05, and the maximum calculated DCR. Figure 5-2 shows the distribution of DCRs for the four exterior walls of WTC 1 under the original design loads. Close-up views are provided for the exterior walls below floor 9 in Fig. 5-3. DCRs for the core columns are provided in Fig. 5-4. 

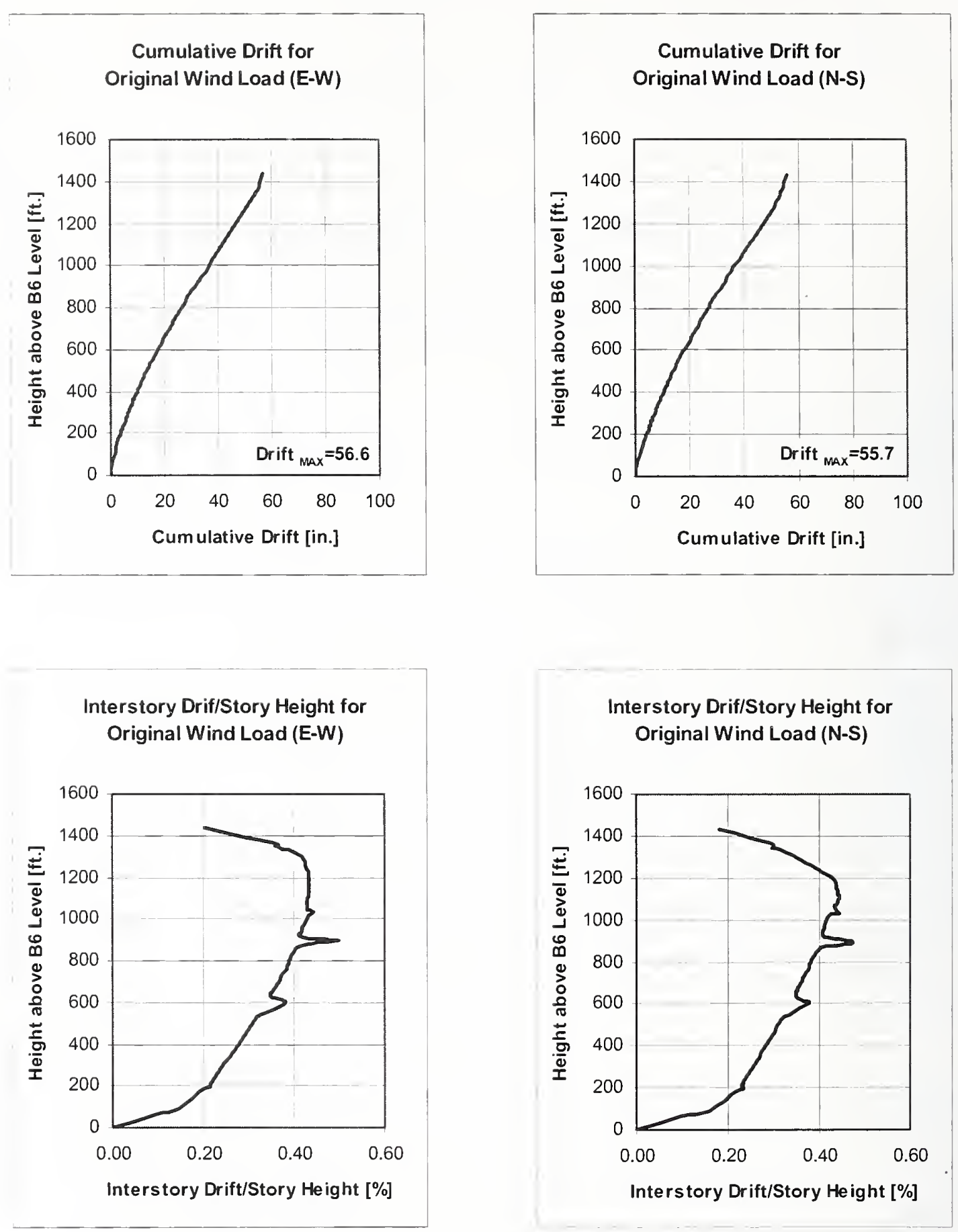

\section{Interstory Drif/Story Height for \\ Original Wind Load (N-S)}

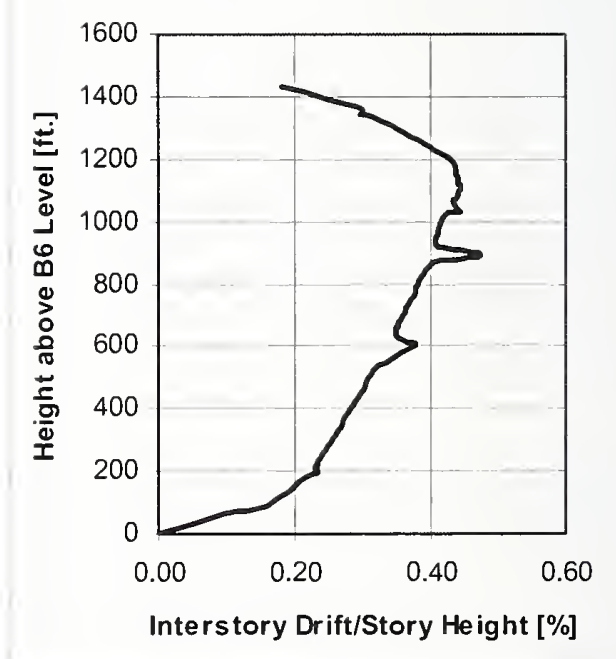

(a)

(b)

Figure 5-1. Drift diagrams of WTC 1 due to original WTC wind loads, (a) AON-E- and (b) $A 75 N+E-$. 
Table 5-1. Statistics of demand/capacity ratios for WTC 1 under original design load case.

\begin{tabular}{|c|c|c|c|c|c|c|c|}
\hline Member Type & $\begin{array}{c}\text { Number } \\
\text { of } \\
\text { Members }\end{array}$ & $\begin{array}{c}\text { Mean } \\
\text { Calculated } \\
\text { DCR }\end{array}$ & $\begin{array}{c}\text { C.O.V. } \\
\text { of } \\
\text { DCR }\end{array}$ & $\begin{array}{c}\text { Percentage } \\
\text { of } \\
\text { Components } \\
\text { with DCR } \\
>1.0\end{array}$ & $\begin{array}{l}\text { Percentage } \\
\text { of } \\
\text { Components } \\
\text { with DCR } \\
>1.05\end{array}$ & $\begin{array}{l}\text { Number of } \\
\text { Components } \\
\text { with DCR } \\
>1.05\end{array}$ & $\begin{array}{c}\text { Maximum } \\
\text { Calculated } \\
\text { DCR }\end{array}$ \\
\hline \multicolumn{8}{|l|}{$\begin{array}{l}\text { Exterior Wall } \\
\text { Columns }\end{array}$} \\
\hline Below floor 1 & 628 & 0.77 & 0.19 & 4.3 & 2.7 & 17 & 1.36 \\
\hline Floor 1 to 9 & 1,122 & 0.74 & 0.25 & 3.3 & 0.5 & 6 & 1.27 \\
\hline Floor 9 to 106 & 31,086 & 0.76 & 0.12 & 1.1 & 0.4 & 121 & 1.31 \\
\hline Above floor 106 & 578 & 0.73 & 0.31 & 12.3 & 10.0 & 58 & 1.46 \\
\hline \multicolumn{8}{|l|}{$\begin{array}{l}\text { Exterior Wall } \\
\text { Spandrels }\end{array}$} \\
\hline Below floor 1 & 420 & 0.44 & 0.46 & 0.7 & 0.7 & 3 & 1.28 \\
\hline Floor 1 to 9 & 610 & 0.34 & 0.45 & 1.1 & 1.0 & 6 & 1.30 \\
\hline Floor 9 to 106 & 31.160 & 0.31 & 0.30 & 0 & 0 & 0 & 0.83 \\
\hline Above floor 106 & 836 & 0.35 & 0.69 & 1.9 & 1.7 & 14 & 1.55 \\
\hline Core Columns & 5,219 & 0.86 & 0.14 & 10 & 5.3 & 278 & 1.36 \\
\hline \multicolumn{8}{|l|}{ Hat Truss System } \\
\hline Columns & 239 & 0.47 & 0.45 & 0.4 & 0.4 & 1 & 1.26 \\
\hline Beams & 499 & 0.24 & 0.87 & 0.4 & 0.2 & 1 & 1.07 \\
\hline Braces & 279 & 0.47 & 0.53 & 2.5 & 0.7 & 2 & 1.06 \\
\hline \multicolumn{8}{|l|}{$\begin{array}{l}\text { Exterior Wall } \\
\text { Bracing }\end{array}$} \\
\hline Below floor 1 & 200 & 0.72 & 0.16 & 2 & 1 & 2 & 1.16 \\
\hline Above floor 106 & 12 & 0.40 & 0.52 & 0 & 0 & 0 & 0.75 \\
\hline
\end{tabular}




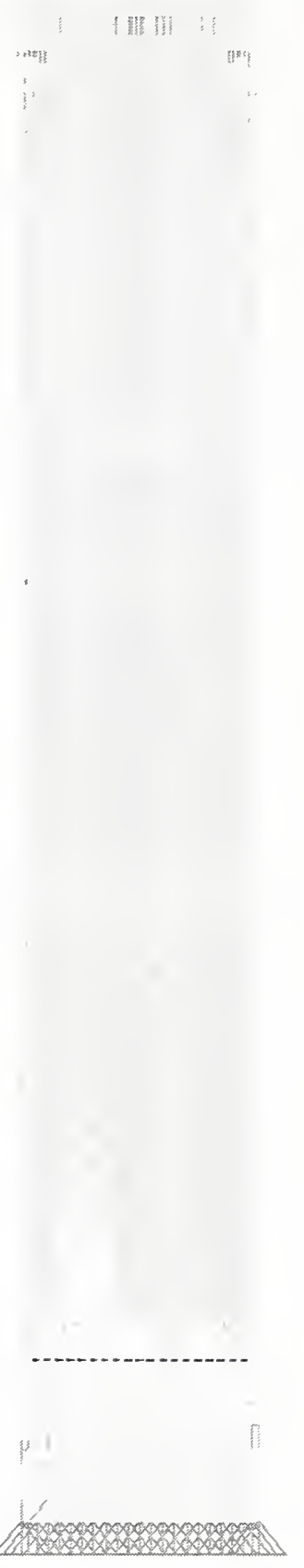

(a)

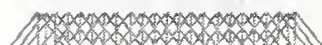

(b)

\begin{tabular}{|l|l|l|l|l|l|l|l|}
\hline & 0.00 & 0.50 & 0.75 & 1.00 & 1.08 & \\
\hline
\end{tabular}

Figure 5-2. Demand/capacity ratios for WTC 1 under original design loads, (a) north elevation and (b) east elevation. 


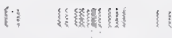

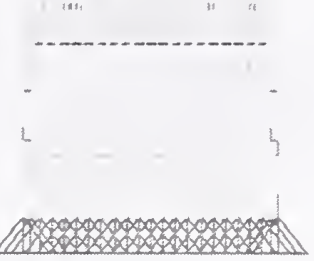

(c)

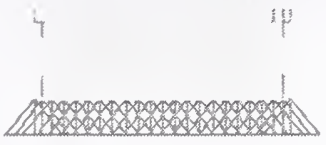

(d)

\begin{tabular}{|l|l|l|l|l|l|l|l|}
\hline & 0.00 & 0.50 & 0.75 & 1.00 & 1.08 \\
\hline
\end{tabular}

Figure 5-2. (c) south elevation and (d) west elevation (continued). 


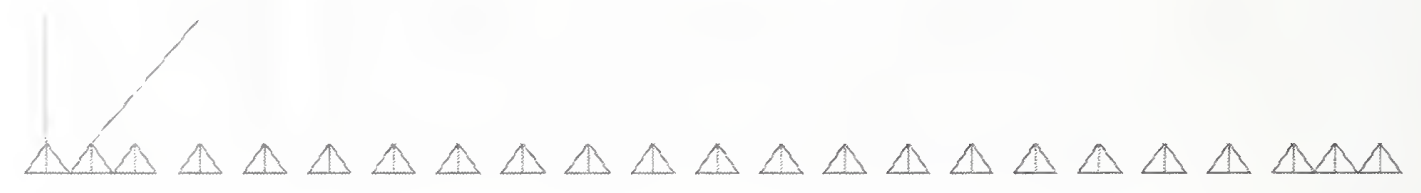

\begin{tabular}{|l|l|l|l|l|l|l|}
\hline & 0.00 & 0.50 & 0.75 & 1.00 & 1.08 \\
\hline
\end{tabular}

(a)

Figure 5-3. Demand/capacity ratios for WTC 1 under original design loads, (a) north elevation below floor 9 . 


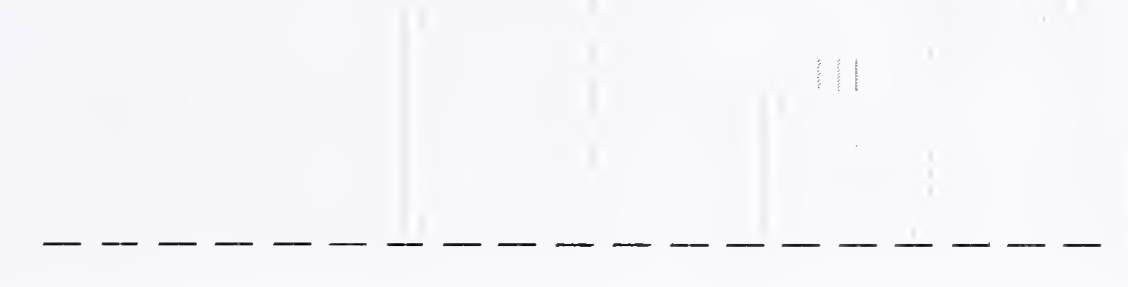

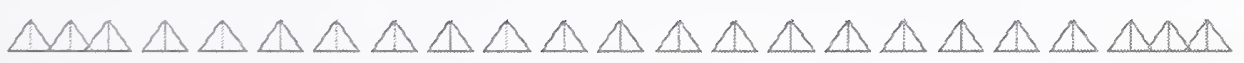

\begin{tabular}{|l|l|l|l|l|l|l|}
\hline & 0.00 & 0.50 & 0.75 & 1.00 & 1.08 & \\
\hline
\end{tabular}

(b)

Figure 5-3. Demand/capacity ratios for WTC 1 under original design loads, (b) east elevation below floor 9 (continued). 


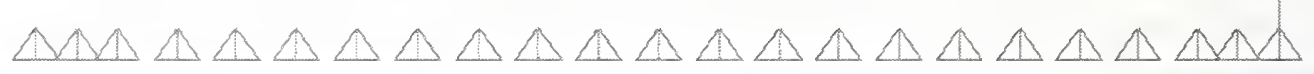

\begin{tabular}{|l|l|l|l|l|l|l|}
\hline & 0.00 & 0.50 & 0.75 & 1.00 & 1.08 & \\
\hline
\end{tabular}

(c)

Figure 5-3. Demand/capacity ratios for WTC 1 under original design loads (c) south elevation below floor 9 (continued). 


\begin{tabular}{|l|l|l|l|l|l|l|l|l|l|}
\hline & 0.00 & 0.50 & 0.75 & 1.00 & 1.08 & \\
\hline
\end{tabular}

(d)

Figure 5-3. Demand/capacity ratios for WTC 1 under original design loads, (d) west elevation below floor 9 (continued). 


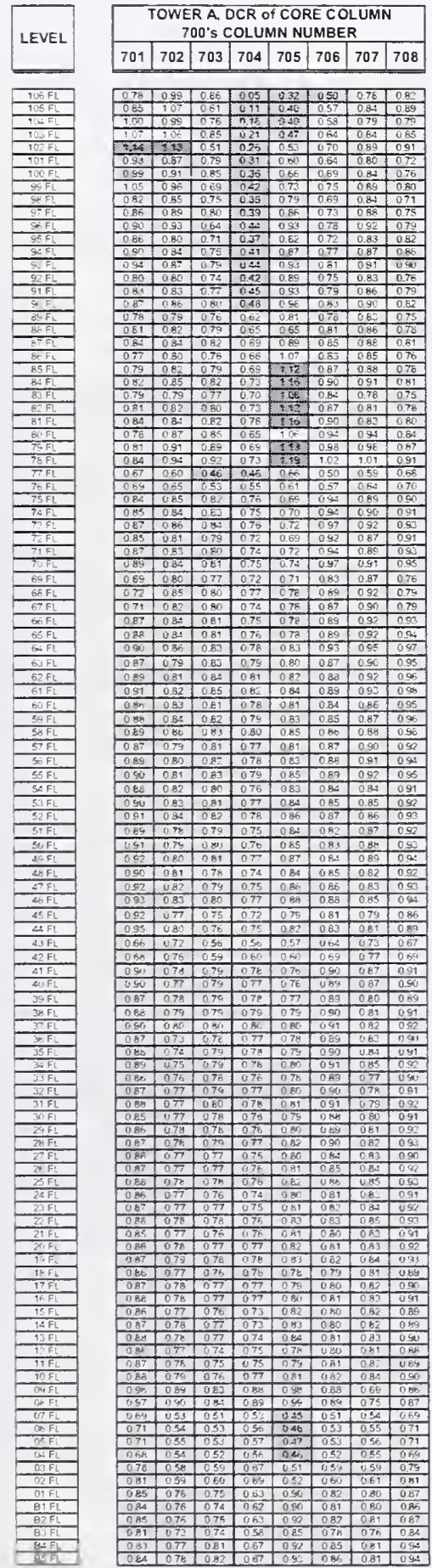

(c)

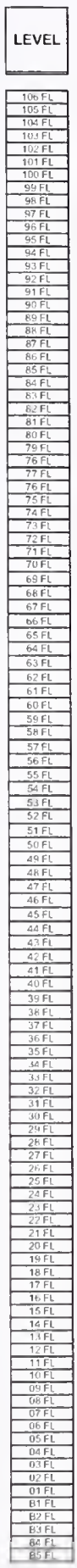

\begin{tabular}{|l|l|l|l|l|l|l|}
\hline \multicolumn{5}{|c|}{ TOWER A, OCR Of CORE COLUMN } \\
\hline 800 'S COLUMN NUMBER \\
\hline 801 & 802 & 803 & 804 & 805 & 806 & 807 \\
\hline
\end{tabular}

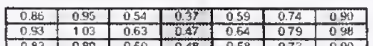

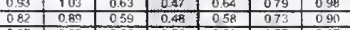

\begin{tabular}{c|c|c|c|c|c|c|}
\hline 093 & 1.01 & 0.47 & 0.64 & 0.66 & 0.81 & 1.01 \\
\hline 073 & 079 & 0.51 & 0.49 & 060 & 076 & 0901 \\
\hline 07 & 0.82 & 0.55 & 0.55 & 0.64 & 0.80 & 0.95 \\
\hline
\end{tabular}

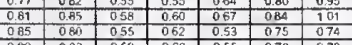

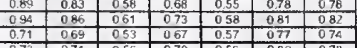

\begin{tabular}{|c|c|c|c|c|c|c|}
\hline 073 & 071 & 056 & 072 & 059 & 0.80 & 078 \\
\hline 0.76 & 073 & 0.58 & 077 & 0.62 & 0.83 & 0.81 \\
\hline 071 & 0.55 & 0.54 & 0.70 & 0.57 & 075 & 0.77 \\
\hline
\end{tabular}

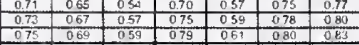

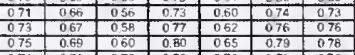

\begin{tabular}{|l|l|l|l|l|l|l|l|}
\hline 075 & 0.69 & 060 & 0.60 & 065 & 0.79 & 0.77 \\
\hline 0.74 & 0.31 & 0.70 & 076 & 0.73 & 0.72 & 0.73 \\
\hline 076 & 073 & 0.72 & 0.79 & 0.76 & 0.74 & 0.75 \\
\hline
\end{tabular}

\begin{tabular}{|c|c|c|c|c|c|c|}
\hline 078 & 0.75 & 075 & 0.82 & 078 & 076 & 078 \\
\hline 0.74 & 070 & 071 & 070 & 0.76 & 072 & 072 \\
\hline
\end{tabular}

\begin{tabular}{|l|l|l|l|l|l|l|}
\hline 076 & 0.72 & 073 & 0.73 & 0.79 & 0.74 & 0.76 \\
\hline 0.78 & 074 & 0.75 & 0.76 & 0.81 & 076 & 0.78 \\
\hline
\end{tabular}

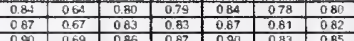

\begin{tabular}{|c|c|c|c|c|c|c|}
\hline 0.90 & 069 & 0.36 & 0.87 & 0.90 & 0.83 & 0.85 \\
\hline 0.69 & 0.55 & 056 & 062 & 0.54 & 0.50 & 068 \\
\hline 0.70 & 0.49 & 058 & 065 & 0.61 & 057 & 071 \\
\hline
\end{tabular}

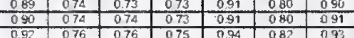

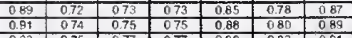

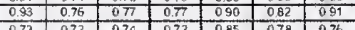

\begin{tabular}{|c|c|c|c|c|c|c|}
\hline 076 & 0,77 & 0,78 & 0.79 & 0.92 & 0.83 & 079 \\
\hline 076 & 075 & 078 & 0.76 & 090 & 0.82 & 0.79 \\
\hline 090 & 077 & 0.80 & 078 & 0.86 & 0.83 & 093 \\
\hline
\end{tabular}

\begin{tabular}{|c|c|c|c|c|c|c|}
\hline 090 & 077 & 080 & 078 & 0.86 & 0.83 & 093 \\
\hline 091 & 0.77 & 0.80 & 079 & 0.86 & 0.89 & 094 \\
\hline 093 & 0.82 & 0.84 & 0.92 & 0.90 & 0.87 & 0.97 \\
\hline
\end{tabular}

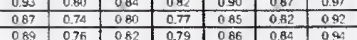

\begin{tabular}{|c|c|c|c|c|c|c|}
\hline 089 & 0.75 & 0.82 & 0.79 & 086 & 0.84 & 0.94 \\
\hline 091 & 077 & 084 & 0.87 & 088 & 085 & 0.95 \\
\hline 088 & 0.79 & 081 & 0.79 & 0.82 & 0.79 & 0.93 \\
\hline
\end{tabular}

\begin{tabular}{|c|c|c|c|c|c|c|}
\hline 088 & 0.79 & 0.81 & 0.79 & 0.82 & 0.79 & 0.93 \\
\hline 090 & 0.80 & 083 & 0.81 & 0.83 & 0.81 & 095 \\
\hline 0.92 & 0.82 & 0.85 & 0.83 & 0.85 & 0.82 & 047 \\
\hline
\end{tabular}

\begin{tabular}{|l|l|l|l|l|l|l|}
\hline 0.89 & 0.75 & 0.82 & 0.78 & 0.86 & 0.83 & 0.94 \\
\hline 0.89 & 077 & 0.84 & 080 & 0.87 & 0.85 & 0.95 \\
\hline
\end{tabular}

\begin{tabular}{|l|l|l|l|l|l|l|}
\hline 0.91 & 078 & 0.55 & 081 & 0.89 & 0.86 & 0.97 \\
\hline 0.87 & 0.80 & 0.83 & 0.80 & 0.83 & 079 & 0.92 \\
\hline
\end{tabular}

\begin{tabular}{|l|l|l|l|l|l|l|}
\hline 0.86 & 0.81 & 0.84 & 0.81 & 0.85 & 0.81 & 0.94 \\
\hline 0.91 & 0.82 & 0.86 & 0.83 & 0.86 & 0.82 & 0.95 \\
\hline
\end{tabular}

\begin{tabular}{|l|l|l|l|l|l|l|}
\hline 0.86 & 076 & 0.86 & 079 & 0.88 & 0.83 & 0.91 \\
\hline 0.87 & 078 & 0.88 & 0.80 & 0.89 & 0.85 & 0.92 \\
\hline
\end{tabular}

\begin{tabular}{|l|l|l|l|l|l|l|l|}
\hline 0.89 & 079 & 0.89 & 0.81 & 0.91 & 086 & 094 \\
\hline 0
\end{tabular}

\begin{tabular}{|c|c|c|c|c|c|c|}
\hline 0.67 & 0.80 & 0.87 & 0.76 & 085 & 080 & 0.91 \\
\hline 0.89 & 0.81 & 0.88 & 078 & 0.87 & 081 & 0.93 \\
\hline 0.91 & 0.83 & 0.90 & 0.79 & 0.88 & 0.88 & 0.94 \\
\hline
\end{tabular}

\begin{tabular}{|c|c|c|c|c|c|c|}
\hline 091 & 0.83 & 0.90 & 0.79 & 0.88 & 0.82 & 0 \\
\hline 070 & 078 & 0.82 & 0.75 & 079 & 0.77 & 07 \\
\hline 073 & 0.40 & 0.85 & 078 & 0.82 & 0.80 & 07 \\
\hline
\end{tabular}

\begin{tabular}{|c|c|c|c|c|c|c|}
\hline 073 & 0.80 & 085 & 078 & 082 & 0.80 & 076 \\
\hline 063 & 0.71 & 060 & 0.55 & 0.70 & 0.62 & 066 \\
\hline 0.65 & 0.75 & 0.52 & 0.58 & 074 & 0.54 & 068 \\
\hline
\end{tabular}

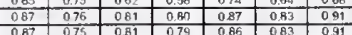

\begin{tabular}{|l|l|l|l|l|l|l|}
\hline 0.86 & 0.77 & 0.83 & 073 & 0.87 & 084 & 0.80 \\
\hline 0.77 & 0.78 & 0.84 & 0.75 & 089 & 085 & 0.91 \\
\hline
\end{tabular}

\begin{tabular}{|c|c|c|c|c|c|c|}
\hline 087 & 0.78 & 0.84 & 0.75 & 0.89 & 085 & 091 \\
\hline 0.89 & 079 & 0.85 & 076 & 0.90 & 086 & 0.92 \\
\hline 0.87 & 0.80 & 0.82 & 0.77 & 0.81 & 0.79 & 0.89 \\
\hline
\end{tabular}

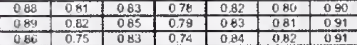

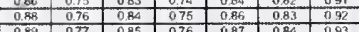

\begin{tabular}{|l|l|l|l|l|l|l|}
\hline 089 & 0.77 & 085 & 0.76 & 6.87 & 0.84 & 193 \\
\hline 0.86 & 078 & 0.84 & 078 & 0.87 & 0.85 & 0.90 \\
\hline
\end{tabular}

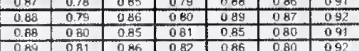

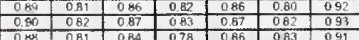

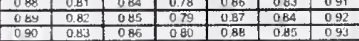

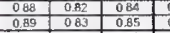

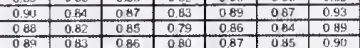

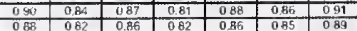

\begin{tabular}{|l|l|l|l|l|l|l|}
\hline 089 & 0.83 & 0.87 & 0.03 & 0.87 & 0.86 & 0.96 \\
\hline 0.90 & 0.84 & 0.08 & 0.63 & 0.88 & 0.87 & 0.00 \\
\hline
\end{tabular}

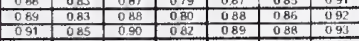

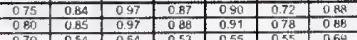

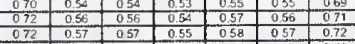

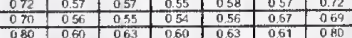

\begin{tabular}{|c|c|c|c|c|c|c|}
\hline 080 & 0.60 & 063 & 0.60 & 0.53 & 0.61 & 0.43 \\
\hline 0.83 & 0.52 & 0.65 & 062 & 065 & 062 & 0.33 \\
\hline 0.84 & 082 & 0.88 & 0.94 & 0.85 & 0.84 & 0.92 \\
\hline
\end{tabular}

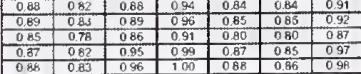

(d)

\begin{tabular}{|l|l|l|l|l|l|}
0.00 & 0.50 & 0.75 & 1.00 & 1.08 & \\
\hline
\end{tabular}

Figure 5-4. Demand/capacity ratios for WTC 1 core columns under original design loads, (c) 700 line and (d) 800 line (continued). 


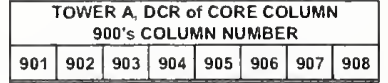

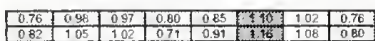

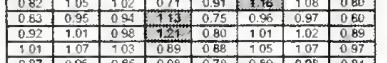

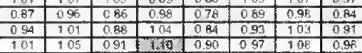

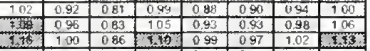

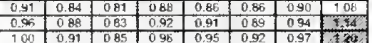

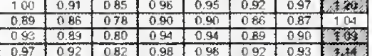

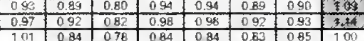

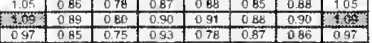

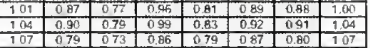

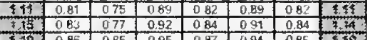

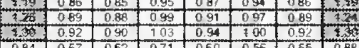

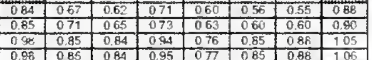

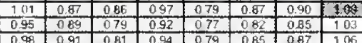

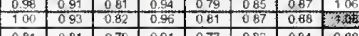

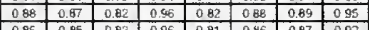

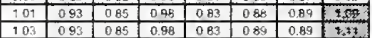

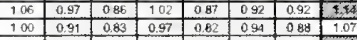

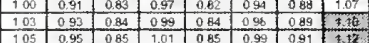

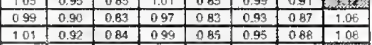

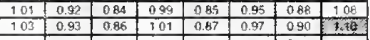

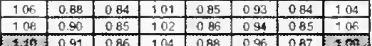

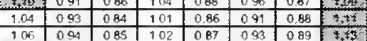

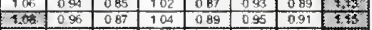

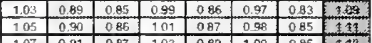

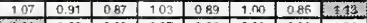

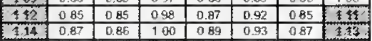

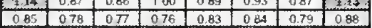

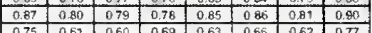

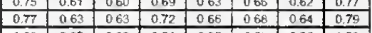

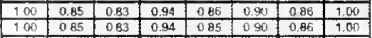

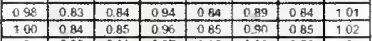

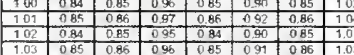

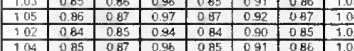

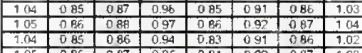

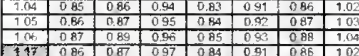

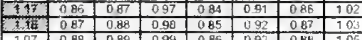

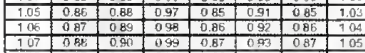

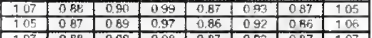

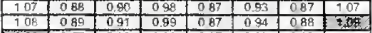

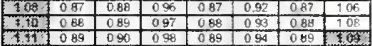

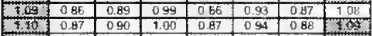

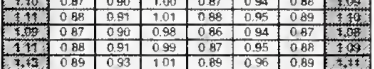

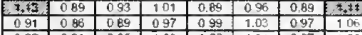

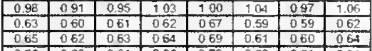

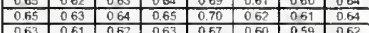

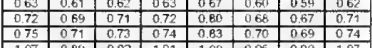

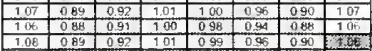

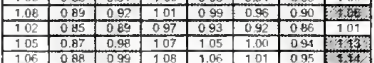

(e)

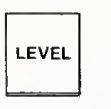

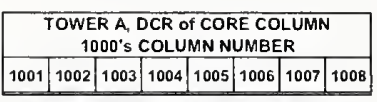

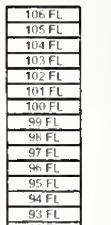

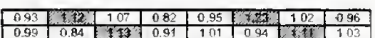

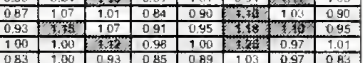

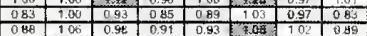

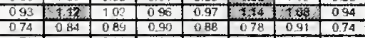

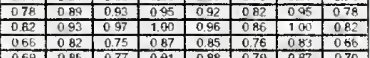

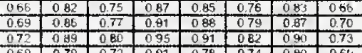

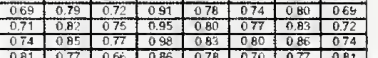

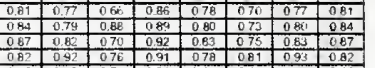

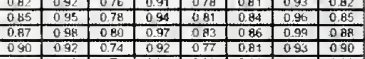

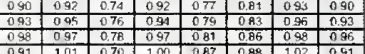

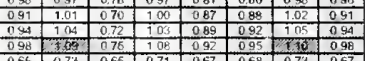

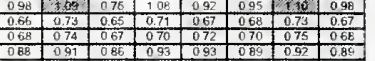

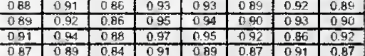

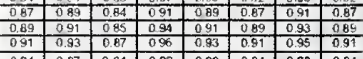

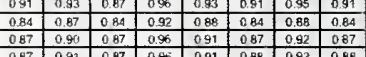

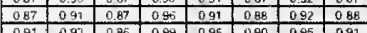

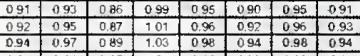

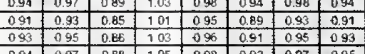
\begin{tabular}{llllllllll}
\hline 0.4 & 0.97 & 0.86 & 105 & 098 & 0.92 & 0.9 & 0.95 \\
\hline
\end{tabular}

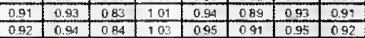

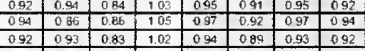

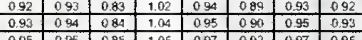

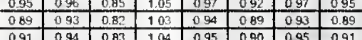

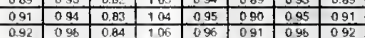

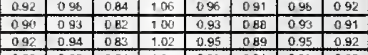

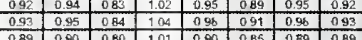

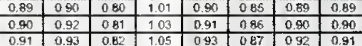

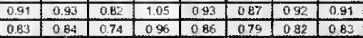

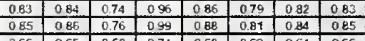

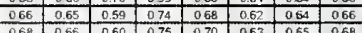

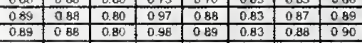

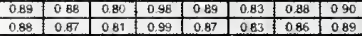

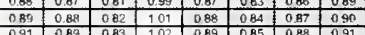

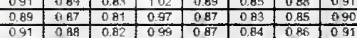

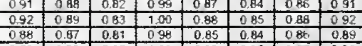

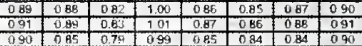

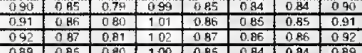

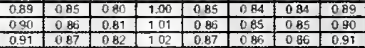

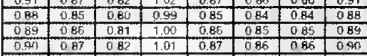

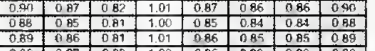

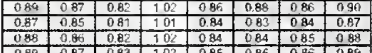

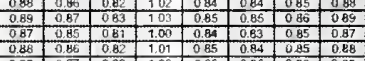

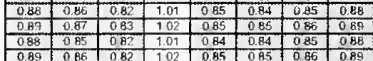

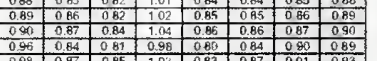

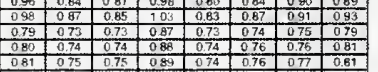

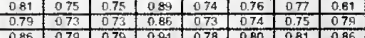

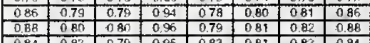

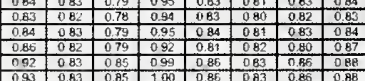
(f)

\begin{tabular}{|l|l|l|l|l|l|l|}
\hline 0.00 & 0.50 & 0.75 & 1.00 & 1.08 & \\
\hline
\end{tabular}

Figure 5-4. Demand/capacity ratios for WTC 1 core columns under original design loads, (e) 900 line and (f) 1000 line (continued). 
The types of members in the exterior wall that had DCRs larger than 1 were calculated for a combination of axial load and bending under a combination of gravity and wind loads and were generally found in three types of location:

1. Columns at the corners;

2. Where the hat truss connects to the exterior wall; and

3. Below floor 9 .

The members in these locations would be expected to experience large forces. The corner columns had some of the highest calculated forces under wind loads. The hat truss-to-exterior wall connections interconnected two major structural systems with large concentrated load transfers. The exterior wall below floor 9 was a highly variable and articulated structural system that had large calculated forces. Given the extraordinary difficulty of replicating with precision a set of engineering calculations performed almost forty years ago with relatively rudimentary computational tools, DCRs in excess of one were observed in the analysis at locations of highest forces and at locations where there was significant complexity of system behavior.

The core columns that had DCRs larger than 1 were calculated for axial stresses due to gravity loads and were generally located on the 600 column line between floors 80 and 106 and at core perimeter columns 901 and 908 for much of their height. The gravity loads on these columns were affected significantly by assumptions about tributary areas, unit construction dead loads and superimposed dead loads, and the sequence of construction of the hat truss. The high degree of stress calculated at these core columns is likely associated with differences in these assumptions between the original and current computations.

Figure 5-5 presents the distribution of the normal stresses due to axial loads (axial column load divided by columns cross sectional area) in the columns of the four exterior walls due to wind loads only (gravity loads are not included in these plots). The axial stresses are presented at three levels along the height of the tower: B6, 39, and 73. The plots show both the tensile and compressive stresses on the columns induced by wind loading, where shear lag effects can be observed. For corner columns 101, 159, 301, and 359 at floor 73, Fig. 5-5(c) indicates that their stresses are smaller than their neighboring columns. This is likely due to the influence of the special corner framing at that floor, i.e., the discontinuous columns and chamfered plan layout of the exterior wall framing.

The results of the baseline performance analyses indicated that tension forces were developed in the exterior walls of WTC 1 under the original WTC design dead and wind loads. The tension forces from the combination of dead and wind loads for all faces are illustrated in Fig. 5-6. The figure indicates that tensile forces are largest at the base of the building and at the corners.

These axial tensile column loads were transferred from one panel to another through the column splices. The exterior wall column splice capacities were calculated from the original details and compared to the tension forces for all four faces of WTC 1. The DCR ratios for the exterior wall splice connections for WTC 1 are summarized in Table 5-2.

For the tower resistance to shear sliding and overturning due to wind, the dead loads that acted on the perimeter walls of the tower provided resistance to shear sliding and overturning at the foundation level. 
Considering the resistance to shear sliding under wind load, the factor of safety was estimated to be approximately 11.5. This was calculated by dividing the resisting force due to dead load on the perimeter wall (a coefficient of friction of 0.7 was used) by the wind shear at the foundation level. Considering resistance to overturning due to wind load, the factors of safety were estimated to be approximately 2.3 and 2.6 for overturning about a north-south axis and for an east-west axis, respectively. This was calculated by dividing the resisting moment due to dead load on the perimeter wall by the overturning moment due to wind load taken at the foundation level.
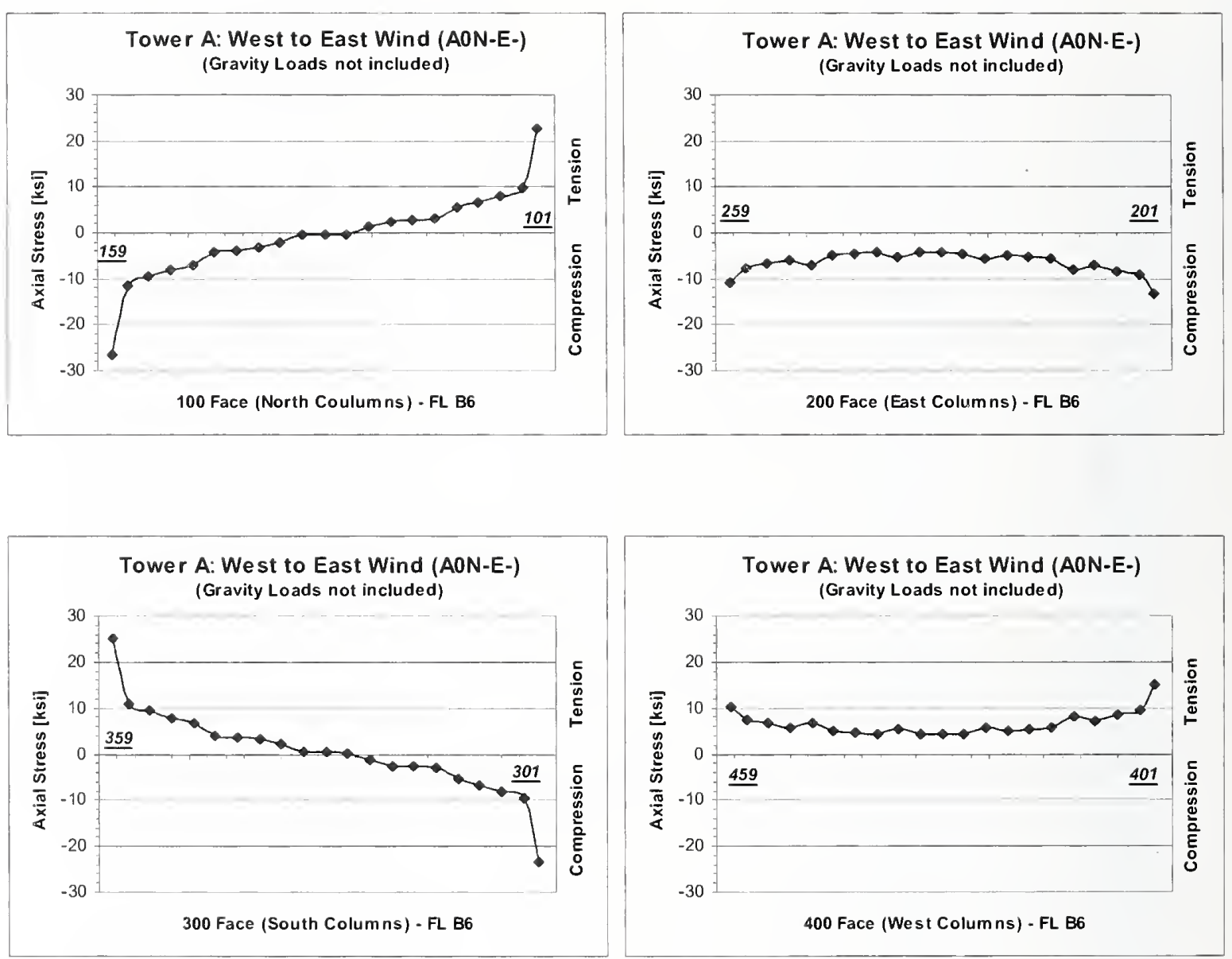

(a)

Figure 5-5. Shear lag diagrams of WTC 1 due to original WTC wind loads at (a) floor B6, (b) floor 39, and (c) floor 73. 

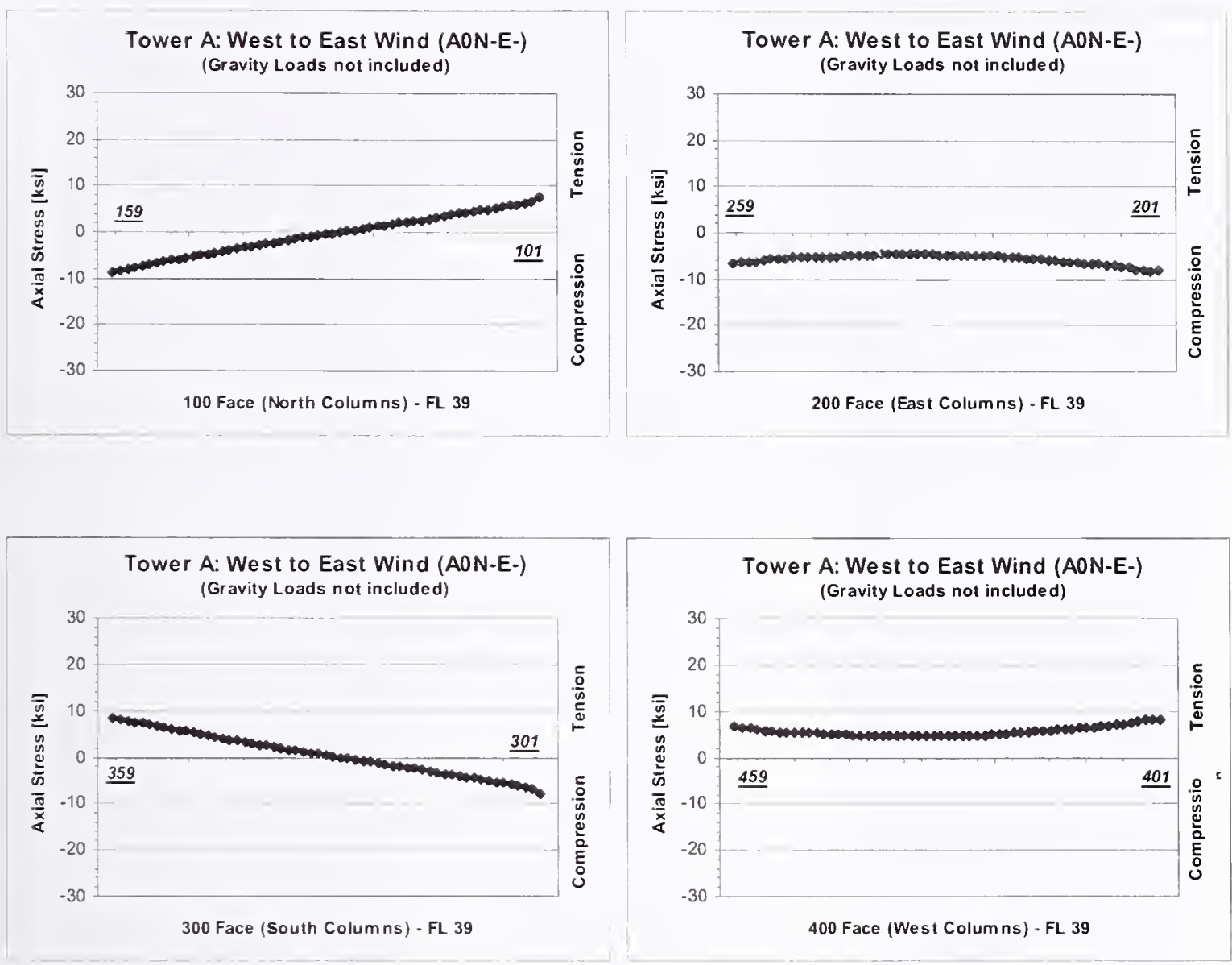

(b)

Figure 5-5. Shear lag diagrams of WTC 1 due to original WTC wind loads at (a) floor B6, (b) floor 39, and (c) floor 73 (continued). 

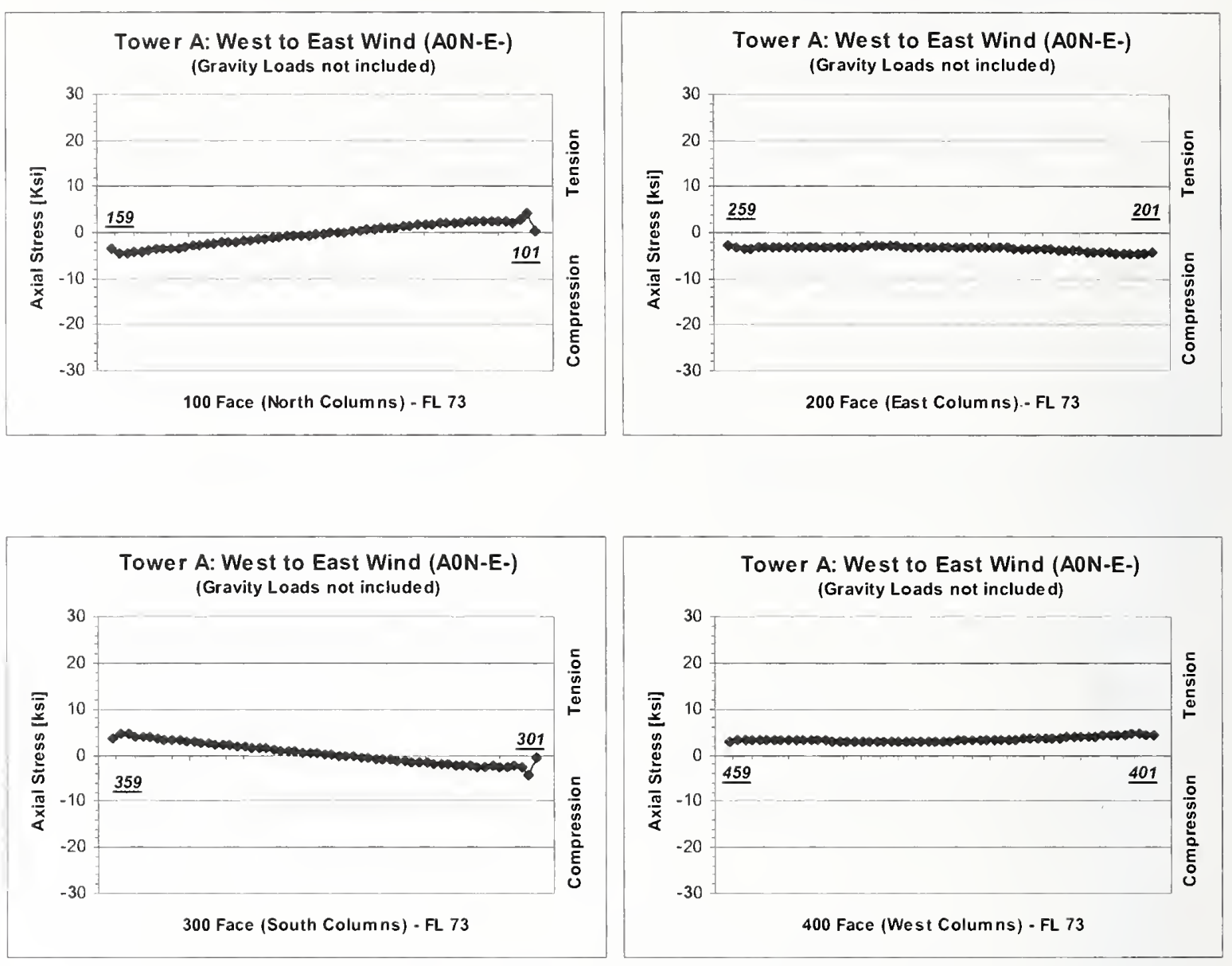

(c)

Figure 5-5. Shear lag diagrams of WTC 1 due to original WTC wind loads at (a) floor B6, (b) floor 39, and (c) floor 73 (continued). 

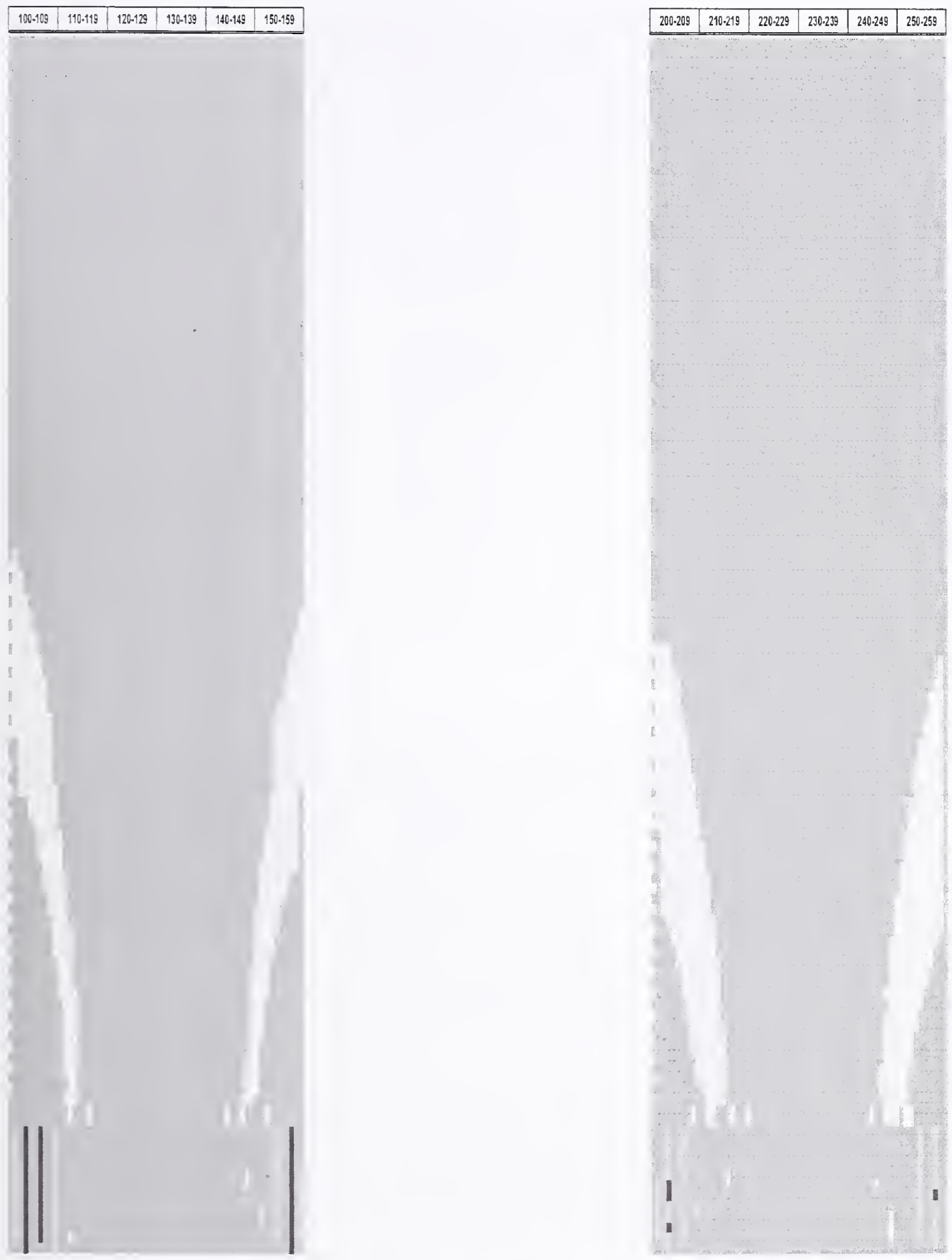

(a)

(b)

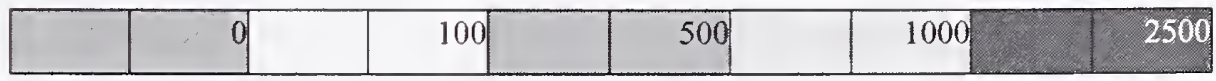

Figure 5-6. Tension force distribution (kip) in the exterior wall columns of WTC 1 under original design dead and wind loads, (a) 100 face (north) and (b) 200 face (east). 


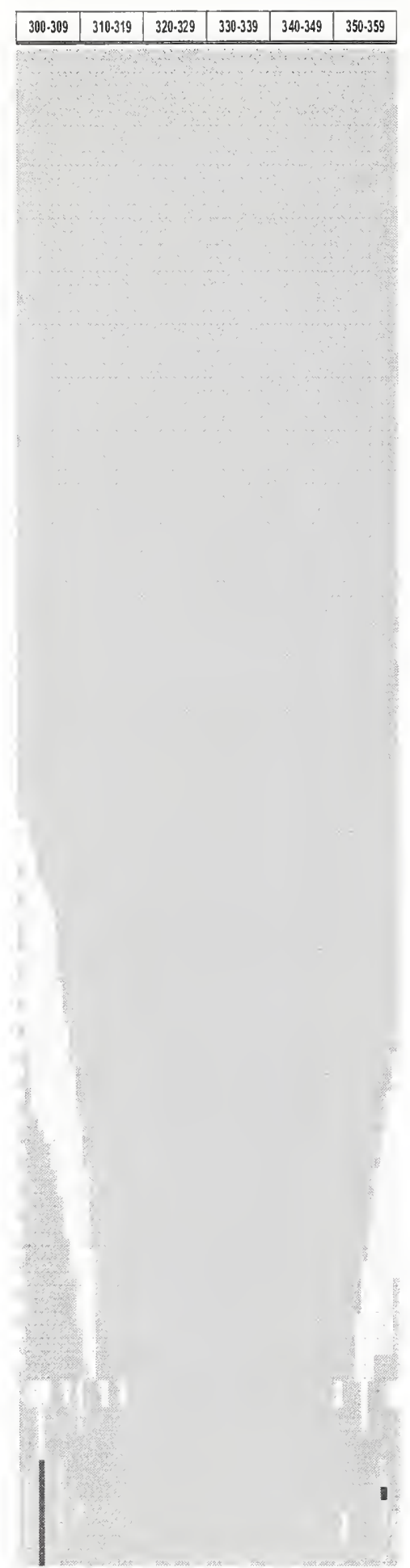

(c)

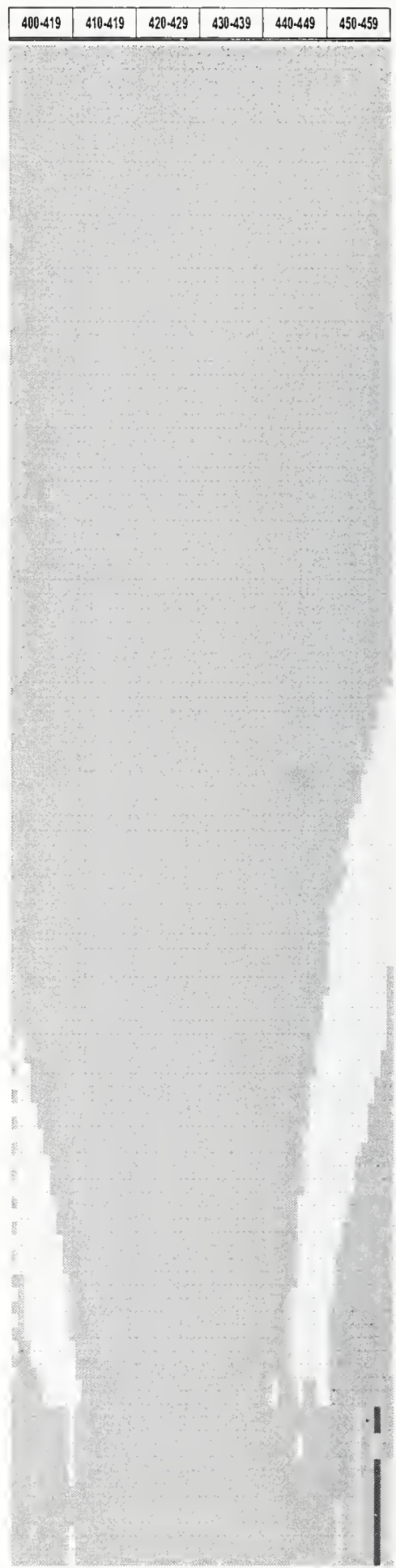

(d)

\begin{tabular}{|l|l|l|l|l|l|l|}
\hline & 9 & 100 & 500 & 1000 & 2500 \\
\hline
\end{tabular}

Figure 5-6. (c) 300 face (south) and (d) 400 face (west) (continued). 
Table 5-2. Maximum calculated demand/capacity ratios (DCRs) for exterior wall column splices for WTC 1 under original design dead and wind load case.

\begin{tabular}{|l|c|c|}
\hline $\begin{array}{c}\text { Exterior } \\
\text { Wall Face }\end{array}$ & $\begin{array}{c}\text { Exterior Wall } \\
\text { Column Splices }\end{array}$ & $\begin{array}{c}\text { Maximum } \\
\text { Calculated DCR }\end{array}$ \\
\hline 100 Face & Below floor 1 & 0.64 \\
(North) & Floor l to 9 & 0.31 \\
& Floor 10 to 41 & 0.96 \\
& Above floor 42 & 0.26 \\
\hline \multirow{3}{*}{ 200 Face } & Below floor 1 & 0.53 \\
(East) & Floor l to 9 & 0.32 \\
& Floor 10 to 41 & 0.63 \\
300 Face & Above floor 42 & 0.14 \\
(South) & Below floor 1 & 0.54 \\
& Floor 1 to 9 & 0.26 \\
& Floor 10 to 41 & 0.77 \\
400 Face & Above floor 42 & 0.15 \\
(West) & Below floor 1 & 0.59 \\
& Floor l to 9 & 0.36 \\
\hline
\end{tabular}

\subsubsection{State-of-the-Practice Case}

The WTC 1 global model was analyzed using the lower estimate, state-of-the-practice loading case, as described in Chapter 4 (see also NIST NCSTAR 1-2). This loading case included dead loads, live loads according to the NYCBC 2001, and wind loads from the Rowan Williams Davies and Irwin, Inc. (RWDI) wind tunnel study, scaled in accordance with NYCBC 2001 wind speed.

The calculated total drift of WTC 1 induced by the lower estimate. state-of-the-practice case was approximately $56.8 \mathrm{in.} \mathrm{(4} \mathrm{ft} 8.8 \mathrm{in}$.) in the $\mathrm{E}-\mathrm{W}$ direction and $68.1 \mathrm{in.}(5 \mathrm{ft} 8.1 \mathrm{in}$.) in the N-S direction. The drifts are equivalent to about $\mathrm{H} / 303$ and $\mathrm{H} / 253$ in the $\mathrm{E}-\mathrm{W}$ and $\mathrm{N}-\mathrm{S}$ directions, respectively.

Figure 5-7 presents the deflected shape (cumulative drift) and the inter-story drifts normalized by the story height for WTC 1 under the state-of-the-practice case. The plots are presented for the E-W and N-S directions for the load combinations producing the maximum cumulative drift.

DCR statistics for WTC 1 global system components under the lower estimate, state-of-the-practice loading case are summarized in Table 5-3. A comparison of the mean values of the DCRs estimated from the original design case (Table 5-1) with those from the state-of-the-practice case (Table 5-3) indicated that the results are very similar. Also, the distribution of the DCRs and the locations of members with DCRs greater than 1.0 were very similar between the original design case and the state-ofthe-practice case. 

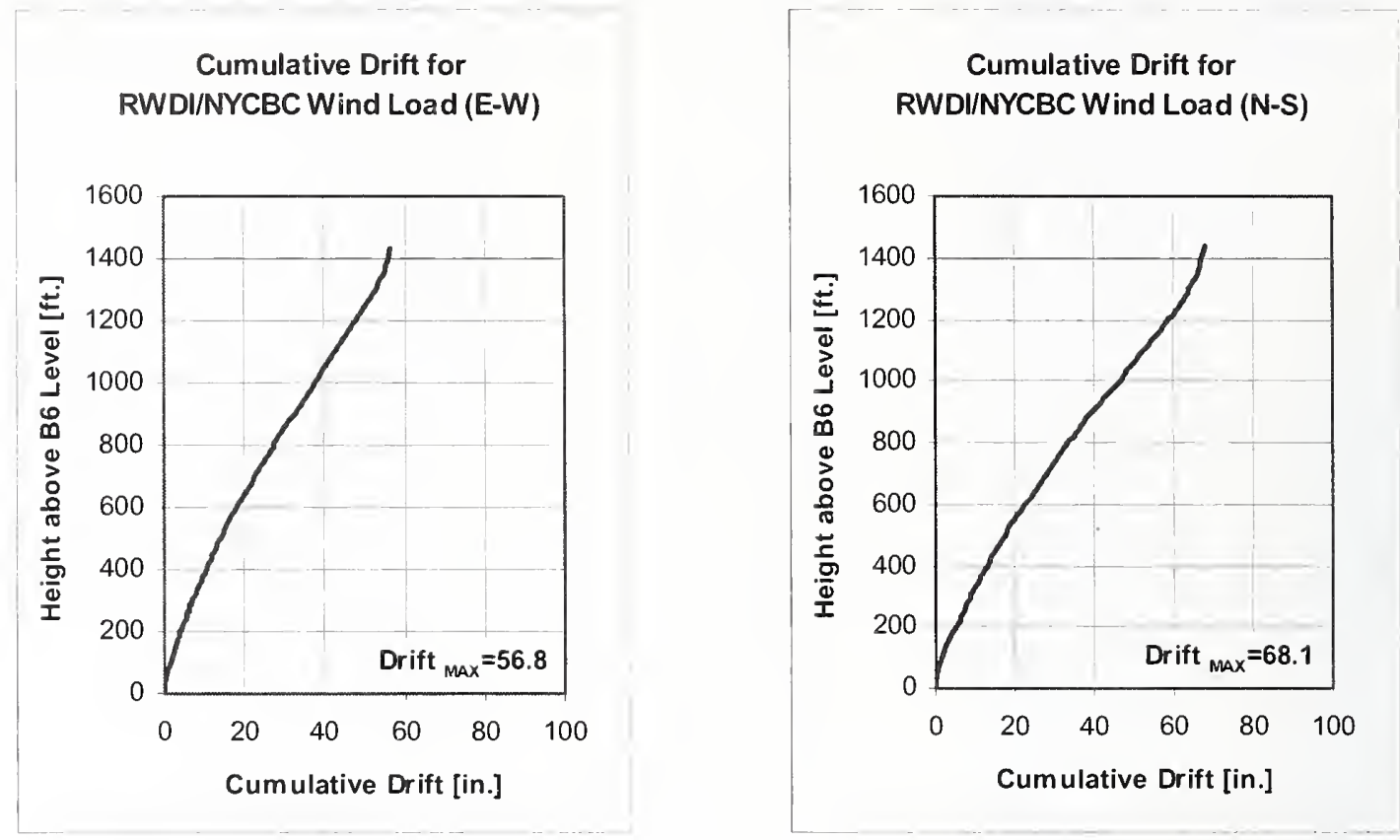

Interstory Drif/Story Height for

RWDI/NYCBC Wind Load (E-W)

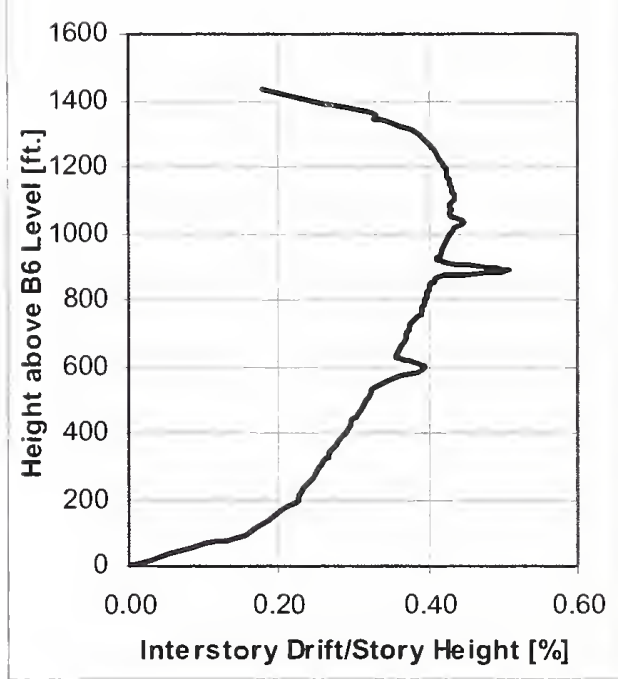

(a)

Interstory Drif/Story Height for

RWDI/NYCBC Wind Load (N-S)

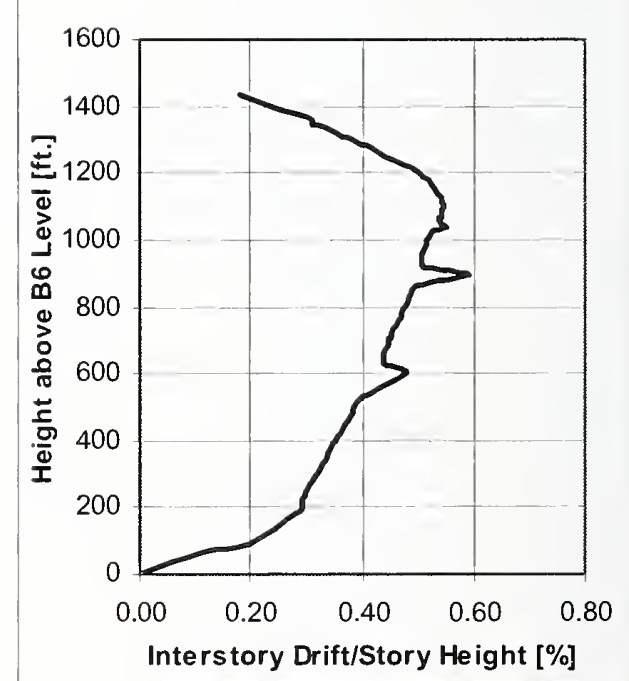

(b)

Figure 5-7. Drift diagrams of WTC 1 due to the lower estimate, state-of-the-practice loads, (a) 1R14PDN and (b) 1R8PDN. 
Table 5-3. Statistics of demand/capacity ratios (DCRs) for WTC 1 under the lower estimate, state-of-the practice case.

\begin{tabular}{|c|c|c|c|c|c|c|c|}
\hline Member Type & $\begin{array}{c}\text { Number } \\
\text { of } \\
\text { Members }\end{array}$ & $\begin{array}{c}\text { Mean } \\
\text { Calculated } \\
\text { DCR }\end{array}$ & $\begin{array}{l}\text { C.O.V. } \\
\text { of DCR }\end{array}$ & $\begin{array}{c}\text { Percentage } \\
\text { of } \\
\text { Components } \\
\text { with DCR } \\
>1.0\end{array}$ & $\begin{array}{l}\text { Percentage } \\
\text { of } \\
\text { Components } \\
\text { with DCR } \\
>1.05\end{array}$ & $\begin{array}{l}\text { Number of } \\
\text { Components } \\
\text { with DCR } \\
>1.05\end{array}$ & $\begin{array}{c}\text { Maximum } \\
\text { Calculated } \\
\text { DCR }\end{array}$ \\
\hline \multicolumn{8}{|l|}{$\begin{array}{l}\text { Exterior Wall } \\
\text { Columns }\end{array}$} \\
\hline Below floor 1 & 628 & 0.77 & 0.19 & 6.1 & 4.0 & 25 & 1.30 \\
\hline Floor 1 to 9 & 1,122 & 0.78 & 0.26 & 13.1 & 5.2 & 58 & 1.15 \\
\hline Floor 9 to 106 & 31.086 & 0.78 & 0.13 & 2 & 0.9 & 281 & 1.44 \\
\hline Above floor 106 & 578 & 0.71 & 0.31 & 10.7 & 7.6 & 44 & 1.36 \\
\hline \multicolumn{8}{|l|}{$\begin{array}{l}\text { Exterior Wall } \\
\text { Spandrels }\end{array}$} \\
\hline Below floor 1 & 420 & 0.49 & 0.46 & 4 & 2.4 & 10 & 1.26 \\
\hline Floor 1 to 9 & 610 & 0.37 & 0.45 & 1.3 & 1.1 & 7 & 1.22 \\
\hline Floor 9 to 106 & 31.160 & 0.32 & 0.29 & 0 & 0 & 0 & 0.80 \\
\hline Above floor 106 & 836 & 0.35 & 0.70 & 1.9 & 1.7 & 14 & 1.57 \\
\hline Core Columns & 5.219 & 0.86 & 0.14 & 9.9 & 5.3 & 278 & 1.36 \\
\hline \multicolumn{8}{|l|}{ Hat Truss System } \\
\hline Columns & 239 & 0.45 & 0.50 & 0.4 & 0.4 & 1 & 1.26 \\
\hline Beams & 499 & 0.23 & 0.93 & 0.2 & 0.2 & 1 & 1.07 \\
\hline Braces & 279 & 0.41 & 0.60 & 1.1 & 0 & 0 & 1.03 \\
\hline \multicolumn{8}{|l|}{$\begin{array}{l}\text { Exterior Wall } \\
\text { Bracing }\end{array}$} \\
\hline Below floor 1 & 200 & 0.76 & 0.16 & 2.5 & 2 & 4 & 1.18 \\
\hline Above floor 106 & 12 & 0.35 & 0.47 & 0 & 0 & 0 & 0.64 \\
\hline
\end{tabular}

\subsubsection{The Refined NIST Estimate Case}

The WTC 1 global model was analyzed using the refined NIST estimate case, as described in Chapter 4 (see also NIST NCSTAR 1-2). This loading case included dead loads, live loads in accordance with the ASCE 7-02 Standard, and wind loads developed by NIST based on critical assessment of information obtained from RWDI and CPP reports and state-of-the-art considerations in wind engineering.

The calculated total drift of WTC 1 induced by the refined NIST estimate case was approximately 70.6 in. ( $5 \mathrm{ft} 10.6 \mathrm{in}$.) in the $\mathrm{E}-\mathrm{W}$ direction and $83.9 \mathrm{in} .(6 \mathrm{ft} 11.9 \mathrm{in}$.) in the $\mathrm{N}-\mathrm{S}$ direction. These drifts are equivalent to about $\mathrm{H} / 244$ and $\mathrm{H} / 205$ in the $\mathrm{E}-\mathrm{W}$ and $\mathrm{N}-\mathrm{S}$ directions, respectively. Figure $5-8$ presents the deflected shape (cumulative drift) and the inter-story drifts normalized by the story height for WTC 1 under the refined NIST wind loads. The plots are presented for the E-W and N-S directions for the load combination producing the maximum cumulative drift. 

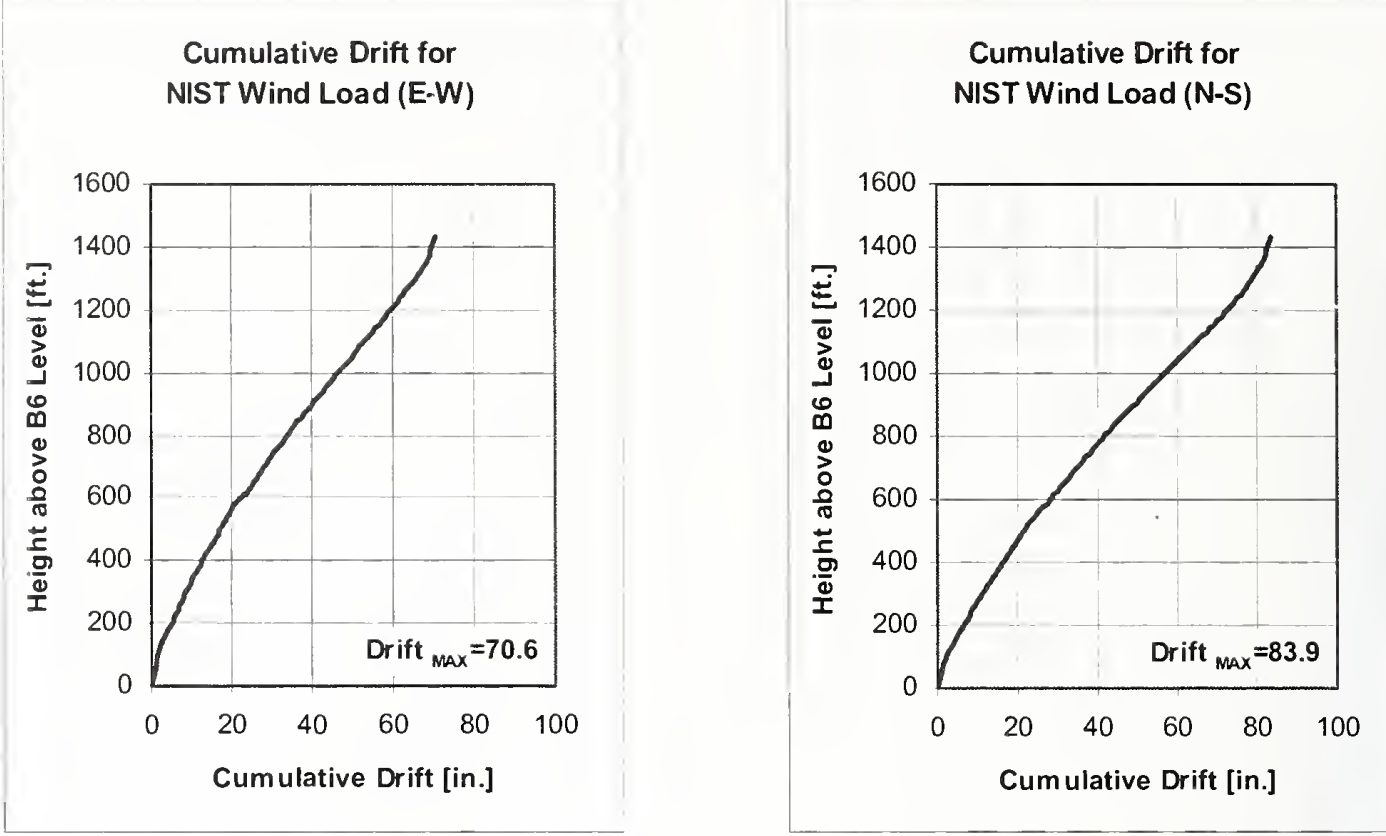

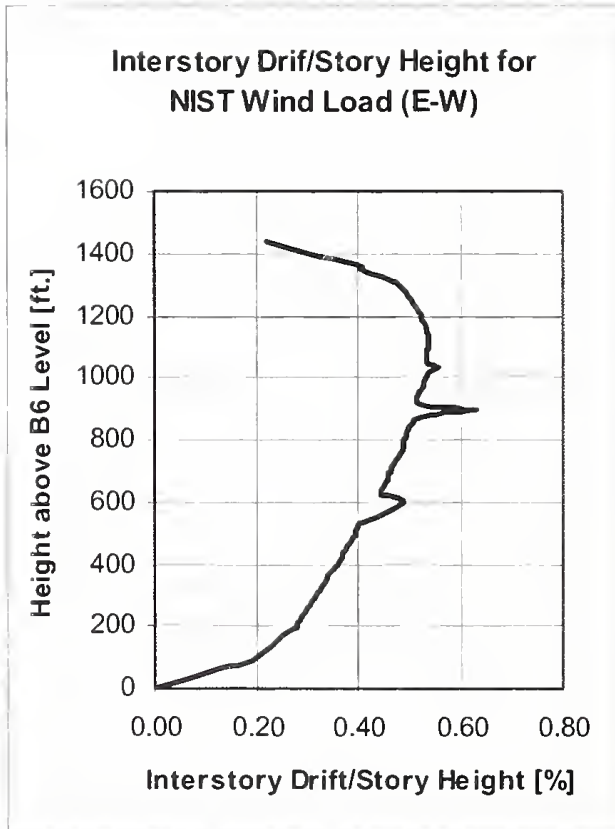

(a)

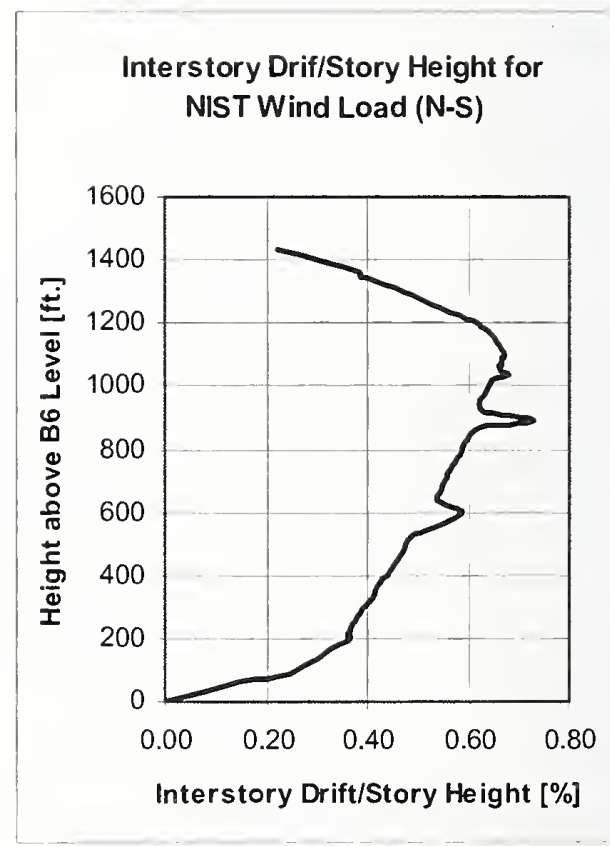

(b)

Figure 5-8. Drift diagrams of WTC 1 due to refined NIST estimate wind loads, (a) 1R14PD and (b) 1R8PD. 
DCR statistics for WTC 1 global systems components under the refined NIST estimate case are summarized in Table 5-4. The DCRs for the core columns and hat truss members estimated from the original design and the state-of-the-practice cases (Tables 5-1 and 5-3, respectively) are generally close to those estimated from the refined NIST estimate case (Table 5-4). This is due to the fact that core columns and hat truss members do not significantly contribute to wind load resistance. The DCRs for the exterior walls, including columns, spandrels, and bracings calculated from the refined NIST estimate case are larger than those estimated from the original design and the state-of-the-practice cases. For example, for the exterior walls, the ratio of the mean DCRs from the refined NIST estimate case to the mean DCRs from the original design case ranged from 1.84 to 1.11 . The ratio of the mean DCRs from the refined NIST estimate case to the mean DCRs from the lower estimate, state-of-the-practice case ranged from 1.65 to 1.14 .

Table 5-4. Statistics of demand/capacity ratios (DCRs) for WTC 1 under the refined NIST estimate case.

\begin{tabular}{|c|c|c|c|c|c|c|c|}
\hline Member Type & $\begin{array}{c}\text { Number } \\
\text { of } \\
\text { Members }\end{array}$ & $\begin{array}{c}\text { Mean } \\
\text { Calculated } \\
\text { DCR }\end{array}$ & $\begin{array}{c}\text { C.O.V. } \\
\text { of } \\
\text { DCR }\end{array}$ & $\begin{array}{c}\text { Percentage } \\
\text { of } \\
\text { Components } \\
\text { with DCR } \\
>1.0\end{array}$ & $\begin{array}{c}\text { Percentage } \\
\text { of } \\
\text { Components } \\
\text { with DCR } \\
>1.05\end{array}$ & $\begin{array}{l}\text { Number of } \\
\text { Components } \\
\text { with DCR } \\
>1.05\end{array}$ & $\begin{array}{c}\text { Maximum } \\
\text { Calculated } \\
\text { DCR }\end{array}$ \\
\hline \multicolumn{8}{|l|}{$\begin{array}{l}\text { Exterior Wall } \\
\text { Columns }\end{array}$} \\
\hline Below floor 1 & 628 & 1.04 & 0.24 & 52.5 & 47.3 & 297 & 1.95 \\
\hline Floor 1 to 9 & 1,122 & 1.11 & 0.27 & 69.0 & 63.6 & 714 & 1.69 \\
\hline Floor 9 to 106 & 31,086 & 1.10 & 0.14 & 72.1 & 59.7 & 18572 & 2.05 \\
\hline Above floor 106 & 578 & 0.81 & 0.28 & 19.7 & 14.2 & 82 & 1.57 \\
\hline \multicolumn{8}{|l|}{$\begin{array}{l}\text { Exterior Wall } \\
\text { Spandrels }\end{array}$} \\
\hline Below floor 1 & 420 & 0.81 & 0.46 & 22.1 & 21.4 & 90 & 2.05 \\
\hline Floor 1 to 9 & 610 & 0.61 & 0.45 & 8.0 & 4.3 & 26 & 2.03 \\
\hline Floor 9 to 106 & 31,160 & 0.52 & 0.29 & 0.5 & 0.3 & 109 & 1.32 \\
\hline Above floor 106 & 836 & 0.41 & 0.68 & 2.4 & 1.9 & 16 & 1.82 \\
\hline Core Columns & 5,219 & 0.84 & 0.15 & 8.9 & 5.2 & 270 & 1.40 \\
\hline \multicolumn{8}{|l|}{ Hat Truss System } \\
\hline Columns & 239 & 0.53 & 0.49 & 3.8 & 0.8 & 2 & 1.26 \\
\hline Beams & 499 & 0.26 & 0.93 & 1.8 & 1.4 & 7 & 1.30 \\
\hline Braces & 279 & 0.49 & 0.55 & 6.1 & 2.5 & 7 & 1.10 \\
\hline \multicolumn{8}{|l|}{$\begin{array}{l}\text { Exterior Wall } \\
\text { Bracing }\end{array}$} \\
\hline Below floor 1 & 200 & 1.11 & 0.18 & 73.0 & 62.0 & 124 & 1.76 \\
\hline Above floor 106 & 12 & 0.52 & 0.42 & 0 & 0 & 0 & 0.90 \\
\hline
\end{tabular}

\subsection{BASELINE PERFORMANCE ANALYSIS OF WTC 2}

The baseline performance analysis of the global model of WTC 2 was performed on a Pentium 4 personal computer with a CPU speed of $3.06 \mathrm{GHz}$ and $1.0 \mathrm{~GB}$ of RAM. The duration of the analysis was about $15 \mathrm{~h}$. The following summarizes the results under the three loading cases. 


\subsubsection{Original WTC Design Load Case}

The analysis reported in this section used the gravity and wind loads used in the original design of the towers, as explained in Chapter 4.

The results of the analysis indicated that for the dead and live loads used in the original WTC design, the core columns and the exterior walls of WTC 2 carried approximately 53 percent and 47 percent, respectively, of the total gravity load at the basement (B6) level.

The calculated total drift of WTC 2 induced by the original WTC design wind loads was approximately

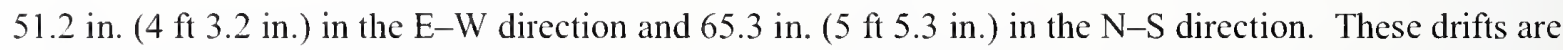
equivalent to about $\mathrm{H} / 335$ and $\mathrm{H} / 263$ in the $\mathrm{E}-\mathrm{W}$ and $\mathrm{N}-\mathrm{S}$ directions, respectively. Similar to WTC 1, building drift under wind loads was not a design criterion and accordingly, no historical project-specific data is available to which the total drifts may be compared. Fig. 5-9 presents the deflected shape (cumulative drift) and the inter-story drifts normalized by the story height for WTC 2 under the original design loads. The plots are presented for the E-W and N-S directions for the cases producing the maximum cumulative drift (wind azimuth 180 and 90 degrees for the $\mathrm{E}-\mathrm{W}$ and N-S directions, respectively, where azimuth 0 indicates towcr north).

DCRs were calculated using the SAP2000 computer program. As was done for WTC 1, the calculations were spot checked for accuracy and to verify that the correct design information was being applied, and the calculations were found to be acceptable. The DCR statistics for WTC 2 global systems components under the original WTC design loading are summarized in Table 5-5. Figure 5-10 shows the distribution of the DCRs for the four exterior walls of WTC 2 under the original design loads. Close-up views are provided for the exterior walls below floor 9 in Fig. 5-11. DCRs for the core columns are illustrated in Fig. 5-12.

The types of members in the exterior wall that had DCRs larger than 1 were calculated for a combination of axial load and bending under a combination of gravity and wind loads and were generally found in three types of location:

1. Columns at the corners;

2. Where the hat truss connects to the exterior wall; and

3. Below floor 9 .

The members in these locations would be expected to experience large forces. The corner columns had some of the highest calculated forces under wind loads. The hat truss-to-exterior wall connections interconnected two major structural systems with large concentrated load transfers. The exterior wall below floor 9 was a highly variable and articulated structural system that had large calculated forces. Given the extraordinary difficulty of replicating with precision a set of engineering calculations performed almost 40 years ago with relatively rudimentary computational tools, DCRs in excess of one were observed in the analysis at locations of highest forces and at locations where there was significant complexity of system behavior. 

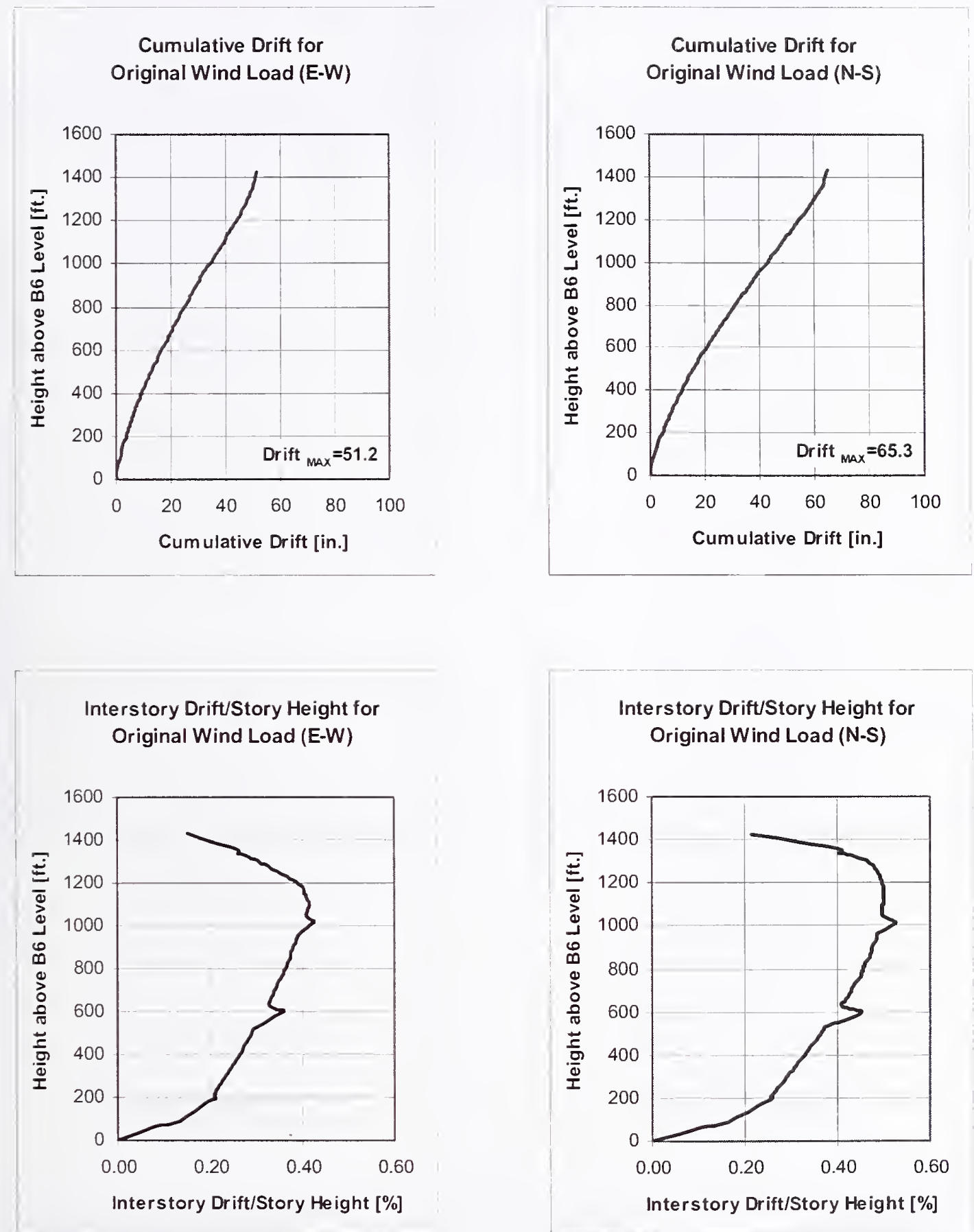

(a)

(b)

Figure 5-9. Drift diagrams of WTC 2 due to original WTC wind loads, (a) B180N+E- and (b) B90N-E+. 
Table 5-5. Statistics of demand/capacity ratios (DCRs) for WTC 2 under original design load case.

\begin{tabular}{|c|c|c|c|c|c|c|c|}
\hline Member Type & $\begin{array}{l}\text { Number } \\
\text { of } \\
\text { Members }\end{array}$ & $\begin{array}{c}\text { Mean } \\
\text { Calculated } \\
\text { DCR }\end{array}$ & $\begin{array}{l}\text { C.O.V. } \\
\text { of DCR }\end{array}$ & $\begin{array}{c}\text { Percentage } \\
\text { of } \\
\text { Components } \\
\text { with DCR } \\
>1.0\end{array}$ & $\begin{array}{c}\text { Percentage } \\
\text { of } \\
\text { Components } \\
\text { with DCR } \\
>1.05\end{array}$ & $\begin{array}{c}\text { Number of } \\
\text { Components } \\
\text { with DCR } \\
>1.05\end{array}$ & $\begin{array}{c}\text { Maximum } \\
\text { Calculated } \\
\text { DCR }\end{array}$ \\
\hline \multicolumn{8}{|l|}{$\begin{array}{l}\text { Exterior Wall } \\
\text { Columns }\end{array}$} \\
\hline Below floor 1 & 577 & 0.74 & 0.22 & 4.2 & 2.9 & 17 & 1.53 \\
\hline Floor 1 to 9 & 1,122 & 0.73 & 0.25 & 2.3 & 0.7 & 8 & 1.19 \\
\hline Floor 9 to 106 & 31,086 & 0.81 & 0.12 & 4.1 & 2.9 & 911 & 1.37 \\
\hline Above floor 106 & 578 & 0.75 & 0.30 & 12.3 & 9.9 & 57 & 1.55 \\
\hline \multicolumn{8}{|l|}{$\begin{array}{l}\text { Exterior Wall } \\
\text { Spandrels }\end{array}$} \\
\hline Below floor 1 & 408 & 0.47 & 0.47 & 2.2 & 1.7 & 7 & 1.37 \\
\hline Floor 1 to 9 & 594 & 0.38 & 0.47 & 1.3 & 1.3 & 8 & 1.47 \\
\hline Floor 9 to 106 & 31,160 & 0.34 & 0.30 & 0 & 0 & 0 & 0.86 \\
\hline Above floor 106 & 836 & 0.34 & 0.71 & 1.7 & 1.4 & 12 & 1.59 \\
\hline Core Columns & 5,245 & 0.86 & 0.15 & 10.8 & 6.6 & 348 & 1.36 \\
\hline \multicolumn{8}{|l|}{ Hat Truss System } \\
\hline Columns & 238 & 0.50 & 0.58 & 4.6 & 3.4 & 8 & 1.48 \\
\hline Beams & 504 & 0.24 & 0.80 & 0.2 & 0 & 0 & 1.01 \\
\hline Braces & 283 & 0.44 & 0.57 & 3.5 & 1.1 & 3 & 1.09 \\
\hline \multicolumn{8}{|l|}{$\begin{array}{l}\text { Exterior Wall } \\
\text { Bracing }\end{array}$} \\
\hline Below floor 1 & 227 & 0.70 & 0.16 & 1.3 & 0 & 0 & 1.04 \\
\hline Above floor 106 & 12 & 0.31 & 0.41 & 0 & 0 & 0 & 0.52 \\
\hline
\end{tabular}




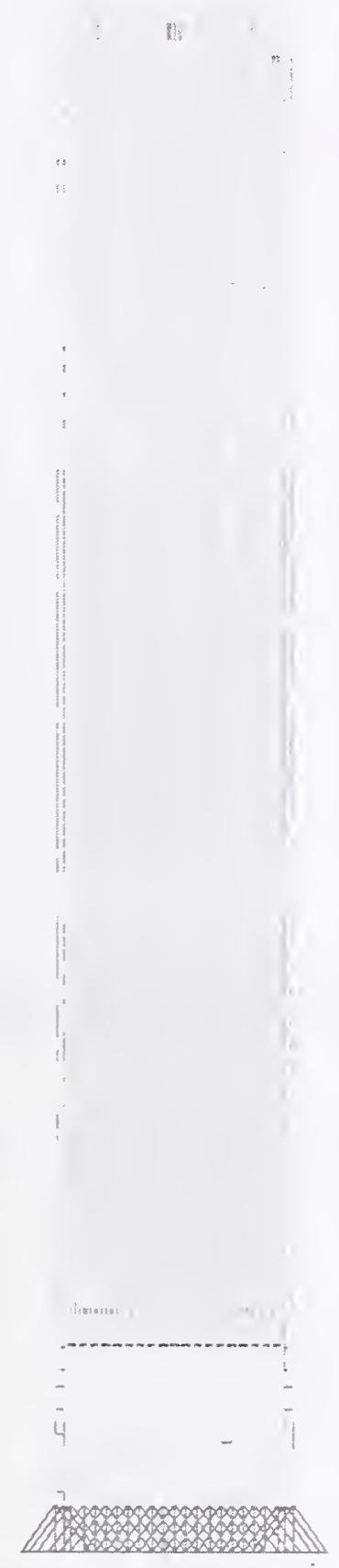

(a)
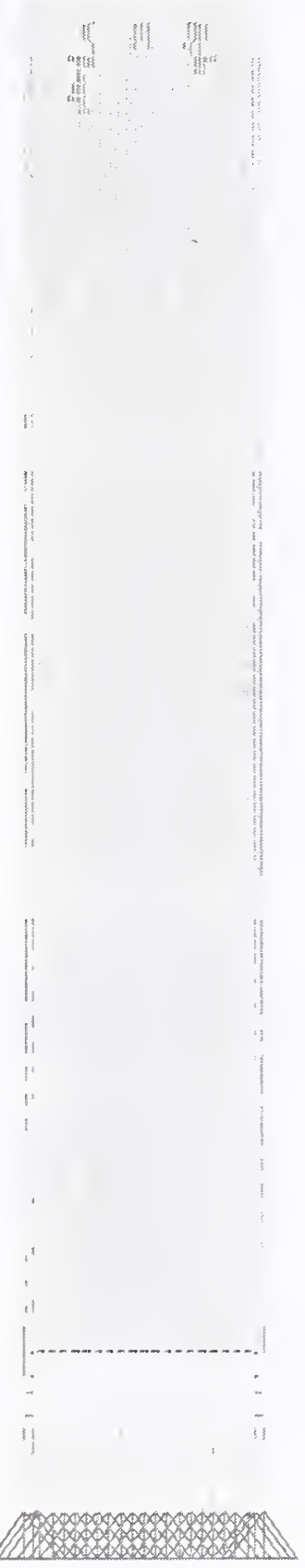

(b)

\begin{tabular}{|l|l|l|l|l|l|l|l|}
\hline & 0.00 & 0.50 & 0.75 & 1.00 & 1.08 & \\
\hline
\end{tabular}

Figure 5-10. Demand/capacity ratios for WTC 2 under original design loads, (a) west elevation and (b) north elevation. 


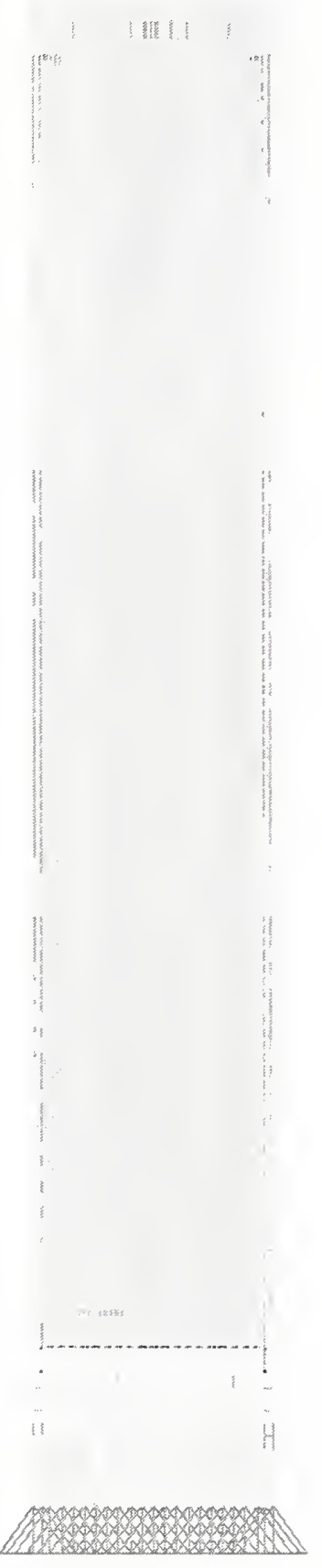

(c)

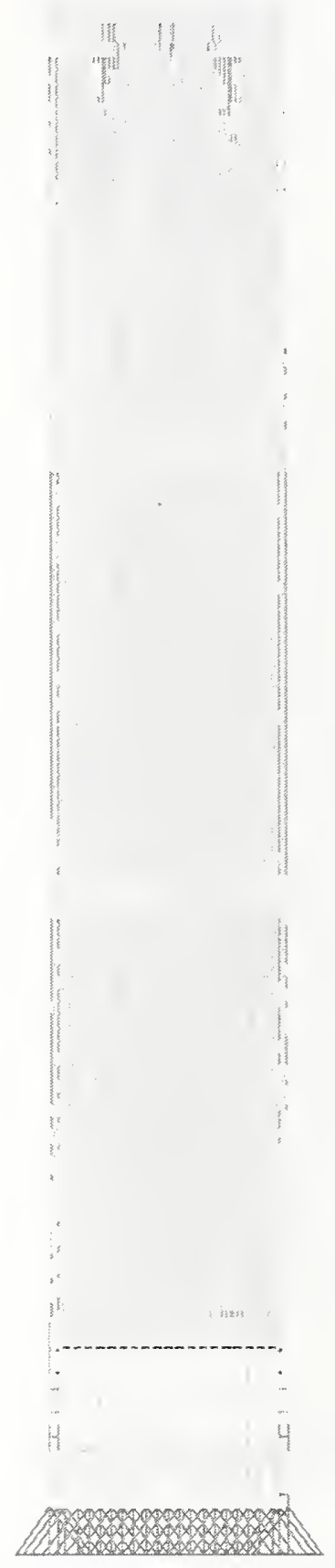

(d)

\begin{tabular}{|l|l|l|l|l|l|l|l|l|}
\hline & 0.00 & 0.50 & 0.75 & 1.00 & 1.08 \\
\hline
\end{tabular}

Figure 5-10. (c) east elevation and (d) south elevation (continued). 
NWNNANANANNANANNNANANANANNA

\begin{tabular}{|c|c|c|c|c|c|c|c|}
\hline & 0.00 & 0.50 & 0.75 & 1.00 & 1.08 \\
\hline
\end{tabular}

(b)

Figure 5-11. Demand/capacity ratios for WTC 2 under original design load case, (b) north elevation below floor 9 (continued). 


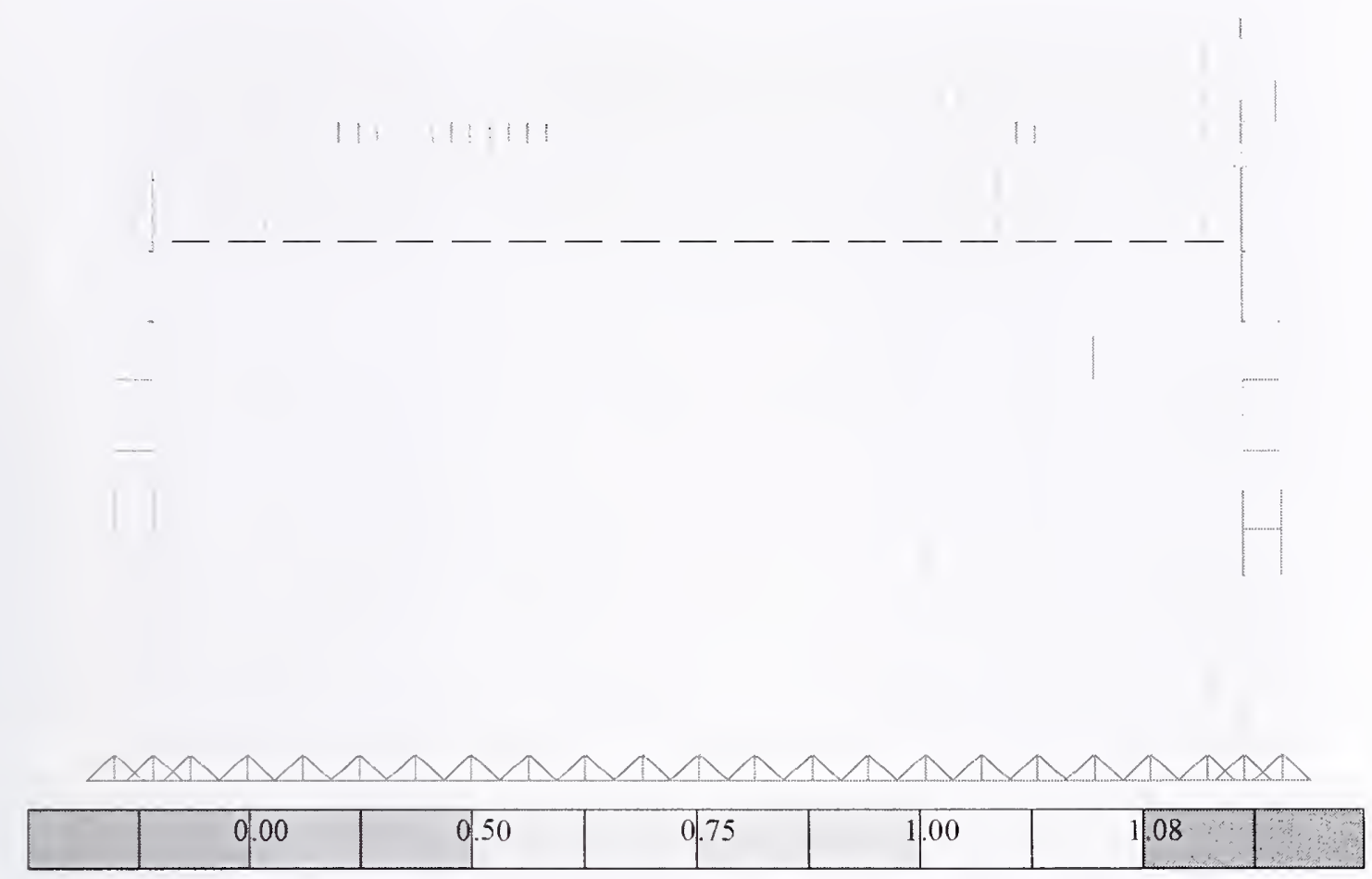

(c)

Figure 5-11. Demand/capacity ratios for WTC 2 under original design load case, (c) east elevation below floor 9 (continued). 


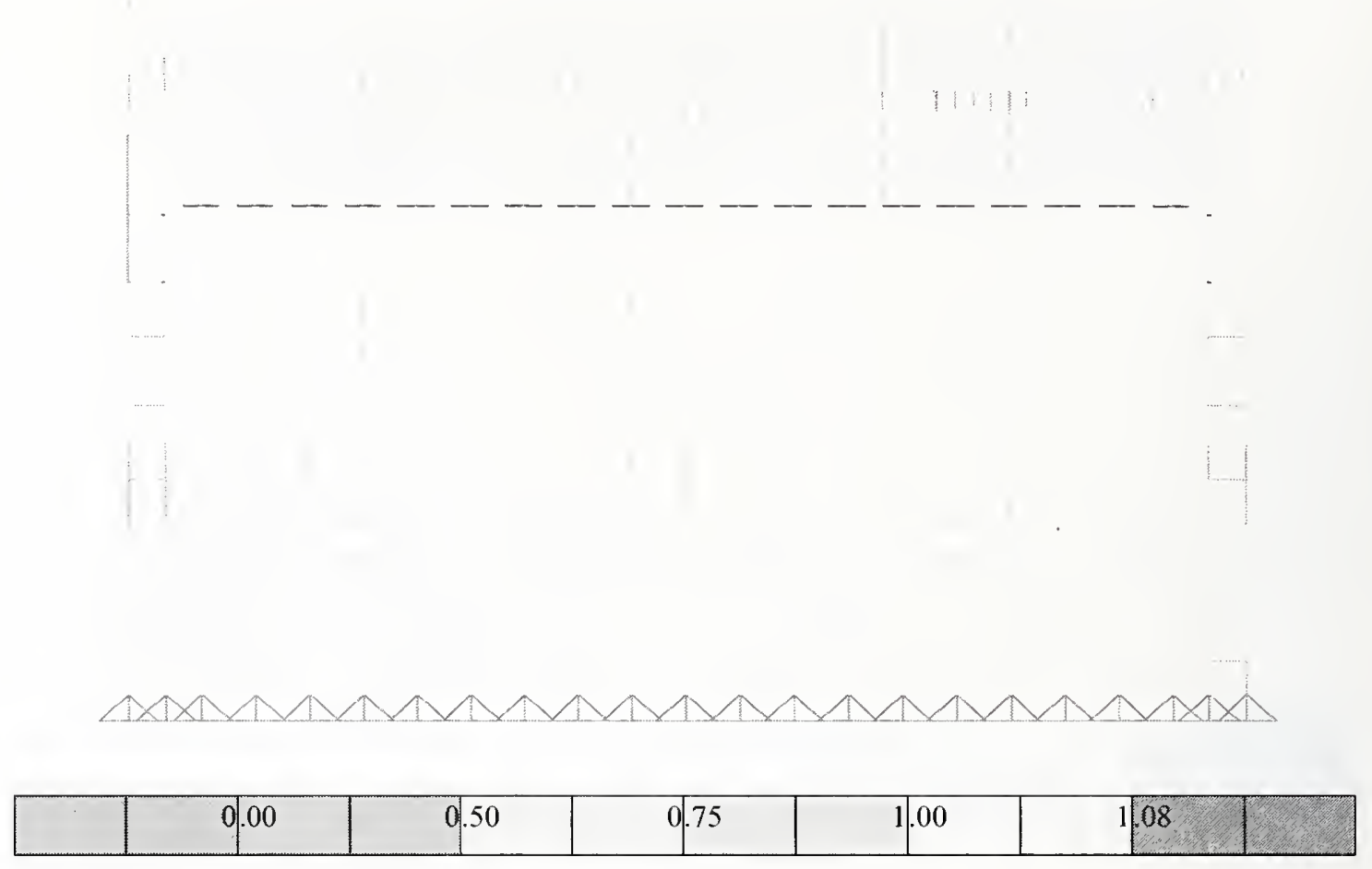

(d)

Figure 5-11. Demand/capacity ratios for WTC 2 under original design load case, (d) south elevation below floor 9 (continued). 

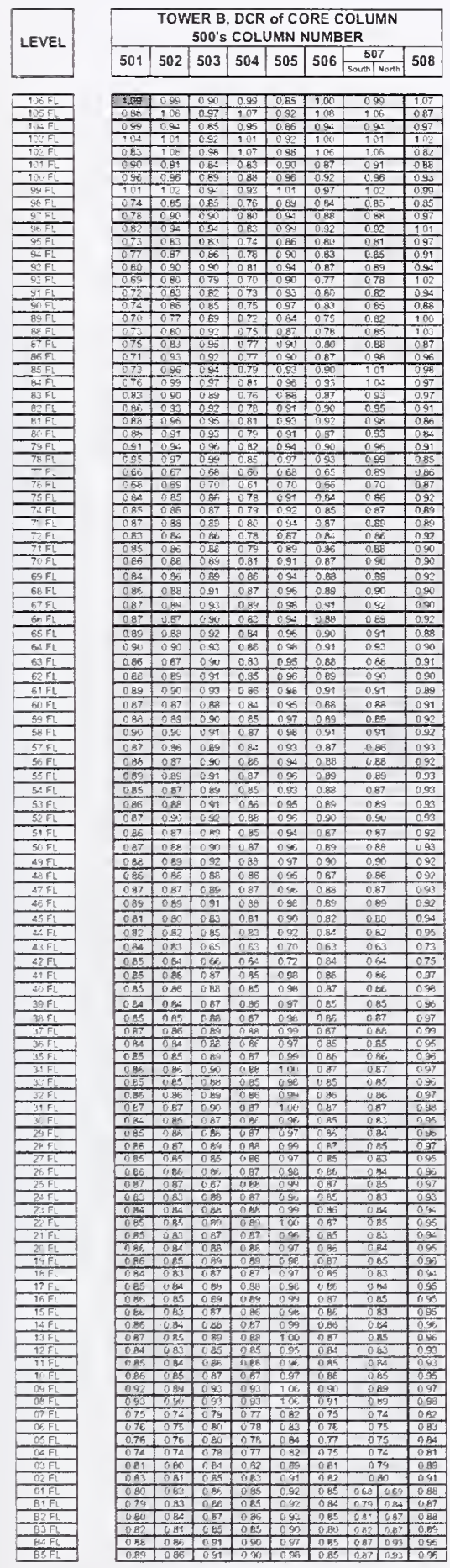

(a)
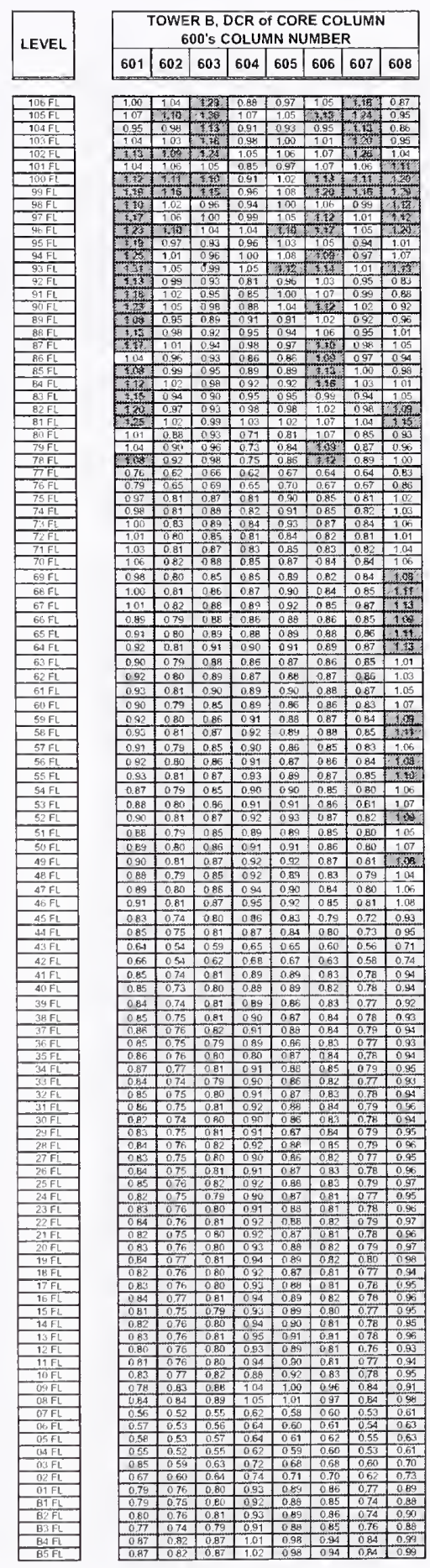

(b)

\begin{tabular}{|l|l|l|l|l|l|l|l|}
\hline & 0.00 & 0.50 & 0.75 & 1.00 & 1.08 & \\
\hline
\end{tabular}

Figure 5-12. Demand/capacity ratios for WTC 2 core columns under original design loads, (a) 500 line and (b) 600 line. 


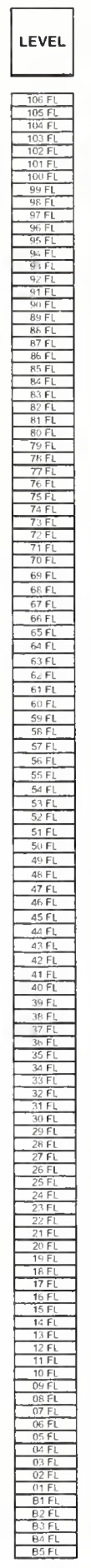

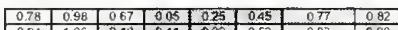

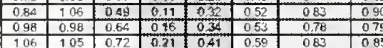

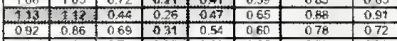

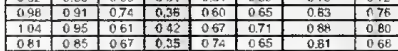

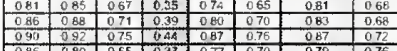

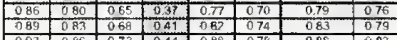

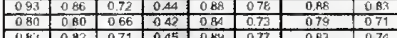

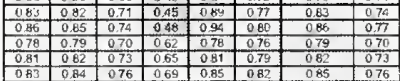

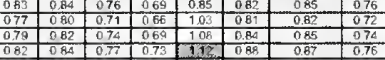

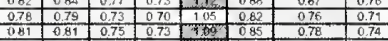

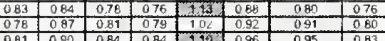

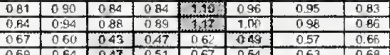

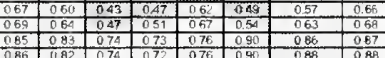

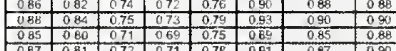

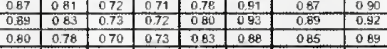

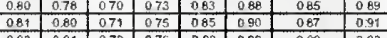

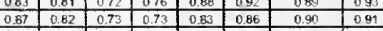

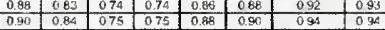

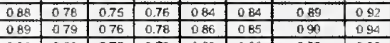

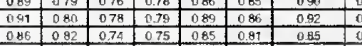

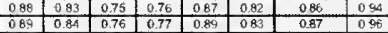

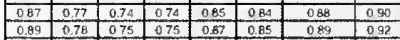

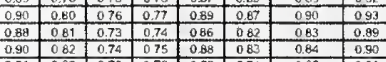

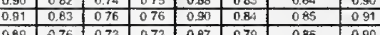
\begin{tabular}{lllllllll}
0.89 & 076 & 0.73 & 0.73 & 0.87 & 079 & 0.85 & 0.90 \\
\hline 0.91 & 077 & 0.74 & 0.74 & 0.89 & 0.90 & 0.57 & 0.99 \\
\hline
\end{tabular}

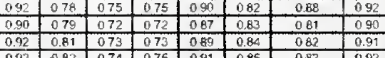
\begin{tabular}{l|lllllllll}
\hline 0.93 & 0.82 & 074 & 0.75 & 0.91 & 0.85 & 0.83 & 0.92 \\
\hline
\end{tabular}

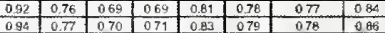

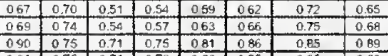

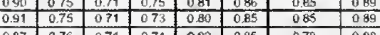

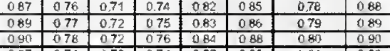

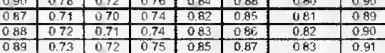

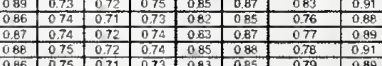

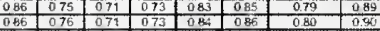

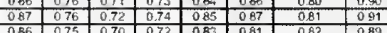

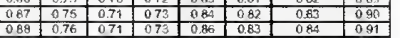

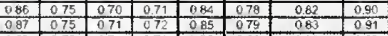

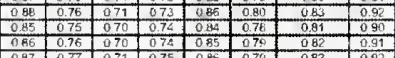

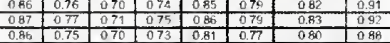

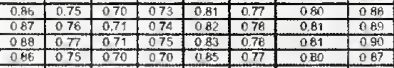

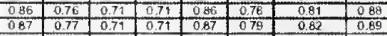

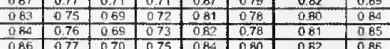

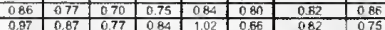

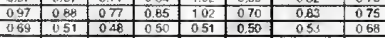

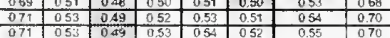

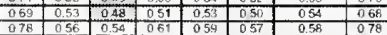

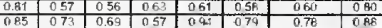

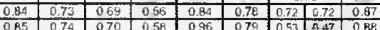

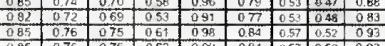

(c)

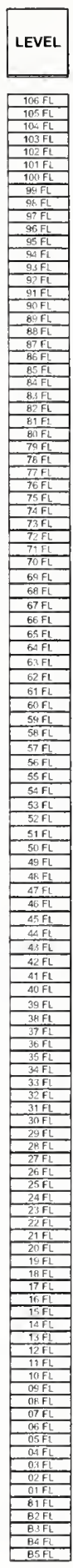

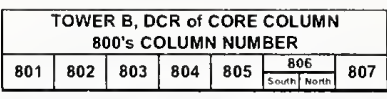

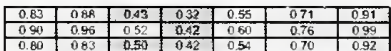

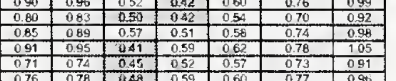

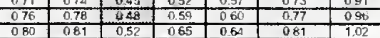

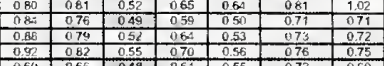

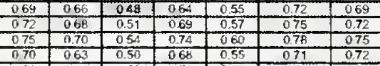

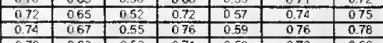

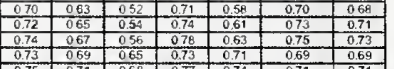

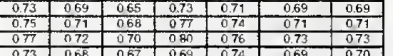

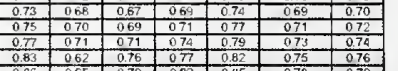

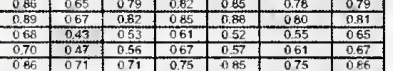

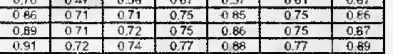

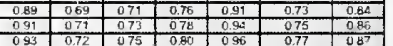

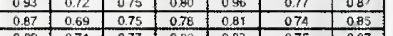

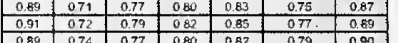
\begin{tabular}{lllllllll}
\hline 0.91 & 075 & 074 & 0.02 & 084 & 080 & 092 \\
\hline
\end{tabular}

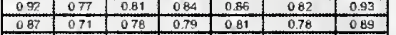

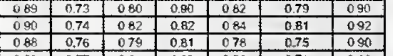
\begin{tabular}{|l|l|l|l|l|l|l|}
\hline 088 & 0.7 & 081 & 083 & 080 & 076 & 092 \\
\hline 0.01 & 0.79 & 0.83 & 0.84 & 0.81 & 0.78 & 0.93 \\
\hline
\end{tabular} \begin{tabular}{|l|l|l|l|l|l|l|}
\hline 0.87 & 073 & 0.80 & 0.80 & 0.82 & 079 & 0.91 \\
\hline 0.09 & 074 & 0.82 & 0.81 & 0.24 & 0.81 & 0.82 \\
\hline
\end{tabular}

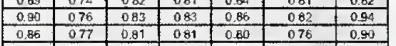

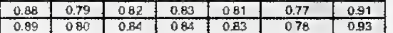
\begin{tabular}{|l|l|l|l|l|l|l|}
\hline 085 & 074 & 0.65 & 0.60 & 0.88 & 080 & 0.86 \\
\hline 0.67 & 0.75 & 0.86 & 0.81 & 0.86 & 0.81 & 0.00 \\
\hline
\end{tabular}

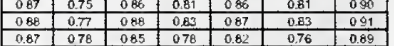

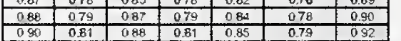

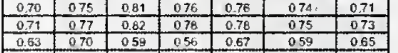

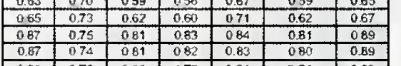

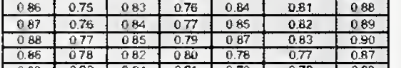

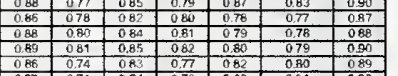

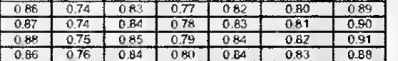

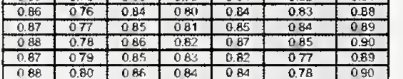

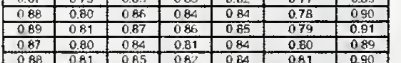

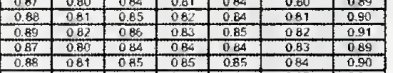

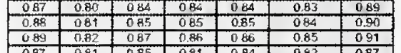
$\frac{\frac{0.89}{0.08}}{0.08}$

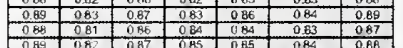

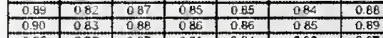

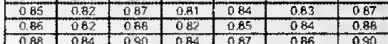

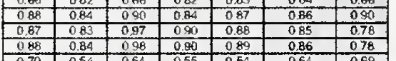

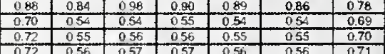

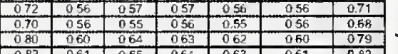

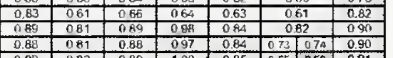

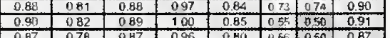

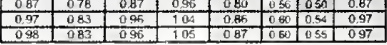

(d)

\begin{tabular}{|l|l|l|l|l|l|l|l|}
\hline & 0.00 & 0.50 & 0.75 & 1.00 & 1.08 & \\
\hline
\end{tabular}

Figure 5-12. Demand/capacity ratios for WTC 2 core columns under original design loads, (c) 700 line and (d) 800 line (continued). 

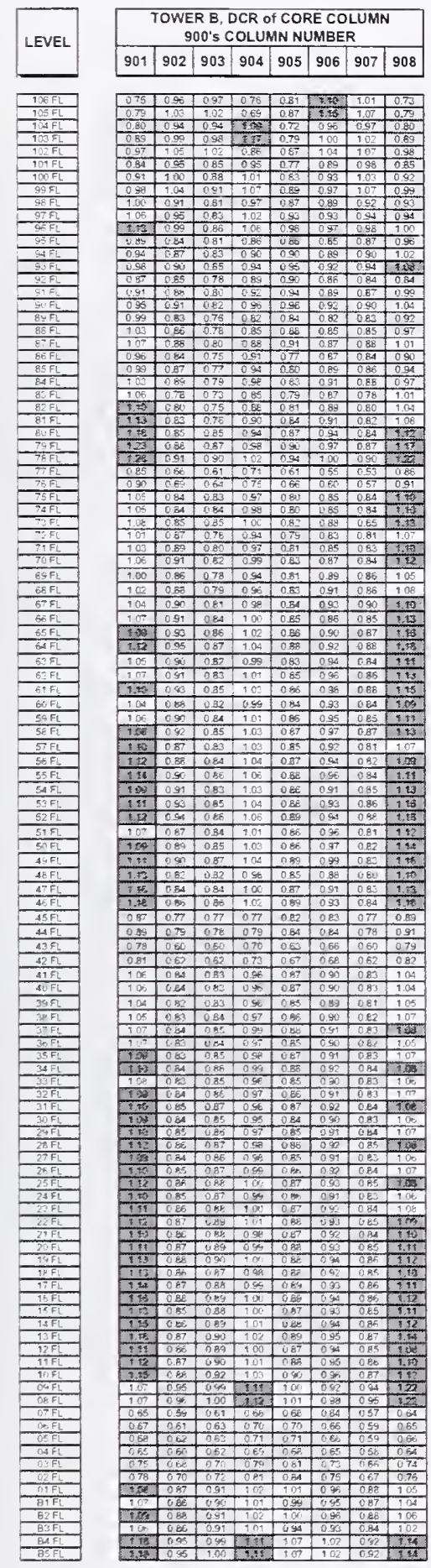

(e)
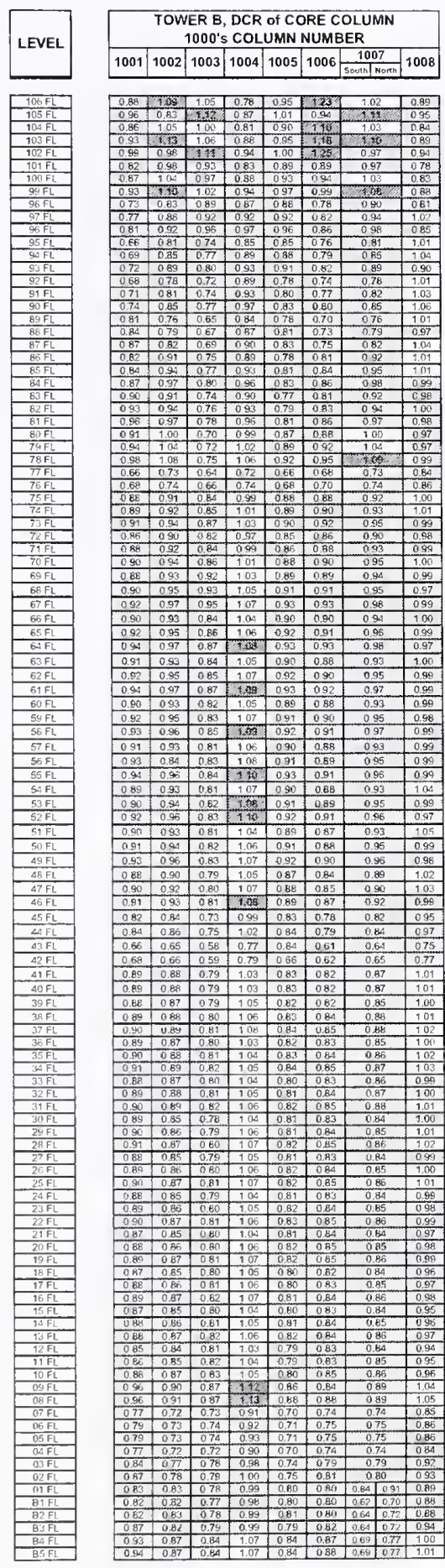

(f)

\begin{tabular}{|l|l|l|l|l|l|l|l|}
\hline & 0.00 & 0.50 & 0.75 & 1.00 & 1.08 & \\
\hline
\end{tabular}

Figure 5-12. Demand/capacity ratios for WTC 2 core columns under original design loads, (e) 900 line and (f) 1000 line (continued). 
The core columns that have DCRs $>1$ were calculated for axial stresses due to gravity loads and were generally located on the 600 column line between floors 80 and 106 and at columns 901 and 908 for much of their height. The gravity loads on these columns were affected significantly by assumptions about tributary areas, unit construction dead loads and superimposed dead loads, and the sequence of construction of the hat truss. The high degree of stress calculated at these core columns is likely associated with diffcrences in these assumptions between the original and current computations.

Figure 5-13 presents the distribution of the normal stresses due to axial loads (axial column load divided by columns cross sectional area) in the columns of the four exterior walls due to wind loads only (gravity loads are not included in these plots). The axial stresses are presented at three levels along the height of the tower: B6, 39, and 73. The plots show both the tensile and compressive stresses on the columns induced by wind loading, where shear lag effects can be observed. For corner columns 101, 159, 301, and 359 at floor 73, Fig. 5-13(c) indicates that their stresses are smaller than their neighboring columns. This is likely due to the influence of the special corner framing at that floor, i.e. the discontinuous columns and chamfered plan layout of the exterior wall framing.

The results of the baseline performance analysis indicated that tension forces were developed in the exterior walls of WTC 2 under the original WTC design dead and wind loads. The tension forces from the combination of dead and wind loads for all faces are illustrated in Fig. 5-14. The figure indicates that forces are largest at the base of the building and at the corners.

These axial tensile column loads were transferred from one panel to another through the column splices. The exterior wall column splice capacities were calculated from the original details and compared to the tension forces for all four faces of WTC 2. The DCR ratios for the exterior wall splice connections for WTC 2 are summarized in Table 5-6.

For the tower resistance to shear sliding and overturning due to wind, the dead loads that acted on the perimeter walls of the tower provided resistance to shear sliding and overturning at the foundation level. Considering the resistance to shear sliding under wind load, the factor of safety was calculated to be approximately 10 . Considering resistance to overturning due to wind load, the factors of safety were calculated to be approximately 1.9 and 2.7 for overturning about a north-south axis and for an east-west axis, respectively. 

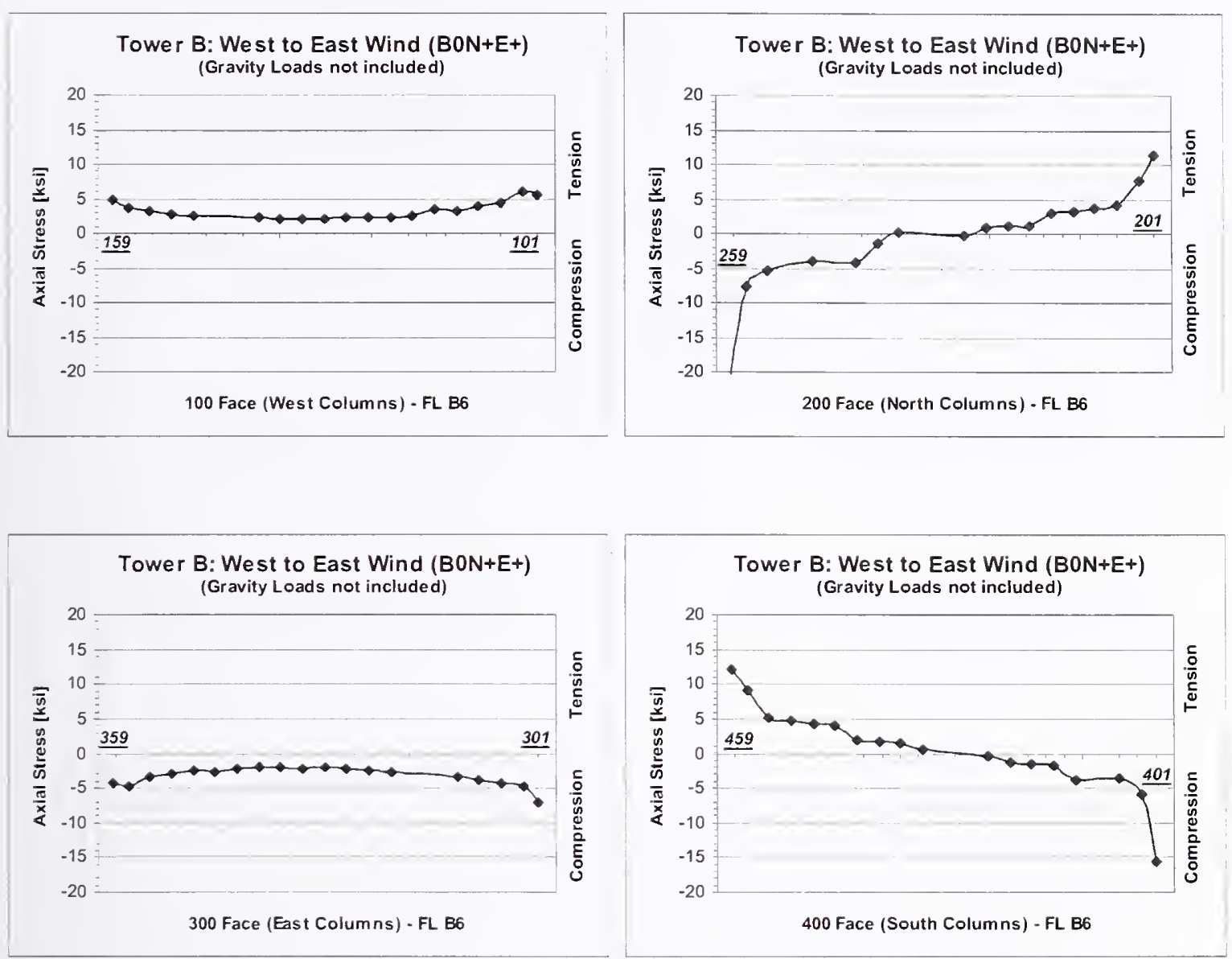

(a)

Figure 5-13. Shear lag diagrams of WTC 2 due to original WTC wind loads at (a) floor B6, (b) floor 39, and (c) floor 73. 

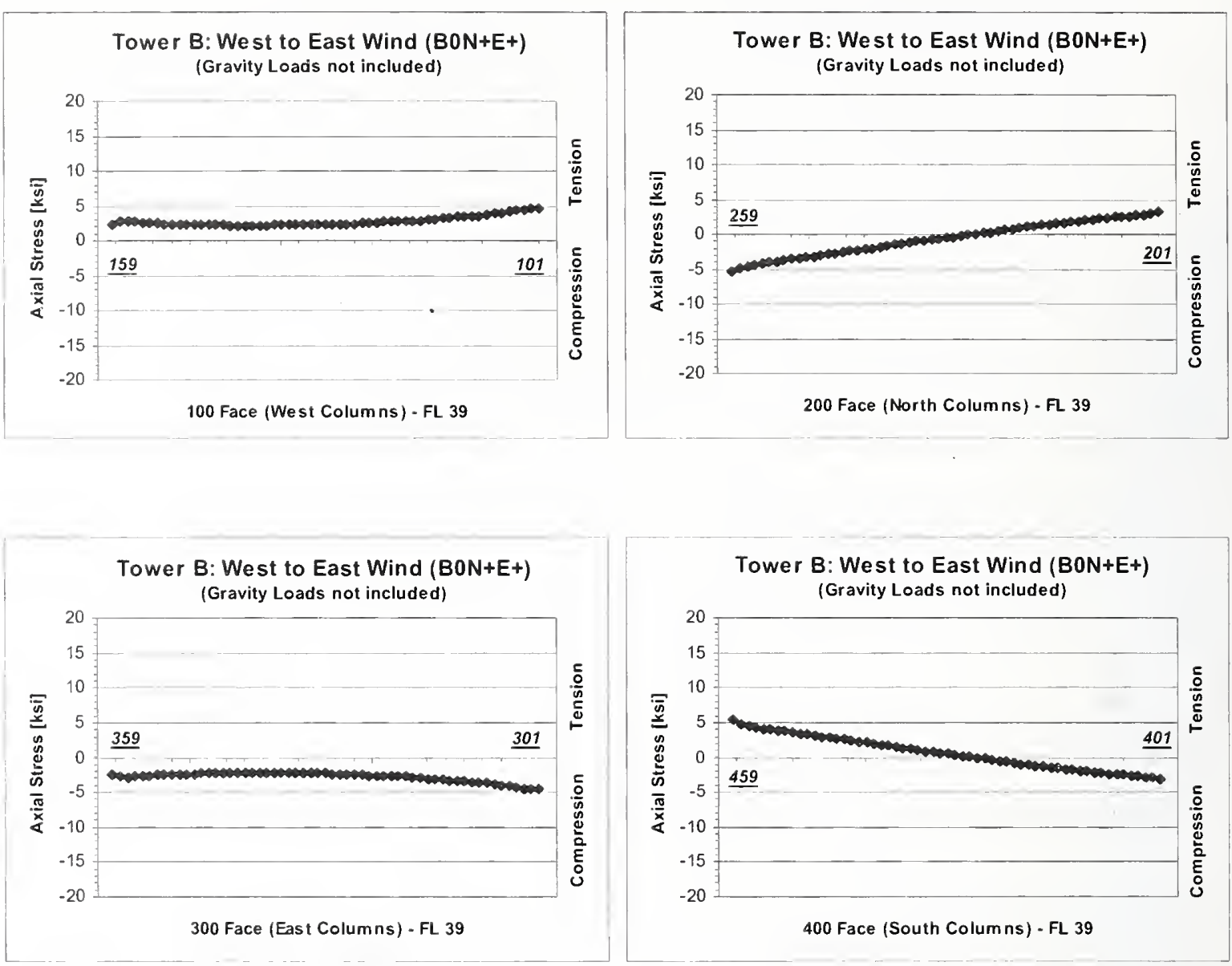

(b)

Figure 5-13. Shear lag diagrams of WTC 2 due to original WTC wind loads at (a) floor B6, (b) floor 39, and (c) floor 73 (continued). 

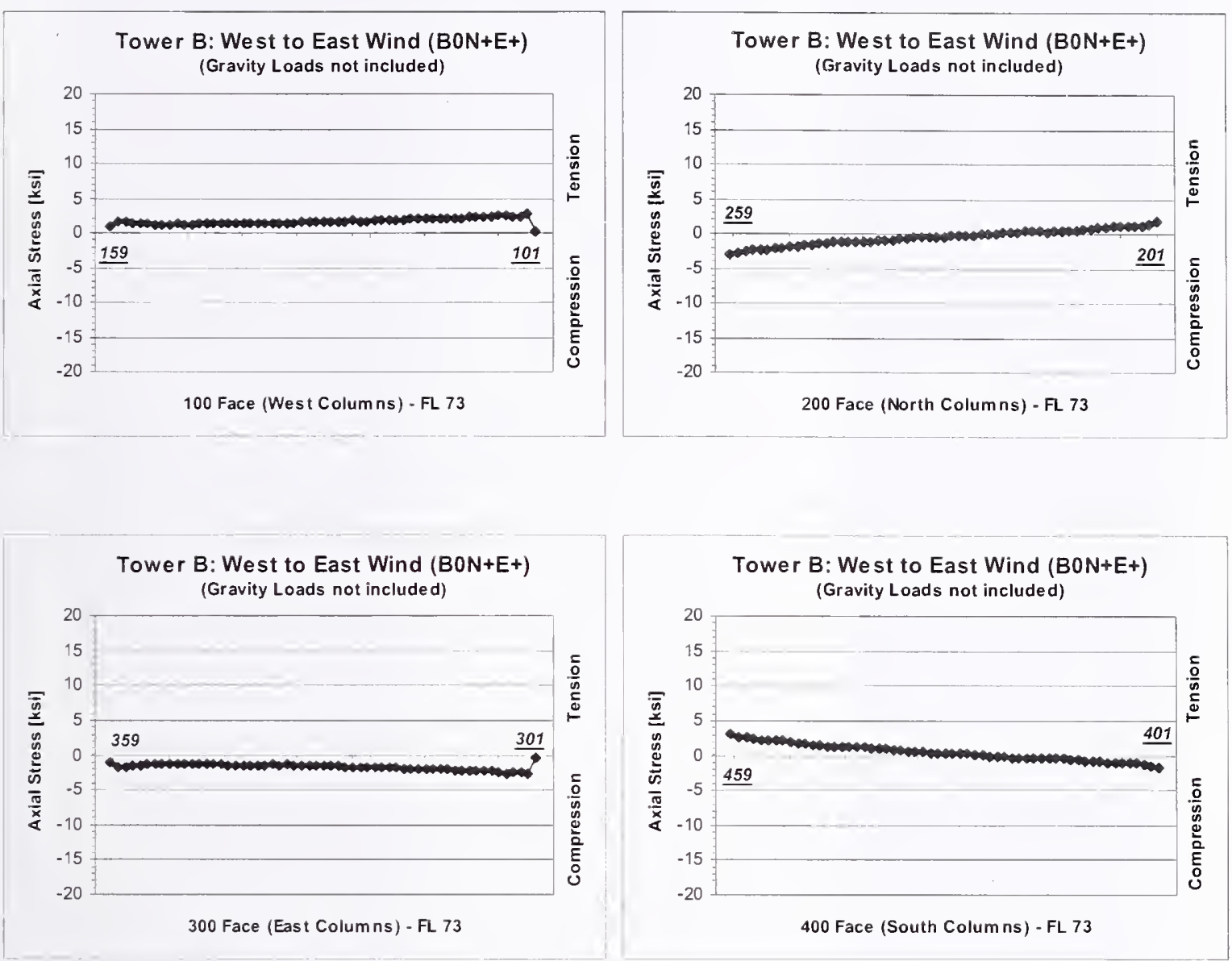

(c)

Figure 5-13. Shear lag diagrams of WTC 2 due to original WTC wind loads at (a) floor B6, (b) floor 39, and (c) floor 73 (continued). 


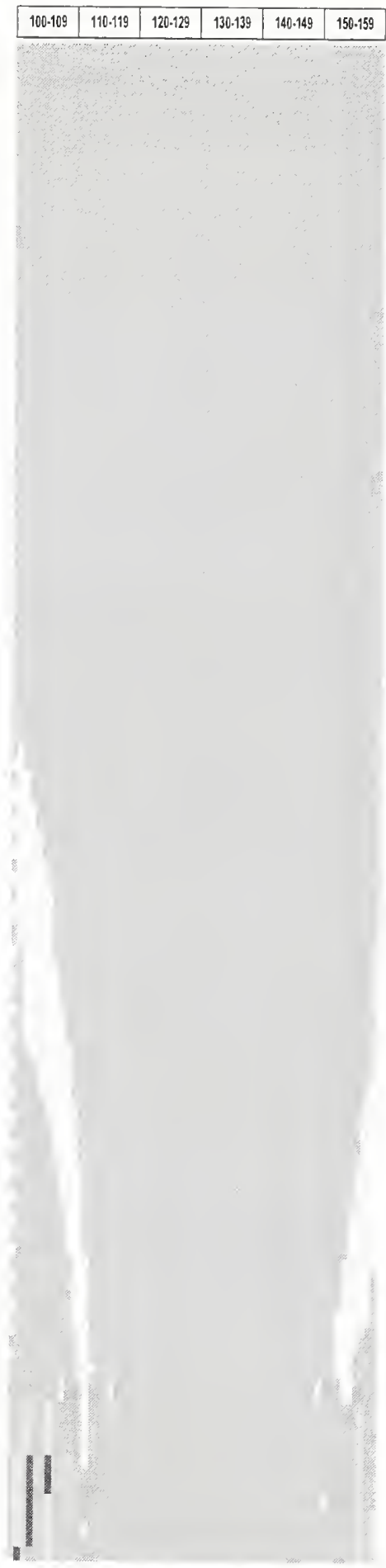

(a)

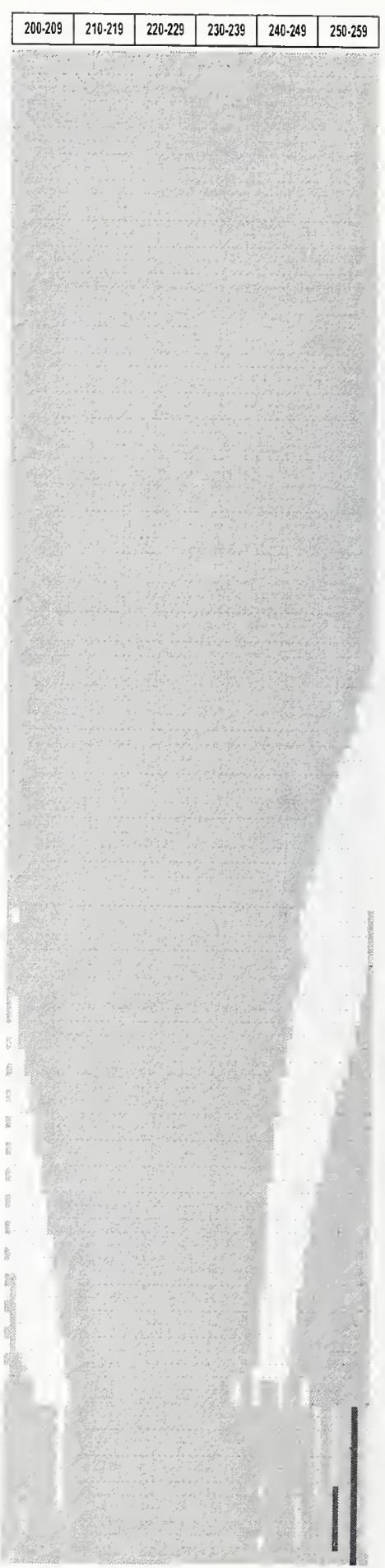

(b)

\begin{tabular}{|l|l|l|l|l|l|}
\hline & 9 & 100 & 500 & 1000 & 2500 \\
\hline
\end{tabular}

Figure 5-14. Tension force distribution (kip) in the exterior wall columns of WTC 2 under original design dead and wind loads, (a) 100 face (west) and (b) 200 face (north). 

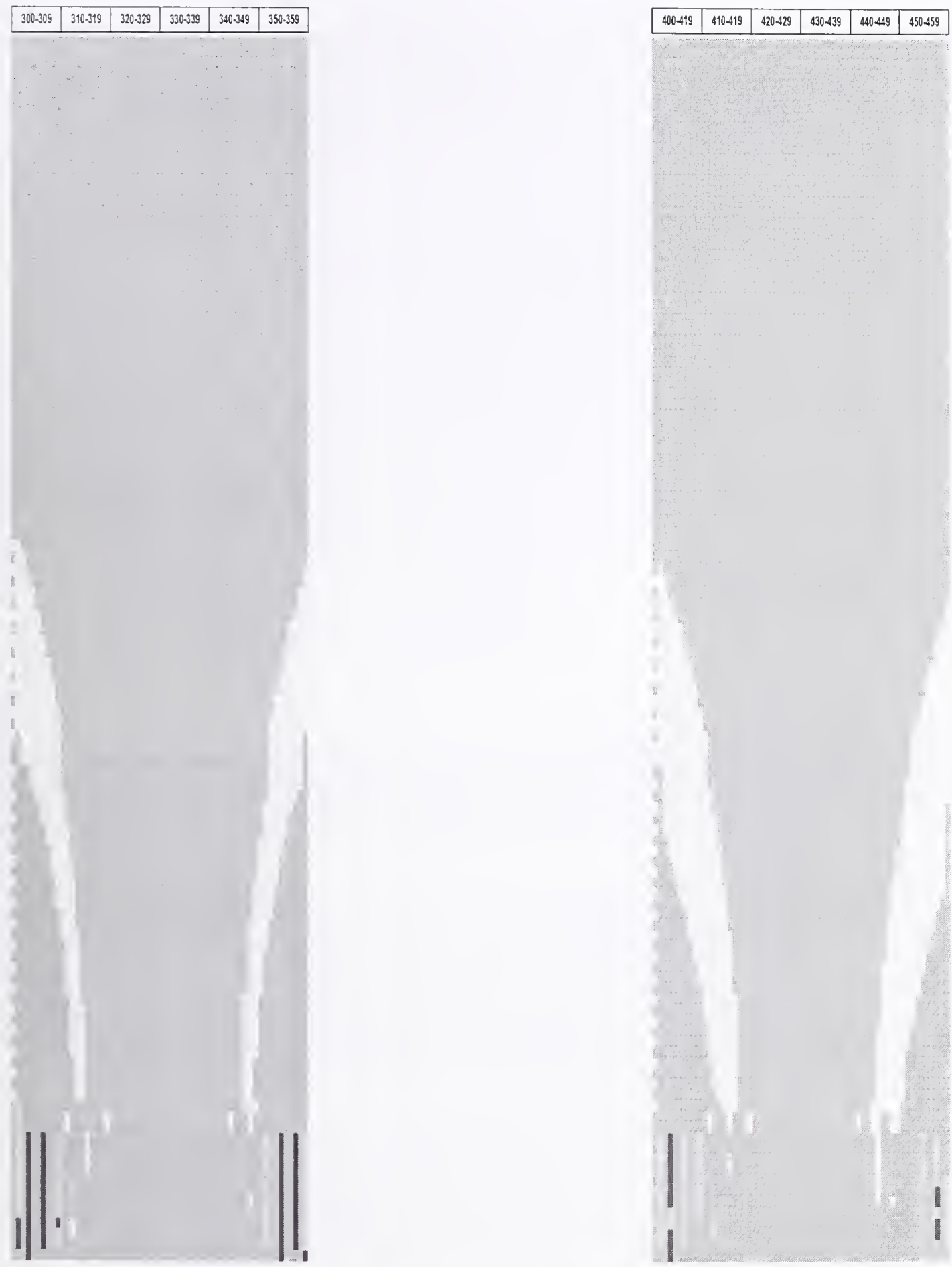

(c)

(d)

\begin{tabular}{|l|l|l|l|l|l|l|}
\hline & 0 & 100 & & 500 & 1000 & 2500 \\
\hline
\end{tabular}

Figure 5-14. (c) 300 face (east) and (d) 400 face (south) (continued). 

Table 5-6. Maximum calculated demand/capacity ratios (DCRs) for exterior wall column
splices for WTC 2 under original design dead and wind load case.

\begin{tabular}{|c|c|c|}
\hline $\begin{array}{c}\text { Exterior } \\
\text { Wall Face }\end{array}$ & $\begin{array}{l}\text { Exterior Wall } \\
\text { Column Splice }\end{array}$ & $\begin{array}{l}\text { Maximum } \\
\text { Calculated DCR }\end{array}$ \\
\hline $\begin{array}{l}100 \text { Face } \\
\text { (West) }\end{array}$ & $\begin{array}{l}\text { Below floor } 1 \\
\text { Floor } 1 \text { to } 9 \\
\text { Floor } 10 \text { to } 41 \\
\text { Above floor } 42\end{array}$ & $\begin{array}{l}0.64 \\
0.25 \\
0.83 \\
0.10\end{array}$ \\
\hline $\begin{array}{l}200 \text { Face } \\
\text { (North) }\end{array}$ & $\begin{array}{l}\text { Below floor } 1 \\
\text { Floor } 1 \text { to } 9 \\
\text { Floor } 10 \text { to } 41 \\
\text { Above floor } 42\end{array}$ & $\begin{array}{l}0.70 \\
0.36 \\
0.99 \\
0.13\end{array}$ \\
\hline $\begin{array}{l}300 \text { Face } \\
\text { (East) }\end{array}$ & $\begin{array}{l}\text { Below floor } 1 \\
\text { Floor } 1 \text { to } 9 \\
\text { Floor } 10 \text { to } 41 \\
\text { Above floor } 42\end{array}$ & $\begin{array}{l}0.75 \\
0.35 \\
0.96 \\
0.16\end{array}$ \\
\hline $\begin{array}{l}400 \text { Face } \\
\text { (South) }\end{array}$ & $\begin{array}{l}\text { Below floor } 1 \\
\text { Floor } 1 \text { to } 9 \\
\text { Floor } 10 \text { to } 41 \\
\text { Above floor } 42\end{array}$ & $\begin{array}{l}0.60 \\
0.33 \\
0.84 \\
0.21\end{array}$ \\
\hline
\end{tabular}

\subsubsection{State-of-the-Practice Case}

The WTC 2 global model was analyzed using the lower estimate, state-of-the-practice loading case, as described in Chapter 4 (see also NIST NCSTAR 1-2). This loading case included dead loads, live loads according to the NYCBC 2001, and wind loads from RWDI wind tunnel study, scaled in accordance with the NYCBC 2001 wind speed.

The calculated total drift of WTC 2 induced by the lower estimate, state-of-the-practice case was approximately $59.7 \mathrm{in}$. (4 ft $11.7 \mathrm{in}$.) in the E-W direction and $55.9 \mathrm{in}$. (4 ft $8.1 \mathrm{in}$.) in the $\mathrm{N}-\mathrm{S}$ direction. These drifts are equivalent to about $\mathrm{H} / 287$ and $\mathrm{H} / 307$ in the $\mathrm{E}-\mathrm{W}$ and $\mathrm{N}-\mathrm{S}$ directions, respectively. Figure 5-15 presents the deflected shape (cumulative drift) and the inter-story drifts normalized by the story height for WTC 2 under the lower estimate, state-of-the-practice case. The plots are presented for the $\mathrm{E}-\mathrm{W}$ and $\mathrm{N}-\mathrm{S}$ directions for the load combinations producing the maximum cumulative drift.

DCR statistics for WTC 2 global systems components under the lower estimate, state-of-the-practice loading case are summarized in Table 5-7. A comparison of the mean values of the DCRs estimated from the original design case (Table 5-5) with those from the state-of-the-practice case (Table 5-7) indicated that the results are very similar. Also the distribution of the DCRs and the locations of members with DCRs greater than 1.0 were very similar between the original design case and the state-of-thepractice case. 

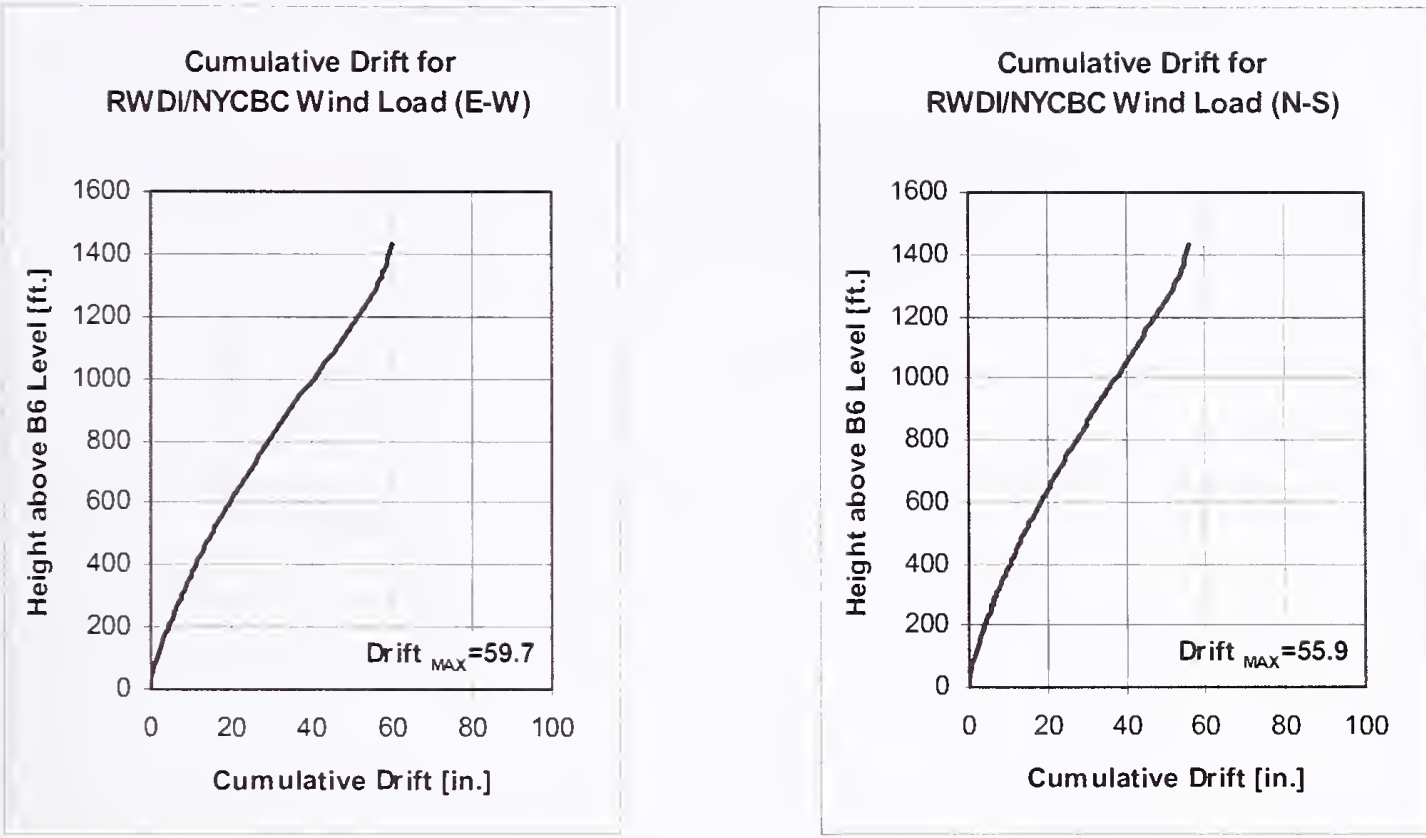

Interstory Drift/Story Height for

RWDI/NYCBC Wind Load (E-W)

\section{Interstory Drift/Story Height for \\ RWDI/NYCBC Wind Load (N-S)}

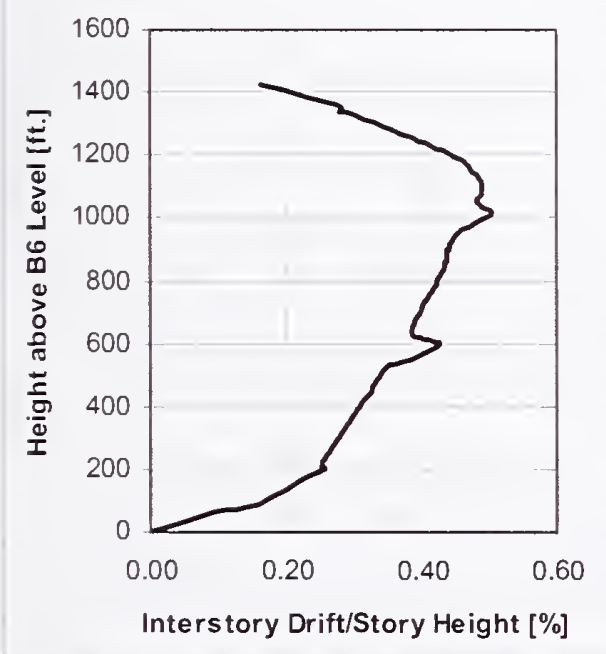

(a)

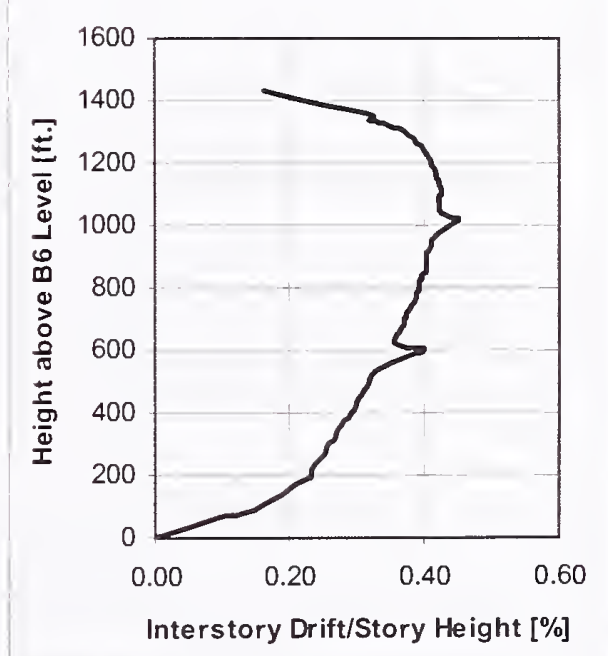

(b)

Figure 5-15. Drift diagrams of WTC 2 due to the lower estimate, state-of-the-practice case, (a) 2R4PDN and (b) 2R11PDN. 
Table 5-7. Statistics of demand/capacity ratios (DCRs) for WTC 2 under the lower estimate, state-of-the practice case.

\begin{tabular}{|c|c|c|c|c|c|c|c|}
\hline Member Type & $\begin{array}{c}\text { Number of } \\
\text { Members }\end{array}$ & $\begin{array}{c}\text { Mean } \\
\text { Calculated } \\
\text { DCR }\end{array}$ & $\begin{array}{l}\text { C.O.V. } \\
\text { of DCR }\end{array}$ & $\begin{array}{c}\text { Percentage } \\
\text { of } \\
\text { Components } \\
\text { with DCR } \\
>1.0\end{array}$ & $\begin{array}{c}\text { Percentage } \\
\text { of } \\
\text { Components } \\
\text { with DCR } \\
>1.05 \\
\end{array}$ & $\begin{array}{l}\text { Number of } \\
\text { Components } \\
\text { with DCR } \\
>1.05\end{array}$ & $\begin{array}{c}\text { Maximum } \\
\text { Calculated } \\
\text { DCR }\end{array}$ \\
\hline \multicolumn{8}{|l|}{$\begin{array}{l}\text { Exterior Wall } \\
\text { Columns }\end{array}$} \\
\hline Below floor 1 & 577 & 0.70 & 0.20 & 3.1 & 1.4 & 8 & 1.30 \\
\hline Floor 1 to 9 & 1,122 & 0.72 & 0.26 & 2.2 & 1.1 & 12 & 1.16 \\
\hline Floor 9 to 106 & 31,086 & 0.77 & 0.13 & 1.8 & 0.6 & 189 & 1.21 \\
\hline Above floor 106 & 578 & 0.71 & 0.30 & 8.7 & 5.4 & 31 & 1.40 \\
\hline \multicolumn{8}{|l|}{$\begin{array}{l}\text { Exterior Wall } \\
\text { Spandrels }\end{array}$} \\
\hline Below floor 1 & 408 & 0.45 & 0.47 & 1.7 & 0.7 & 3 & 1.15 \\
\hline Floor 1 to 9 & 594 & 0.37 & 0.44 & 0.7 & 0.7 & 4 & 1.19 \\
\hline Floor 9 to 106 & 31,160 & 0.31 & 0.27 & 0 & 0 & 0 & 0.73 \\
\hline Above floor 106 & 836 & 0.33 & 0.70 & 1.7 & 1.4 & 12 & 1.47 \\
\hline Core Columns & 5.245 & 0.86 & 0.15 & 10.8 & 6.6 & 345 & 1.36 \\
\hline \multicolumn{8}{|l|}{ Hat Truss System } \\
\hline Columns & 238 & 0.48 & 0.57 & 3.8 & 2.5 & 6 & 1.35 \\
\hline Beams & 504 & 0.23 & 0.82 & 0.2 & 0 & 0 & 1.01 \\
\hline Braces & 283 & 0.40 & 0.57 & 0.7 & 0 & 0 & 1.04 \\
\hline \multicolumn{8}{|l|}{$\begin{array}{l}\text { Exterior Wall } \\
\text { Bracing }\end{array}$} \\
\hline Below floor 1 & 227 & 0.69 & 0.17 & 0.9 & 0.4 & 1 & 1.13 \\
\hline Above floor 106 & 12 & 0.27 & 0.31 & 0 & 0 & 0 & 0.41 \\
\hline
\end{tabular}

\subsubsection{The Refined NIST Estimate Case}

The WTC 2 global model was analyzed using the refined NIST estimate case as described in Chapter 4 (see also NIST NCSTAR 1-2). This loading case included dead loads, live loads in accordance with the current ASCE 7-02 Standard, and wind loads developed by NIST based on critical assessment of information obtained from RWDI and CPP reports and state-of-the-art considerations in wind engineering.

The calculated total drift of WTC 2 induced by the refined NIST estimate case was approximately 75.6 in. ( $6 \mathrm{ft} 3.6 \mathrm{in}$.) in the $\mathrm{E}-\mathrm{W}$ direction and $70.8 \mathrm{in} .(5 \mathrm{ft} 11 \mathrm{in}$.) in the $\mathrm{N}-\mathrm{S}$ direction. These drifts are equivalent to about $\mathrm{H} / 227$ and $\mathrm{H} / 242$ in the $\mathrm{E}-\mathrm{W}$ and $\mathrm{N}-\mathrm{S}$ directions, respectively. Fig. 5-16 presents the deflected shape (cumulative drift) and the inter-story drifts normalized by the story height for WTC 2 under the refined NIST wind loads. The plots are presented for the E-W and N-S directions for the load combinations producing the maximum cumulative drift. 


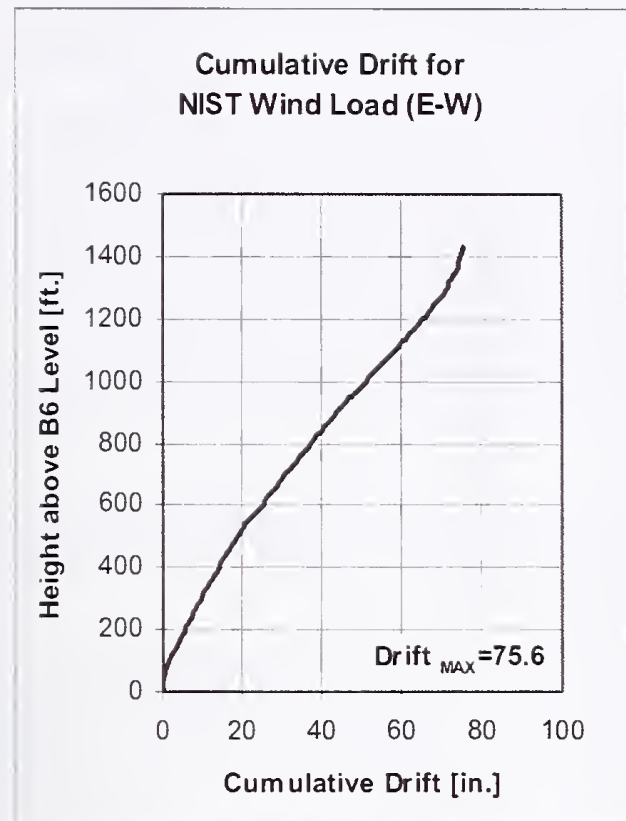

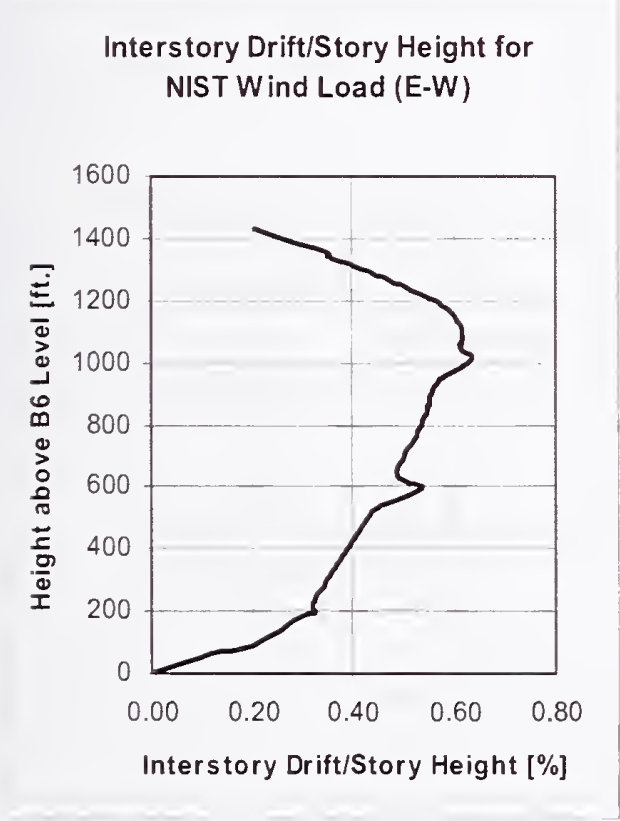

(a)

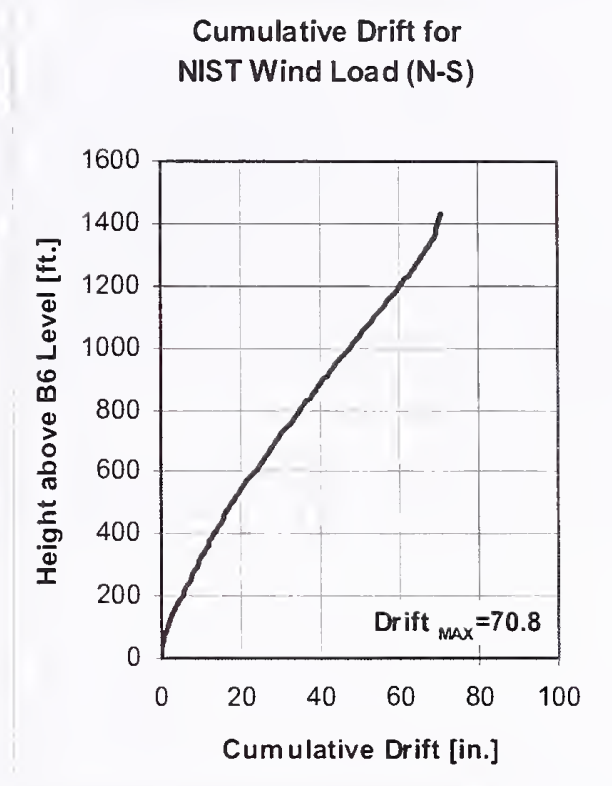

Cumulative Drift for NIST Wind Load (N-S)

Interstory Drift/Story Height for NIST W ind Load (N-S)

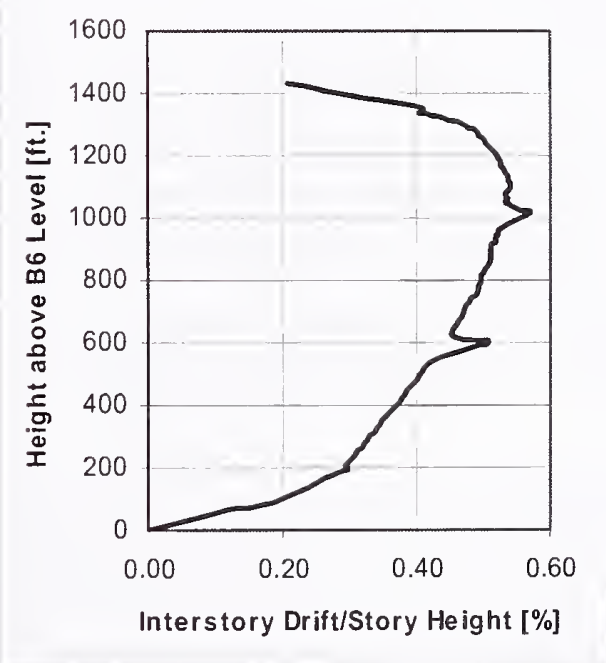

(b)

Figure 5-16. Drift diagrams of WTC 2 due to refined NIST estimate wind loads, (a) 2R4PD and (b) 2R11PD. 
DCR statistics for WTC 2 global systems components under the refined NIST estimate case are summarized in Table 5-8. The DCRs for the core columns and hat truss members estimated from the original design and the state-of-the-practice cases (Tables 5-5 and 5-7, respectively) are generally close to those estimated from the refined NIST estimate case (Table 5-8). This is due to the fact that core columns and hat truss members do not significantly contribute to wind load resistance. The DCRs for the exterior walls, including columns, spandrels, and bracings estimated from the refined NIST estimate case are larger than those estimatcd from the original design and the state-of-the-practice cases. For example, for the exterior wall, the ratio of the mean DCRs from the refined NIST estimate case to the mean DCRs from the original design case ranged between 1.60 and 1.11. The ratio of the mean DCRs from the refined NIST estimate case to the mean DCRs from the lower estimate, state-of-the-practice case ranged between 1.65 and 1.17 .

Table 5-8. Statistics of demand/capacity ratios (DCRs) for WTC 2 under the refined NIST estimate case.

\begin{tabular}{|c|c|c|c|c|c|c|c|}
\hline Member Type & $\begin{array}{l}\text { Number } \\
\text { of } \\
\text { Members }\end{array}$ & $\begin{array}{c}\text { Mean } \\
\text { Calculated } \\
\text { DCR }\end{array}$ & $\begin{array}{l}\text { C.O.V. } \\
\text { of DCR }\end{array}$ & $\begin{array}{c}\text { Percentage } \\
\text { of } \\
\text { Components } \\
\text { with DCR } \\
>1.0\end{array}$ & $\begin{array}{c}\text { Percentage } \\
\text { of } \\
\text { Components } \\
\text { with DCR } \\
>1.05\end{array}$ & $\begin{array}{l}\text { Number of } \\
\text { Components } \\
\text { with DCR } \\
>1.05\end{array}$ & $\begin{array}{c}\text { Maximum } \\
\text { Calculated } \\
\text { DCR }\end{array}$ \\
\hline \multicolumn{8}{|l|}{$\begin{array}{l}\text { Exterior Wall } \\
\text { Columns }\end{array}$} \\
\hline Below floor 1 & 577 & 0.96 & 0.25 & 42 & 41.1 & 229 & 1.95 \\
\hline Floor 1 to 9 & 1,122 & 1.04 & 0.27 & 63.7 & 58.0 & 651 & 1.69 \\
\hline Floor 9 to 106 & 31,086 & 1.09 & 0.14 & 73.5 & 60.9 & 18,941 & 1.78 \\
\hline Above floor 106 & 578 & 0.83 & 0.28 & 19.6 & 15.1 & 87 & 1.66 \\
\hline \multicolumn{8}{|l|}{$\begin{array}{l}\text { Exterior Wall } \\
\text { Spandrels }\end{array}$} \\
\hline Below floor 1 & 408 & 0.73 & 0.46 & 15.9 & 13.7 & 56 & 1.78 \\
\hline Floor 1 to 9 & 594 & 0.61 & 0.44 & 7.7 & 5.2 & 31 & 2.02 \\
\hline Floor 9 to 106 & 31,160 & 0.51 & 0.28 & 0.4 & 0.2 & 61 & 1.21 \\
\hline Above floor 106 & 836 & 0.39 & 0.68 & 2.0 & 1.9 & 16 & 1.73 \\
\hline Core Columns & 5.245 & 0.83 & 0.16 & 10.6 & 6.0 & 315 & 1.42 \\
\hline \multicolumn{8}{|l|}{ Hat Truss System } \\
\hline Columns & 238 & 0.59 & 0.59 & 14.3 & 10.5 & 25 & 1.95 \\
\hline Beams & 504 & 0.28 & 0.82 & 1.0 & 0.8 & 4 & 1.12 \\
\hline Braces & 283 & 0.49 & 0.52 & 3.9 & 2.8 & 8 & 1.09 \\
\hline \multicolumn{8}{|l|}{$\begin{array}{l}\text { Exterior Wall } \\
\text { Bracing }\end{array}$} \\
\hline Below floor 1 & 227 & 1.01 & 0.18 & 48.0 & 38.8 & 88 & 1.04 \\
\hline Above floor 106 & 12 & 0.43 & 0.31 & 0 & 0 & 0 & 0.64 \\
\hline
\end{tabular}

\subsection{SUMMARY}

This chapter presented the results of the baseline performance analysis for the WTC 1 and WTC 2 global models under three gravity and wind loading cases: (1) the original WTC design load case, (2) the lowerestimate, state-of-the-practices case, and (3) the refined NIST estimate case. The baseline performance 
results included total and inter-story drift, demand/capacity ratios, exterior columns behavior (shear lag effects and presence of tensile forces), behavior of exterior wall splice connections, and the towers' resistance to shear sliding and overturning.

Under the original WTC design loads, the cumulative drifts at the top of the WTC 1 tower were about 56.6 in. $(\mathrm{H} / 304)$ and 55.7 in. $(\mathrm{H} / 309)$ in the $\mathrm{E}-\mathrm{W}$ and $\mathrm{N}-\mathrm{S}$ direction, respectively. These drifts were about 51.2 in. $(\mathrm{H} / 335)$ in the $\mathrm{E}-\mathrm{W}$ direction and $65.3 \mathrm{in} .(\mathrm{H} / 263)$ in the $\mathrm{N}-\mathrm{S}$ direction for WTC 2. For the lower estimate, state-of-the-practice case, the drifts for WTC 1 were larger than those from the original design case by about 0.5 percent and 22 percent for the E-W and N-S directions, respectively. For the lower estimate, state-of-the-practice case for WTC 2, the E-W drift was larger than that from the original design case by about 16 percent, while the N-S drift was smaller by about 15 percent. These differences are consistent with the differences between the base shears for the two cases (see Tables 4-3 and 4-4 of Chapter 4). The drifts obtained from the refined NIST estimate case were about 25 percent larger than those from the state-of-the practice case.

The demand/capacity ratios (DCR) were based on the allowable stress design procedure and were estimated using the AISC Specifications (1989). The results indicated that DCRs estimated from the original WTC design load case were, in general. close to those obtained for the lower estimate, state-ofthe practice case. For both cases, a small fraction of structural components had DCRs larger than 1.0. These were mainly observed in both towers at (1) the exterior walls: at the columns around the corners, where the hat truss connected to the exterior walls, and below floor 9; and (2) the core columns on the 600 line between floors 80 and 106 and at core perimeter columns 901 and 908 for much of their height.

The DCRs obtained for the refined NIST estimate case were higher than those from the original WTC design and the lower estimate, state-of-the-practice load cases, owing to the following rcasons:

- The NIST estimated wind loads were higher than those used in the lower estimate, state-ofthe-practice case by about 25 percent (about 10 percent difference between the RWDI loads scaled to the NYCBC 2001 wind spced and RWDI loads scaled to the ASCE 7-02 wind speed, in addition to the 15 percent increase estimated by NIST, see Sec. 4.4.3). It is noted that the NIST estimated wind loads were about 20 percent smaller than those estimated by CPP (an uppcr estimate state-of-the practice case, see Chapter 4).

- The original WTC design and the state-of-the-practice cases used NYCBC load combinations, which result in lower DCRs than the ASCE 7-02 load combinations used for the refined NIST case.

Under a combination of the original WTC design dead and wind loads, tension forces were developed in the exterior walls of WTC 1 and WTC 2. The forces were largest at the base of the building and at the corners. These tensile column loads were transferred from one panel to another through the column splices. The DCR ratios for the exterior wall splice connections under these tensile forces for both towers were shown to be less than 1.0 .

For the towers' resistance to shear sliding and overturning due to wind, the dead loads that acted on the perimeter walls of the towers provided resistance to shear sliding and overturning at the foundation level. Considering the resistance to shear sliding under wind load, the factor of safety was calculated to be 
between 10 and 11.5, while the factor of safety against overturning ranged from 1.9 to 2.7 for both towers.

\section{$5.6 \quad$ REFERENCES}

AISC Specification 1989: American Institute of Steel Construction, Specification for Structural Steel Buildings - Allowable Stress Design and Plastic Design $-9^{\text {th }}$ Edition, Chicago, IL, 1989.

ASCE 7-02: American Society of Civil Engineers, ASCE 7 Standard Minimum Design Loads for Buildings and Other Structures, Reston, VA, 2002.

NYCBC 2001: Building Code of the City of New York, 2001 Edition, Gould Publications, Binghamton, NY. 


\section{Chapter 6 \\ Baseline Performance Analysis of Typical Floor Models}

\section{$6.1 \quad$ INTRODUCTION}

This chapter presents the results of the baseline performance analysis for the typical floor models discussed in Chapter 3. These models included the typical truss-framed floor (floor 96 of World Trade Center [WTC] 1, see Sec. 3.3) and the typical beam-framed floor (floor 75 of WTC 2, see Sec. 3.4).

For application to the floor models, gravity loads were separated into three categories: construction dead loads (CDL), superimposed dead loads (SDL), and live loads (LL). CDL is defined as the self-weight of the structural system. The self-weight of the floor trusses, floor beams, and concrete slabs were automatically generated in SAP2000. SDL is defined as the added dead load associated with architectural and mechanical/electrical/plumbing systems (curtain wall, floor finishes, mechanical equipment and ducts, transformers, etc.) The CDL and SDL were based on the WTC architectural and structural drawings and on the original WTC Design Criteria.

Two independent sets of live loads were applied in combination with the dead loads. The first was taken from the original WTC Design Criteria and the second from the American Society of Civil Engineers (ASCE 7-02) Standard. The live loads in the New York City Building Code (NYCBC 2001) are essentially identical to the American Society of Civil Engineers (ASCE) 7-02 live loads. Live load reductions were taken from the original WTC Design Criteria and from the ASCE 7-02 Standard, each for use with its respective live loads.

For the baseline performance analysis for the floor systems, demand/capacity ratios (DCRs) for structural components were estimated using the Allowable Stress Design (ASD) procedure as specified in the American Institute of Steel Construction (AISC) Specification (1989), see Chapter 5. The DCRs were calculated by dividing component demands by component capacities, taken at unfactored (working) loads and at working stresses, not at ultimate loads or yield stresses. These DCRs for the structural components were determined as follows:

1. The component demands were taken from the results of the baseline performance analysis using the reference floor models, making use of working loads.

2. The component capacities were determined based on the nominal steel strength as specified in the original design documents and using the AISC Specification (1989).

This chapter reports on the results of the baseline performance analysis for the floor systems under gravity loading. Sections 6.2 and 6.3 present the loading and baseline performance analysis results for the trussframed floor and the beam-framed floor, respectively. 


\subsection{TYPICAL TRUSS-FRAMED FLOOR}

The analysis of the typical truss-framed floor was performed on the computer model of floor 96 of WTC 1 (see Sec. 3.3). This section describes the gravity loads applied to the model along with the results of the baseline performance analysis.

\subsubsection{Gravity Loads}

\section{Areas Outside Core}

The CDL was calculated based on the member's geometry and material properties. The SDL allowance was typically 11.5 psf to 13.5 psf outside the core. Figure 6-1 shows the WTC Design Criteria reduced live load for the floor design. Table 6-1 provides a comparison between the live loads from the WTC Design Criteria, NYCBC 2001, and the ASCE 7-02 Standard.

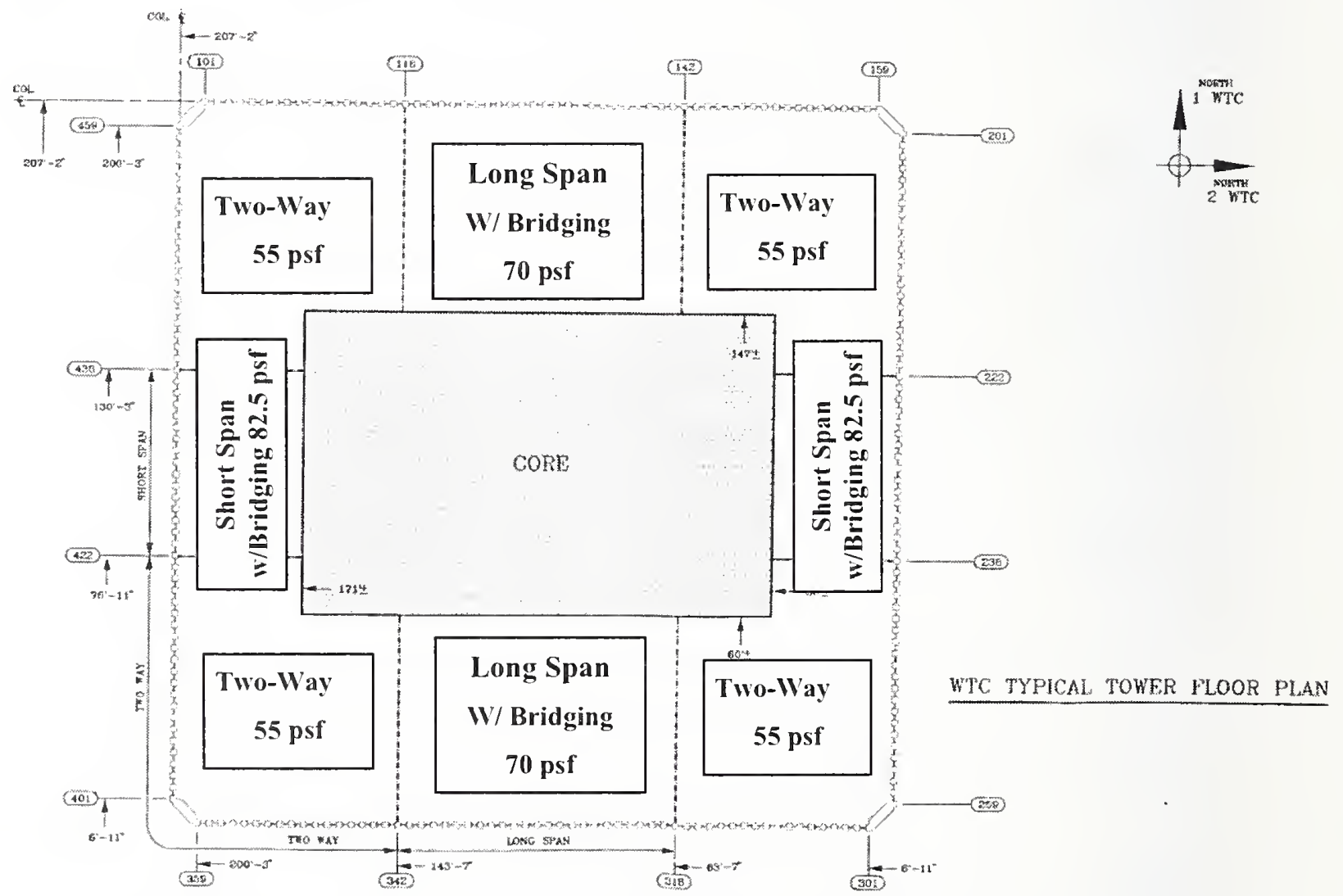

Source: Reproduced with permission of The Port Authority of New York and New Jersey. Enhanced by NIST.

Figure 6-1. Summary of WTC-design criteria reduced live loads for floor design: design load of 100 psf - partition load is included in LL allowance. 
Table 6-1. Summary of typical truss-framed floor live loads and (reduced live loads) for areas outside of core.

\begin{tabular}{|l|c|c|c|c|c|}
\hline \multicolumn{1}{|c|}{ Criteria } & Design & Two-Way Zone & Long Span & Short Span & Partition \\
\hline WTC Design Criteria & Floor & $100 \mathrm{psf}(55 \mathrm{psf})$ & $100 \mathrm{psf}(70 \mathrm{psf})$ & $100 \mathrm{psf}(82.5 \mathrm{psf})$ & Included in LL \\
\hline NYC Building Code & Floor & $50 \mathrm{psf}(25 \mathrm{psf})$ & $50 \mathrm{psf}(39 \mathrm{psf})$ & $50 \mathrm{psf}(47 \mathrm{psf})$ & $6 \mathrm{psf}$ \\
\hline ASCE 7-02 & Floor & $50 \mathrm{psf}(25 \mathrm{psf})$ & $50 \mathrm{psf}(39 \mathrm{psf})$ & $50 \mathrm{psf}(47 \mathrm{psf})$ & $6 \mathrm{psf}$ \\
\hline
\end{tabular}

\section{Areas Inside Core}

Table 6-2 shows the CDL and SDL used inside the core area along with the live loads from the WTC Design Criteria. NYCBC 2001, and the ASCE 7-02 Standard. Loads are shown for the various occupancies within the core area.

Table 6-2. Area inside core: loading floor 96, WTC 1.

\begin{tabular}{|c|c|c|c|c|c|}
\hline \multirow[b]{3}{*}{ Area } & \multirow[b]{3}{*}{ CDL } & \multicolumn{3}{|c|}{ Loading (psf) } & \\
\hline & & & \multicolumn{3}{|c|}{ Live Load for Floor Design } \\
\hline & & SDL & $\begin{array}{l}\text { WTC Design } \\
\text { Criteria }\end{array}$ & $\begin{array}{c}\text { ASCE } \\
7-02\end{array}$ & NYCBC 2001 \\
\hline Tenant Space & \multirow{5}{*}{$\begin{array}{c}\text { Varies } \\
\text { See Original } \\
\text { Structural } \\
\text { Drawings }\end{array}$} & 33 & 100 & 50 & 50 \\
\hline Toilets & & 49 & 40 & 40 & 40 \\
\hline Stair, Serice, Closet & & 29 & 100 & 100 & 100 \\
\hline Elerator Lobby, Corridor & & 41 & 75 & 80 & 80 \\
\hline Telephone. Electric Closet & & 29 & 75 & 75 & 75 \\
\hline
\end{tabular}

\subsubsection{Results of Baseline Analysis}

The maximum mid-span deflections for each of the long-span, short-span, and two-way zones for the original WTC Design Criteria and ASCE 7-02 total loads are provided in Table 6-3.

Table 6-3. Summary of maximum deflections for typical truss-framed floor under DL + LL for areas outside of core.

\begin{tabular}{|c|c|c|c|}
\hline Criteria & Two-Way Zone & Long Span & Short Span \\
\hline WTC Design Criteria & $1.44 \mathrm{in.}$ & $1.79 \mathrm{in.}$ & $0.57 \mathrm{in.}$ \\
\hline NYCBC ASCE 7-02 & $1.14 \mathrm{in.}$ & $1.43 \mathrm{in.}$ & $0.44 \mathrm{in.}$ \\
\hline
\end{tabular}

For the components of the truss-framed floors, DCRs were calculated using the SAP2000 program. Calculations were made for the top and bottom chords, the diagonals and the verticals of the primary and bridging trusses, and for the beams and girders of the core. Since the top chords consisted of a pair of steel angles plus the concrete slab, the capacity of the concrete slab predominated and was much greater than the capacity of the top chord; therefore, a calculation of the stress in the slab seemed irrelevant and would have required significant intervention to SAP's post-processor to establish a proper design calculation. 
DCRs were not calculated for the following elements in this computer model:

- Strap elements

- Damper elements

- Frame connections assigned as "plate" elements and similar connectors

- Rigid links

- Core columns, spandrels, and exterior columns

- Deck support angles

- Core perimeter channel members within close proximity to supports

The calculations were spot checked for accuracy and to verify that the correct design information was applied. For most of the component calculations checked, the standard SAP2000-generated calculations were found to be acceptable; however, for some components, the computer model did not accurately represent the actual construction, and for other components, the standard SAP2000 calculations yielded erroneous results. As a result, for estimating the DCRs of the structural components, the following adjustments to the design parameters were applied to the floor model to yield accurate results:

- Length factors were assigned to truss web members to reflect the length of the actual constructed member. For example, in the model, to account for the participation of the composite slab, the distance between the top and bottom chord of the primary floor trusses was taken as $30 \mathrm{in}$. However, this distance was actually $28 \mathrm{in}$. Therefore, a length modifier was applied to the primary truss diagonals to account for the actual length of the diagonal. In general, the length modifier was determined by measuring the diagonal distance from the underside of the top chord to the centerline of the bottom chord (see Fig. 6-2).

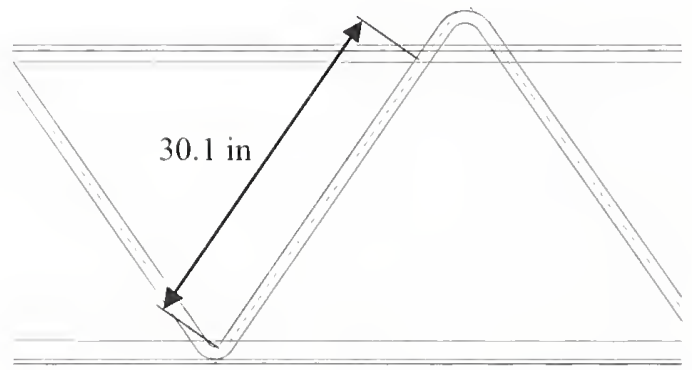

Theoretical unbraced length $=30.1$ inches, measured from the face of top chord to the centerline of the bottom chord.

The unbraced length is adjusted in the SAP2000 computer model by a factor of $30.1^{\prime \prime} / 36.0^{\prime \prime}=0.84$

Figure 6-2. Unbraced length of truss diagonal.

- Significant out-of-plane bending is not expected in the members of planar trusses subjected to concentric vertical loading. However, due to the complexity of the floor model, significant out-of-plane (i.e., minor axis) bending moments were observed in some truss diagonals and bottom chord members. As a result, the allowable minor axis bending stress was substantially increased to effectively eliminate these bending moments from the DCR calculation. 
- The allowable shear stress for truss diagonals with additional bar reinforcement was substantially increased since for these members, the SAP2000 program computed an erroneous shear area.

For the area outside the core, the DCRs for all floor trusses were less than 1.14 for the original WTC Design Criteria and less than 0.86 for the ASCE 7-02 loading and (by comparison) for the NYCBC 2001 loading. Under the original WTC Design Criteria loading, the DCR was less than 1.00 for 99.4 percent of the floor truss components. For the core area, the DCRs for all floor beams inside the core were less than 1.08 and more than 99 percent had a DCR of less than 1.0.

DCR statistics for the truss-framed floor model are summarized in Table 6-4 for the original design loading case and in Table 6-5 for the ASCE 7-02 loading case. For the area outside the core, the average ratio of the DCRs estimated from the ASCE 7-02 loading to the DCRs from the original WTC Design Criteria loading for all floor trusses was about 0.80 .

Table 6-4. Statistics of demand/capacity ratios for floor 96 under original design load case.

\begin{tabular}{|c|c|c|c|c|c|c|c|}
\hline Member Type & $\begin{array}{l}\text { Number of } \\
\text { Members }\end{array}$ & $\begin{array}{c}\text { Mean } \\
\text { Calculated } \\
\text { DCR } \\
\end{array}$ & $\begin{array}{c}\text { C.O.V. of } \\
\text { DCR }\end{array}$ & $\begin{array}{c}\text { Percentage of } \\
\text { Components } \\
\text { with DCR } \\
>1.0\end{array}$ & $\begin{array}{c}\text { Percentage of } \\
\text { Components } \\
\text { with DCR } \\
>1.05\end{array}$ & \begin{tabular}{|c|} 
Number of \\
Components \\
with DCR \\
$>1.05$ \\
\end{tabular} & $\begin{array}{c}\text { Maximum } \\
\text { Calculated } \\
\text { DCR } \\
\end{array}$ \\
\hline $\begin{array}{l}\text { One-Way Long } \\
\text { Span Zone }\end{array}$ & & & & & & & \\
\hline Web members & 1,792 & 0.44 & 0.61 & 3.7 & 1.28 & 23 & 1.14 \\
\hline $\begin{array}{l}\text { Bottom chord } \\
\text { members }\end{array}$ & 1,038 & 0.74 & 0.26 & 0 & 0 & 0 & 0.99 \\
\hline $\begin{array}{l}\text { One-Way Short } \\
\text { Span Zone }\end{array}$ & & & & & & & \\
\hline Web members & 640 & 0.33 & 0.61 & 0 & 0 & 0 & 0.92 \\
\hline $\begin{array}{l}\text { Bottom chord } \\
\text { members }\end{array}$ & 288 & 0.37 & 0.32 & 0 & 0 & 0 & 0.55 \\
\hline Two-Way Zone & & & & & & & \\
\hline Web members & 3,086 & 0.30 & 0.80 & 0.3 & 0.26 & 8 & 1.06 \\
\hline $\begin{array}{l}\text { Bottom chord } \\
\text { members }\end{array}$ & 2,035 & 0.48 & 0.54 & 0 & 0 & 0 & 0.94 \\
\hline $\begin{array}{l}\text { Bridging Trusses } \\
\text { within One-Way } \\
\text { Span Zones }\end{array}$ & & & & & & & \\
\hline Web members & 692 & 0.16 & 1.25 & 1 & 0 & 0 & 1.02 \\
\hline $\begin{array}{l}\text { Bottom chord } \\
\text { members }\end{array}$ & 327 & 0.12 & 1.33 & 0 & 0 & 0 & 0.95 \\
\hline Core Beams & & & & & & & \\
\hline Beams within core & 1,361 & 0.33 & 0.67 & 0.9 & 0.3 & 4 & 1.07 \\
\hline $\begin{array}{l}\text { Core perimeter } \\
\text { channels }\end{array}$ & 686 & 0.36 & 0.58 & 1.0 & 0.6 & 4 & 1.08 \\
\hline
\end{tabular}


Table 6-5. Statistics of demand/capacity ratios (DCRs) for floor 96 under the ASCE 7-02 loading case.

\begin{tabular}{|c|c|c|c|c|c|c|}
\hline Member Type & $\begin{array}{c}\text { Number } \\
\text { of } \\
\text { Members }\end{array}$ & $\begin{array}{c}\text { Mean } \\
\text { Calculated } \\
\text { DCR }\end{array}$ & $\begin{array}{l}\text { C.O.V. of } \\
\text { DCR }\end{array}$ & 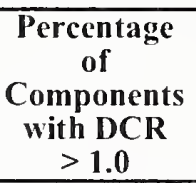 & $\begin{array}{c}\begin{array}{c}\text { Percentage } \\
\text { of }\end{array} \\
\text { Components } \\
\text { with DCR } \\
>1.05\end{array}$ & $\begin{array}{l}\text { Maximum } \\
\text { Calculated } \\
\text { DCR }\end{array}$ \\
\hline \multicolumn{7}{|l|}{$\begin{array}{l}\text { One-Way Long Span } \\
\text { Zone }\end{array}$} \\
\hline Web members & 1,792 & 0.35 & 0.60 & 0 & 0 & 0.86 \\
\hline Bottom chord members & 1,038 & 0.59 & 0.25 & 0 & 0 & 0.80 \\
\hline \multicolumn{7}{|l|}{$\begin{array}{l}\text { One-Way Short Span } \\
\text { Zone }\end{array}$} \\
\hline Web members & 640 & 0.26 & 0.65 & 0 & 0 & 0.69 \\
\hline Bottom chord members & 288 & 0.30 & 0.33 & 0 & 0 & 0.43 \\
\hline \multicolumn{7}{|l|}{ Two-Way Zone } \\
\hline Web members & 3,086 & 0.24 & 0.79 & 0 & 0 & 0.78 \\
\hline Bottom chord members & 2,035 & 0.38 & 0.55 & 0 & 0 & 0.74 \\
\hline \multicolumn{7}{|l|}{$\begin{array}{l}\text { Bridging Trusses within } \\
\text { One-Way Span Zones }\end{array}$} \\
\hline Web members & 692 & 0.11 & 1.55 & 0 & 0 & 0.95 \\
\hline Bottom chord members & 327 & 0.09 & 1.44 & 0 & 0 & 0.81 \\
\hline \multicolumn{7}{|l|}{ Core Beams } \\
\hline Beams within core & 1,361 & 0.28 & 0.64 & 0.1 & 0.1 & 1.05 \\
\hline Core perimeter channels & 686 & 0.28 & 0.61 & 0 & 0 & 0.86 \\
\hline
\end{tabular}

\subsection{TYPICAL BEAM-FRAMED FLOOR}

The analysis of the typical beam-framed floor was performed on the model of floor 75 of WTC 2 (see Sec. 3.4). This section describes the gravity loads applied to the model along with the results of the baseline performance analysis.

\subsubsection{Gravity Loads}

Comparing the live loads from the original WTC design criteria, NYCBC 2001, and the ASC E7-02 Standard for this floor, it was found that the three sets of loads were nearly identical. The only difference was that the live load for the corridor within the core was $100 \mathrm{psf}$ in the original WTC design criteria, 75 psf in NYCBC 2001, and 80 psf in ASCE 7-02. As a result, only the original WTC design criteria loads were applied to the computer model.

In the areas outside of the core, the superimposed dead load was taken from the original design criteria as $141 \mathrm{psf}$, including $75 \mathrm{psf}$ for equipment loads, and the live load was $75 \mathrm{psf}$.

Table 6-6 shows the CDL and SDL used inside the core area along with the live loads from the WTC Design Criteria, NYCBC 2001, and the ASCE 7-02 Standard. Loads are shown for the various occupancies within the core area. 
Table 6-6. Beam-framed core area: loading floor 75, WTC 2.

\begin{tabular}{|c|c|c|c|c|c|}
\hline \multirow[b]{3}{*}{ Area } & \multicolumn{5}{|c|}{ Loading (psf) } \\
\hline & \multirow[b]{2}{*}{$\mathrm{CDL}$} & \multirow[b]{2}{*}{ SDL } & \multicolumn{3}{|c|}{ Live Load for Floor Design } \\
\hline & & & WTC-DC & ASCE 7-02 & NYCBC 2001 \\
\hline Return Air Plenum & \multirow{10}{*}{$\begin{array}{c}\text { Varies } \\
\text { See Original } \\
\text { Structural } \\
\text { Drawings }\end{array}$} & 66 & 75 & 75 & 75 \\
\hline Toilets & & 66 & 40 & 40 & 40 \\
\hline Stair, Service, Closet & & 25 & 100 & 100 & 100 \\
\hline Corridor & & 66 & 100 & 80 & 75 \\
\hline Motor Generator Room & & 141 & 75 & 75 & 75 \\
\hline Pump Platform & & 141 & 75 & 75 & 75 \\
\hline Electric Sub-Station & & 141 & 75 & 75 & 75 \\
\hline Mail Room & & 141 & 75 & 75 & 75 \\
\hline Secondary Motor Room & & 141 & 75 & 75 & 75 \\
\hline Unassigned Space & & 66 & 75 & 75 & 75 \\
\hline
\end{tabular}

\subsubsection{Results of Baseline Analysis}

The maximum mid-span deflections of the long-span and short-span zones under the original WTC Design Criteria loads were approximately 1.55 in. and 0.70 in., respectively.

Using the SAP2000 computer program. DCRs were calculated for the components of the floor framing. The calculations were spot checked for accuracy and to verify that the correct design information was being applied. For most of the component calculations checked, the SAP2000 calculations were found to be acceptable.

DCRs were not calculated for the bridging members and anchor straps as they were not a part of the primary floor framing system. Also, DCRs were not calculated for the spandrels and columns as their DCRs were calculated in the global systems computer models.

Except for the two $30 \mathrm{WF} 116$ beams running in the east-west direction and cantilevering from the core columns 501 and 508 (see Fig. 6-3), the DCRs for all beam-framed floor components were less than 1.0 for the original WTC design criteria loading. For the two beams cited above, the DCRs from the axial load and moment interaction equation were less than 1.0, while the shear DCRs were 1.125 and 1.09 . These shear DCRs occurred in the section of the $30 \mathrm{WF} 116$ beams located near the support between beam $30 \times 10 \frac{1}{2} \mathrm{WF}^{3}$ and the centerline of the column.

3 This beam designation was used in original contract drawings to indicate a 30 in. deep wide flange beam with cover plates and is used here for consistency. 


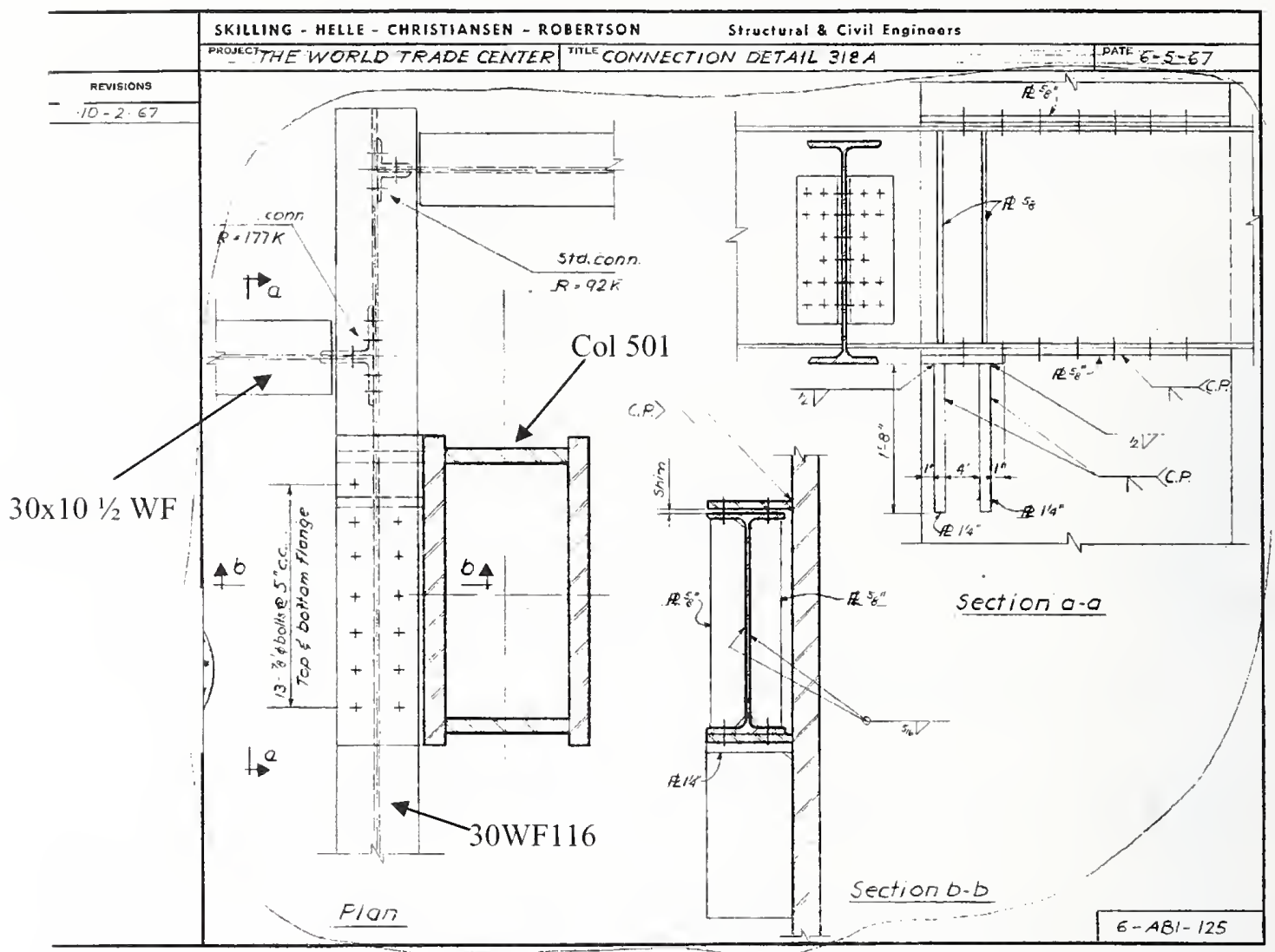

Source: Drawing reproduced with permission of The Port Authority of New York and New Jersey. Enhanced by NIST.

Figure 6-3. Connection detail for beam 30WF116, floor 75 of WTC 2.

Figure 6-4 shows the distribution of DCRs for the floor framing. The figure shows the location of the two beams with DCR greater than 1.0. DCR statistics for the beam-framed floor model are summarized in Table 6-7 for the original design loading case. The statistics are provided for member groups that are shown in Fig. 6-5. 

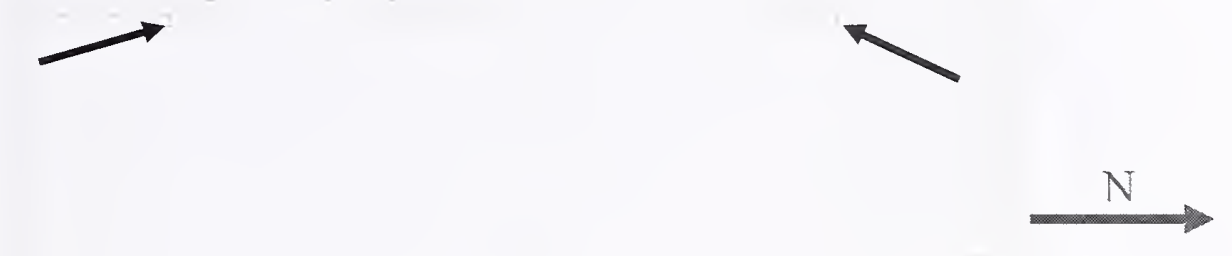

\begin{tabular}{|l|l|l|l|l|l|l|}
\hline & 0.00 & 0.50 & 0.75 & 1.00 & 1.08 & \\
\hline
\end{tabular}

Figure 6-4. Demand/capacity ratios for floor 75, WTC 2: original WTC design criteria loading.

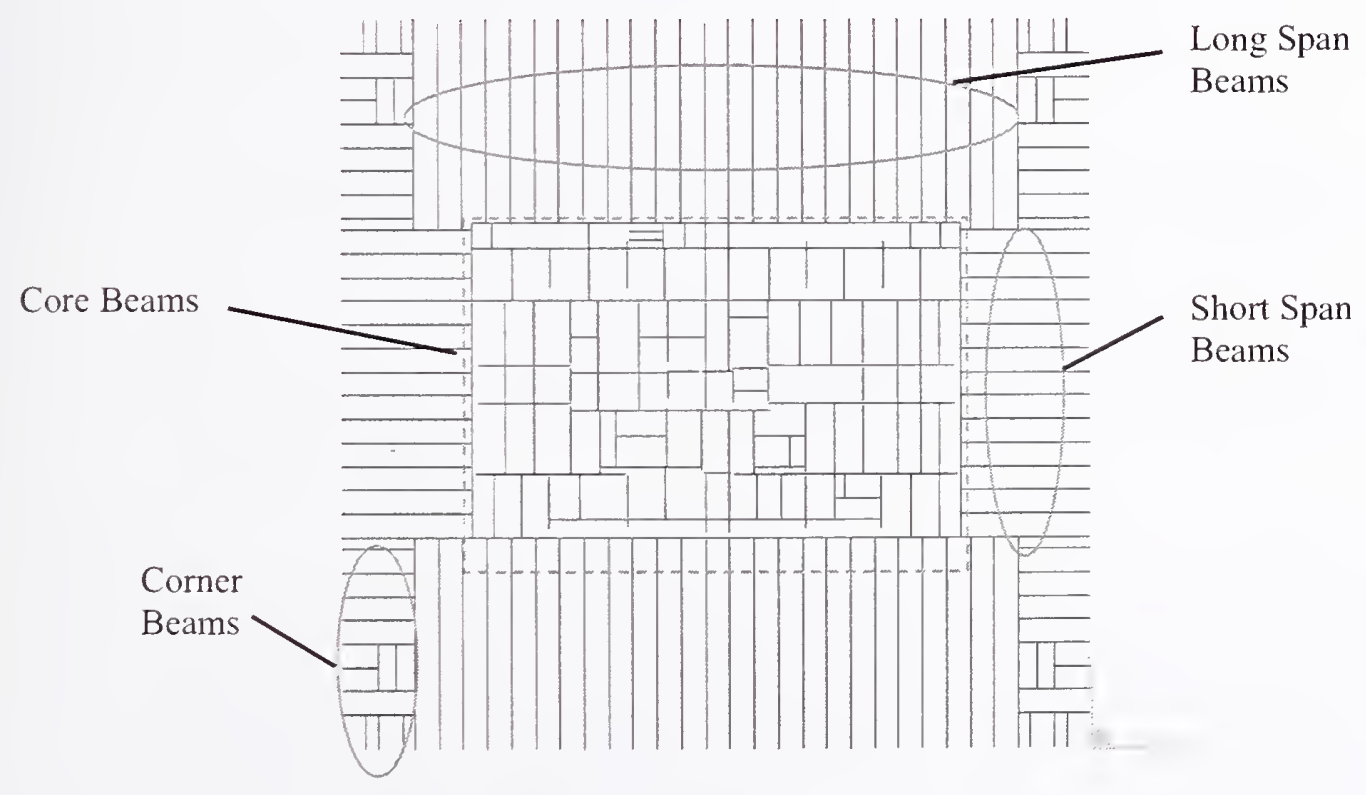

Figure 6-5. Beam-framed floor member groups. 
Table 6-7. Statistics of demand/capacity ratios for floor 75 under the original design loading case.

\begin{tabular}{|l|c|c|c|c|}
\hline \multicolumn{1}{|c|}{ Member Type } & $\begin{array}{c}\text { Number } \\
\text { of } \\
\text { Members }\end{array}$ & $\begin{array}{c}\text { Mean } \\
\text { Calculated } \\
\text { DCR }\end{array}$ & $\begin{array}{c}\text { C.o.v. of } \\
\text { DCR }\end{array}$ & $\begin{array}{c}\text { Maximum } \\
\text { Calculated } \\
\text { DCR }\end{array}$ \\
\hline Long Span Beams & 156 & 0.64 & 0.16 & 0.83 \\
\hline Short Span Beams & 84 & 0.65 & 0.12 & 0.89 \\
\hline Core Beams & 156 & 0.31 & 0.77 & 1.13 \\
\hline Corner Beams & 32 & 0.49 & 0.35 & 0.90 \\
\hline
\end{tabular}




\section{Chapter 7 \\ SUMMARY}

This report presented the work conducted to establish the baseline performance of the North and South World Trade Center Towers (WTC 1 and WTC 2) under design gravity and wind loading conditions. Baseline performance results include basic information about the behavior of the towers, such as total and inter-story drift under wind loads, floor deflections under gravity loads, demand/capacity ratios for primary structural components, exterior columns response (shear lag effects and presence of tensile forces under a combination of dead and wind loads), performance of connections, and the towers' resistance to shear sliding and overturning.

The following tasks were undertaken to allow performing the baseline performance analyses of the towers:

- Development of structural databases of the primary components of the WTC 1 and WTC 2 towers. The electronic databases were developed from original computer printouts of the structural design documents, including modifications made after construction. The task included the scanning and digitization of the original drawing books, a four-step quality control procedure, cross-section property calculations, and development of the relational databases to link the generated database files into a format suitable for the development of the structural models.

- Development of reference structural analysis models that captured the intended behavior of each of the two towers using the generated databases. These reference models were used to establish the baseline performance of the towers and also served as a reference for more detailed models for aircraft impact damage analysis and thermal-structural response and collapse initiation analysis. The main types of models developed were:

- Two global models of the major structural components and systems for the towers, one each for WTC 1 and WTC 2. The models included all primary structural components in the towers, including exterior walls (columns and spandrel beams), core columns, exterior wall bracing in the basement floors, core bracing at the main lobby atrium levels, hat trusses, and rigid and flexible diaphragms representing the floor systems. To validate the global models, the calculated natural frequencies of WTC 1 were compared with those measured on the tower, and good agreement between the calculated and measured values was obtained.

- One model each of the typical truss-framed floor (floor 96 of WTC 1) and typical beamframed floor (floor 75 of WTC 2) in the impact and fire zone of the towers. The models included all major structural components in the floor system, including primary and bridging trusses, beams, strap anchors and horizontal trusses, concrete slabs, and viscoelastic dampers. To validate the floor models, several studies were carried out to compare stresses and deflections estimated from the model with hand calculations for 
representative composite sections. Good agreement was obtained between the model results and hand calculations.

Parametric studies were performed to evaluate the behavior of typical portions of the structure and to develop simplified models for implementation into the global models. These parametric studies included detailed and simplified models of typical extcrior and corner wall panels and floor systems.

- Development of estimates of design gravity and wind loads on the towers for implementation into the reference structural models and use in the baseline performance analysis. Various wind load cases were considered in this study, including wind loads used in the original WTC design, wind loads based on two recent wind tunnel studies conducted in 2002 by Cermak Peterka Peterson, Inc. (CPP) and Rowan Williams Davies and Irwin, Inc. (RWDI) for insurance litigation concerning the towers, and wind load estimates developed by NIST from critical assessment of information obtained from the CPP and RWDI reports and stateof-the-art considerations. The following threc loading cases were considered for the baseline performance analysis:

- Original WTC design loads case. Loads included dead and live loads as in original WTC design, in conjunction with original WTC design wind loads.

- State-of-the-practice case. Loads included dead loads; New York City Building Code (NYCBC) 2001 live loads; and wind loads from the RWDI wind tunnel study, scaled in accordance with NYCBC 2001 wind speed.

- Refined NIST estimate case. Loads included dead loads; live loads from the American Society of Civil Engineers (ASCE 7-02) Standard; and wind loads developed by NIST.

The purpose of using the original WTC design loads was to evaluate the performance of the towers under original design loading conditions and ascertain whether those loads and the corresponding design were adequate given the knowledge available at the time of the design. The purpose of considering the state-of-the-practice case and the refined NIST estimate case was to better understand and assess the effects of successive changes in standards, codes, and practices on wind design practices for tall buildings.

The study indicated that the original WTC design wind load estimates exceeded those established by the NYCBC prior to 1968, when the WTC towers were designed, and up to and including 2001. The design values were also higher than those required by other prescriptive building codes of the time.

The two orthogonal base shcar and base moment components used in the original design were, in general, smaller than the CPP, RWDI, and NIST estimates. However, the most unfavorable combined peaks from the original design were larger, or smaller by at most 15 percent, than estimates based on the CPP, RWDI, and NIST estimates. This is due to the conservative procedure used to combine the loads in the original design.

The estimated wind-induced loads on the towers varied by as much as 40 percent between the wind tunnel/climatological studies conducted by CPP and RWDI in 2002. 
The WTC 1 and WTC 2 global models were each analyzed under the three loading cases described above to establish their baseline performance. The following is a summary of the results:

- Under the original WTC design loads, the cumulative drifts at the top of the WTC 1 tower were about 56.6 in. $(\mathrm{H} / 304)$ and 55.7 in. $(\mathrm{H} / 309)$ in the E-W and $\mathrm{N}-\mathrm{S}$ direction, respectively. These drifts were about $51.2 \mathrm{in}$. (H/335) in the E-W direction and 65.3 in. $(\mathrm{H} / 263)$ in the N-S direction for WTC 2. For the lower estimate, state-of-the-practice case, the drifts for WTC 1 were larger than those from the original design case by about 0.5 percent and 22 percent for the $\mathrm{E}-\mathrm{W}$ and $\mathrm{N}-\mathrm{S}$ directions, respectively. For the lower estimate, state-of-the-practice case for WTC 2, the E-W drift was larger than that from the original design case by about 16 percent, and the $\mathrm{N}-\mathrm{S}$ drift was smaller by about 15 percent. The drifts obtained from the refined NIST estimate case were about 25 percent larger than those from the state-of-the practice case. These differences are consistent with the differences among the base shears for the three loading cases.

- The demand/capacity ratios (DCRs) were based on the allowable stress design procedure and were estimated using the American Institute of Steel Construction (AISC) Specifications (1989). The results indicated that DCRs estimated from the original WTC design load case were, in general, close to those obtained for the lower estimate, state-of-the practice case. For both cases, a small fraction of structural components had DCRs larger than 1.0. These were mainly observed in both towers at (1) the exterior walls: at the columns around the corners, where the hat truss connected to the exterior walls, and below floor 9; and (2) the core columns on the 600 line between floors 80 and 106 and at core perimeter columns 901 and 908 for much of their height.

- The refined National lnstitute of Standards and Technology (NIST) case estimated DCRs were higher than those of the original WTC design estimates and the lower state-of-thepractice estimates for the following reasons: The NIST estimated wind loads were about 25 percent higher than those used in the lower state-of-the-practice estimate, and mixed, some higher and others lower than the original WTC design wind loads. It is noted that the NIST estimated wind loads are about 20 percent smaller than those estimated by CPP (an upper estimate, state-of-the practice case). In addition, the original IVTC design and the state-ofthe-practice cases used NYCBC load combinations. which result in lower DCRs than the ASCE 7-02 load combinations used for the refined NIST case.

- Under a combination of the original WTC design dead and wind loads, tension forces were developed in the exterior walls of WTC 1 and WTC 2. The forces were largest at the base of the building and at the corners. These tensile column loads were transferred from one panel to another through the column splices. The DCR ratios for the exterior wall splice connections under the effect of the tensile forces for the two towers were shown to be less than 1.0 .

- For the towers' resistance to shear sliding and overturning due to wind, the dead loads that acted on the perimeter walls of the tower provided resistance to shear sliding and overturning at the foundation level. Considering the resistance to shear sliding under wind load, the factor of safety was calculated to be between 10 and 11.5 , while the factor of safety against overturning ranged from 1.9 to 2.7 for both towers. 
Two typical floor models were each analyzed under gravity loads. The following is a summary of the results:

- For the typical truss-framed floor (floor 96 of WTC 1), the DCRs for all floor trusses were less than 1.14 for the original WTC Design Criteria loads and less than 0.86 for the ASCE 7-02 loading. Under the original WTC Design Criteria loading, the DCR was less than 1.00 for 99.4 percent of the floor truss components. For the area outside the core, the average ratio of the DCRs under the ASCE 7-02 loading to the DCRs under the original WTC Design Criteria loading for all floor trusses was about 0.80 . For the core area, the DCRs for all floor beams inside the core were less than 1.08, and more than 99 percent had a DCR of less than 1.0. Under the original WTC Design Criteria loading, the maximum floor deflections were 1.79 in., 0.57 in., and 1.44 in. for the long-span one-way trusses, short-span one-way trusses, and the two-way zone, respectively.

- For the typical beam-framed floor (floor 75 of WTC 2) under the original WTC Design Criteria loading, the DCRs for all floor beams were less than 1.0 except for two core beams where the shear DCRs were 1.125 and 1.09. The maximum mid-span deflections of the longspan and short-span zones under the original WTC Design Criteria loads were about 1.55 in. and $0.70 \mathrm{in}$., respectively. 


\section{Appendix A \\ WTC TOWER STRUCTURAL DRAWINGS INDEX FOR \\ LARGE-SIZE SHEETS}

\section{WTC TOWER A STRUCTURAL STEEL DRAWING INDEX - (18-MAY-73)}

Drawing No.

\section{Latest Revision \\ Date}

\begin{tabular}{|c|c|c|c|}
\hline LA-1 & \multicolumn{3}{|c|}{ Foundation loading plan } \\
\hline $\mathrm{SA}-1$ & \multicolumn{3}{|l|}{ Foundation plan } \\
\hline $\mathrm{SA}-2$ & Plan sub-level 5 & \multicolumn{2}{|c|}{ EL.242 } \\
\hline $\mathrm{SA}-3$ & \multicolumn{3}{|c|}{ Framing plan sub-level 4} \\
\hline $\mathrm{SA}-4$ & \multicolumn{2}{|c|}{ Framing plan sub-level 3} & EL.264 \\
\hline $\mathrm{SA}-5$ & \multicolumn{2}{|c|}{ Framing plan sub-level 2} & EL.274 \\
\hline SA-6 & \multicolumn{2}{|c|}{ Framing plan sub-level 1} & EL. 284 \\
\hline $\mathrm{SA}-7$ & \multicolumn{3}{|c|}{ Framing plan service level EL.294 } \\
\hline SA-8 & Framing plan floor & \multicolumn{2}{|l|}{1} \\
\hline SA-9 & \multicolumn{3}{|c|}{ Framing plan intermediate level } \\
\hline SA-10 & Framing plan floor & \multicolumn{2}{|l|}{2} \\
\hline SA-11 & Framing plan floor & \multicolumn{2}{|l|}{3} \\
\hline $\mathrm{SA}-12$ & Framing plan floor & \multicolumn{2}{|l|}{4} \\
\hline SA-13 & Framing plan floor & \multicolumn{2}{|l|}{5} \\
\hline SA-14 & Framing plan floor & \multicolumn{2}{|l|}{6} \\
\hline SA-15 & Framing plan floor & \multicolumn{2}{|l|}{7} \\
\hline SA-16 & Framing plan floor & \multicolumn{2}{|l|}{8} \\
\hline SA-17 & Framing plan floor & \multicolumn{2}{|l|}{9} \\
\hline SA-18 & Framing plan floors & \multicolumn{2}{|c|}{$10-11$} \\
\hline SA-19 & Not used & & \\
\hline $\mathrm{SA}-20$ & Framing plan floors & \multicolumn{2}{|c|}{$12-16$} \\
\hline $\mathrm{SA}-21$ & \multicolumn{3}{|l|}{ Not used } \\
\hline $\mathrm{SA}-22$ & \multicolumn{3}{|l|}{ Not used } \\
\hline $\mathrm{SA}-23$ & \multicolumn{3}{|l|}{ Not used } \\
\hline SA-24 & \multicolumn{3}{|l|}{ Not used } \\
\hline SA -25 & Framing plan floor & \multicolumn{2}{|l|}{17} \\
\hline SA-26 & Framing plan floor & \multicolumn{2}{|l|}{18} \\
\hline SA-27 & Framing plan floor & \multicolumn{2}{|l|}{19} \\
\hline SA-28 & Framing plan floor & \multicolumn{2}{|l|}{20} \\
\hline SA-29 & Framing plan floors & \multicolumn{2}{|c|}{$21-23$} \\
\hline $\mathrm{SA}-30$ & \multicolumn{3}{|l|}{ Not used } \\
\hline
\end{tabular}

27-Apr-67

29-Aug-68

09-Apr-69

09-Apr-69

07-Oct-68

17-Jul-68

$07-$ Oct-68

17-Jul-68

17-Jul-68

17-Jul-68

17-Jul-68

17-Jul-68

17-Jul-68

17-Jul-68

17-Jul-68

17-Jul-68

17-Jul-68

17-Jul-68

09-Oct-68

09-Oct-68

09-Oct-68

$09-$ Oct-68

09-Oct-68

09-Oct-68

$09-$ Oct-68 
Drawing No.

\begin{tabular}{|c|c|c|c|}
\hline SA-31 & Not used & & \\
\hline SA-32 & Framing plan floor & 24 & $09-$ Oct-68 \\
\hline SA-33 & Framing plan floor & 25 & $09-$ Oct-68 \\
\hline SA-34 & Framing plan floor & 26 & $09-O c t-68$ \\
\hline SA -35 & Framing plan floor & 27 & $09-O c t-68$ \\
\hline SA-36 & Framing plan floors & $28-31$ & $09-$ Oct-68 \\
\hline SA-37 & Not used & & \\
\hline SA-38 & Not used & & \\
\hline SA-39 & Not used & & \\
\hline SA-40 & Framing plan floor & 32 & $09-$ Oct-68 \\
\hline SA-41 & Framing plan floor & 33 & $09-$ Oct-68 \\
\hline $\mathrm{SA}-42$ & Framing plan floor & 34 & $09-$ Oct-68 \\
\hline SA -43 & Framing plan floor & 35 & $09-$ Oct-68 \\
\hline SA-44 & Framing plan floors & $36-38$ & $09-$ Oct-68 \\
\hline SA-45 & Not used & & \\
\hline SA-46 & Not used & & \\
\hline SA -47 & Framing plan floor & 39 & $09-$ Oct-68 \\
\hline SA-48 & Framing plan floor & 40 & $09-$ Oct-68 \\
\hline SA-49 & Framing plan floor & 41 & 10-Jan-69 \\
\hline SA-50 & Framing plan floor & 42 & 10-Jan-69 \\
\hline SA-51 & Framing plan floor & 43 & 10-Jan-69 \\
\hline SA-52 & Framing plan floor & 44 & 01-Sep-70 \\
\hline SA-53 & Framing plan floor & 45 & $01-$ Sep-70 \\
\hline SA-54 & Framing plan floor & 46 & 10-Jan-69 \\
\hline SA-55 & Framing plan floor & 47 & 10-Jan-69 \\
\hline SA -56 & Framing plan floor & 48 & 22-Nov-68 \\
\hline SA -57 & Framing plan floor & 49 & 22-Nov-68 \\
\hline SA-58 & Framing plan floor & 50 & $22-$ Nov-68 \\
\hline SA-59 & Framing plan floors & $51-54$ & $22-$ Nov- 68 \\
\hline SA-60 & Not used & & \\
\hline SA-61 & Not used & & . \\
\hline SA-62 & Not used & & \\
\hline SA-63 & Framing plan floor & 55 & $22-$ Nov-68 \\
\hline SA-64 & Framing plan floor & 56 & $22-N o v-68$ \\
\hline SA-65 & Framing plan floor & 57 & 22-Nov-68 \\
\hline SA-66 & Framing plan floor & 58 & 22-Nov-68 \\
\hline SA-67 & Framing plan floor & 59 & 22-Nov-68 \\
\hline SA-68 & Framing plan floor & 60 & 22-Nov-68 \\
\hline SA-69 & Framing plan floor & 61 & $22-$ Nov-68 \\
\hline
\end{tabular}


Drawing No.

SA -70

SA-71

SA -72

SA -73

SA-74

SA -75

SA-76

SA-77

SA-78

SA-79

SA -80

SA-81

SA -82

SA-83

SA -84

SA -85

SA-86

SA -87

SA- 88

SA- 89

SA-90

SA-91

SA-92

SA-93

SA-94

SA-95

SA-96

SA-97

SA-98

SA-99

SA- 100

SA-101

SA-102

SA-103

SA-104

SA-105

SA-106

SA-107

SA-106
Drawing Title

Framing plan floor

62

63

Framing plan floo

64

Framing plan floor 65

Framing plan floor 66

Framing plan floor 67

Framing plan floor 68

Framing plan floor 69

Framing plan floor $\quad 70$

Framing plan floor 71

Framing plan floor 72

Framing plan floor 73

Framing plan floor $\quad 74$

Framing plan floor 75

Framing plan floor 76

Framing plan floor 77

Framing plan floor 78

Framing plan floor 79

Framing plan floor 80

Framing plan floor 81

Framing plan floor $\quad 82$

Framing plan floor 83

Framing plan floor $\quad 84-86$

Not used

Not used

Framing plan floor

87

88

89

90,91

Framing plan floor

Not used

Framing plan floor 92

93

Framing plan floor

93

94

95

96

97-100
Latest Revision

Date

22-Nov-68

22-Nov-68

22-Nov-68

22-Nov-68

12-Dec-69

12-Dec-69

12-Dec-69

22-Nov-68

22-Nov-68

22-Nov-68

22-Nov-68

22-Nov-68

22-Nov-68

25-Sep-68

25-Sep-68

25-Sep-68

18-Aug-69

01-Aug-69

01-Aug-69

27-Nov-68

01-Aug-69

01-Aug-69

01-Aug-69

01-Aug-69

01-Aug-69

01-Aug-69

01-Aug-69

01-Aug-69

01-Aug-69

01-Aug-69

01-Aug-69

01-Aug-69

01-Aug-69 
Drawing No.

SA-107 Not used

SA-109 Framing plan floor 101

01-Aug-69

SA-110 Framing plan floor 102

01-Aug-69

SA-111

Framing plan floor 103

01-Aug-69

SA-112

Framing plan floor 104

01-Aug-69

SA-113 Framing plan floor 105

07-Jan-71

SA-114 Framing plan floor 106

16-Jun-72

SA-115

Framing plan floor 107

SA-116

Framing plan floor 107 upper

16-Jun-72

Void

SA-117

Framing plan floor 108

20-Oct-70

SA-118

Framing plan floor 109

20-Oct-70

SA-119

Framing plan floor 110

02-Jul-71

SA-120

Framing plan p.h. roof

07-May-71

SA-121

Not used

SA-122

Floor panel fireproofing plan

Hold

SA-123

Not used

SA-124

Floor panel schedule

06-Jan-69

SA-125

Ext. wall to 9th - elevation wall 100

07-Apr-67

SA-126

Ext. wall to 9th - elevation wall 200

08-May-67

SA-127

Ext. wall to 9th - elevation wall 300

07-Apr-67

SA-128

Ext. wall to 9th - elevation wall 400

08-May-67

SA-129

129 thru 139 not used

SA-140 Ext. wall above 9th - elevation wall 100

08-Sep-69

SA-141 Ext. wall above 9th - elevation wall 200

08-Sep-69

SA-142 Ext. wall above 9th - elevation wall 300

08-Sep-69

SA-143

Ext. wall above 9th - elevation wall 300

08-Sep-69

SA-144 144 thru 150 not used

SA-151 Grillage details

29-Aug-68

SA-152 Grillage details

15-Nov-67

SA-153 Not used

SA-154 Not used

SA-155 Not used

For SA-156 and above see Tower A \& B Index

SA-401 T/V mast support el. lines 500, $600 \& 700$

$12-$ Oct-70

SA-402 T/V mast support el. lines $800,900 \& 1000$

12-Oct-70

SA -403

$\mathrm{T} / \mathrm{V}$ mast support el. lines $001,002,003 \& 004$

10-Jul-70

$\mathrm{SA}-404$

$\mathrm{T} / \mathrm{V}$ mast support el. lines 005, 006, $007 \& 008$

10-Jul-70 


\section{WTC Tower A Structural Concrete Drawing Index - (18-May-73)}

SCA-1 Concrete plan sub level 5 el.242

$18-$ Dec-68

SCA-2 Concrete plan sub level 4 el.253

10-Dec-68

SCA-3 Concrete plan sub level 3 el.264 - core

17-Jan-69

$\mathrm{SCA}-4$

Concrete plan sub level 3 el.264 - floor

23-Jan-69

$\mathrm{SCA}-5$

Concrete plan sub level 2 el.274 - core

22-Jan-69

SCA-6

Concrete plan sub level 2 el.274 - floor

22-Jan-69

SCA-7

Concrete plan sub level 1 el.284 - core

28-Jan-69

SCA-8

Concrete plan sub level 1 el.284 - floor

28-Jan-69

SCA-9

Concrete plan service level el.294 - core

03-Feb-69

SCA-10

Concrete plan service level el.294 - floor

03-Feb-69

SCA-11

Concrete plan floor 1 el.310 - core

10-Dec-68

SCA-12

Concrete plan floor 1

el.310 - floor

19-Mar-69

SCA-13

Concrete plan intermediate level

02-Dec-69

$\mathrm{SCA}-14$

Concrete plan floor 2 - core

17-Jan-69

SCA-15

Concrete plan floor 2 - floor

04-Oct-71

SCA-16

Concrete plan floor 3-6 - floor

02-Dec-69

SCA-17

Concrete plan floor 7 - core

02-Dec-69

SCA-18

Concrete plan floor 7 - floor

26-May-69

SCA-19

Concrete plan floor 8 - core

16-Mar-70

SCA-20

Concrete plan floor 9 - core

16-Mar-70

SCA-21

Concrete plan floor 9 - floor

11-Feb-69

SCA-22

Not used

SCA-23

Concrete plan floors 10-40 - floor

19-Mar-70

SCA-24

Concrete plan floors 10-16 - core

19-Mar-70

SCA-25

Not used

SCA-26

Not used

SCA-27 Not used

SCA-28 Not used

SCA-29 Not used

SCA-30 Concrete plan floor 17 - core

15-Apr-70

SCA-31 Concrete plan floor 18 - core

15-Apr-70

SCA-32

Concrete plan floor 19 - core

15-Apr-70

SCA-33

Concrete plan floor 20 - core

15-Apr-70

SCA-34

Concrete plan floors 21-23 - core

15-Apr-70

SCA-35 Not used

SCA-36 Not used

SCA-37 Concrete plan floor 24 - core

12-Mar-69

SCA-38 Concrete plan floor 25 - core

15-Apr-70

SCA-39 Concrete plan floor 26 - core

15-Apr-70 
SCA-40 Concrete plan floor 27 - core

15-Apr-70

SCA-41 Concrete plan floors 28-31 - core

15-Apr-70

SCA-42 Not used

SCA-43 Not used

SCA-44 Not used

SCA-45 Concrete plan floor 32 - core

12-Mar-69

SCA-46 Concrete plan floor 33 - core

15-Apr-70

SCA-47 Concrete plan floor 34 - core

15-Apr-70

SCA-48 Concrete plan floor 35 - core

15-Apr-70

SCA-49 Concrete plan floors 36-40 - core

15-Apr-70

SCA-50

Not used

SCA-51 Not used

SCA-52 Not used

SCA-53 Not used

SCA-54 Concrete plan floor 41 - core

10-Aug-70

SCA-55 Concrete plan floor 41 - floor

10-Aug-70

SCA-56 Concrete plan floor 42 - core

10-Aug-70

SCA-57

Concrete plan floor 43 - core

24-Oct-69

SCA-58 Concrete plan floor 43 - floor

$20-$ Feb-70

SCA-59

Concrete plan floor 44 - core

24-Oct-69

SCA-60

Concrete plan floor 44 - floor

20-Feb-70

SCA-61

Concrete plan floor 45 - core

10-Aug-70

SCA -62

Concrete plan floor 45 - floor

10-Aug-70

SCA-63

Concrete plan floor 46 - core

10-Aug-70

SCA-64

Concrete plan floors $46,47,48$ - floor

10-Aug-70

SCA-65

Concrete plan floor 47 - core

18-Sep-70

SCA-66

Concrete plan floor 48 - core

10-Aug-70

SCA-67

Not used

SCA-68 Concrete plan floors 49-74 - floor

10-Aug-70

SCA-68

Alt concrete plan floors 49-74 -floor

04-May-70

SCA-69

Concrete plan floors 57,58 -core

10-Aug-70

SCA-70

Not used

SCA-71 Not used

SCA-72 Not used

SCA-73 Not used

SCA-74 Concrete plan floor 54 - core

03-Nov-69

SCA-75 Concrete plan floor 55 - core

10-Aug-70

SCA-76 Concrete plan floor 56 - core

10-Aug-70

SCA-77

Concrete plan floors 57,58 -core

10-Aug-70

SCA-78

Not used

SCA-79 Concrete plan floor 59 - core

03-Nov-69 


\begin{tabular}{|c|c|c|}
\hline SCA- 80 & Concrete plan floor 60 - core & $10-$ Aug-70 \\
\hline SCA-81 & Concrete plan floor 61 - core & 03-Nov-69 \\
\hline SCA-82 & Concrete plan floor 62 - core & $10-$ Aug-70 \\
\hline SCA-83 & Concrete plan floor 63 - core & 10 -Aug-70 \\
\hline SCA-84 & Concrete plan floor 64 - core & $10-$ Aug-70 \\
\hline SCA-85 & Concrete plan floor 65 - core & $10-$ Aug-70 \\
\hline SCA-86 & Concrete plan floor 66 - core & 01-May-70 \\
\hline SCA-87 & Concrete plan floor 67 - core & 15-May-70 \\
\hline SCA-88 & Concrete plan floor 68 - core & 15-May-70 \\
\hline SCA-89 & Concrete plan floor 69 - core & 24-Aug-70 \\
\hline SCA-90 & Concrete plan floors $70-73$ - core & 24-Aug-70 \\
\hline SCA-91 & Not used & \\
\hline SCA-92 & Not used & \\
\hline SCA-93 & Not used & \\
\hline SCA-94 & Concrete plan floor 74 - core & 24-Aug-70 \\
\hline SCA-95 & Concrete plan floor 75 - core & 01-May-70 \\
\hline SCA-96 & Concrete plan floor 75 - floor & 25-Aug-70 \\
\hline SCA-97 & Concrete plan floor 76 - core & 25-Aug-70 \\
\hline SCA-98 & Concrete plan floor 77 - core & 25 -Aug-70 \\
\hline SCA-99 & Concrete plan floor 77 - floor & 25-Aug-70 \\
\hline SCA-100 & Concrete plan floor 78 - core & 25 -Aug-70 \\
\hline SCA-101 & Concrete plan floor 78 - floor & 25 -Aug-70 \\
\hline SCA-102 & Concrete plan floor 79 - core & 25 -Aug-70 \\
\hline SCA-103 & Concrete plan floor 79 - floor & 13-Jul-70 \\
\hline SCA-104 & Concrete plan floor 80 - core & $25-$ Aug-70 \\
\hline SCA-105 & Concrete plan floors $80,81,82$ - floor & 13-Jul-70 \\
\hline SCA-106 & Concrete plan floor 81 - core & 25 -Aug-70 \\
\hline SCA-107 & Concrete plan floor 82 - core & 25 -Aug-70 \\
\hline SCA-108 & Concrete plan floor 106A - floor & 16-Jun-72 \\
\hline SCA-109 & Concrete plan floors 83-103A-83-104B-floor & $01-$ Sep-70 \\
\hline SCA-109 & Alt Concrete plan floors 83-103A-83-104B-floor & 04-May-70 \\
\hline SCA-110 & Concrete plan floors 104-105A-105-106A-floor & $01-$ Sep-70 \\
\hline SCA-111 & Concrete plan floor 83-core & 25 -Aug-70 \\
\hline SCA-112 & Concrete plan floors $84-86$ - core & 25-Aug-70 \\
\hline SCA-113 & Not used & \\
\hline SCA-114 & Concrete plan floor 87 - core & 25-Aug-70 \\
\hline SCA-115 & Concrete plan floor 88 - core & 25-Aug-70 \\
\hline SCA-116 & Concrete plan floors $89,90,91$ - core & 25-Aug-70 \\
\hline SCA-117 & Not used & \\
\hline SCA-118 & Not used & \\
\hline SCA-119 & Concrete plan floor 92 - core & 25-Aug-70 \\
\hline
\end{tabular}


SCA-120 Concrete plan floor 93 - core 11-Aug-70

SCA-121 Concrete plan floor 94 - core 15-Mar-71

SCA-122 Concrete plan floor 95 - core 15-Mar-71

SCA-123 Concrete plan floors 96-99A-96-1008-core 15-Mar-71

SCA-124 Not used

SCA-125 Not used

SCA-126 Not used

SCA-127 Concrete plan floor 100 - core

01-May-70

SCA-128 Concrete plan floor 101 - core

15-Mar-71

SCA-129 Concrete plan floor 102 - core

15-Mar-71

SCA-130 Concrete plan floor 103 - core

01-Dec-70

SCA-131 Concrete plan floor 104 - core

01-Mar-71

SCA-132

Concrete plan floors 105 - core

15-May-72

SCA-133

Concrete plan floors 106 - core

07-Jul-72

SCA-134 Concrete plan floor 107 - floor

16-Jun-72

SCA-135 Concrete plan floor 107 - core

16-Jun-72

SCA-136 Concrete plan floor 108 - core

15-May-72

SCA-137

Concrete plan floor 108 - floor

01-Mar-71

SCA-138 Concrete plan floor 109 - core

30-Jul-71

SCA-139

Concrete plan floor 110 - core

15-May-72

SCA-140 Concrete plan floor 110 - floor

28-Jul-71

SCA-141 Concrete plan penthouse roof - core

02-Sep-71

SCA-142

Concrete plans secondary levels

01-Dec-70

SCA-143

Concrete plan sub stations, escalator pits

SCA-145

Concrete plan el.264, post tension

01-Dec-70

SCA-146 Concrete plan penthouse roof lower level

Void

SCA-147 Concrete plan penthouse roof upper level

12-Jul-71

SCA-148

Concrete plan raised floor 107 - core

01-Oct-71

SCA-149

Concrete plan raised floor 107 -floor

07-Jul-72

16-Jun-72

SCA-150 Concrete plan raised floor 106 - floor

16-Jun-72 


\section{WTC TOWER B STRUCTURAL STEEL DRAWING INDEX - (18-MAY-73)}

SB-L1 Tower B foundation loading plan

21-Mar-68

SB-1

Foundation plan

06-Sep-68

SB-2

Plan sub-level 5

el. 242

25-Sep-68

SB-3

Framing plan sub-level 4

el. 253

25-Sep-68

SB-4

Framing plan sub-level 3

el.264

07-Oct-68

SB-5

Framing plan sub-level 2

el. 274

17-Jul-68

SB-6

Framing plan sub-level 1

el. 284

07-Oct-68

SB-7

Framing plan service level

el.294

28-May-69

SB-8

Framing plan floor 1

17-Jul-68

SB-9 Framing plan intermediate level

17-Jul-68

SB-10

Framing plan floor 2

17-Jul-68

SB-11

Framing plan floor 3

17-Jul-68

SB-12

Framing plan floor

17-Jul-68

SB-13

Framing plan floor

17-Jul-68

SB-14

Framing plan floor

17-Jul-68

SB-15

Framing plan floor

13-Mar-69

SB-16

Framing plan floor

17-Jul-68

SB-17

Framing plan floor

17-Aug-68

SB-1 8

Framing plan floor

19-Mar-69

SB-19

Framing plan floor

19-Mar-69

SB-20

Framing plan floor

19-Mar-69

SB-21

Framing plan floor

19-Mar-69

*SB-22

Framing plan floors

13

09-Oct-68

SB-23

Not used

SB-24

Not used

*SB-25

Framing plan floor

17

09-Oct-68

*SB-26

Framing plan floor

18

09-Oct-68

*SB-27

Framing plan floor

19

09-Oct-68

*SB-28

Framing plan floor

20

*SB-29

Framing plan floors

21-23

09-Oct-68

SB-30

Not used

SB-31 Not used

SB-32

Framing plan floor

24

09-Oct-68

*SB-33

Framing plan floor

25

09-Oct-68

*SB-34

Framing plan floor

26

09-Oct-68

*SB-35

Framing plan floor

27

09-Oct-68

*SB-36

Framing plan floors

28-31

09-Oct-68

SB-37 Not used

SB-38

Not used 


\begin{tabular}{|c|c|c|c|}
\hline SB-39 & Not used & & \\
\hline SB-40 & Framing plan floor & 32 & $09-$ Oct-68 \\
\hline *SB-41 & Framing plan floor & 33 & $09-$ Oct-68 \\
\hline *SB-42 & Framing plan floor & 34 & $09-$ Oct-68 \\
\hline *SB-43 & Framing plan floor & 35 & $09-$ Oct-68 \\
\hline *SB-44 & Framing plan floors & $36-38$ & $09-$ Oct-68 \\
\hline SB-45 & Not used & & \\
\hline SB-46 & Not used & & \\
\hline$* \mathrm{SB}-47$ & Framing plan floor & 39 & $09-$-Oct-68 \\
\hline *SB-48 & Framing plan floor & 40 & $09-O c t-68$ \\
\hline *SB-49 & Framing plan floor & 41 & $10-J a n-69$ \\
\hline *SB-50 & Framing plan floor & 42 & $10-J a n-69$ \\
\hline *SB-51 & Framing plan floor & 43 & 10-Jan-69 \\
\hline SB-52 & Framing plan floor & 44 & $01-$ Sep-70 \\
\hline$*$ SB-53 & Framing plan floor & 45 & 22-Nov-68 \\
\hline *SB-54 & Framing plan floor & 46 & 22-Nov-68 \\
\hline *SB-55 & Framing plan floor & 47 & 22-Nov-68 \\
\hline *SB-56 & Framing plan floor & 48 & 22-Nov-68 \\
\hline *SB-57 & Framing plan floor & 49 & 22-Nov-68 \\
\hline *SB-58 & Framing plan floor & 50 & 22-Nov-68 \\
\hline$*$ SB-59 & Framing plan floors & $51-54$ & 22-Nov-68 \\
\hline SB-60 & Not used & & \\
\hline SB-61 & Not used & & \\
\hline SB-62 & Not used & & \\
\hline *SB-63 & Framing plan floor & 55 & 22-Nov-68 \\
\hline *SB-64 & Framing plan floor & 56 & 22-Nov-68 \\
\hline$*$ SB-65 & Framing plan floor & 57 & 22-Nov-68 \\
\hline$*$ SB-66 & Framing plan floor & 58 & $22-$ Nov- 68 \\
\hline$*$ SB-67 & Framing plan floor & 59 & 22-Nov-68 \\
\hline$*$ SB-68 & Framing plan floor & 60 & 22-Nov-68 \\
\hline$*$ SB-69 & Framing plan floor & 61 & 22-Nov-68 \\
\hline$*$ SB-70 & Framing plan floor & 62 & $22-$ Nov- 68 \\
\hline$*$ SB-71 & Framing plan floor & 63 & 22-Nov-68 \\
\hline$*$ SB-72 & Framing plan floor & 64 & 22-Nov-68 \\
\hline *SB-73 & Framing plan floors & 65,66 & 22-Nov-68 \\
\hline SB-74 & Not used & & \\
\hline SB-75 & Framing plan floor & 67 & 22-Nov-68 \\
\hline SB-76 & Framing plan floor & 68 & 22-Nov-68 \\
\hline SB-77 & Framing plan floor & 69 & $22-$ Nov- 68 \\
\hline *SB-78 & Framing plan floor & 70 & 22-Nov-68 \\
\hline *SB-79 & Framing plan floor & 71 & 22-Nov-68 \\
\hline
\end{tabular}




\begin{tabular}{|c|c|c|c|}
\hline *SB-80 & Framing plan floor & 72 & 22-Nov-68 \\
\hline *SB-81 & Framing plan floor & 73 & 22-Nov-68 \\
\hline *SB-82 & Framing plan floor & 74 & $22-N o v-68$ \\
\hline *SB-83 & Framing plan floor & 75 & 27-Nov-68 \\
\hline *SB-84 & Framing plan floor & 76 & 01-Aug-69 \\
\hline *SB-85 & Framing plan floor & 77 & $27-N o v-68$ \\
\hline$* \mathrm{SB}-86$ & Framing plan floor & 78 & 18-Mar-69 \\
\hline *SB-87 & Framing plan floor & 79 & 01-Aug-69 \\
\hline *SB-88 & Framing plan floor & 80 & 01-Aug-69 \\
\hline *SB-89 & Framing plan floor & 81 & $27-$ Nov- 68 \\
\hline$*$ SB-90 & Framing plan floor & 82 & $27-$ Nov- 68 \\
\hline *SB-91 & Framing plan floor & 83 & 01-Aug-69 \\
\hline *SB-92 & Framing plan floor & $84-86$ & 27-Nov-68 \\
\hline SB-93 & Not used & & \\
\hline SB-94 & Not used & & \\
\hline *SB-95 & Framing plan floor & 87 & 01-Aug-69 \\
\hline *SB-96 & Framing plan floor & 88 & 01 -Aug-69 \\
\hline *SB-97 & Framing plan floor & 89 & 01-Aug-69 \\
\hline *SB-98 & Framing plan floor & $90,91,93$ & $01-$ Sep-70 \\
\hline SB-99 & Not used & & \\
\hline *SB-100 & Framing plan floor & 92 & 27-Nov-68 \\
\hline SB-101 & Not used & & \\
\hline *SB-102 & Framing plan floor & 94 & 01-Aug-69 \\
\hline *SB-103 & Framing plan floor & 95 & 01-Aug-69 \\
\hline *SB-104 & Framing plan floor & 96 & 01-Aug-69 \\
\hline$*$ SB-105 & Framing plan floors & $97-100$ & 01 -Aug-69 \\
\hline SB-106 & Not used & & \\
\hline SB-107 & Not used & & \\
\hline SB-108 & Not used & & \\
\hline$*$ SB-109 & Framing plan floor & 101 & 01-Aug-69 \\
\hline *SB-110 & Framing plan floor & 102 & 01-Aug-69 \\
\hline *SB-111 & Framing plan floor & 103 & 01-Aug-69 \\
\hline *SB-112 & Framing plan floor & 104 & 01-Aug-69 \\
\hline *SB-113 & Framing plan floor & 105 & 10-Dec-69 \\
\hline *SB-114 & Framing plan floor & 106 & 10-Dec-69 \\
\hline *SB-115 & Framing plan floor & 107 & 05-Mar-71 \\
\hline *SB-1 16 & Framing plan floor & 107 upper & void \\
\hline *SB-117 & Framing plan floor & 108 & 05-Mar-71 \\
\hline *SB-118 & Framing plan floor & 109 & $05-\mathrm{Mar}-71$ \\
\hline *SB-119 & Framing plan floor & 110 & 02-Jul-71 \\
\hline SB-120 & \multicolumn{2}{|c|}{ Framing plan p.h. roof upper level } & 27-Sep-71 \\
\hline
\end{tabular}


SB-121 Framing plan p.h. roof lower level

27-Sep-71

SB-122 Not used

SB-123 Framing plan truck ramp

void

SB-124 Floor panel schedule

28-Mar-69

SB-125

Ext. wall to 9th -elevation wall 100

15-Feb-68

SB-126

Ext. wall to 9 th -elevation wall 200

15-Feb-68

SB-127

Ext. wall to 9 th -elevation wall 300

$15-$ Feb-68

SB-128

Ext. wall to 9 th - elevation wall 400

15 -Feb-68

SB-129 129 thru 139 not used

SB-140

Ext. wall above 9th -elevation wall 100

08-Sep-69

SB-141

Ext. wall above 9th -elevation wall 200

08-Sep-69

SB-142

Ext. wall above 9th -elevation wall 300

08-Sep-69

SB-143

Ext. wall above 9 th -elevation wall 400

08-Sep-69

SAB-144 144 thru 150 not used

SB-151 Grillage details

08-Sep-69

SB-151.1 Anchor Bolt Details

08-Sep-69

SB-151.2 Anchor Bolt Details

$08-\operatorname{Sep}-69$

SB-151.3 Anchor Bolt Details

08-Sep-69

SB-152 Grillage details

09-Feb-68

SB-153 Grillage details

15-Nov-67

SB-154 Grillage details

13-Dec-67

SB-155 Not used

SB-401 TV mast support elev. Lines $500,600,700$

05-Mar-71

SB-402 TV mast support elev. Lines $800,900,1000$

05-Mar-71

SB-403 TV mast support elev. Lines 001,002,003,004

05-Mar-71

SB-404 TV mast support elev. Lines $005,006,007,008$

14-Dec-70

* formerly included with tower $A$ 


\section{WTC TOWER B STRUCTURAL CONCRETE DRAWING INDEX - (18-MAY-73)}

\begin{tabular}{|c|c|c|}
\hline SCB-1 & Concrete plan sub level 5 el.242 & 02-Jan-70 \\
\hline SCB-2 & Concrete plan sub level 4 el.253 & 11-Apr-69 \\
\hline SCB-3 & Concrete plan sub level 3 el.264 - core & 05-Aug-69 \\
\hline SCB-4 & Concrete plan sub level 3 el.264 - floor & 05-Aug-69 \\
\hline SCB-5 & Concrete plan sub level 2 el.274 - core & 05-Aug-69 \\
\hline SCB-6 & Concrete plan sub level 2 el.274 - floor & 05-Aug-69 \\
\hline SCB-7 & Concrete plan sub level 1 el.284 - core & 05-Aug-69 \\
\hline SCB-8 & Concrete plan sub level 1 el.284 - floor & 05-Aug-69 \\
\hline SCB-9 & Concrete plan service level el.294 - core & 10-Jul-69 \\
\hline SCB-10 & Concrete plan service level el.294 - floor & 10-Jul-69 \\
\hline SCB-11 & Concrete plan floor 1 el.310 - core & 11-Jul-69 \\
\hline SCB-12 & Concrete plan floor 1 el.310 - floor & 11-Jul-69 \\
\hline SCB-13 & Concrete plan intermediate level & see SCA-13 \\
\hline *SCB-14 & Concrete plan floor 2 - core & 06-Dec-69 \\
\hline SCB-15 & Concrete plan floor 2 - floor & see SCA-15 \\
\hline SCB-16 & Concrete plan floors 3-6 - core & see SCA-16 \\
\hline SCB-17 & Concrete plan floor 7 - core & see SCA-17 \\
\hline SCB-18 & Concrete plan floor 7 - floor & 02-Dec-69 \\
\hline SCB-19 & Concrete plan floor 8 - core & see SCA-19 \\
\hline SCB-20 & Concrete plan floor 9 - core & see SCA-20 \\
\hline SCB-21 & Concrete plan floor 9 - floor & 16-Mar-70 \\
\hline SCB-22 & Concrete plan floor 10 - floor & 19-Mar-70 \\
\hline$*$ SCB -23 & Concrete plan floor 10 - core & 19-Mar-70 \\
\hline$* \mathrm{SCB}-24$ & Concrete plan floor 11 - core & 19-Mar-70 \\
\hline SCB-25 & Concrete plan floor 11 - floor & 19-Mar-70 \\
\hline SCB-26 & Concrete plan floor 12 - floor & 19-Mar-70 \\
\hline SCB-27 & Concrete plan floor 12 - core & 19-Mar-70 \\
\hline SCB-28 & Concrete plan floor 13 - floor & 19-Mar-70 \\
\hline SCB-29 & Not used & \\
\hline SCB-30 & Concrete plan floor 17 - core & see $\mathrm{SCA}-30$ \\
\hline SCB-31 & Concrete plan floor 18 - core & see SCA-31 \\
\hline SCB-32 & Concrete plan floor 19 - core & see SCA-32 \\
\hline SCB-33 & Concrete plan floor 20 - core & see SCA-33 \\
\hline SCB-34 & Concrete plan floor 21-23 - core & see SCA-34 \\
\hline SCB-35 & Not used & \\
\hline SCB-36 & Not used & \\
\hline SCB-37 & Concrete plan floor 24 - core & 15-Apr-70 \\
\hline SCB-38 & Concrete plan floor 25 - core & see SCA-38 \\
\hline SCB-39 & Concrete plan floor 26 - core & see SCA-39 \\
\hline
\end{tabular}


SCB-40 Concrete plan floor 27 - core

see $\mathrm{SCA}-40$

SCB-41 Concrete plan floor 28-31 - core

see $\mathrm{SCA}-41$

SCB-42 Not used

SCB-43 Not used

SCB-44 Not used

SCB-45 Concrete plan floor 32 - core

15-Apr-70

SCB-46 Concrete plan floor 33 - core

see SCA-46

SCB-47 Concrete plan floor 34 - core

see $\mathrm{SCA}-47$

SCB-48 Concrete plan floor 35 - core

see $\mathrm{SCA}-48$

SCB-49 Concrete plan floor 36-40 - core

see SCA-49

SCB-50 Not used

SCB-51 Not used

SCB-52 Not used

SCB-53 Not used

SCB-54 Concrete plan floor 41 - core

see SCA- 54

SCB-55 Concrete plan floor 41 - floor

see $\mathrm{SCA}-55$

SCB-56 Concrete plan floor 42 - core

see SCA-56

SCB-57 Concrete plan floor 43 - core

10-Aug-70

10-Aug-70

SCB-58 Concrete plan floor 43 - floor

24-Sep-70

Concrete plan floor 44 - core

24-Sep-70

SCB-60 Concrete plan floor 44 - floor

see SCA-61

SCB-61 Concrete plan floor 45 - core

see SCA-62

SCB-62 Concrete plan floor 45 - floor

see $\mathrm{SCA}-63$

SCB-63 Concrete plan floor 46 - core

see $\mathrm{SCA}-64$

SCB-64 Concrete plan floors 46-48 - floor

see SCA-65

SCB-65 Concrete plan floor 47 - core

see SCA-66

SCB-66 Concrete plan floor 48 - core

see SCA-68

SCB-68

Not used

Concrete plan floors 49-74 - floor

see SCA-69

SCB-70

Concrete plan floors 49-54 - core

Not used

SCB-71

Not used

SCB-72

Not used

SCB-73 Not used

SCB-74 Not used

SCB-75 Concrete plan floor 55 - core

see SCA-75

SCB-76 Concrete plan floor 56 - core

see $\mathrm{SCA}-76$

SCB-77 Concrete plan floors 57-58 - core

see $\mathrm{SCA}-77$

SCB-78 Not used

SCB-79 Concrete plan floor 59 - core

see SCA-79

SCB-80 Concrete plan floor 60 - core

see $\mathrm{SCA}-80$ 
SCB-81 Concrete plan floor 61 - core

10-Aug-70

SCB-82 Concrete plan floor 62 - core

see SCA- 82

SCB-83 Concrete plan floor 63 - core

see SCA- 83

SCB-84 Concrete plan floor 64 - core

see $\mathrm{SCA}-84$

SCB-85 Concrete plan floor 65 - core

see SCA-85

SCB-86 Concrete plan floor 66 - core

24-Aug-70

SCB-87 Concrete plan floor 67 - core

24-Aug-70

SCB-88 Concrete plan floor 68 - core

24-Aug-70

SCB-89 Concrete plan floor 69 - core

see SCA-89

SCB-90 Concrete plan floors 70-73 - core

see $\mathrm{SCA}-90$

SCB-91 Not used

SCB-92 Not used

SCB-93 Not used

SCB-94 Concrete plan floor 74 - core

see SCA-94

SCB-95 Concrete plan floor 75 - core

see SCA-95

SCB-96 Concrete plan floor 75 - floor

see SCA-96

SCB-97 Concrete plan floor 76 - core

see SCA-97

SCB-98

Concrete plan floor 77 - core

see SCA-98

SCB-99

Concrete plan floor 77 - floor

see SCA-99

SCB-100 Concrete plan floor 78 - core

see SCA-100

SCB-101 Concrete plan floor 78 - floor

see SCA-101

SCB-102 Concrete plan floor 79 - core

see SCA-102

SCB-103 Concrete plan floor 79 - floor

see SCA-103

SCB-104 Concrete plan floor 80 - core

see SCA-104

SCB-105 Concrete plan floor 80-82 - floor

see SCA-105

SCB-106 Concrete plan floor 81 - core

see SCA-106

SCB-107 Concrete plan floor 82 - core

see SCA-107

SCB-108 Not used

SCB-109 Concrete plan floors 83-106 - floor

see SCA-109

SCB-110 Not used

SCB-111 Concrete plan floor 83 - core

see SCA-111

SCB-112 Concrete plan floor 84-86 - core

see SCA-112

SCB-113 Not used

SCB-114 Concrete plan floor 87 - core

see SCA-114

SCB-115

see SCA-115

SCB-116 Concrete plan floors 89,90,91 - core

see SCA-116

SCB-117 Not used

SCB-118 Not used

SCB-119 Concrete plan floor 92 - core

see SCA-119

SCB-120 Concrete plan floor 93 - core

15-Mar-71

SCB-121 Concrete plan floor 94 - core see SCA-121 
SCB-122 Concrete plan floor 95 - core

see SCA-122

SCB-123 Concrete plan floors 96-100 - core

see SCA-123

SCB-124 Not used

SCB-125 Not used

SCB-126 Not used

SCB-127 Not used

SCB-128 Concrete plan floor 101 - core

see SCA-128

SCB-129 Concrete plan floor 102 - core

see SCA-129

SCB-130 Concrete plan floor 103 - core

see SCA-130

SCB-131 Concrete plan floor 104 - core

15-Mar-71

SCB-132 Concrete plan floor 105 - core

18-Jun-71

SCB-133 Concrete plan floor 106 - core

18-Jun-71

SCB-134 Concrete plan floor 107 - floor

30-Jul-71

SCB-135 Concrete plan floor 107 - core

30-Jul-71

SCB-136 Concrete plan floor 108 - core

30-Jul-71

SCB-137 Concrete plan floor 108 - floor

01-Dec-71

SCB-138 Concrete plan floor 109 - core

see SCA-138

SCB-139 Concrete plan floor 110 - core

03-Sep-71

SCB-140 Concrete plan floor 110 - floor

03-Sep-71

SCB-141 Concrete plan penthouse roof - core

10-Apr-72

SCB-142 Concrete plans secondary levels

see SCA-142

SCB-143 Concrete plan sub stations, escalator pits

see SCA-143

SCB-144 Sections, truck ramp el.284

11-Jul-69

SCB-145 Concrete plan el.264, post tension

Void

SCB-146

Concrete plan penthouse low roof - floor

26-Mar-73

SCB-147 Concrete plan penthouse high roof - floor

22-Sep-72

SCB-148

Core plan observation deck

08-Mar-73

* Formerly included with Tower A

Note- Tower B Concrete plan floors 14-40 - floor see SCA-23

Tower B Concrete plans floors 13-16 - core see SCA-24 


\section{WTC TOWER A \& B STRUCTURAL STEEL DECK DRAWING INDEX - (18-MAY-73)}

$\begin{array}{clc}\text { SA-156 } & \text { Steel deck plan floor } & 7 \\ \text { SA-157 } & \text { Steel deck plan floor } & 9 \\ \text { SA-158 } & \text { Steel deck plan floors } & 19-40 \\ \text { SA-159 } & \text { Steel deck plan floor } & 41 \\ \text { SA-160 } & \text { Steel deck plan floor } & 43 \\ \text { SB-160 } & \text { Steel deck plan floor } & 43 \\ \text { SAB-161 } & \text { Steel deck plan floor } & 45 \\ \text { SA-162 } & \text { Steel deck plan floor } & 44 \\ \text { SB-162 } & \text { Steel deck plan floor } & 44\end{array}$

SAB-163 Steel deck plan floors $46-49$

SAB-164 Steel deck plan floors $50-58$

SAB-165 Steel deck plan floors 59-62

SAB-166 Steel deck plan floors 63-66

SAB-167 Steel deck plan floors $\quad 67-70$

SAB-168 Steel deck plan floors 71-74

SAB-169 Steel deck plan floors 65-69

SB-169

SAB-170 Steel deck plan floor 75

SAB-171 Steel deck plan floor 77

SAB-172 Steel deck plan floors 78-79

SAB-173 Steel deck plan floors $80-81$

SAB-174 Steel deck plan floors 82-83

SAB-175 Steel deck plan floors 84-89

SAB-176 Steel deck plan floors 90-94

SAB-177 Steel deck plan floors 95-101

SAB-178 Steel deck plan floors 102-106

SA-179 Steel deck plan floor 107

SB-179 Steel deck plan floor 107

SA-180 Steel deck plan floor 108

SB-180 Steel deck plan floor 108

SA-181 Steel deck plan floor 110

SB-181 Steel deck plan floor 110

SB-182 Steel deck plan floor 7

SB-183 Steel deck plan floor 9

SB-184 Steel deck plan floor 10

SB-185 Steel deck plan floor 11

SB-186 Steel deck plan floor 12

SB-187 Steel deck plan floor 13
28-Mar-69

28-Mar-69

28-Mar-69

17-Jun-68

27-Aug-69

27-Aug-69

17-Jun-68

27-Aug-69

27-Aug-69

11-6-67, 6-17-

68

17-Jun-68

17-Jun-68

12-Dec-69

12-Dec-69

17-Jun-68

17-Jun-68

17-Jun-68

17-Jun-68

18-Mar-69

17-Jun-68

17-Jun-68

17-Jun-68

17-Jun-68

17-Jun-68

02-Jul-71

08-Sep-70

01-Oct-70

08-Sep-70

01-Oct-70

08-Sep-70

29-Jan-72

28-Mar-69

28-Mar-69

28-Mar-69

28-Mar-69

28-Mar-69

07-Nov-69 


\section{Miscellaneous}

$\begin{array}{lll}\text { SX-105 Framing plan-typical office floor } & \text { 21-Dec-70 }\end{array}$

SX-144 Sewer ejector \& sump pits

20-Mar-69

SX-146

Closure tieback anchorage perimeter

24-Jun-68

?SAB-240

Floor plan el.229

*(original print missing)

12-Sep-66 


\section{Appendix B \\ DRAWING BOOK 19 MODIFICATIONS FOR STRUCTURAL ELEMENTS NOT INCLUDED IN THE DATABASE}

The following is a table of Drawing Book 19 (Revisions After Fabrication) changes not included in the database because they were considered to not significantly affect the member properties pertaining to the reference structural models. The listed modifications only pertain to tower modifications. Modifications outside of the towers are not included.

\begin{tabular}{|c|c|c|c|}
\hline Drawing Number(s) & Title & Date & Description \\
\hline $19-B-913$ & Detail 913 & $10 / 9 / 68$ & $1 / 2$ in. by 1 in. shim plates for $p / t$ cells. \\
\hline 19-A-914 & Detail 914 & $11 / 20 / 68$ & $\begin{array}{l}\text { Clip angle location changed for seated } \\
\text { connection. }\end{array}$ \\
\hline $19-\mathrm{A}-918$ & Detail 918 & $1 / 15 / 69$ & $\begin{array}{l}\text { Additional studs and flange plates for } \\
\text { beam in beam framed between core and } \\
\text { exterior wall in WTC 1, elevation } 274 \mathrm{ft} \text {. }\end{array}$ \\
\hline 19-A-921 & Detail 921 & $1 / 27 / 69$ & $\begin{array}{l}\text { Additional flange plate for beam in core } \\
\text { framing in WTC } 1 \text {, elevation } 284 \mathrm{ft} \text {. }\end{array}$ \\
\hline 19-B-975 & $\begin{array}{l}\text { Beam repair det. Floor } 59 \\
\text { and } 92\end{array}$ & $10 / 28 / 70$ & $\begin{array}{l}\text { Beam reinforcing for conduits passing } \\
\text { through core channel. }\end{array}$ \\
\hline $19-\mathrm{A}-982.1,982.2$ & $\begin{array}{l}\text { Floor } 106 \text { beam cover } \\
\text { plate }\end{array}$ & $1 / 17 / 71$ & Beam cover plates Floor 106. \\
\hline 19-B-994 & $\begin{array}{l}\text { Column splice repair Floor } \\
107\end{array}$ & $3 / 15 / 71$ & Column Splice Repair Floor 107 \\
\hline $\begin{array}{l}\text { 19-A-1001, } \\
19-\mathrm{AB}-1002,1003\end{array}$ & $\begin{array}{l}245 \text { A } 12-9 \\
\text { Seat detail }\end{array}$ & $6 / 5 / 69$ & $\begin{array}{l}\text { Truss seat modifications Floor } 10-12, \\
\text { Column } 246, \text { WTC } 1 \text { and seat detail } \\
\text { dimensional modifications Floor 10-107, } \\
\text { WTC } 1 \text { and WTC } 2 \text {. }\end{array}$ \\
\hline $\begin{array}{l}19-\mathrm{AB}-1004.1 \\
1004.2\end{array}$ & $\begin{array}{l}\text { Column splice repair } \\
\text { procedure }\end{array}$ & $6 / 20 / 69$ & $\begin{array}{l}\text { Additional weld for exterior wall column } \\
\text { splice connections. }\end{array}$ \\
\hline $\begin{array}{l}19-B-2100.1- \\
2100.4\end{array}$ & $\begin{array}{l}\text { Modification to pent house } \\
\text { roof framing plan }\end{array}$ & $9 / 27 / 71$ & $\begin{array}{l}\text { Raised girder using stubs on roof level } \\
\text { framing. }\end{array}$ \\
\hline
\end{tabular}


This page intentionally left blank. 


\section{Appendix C \\ WTC DRAWING BOOK FLOWCHARTS}

This Appendix presents the drawing books flowcharts that illustrate the flow of the drawing book links. These flowcharts were used to organize the links of the electronic databases within the relational database. For the flowcharts presented in Figs. $\mathrm{C}-1$ through $\mathrm{C}-9$, the following notes are common:

- "4-AB-*" denotes Drawing Book 4, Tower A, B or AB, and page number

- $\quad\left[{ }^{*} \mathrm{TC}\right]$ denotes number of pages and type, where page types include:

- TC: computer generated tables; TH: hand written tables; and D: diagrams

- *.xls denotes Microsoft Excel spreadsheet file name; and ( $\left.\mathrm{AB}_{-}^{* * *}\right)$ denotes database heading

- $\left(\left(^{*}\right)\right)$ denotes reference note key from original Drawing Book information table.

- $\{*\}$ denotes relational database link (i.e. Microsoft Excel column number) from previous *.xls file.

- Figures of columns and panels are shown from inside of building looking out, unless otherwise noted. 


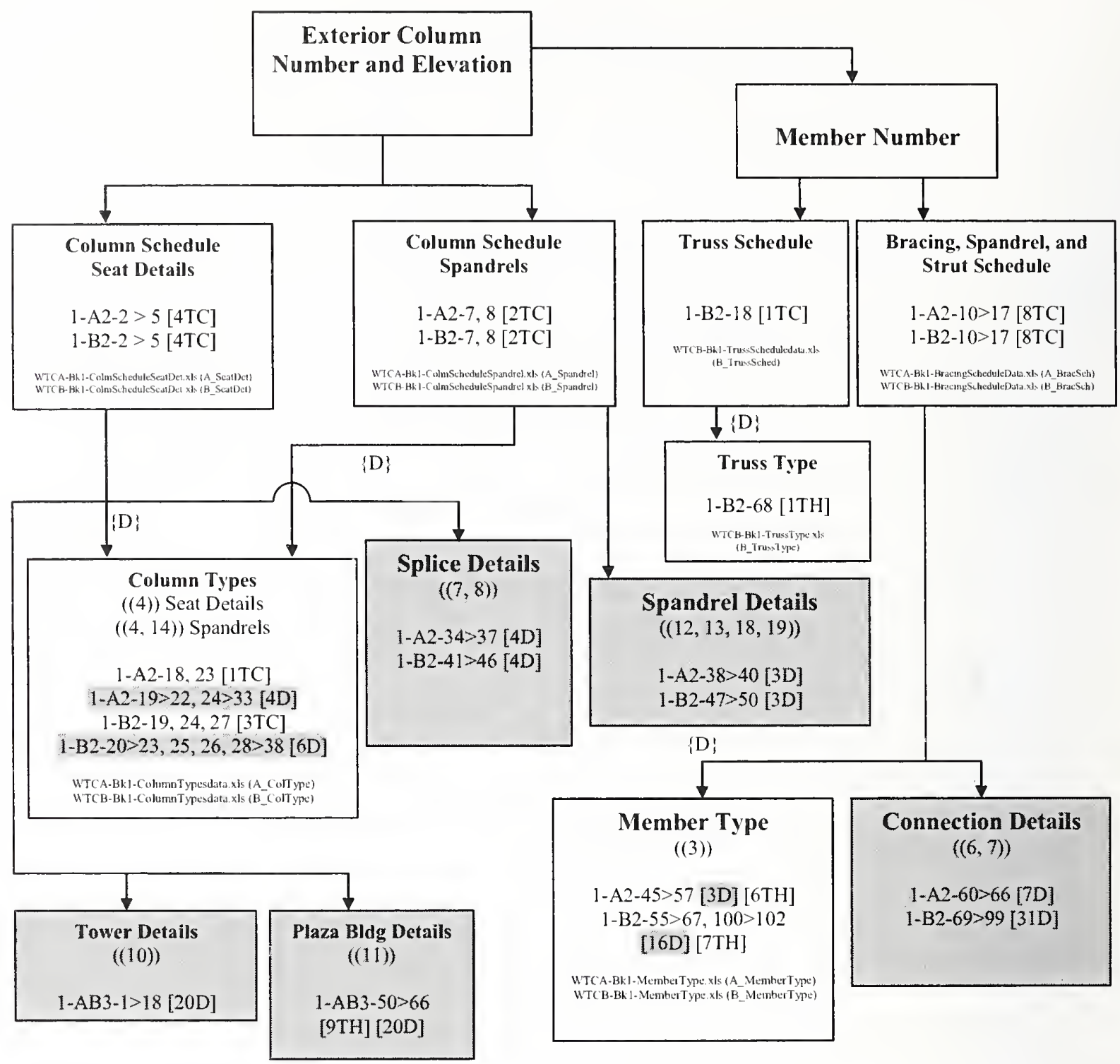

Figure C-1. Drawing Book 1 - WTC 1 and WTC 2 exterior wall to elevation $363 \mathrm{ft}$. 


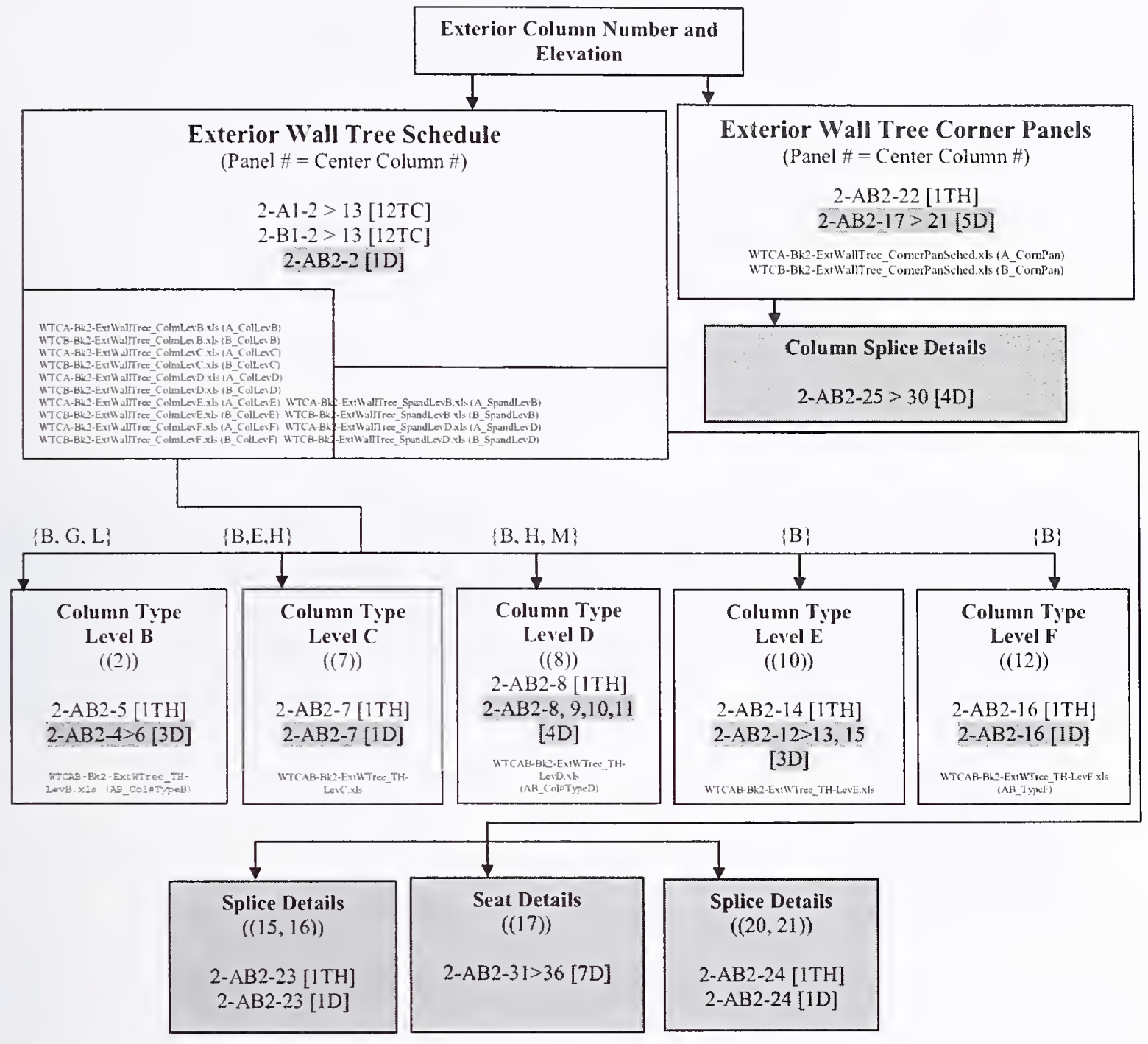

Figure C-2. Drawing Book $2-$ WTC 1 and WTC 2 exterior wall tree, elevation $363 \mathrm{ft}$ to floor 9 . 


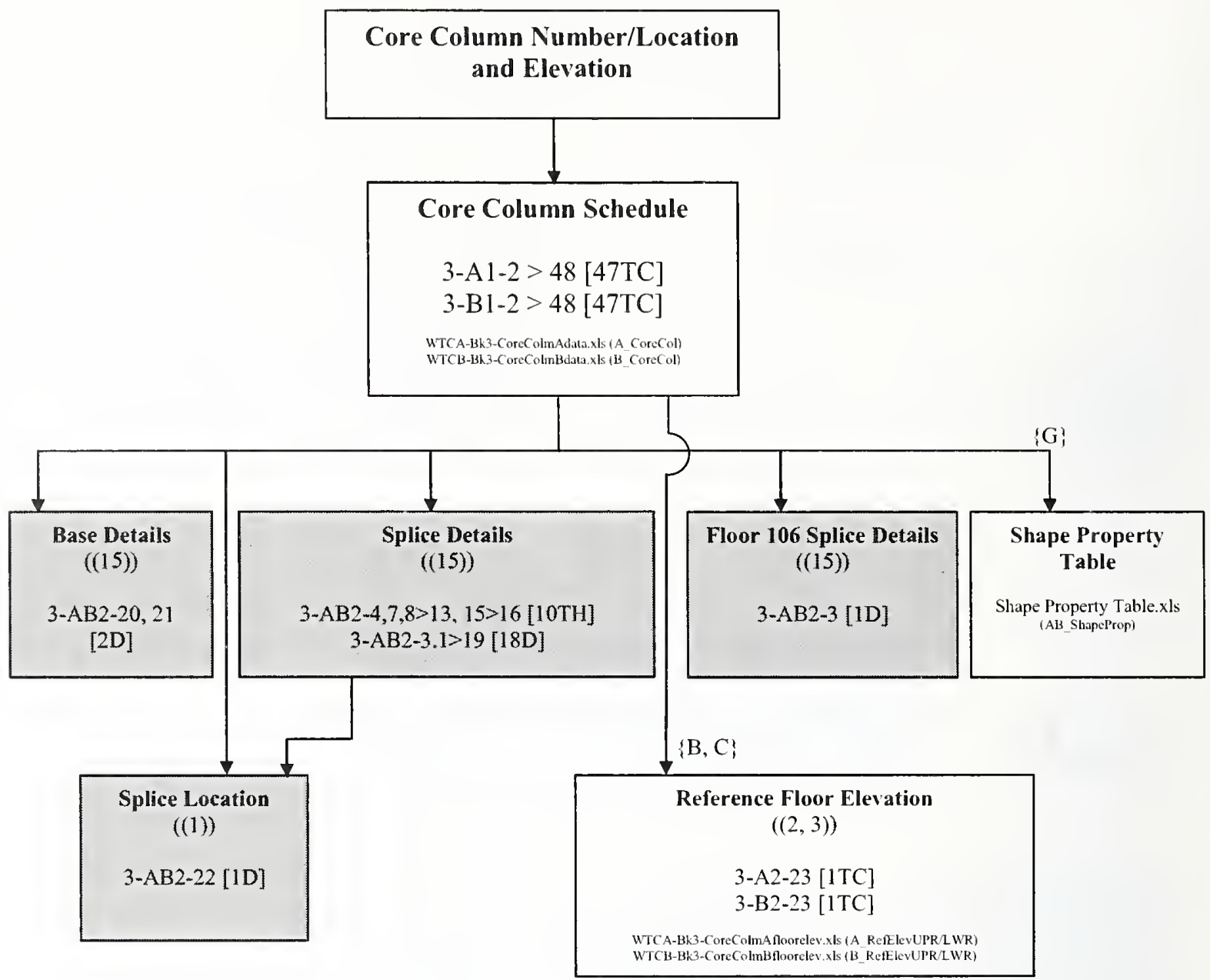

Figure C-3. Drawing Book 3 - WTC 1 and WTC 2 core columns, foundations to floor 106. 


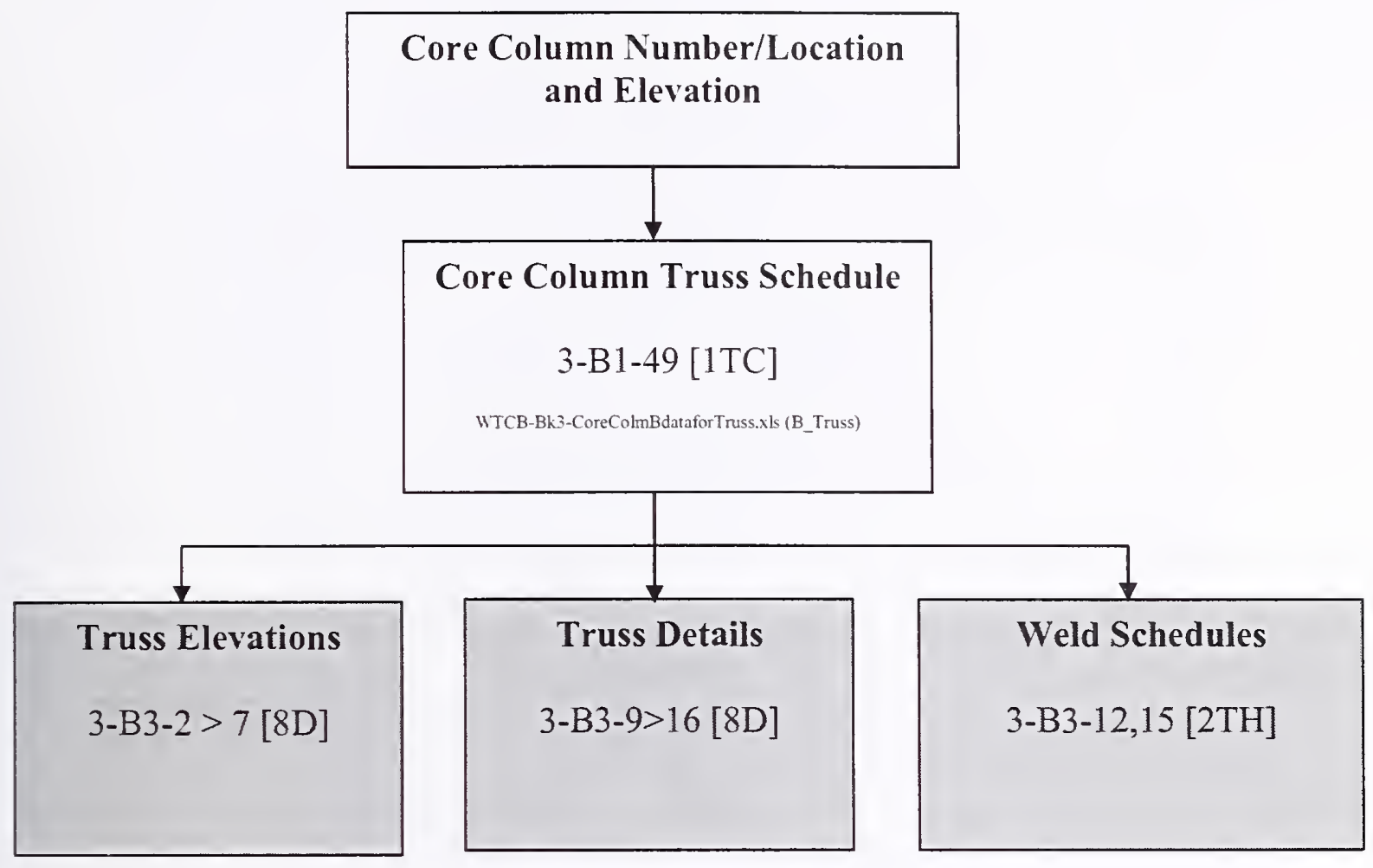

Figure C-4. Drawing Book $3-$ WTC 1 and WTC 2 core column trusses. 


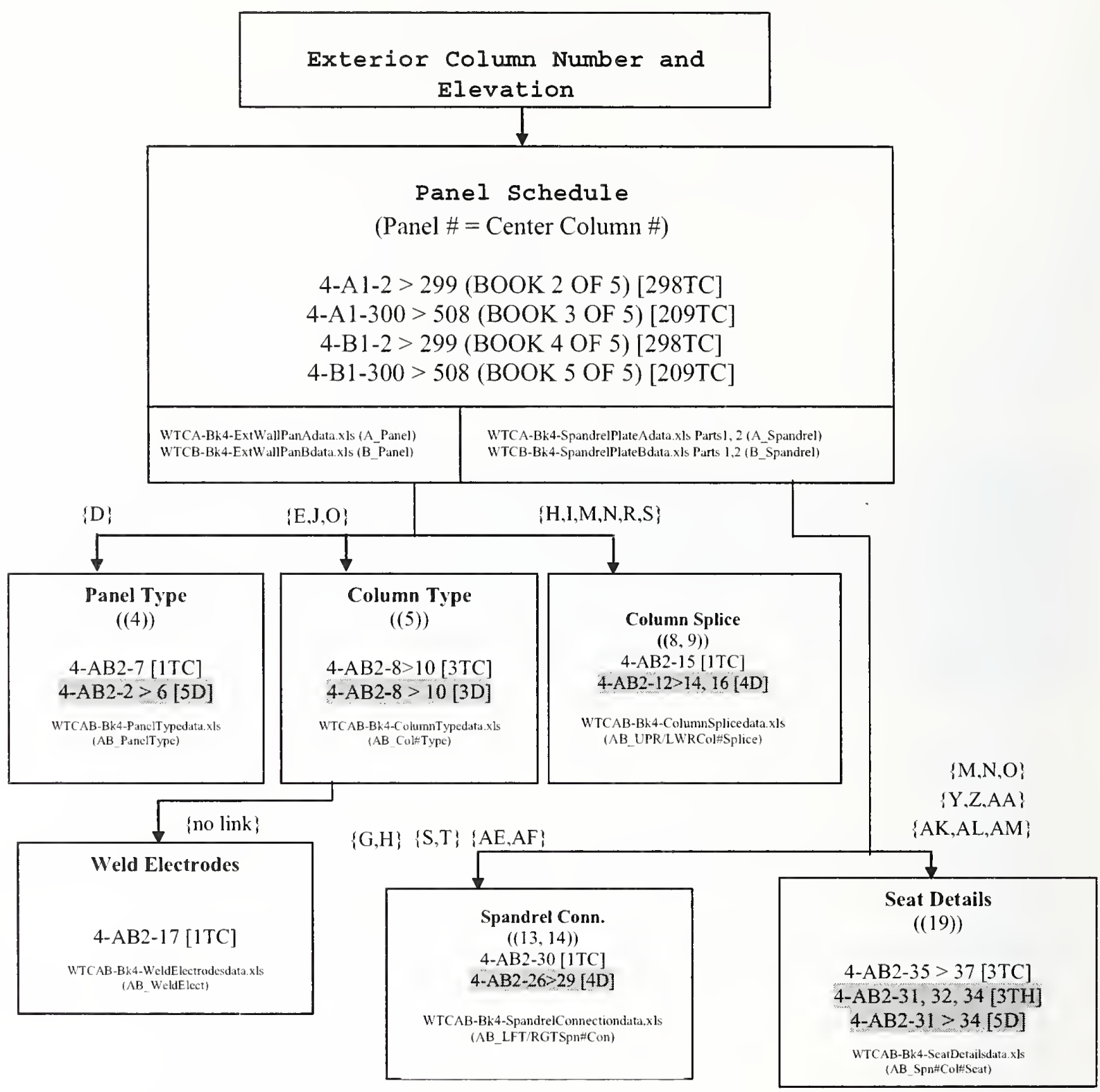

Figure C-5. Drawing Book 4-WTC 1 and WTC 2 exterior wall, floors 9 to 106. 


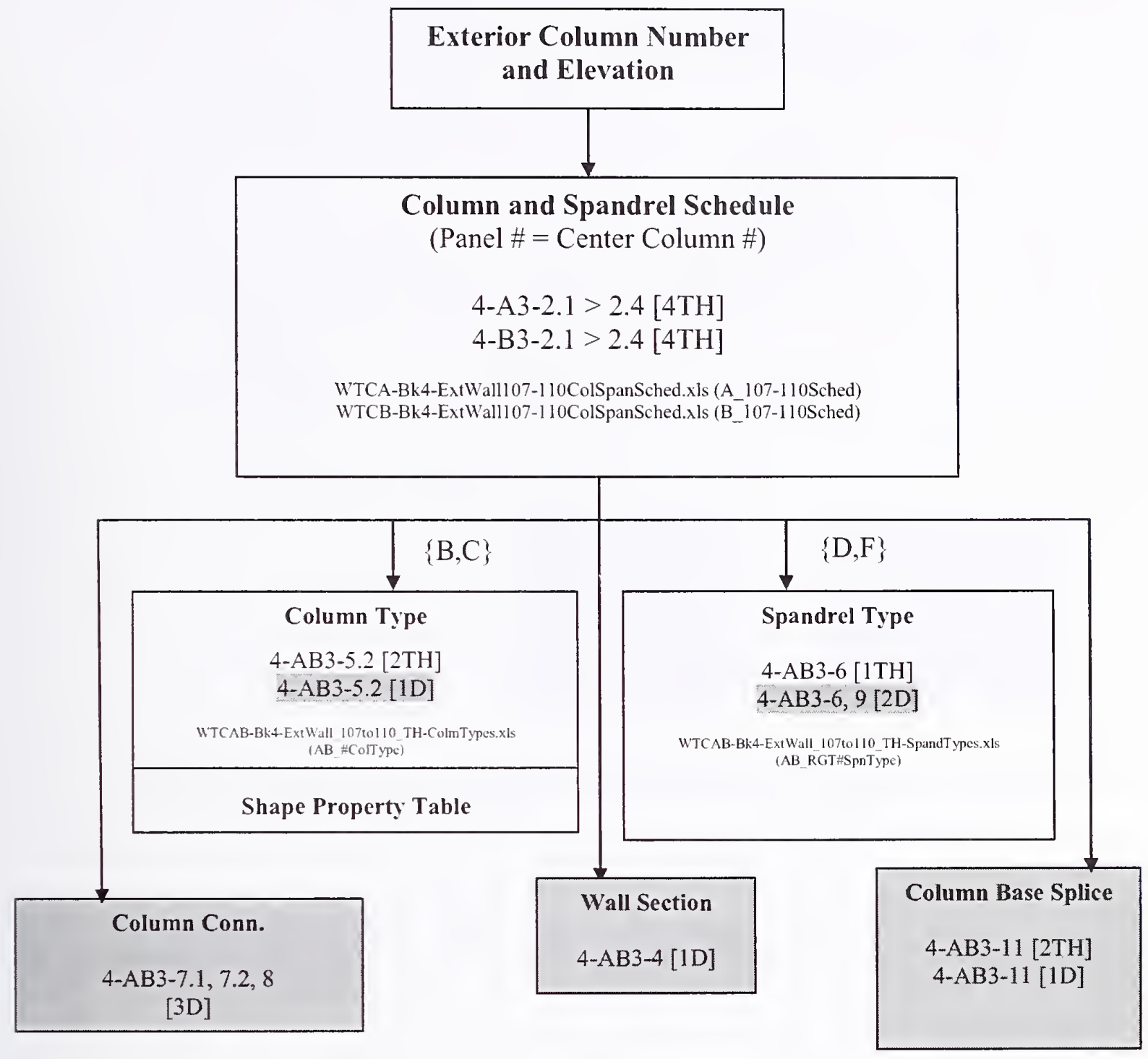

Figure C-6. Drawing Book 4 - WTC 1 and WTC 2 exterior wall, floors 107 to 110. 


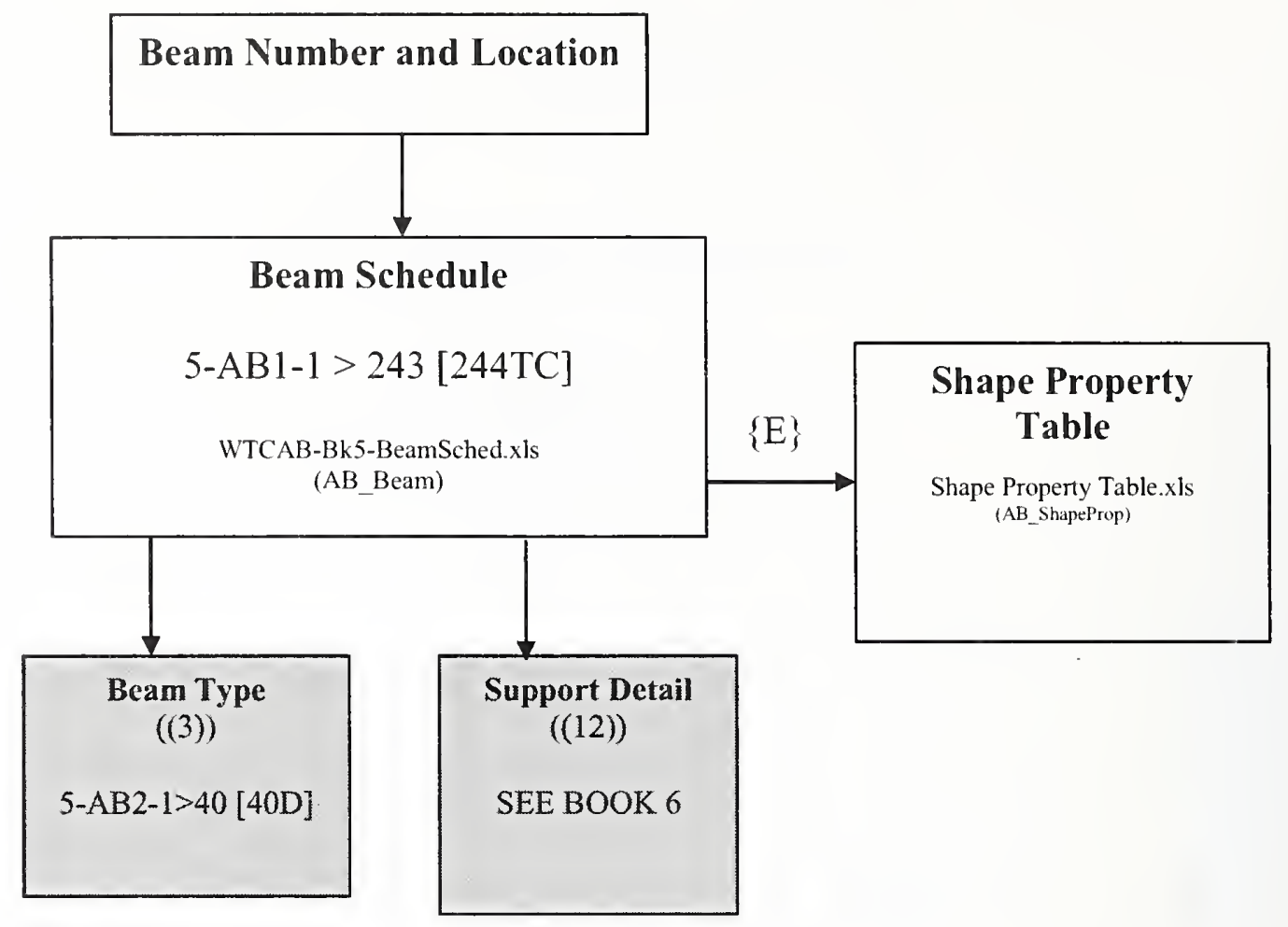

Figure C-7. Drawing Book $5-$ WTC 1 and WTC 2 beam schedule and types. 


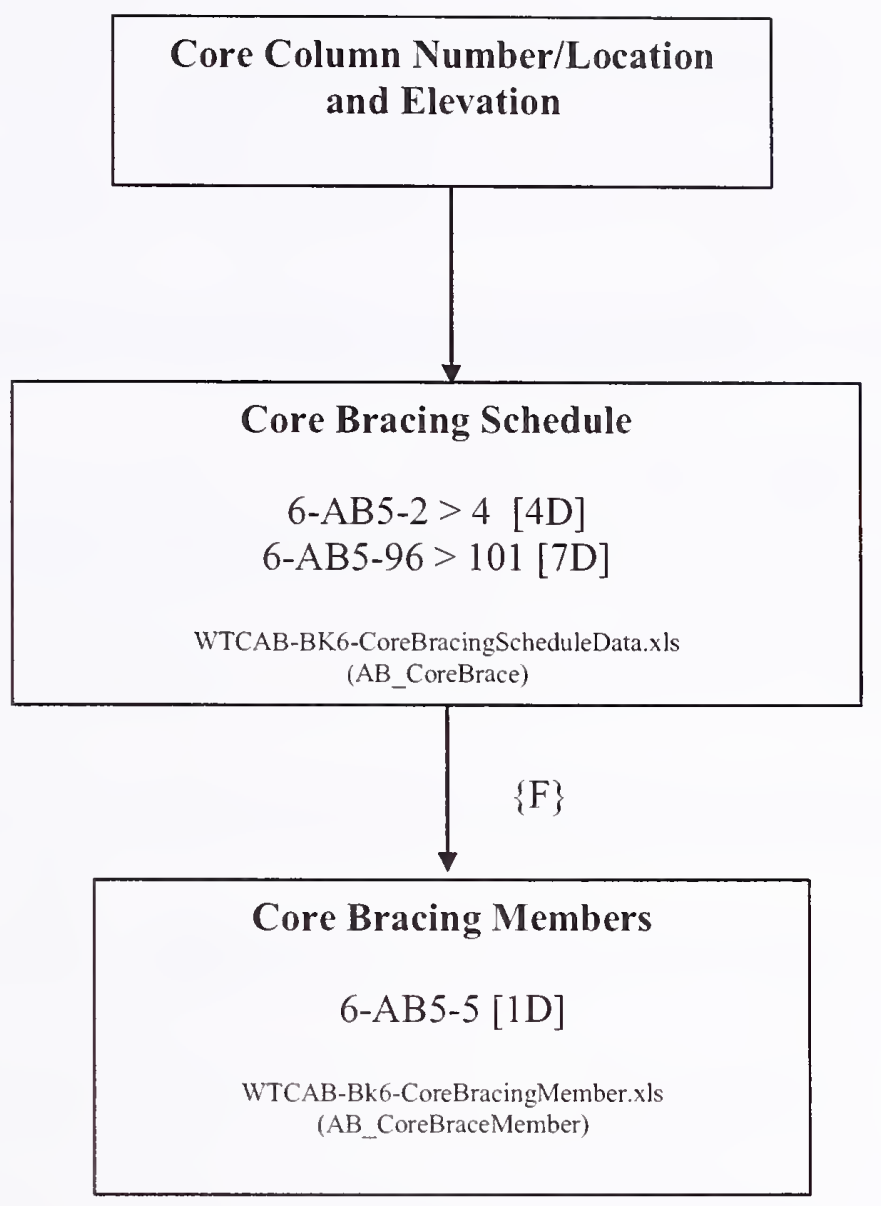

Figure C-8. Drawing Book $6-$ WTC 1 and WTC 2 core bracing schedule and types. 


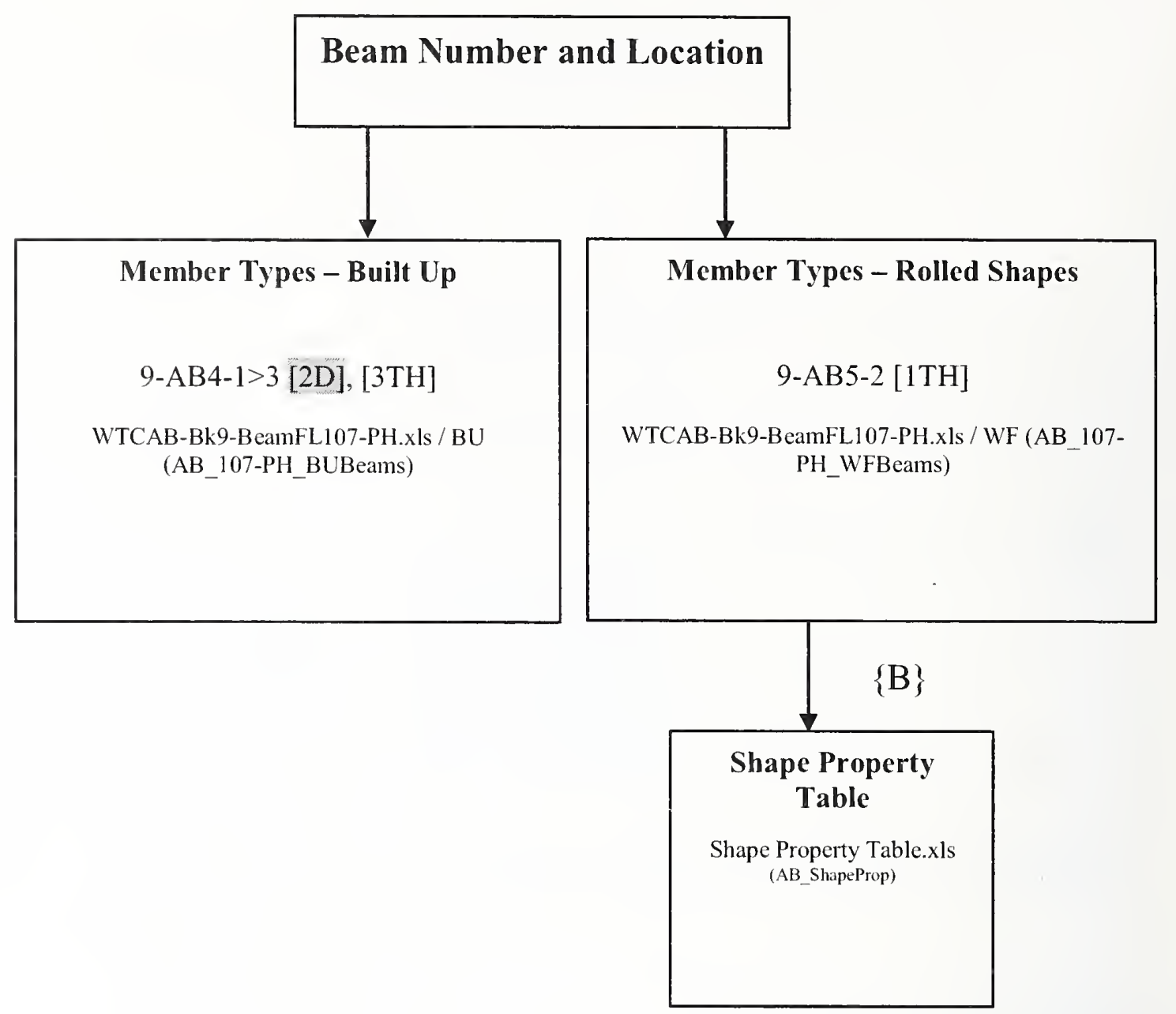

Figure C-9. Drawing Book $9-$ WTC 1 and WTC 2 floor 107 to penthouse beam schedule. 


\section{Appendix D \\ EXCEL FILE LIST AND DESCRIPTION}

Files with (*) include section property calculations

Files with (A) include multiple section properties calculations for some members

\section{Drawing Book 1}

WTCA-Bk1-ColumnTypesdata.xls * A

WTC Drawing Book 1: Tower A Exterior Wall to EL 363' Column Types

WTCA-Bk1-BracingScheduleData.xls

WTC Drawing Book 1: Tower A Exterior Wall to EL 363' Bracing, Spandrel and Strut Schedule

WTCA-Bk1-ColmScheduleSeatDet.xls

WTC Drawing Book 1: Tower A Exterior Wall to EL 363' Column Schedule - Seat Details

WTCA-Bk 1-ColmScheduleSpandrel.xls

WTC Drawing Book 1: Tower A Exterior Wall to EL 363' Column Schedule - Spandrels

WTCA-Bk1-MemberTypes.xls*

WTC Drawing Book 1: Tower A Exterior Wall to EL 363' Member Type

WTCB-Bk1-ColumnTypesdata.xls * ^

WTC Drawing Book 1: Tower B Exterior Wall to EL 363' Column Types

WTCB-Bk1-BracingScheduledata.xls

WTC Drawing Book 1: Tower B Exterior Wall to EL 363'Bracing, Spandrel and Strut Schedule

WTCB-Bk1-ColmScheduleSeatDet.xls

WTC Drawing Book 1: Tower B Exterior Wall to EL 363' Column Schedule - Seat Details

WTCB-Bk1-ColmScheduleSpandrel.xls

WTC Drawing Book 1: Tower B Exterior Wall to EL 363' Column Schedule - Spandrels

WTCB-Bk1-MemberTypes.xls *

WTC Drawing Book 1: Tower B Exterior Wall to EL 363' Member Type

WTCB-Bk1-TrussScheduledata.xls *

WTC Drawing Book 1: Tower B Exterior Wall to EL 363'Truss Schedule

WTCB-Bkl-TrussType.xls

WTC Drawing Book 1: Tower B Exterior Wall to EL 363'Truss Type 


\section{Drawing Book 2}

WTCAB-Bk2-ExtWTree_TH-LevB.xls*

WTC Drawing Book 2: Tower A and B Exterior Wall Tree EL 363' to Floor 9 - Colum Type at Level $B$

WTCAB-Bk2-ExtWTree_TH-LevC.xls *

WTC Drawing Book 2: Tower A and B Exterior Wall Tree EL 363' to Floor 9 - Column Type at Level C

WTCAB-Bk2-ExtWTree_TH-LevD.xls *

WTC Drawing Book 2: Tower A and B Exterior Wall Tree EL 363' to Floor 9 - Column Type at Level $D$

WTCAB-Bk2-ExtWTree_TH-LevE.xls * *

WTC Drawing Book 2: Tower A and B Exterior Wall Tree EL 363' to Floor 9 - Column Type at Level E

WTCAB-Bk2-ExtWTree_TH-LevF.xls *

WTC Drawing Book 2: Tower A and B Exterior Wall Tree EL 363' to Floor 9 - Column Type at Level $F$

WTCA-Bk2-ExtWallTree ColmLevB.xls

WTC Drawing Book 2: Tower A Exterior Wall Tree EL 363' to Floor 9 - Exterior Wall Tree Schedule at Level $B$

WTCA-Bk2-ExtWallTree_ColmLevC.xls

WTC Drawing Book 2: Tower A Exterior Wall Tree EL 363' to Floor 9 - Exterior Wall Tree Schedule at Level C

WTCA-Bk2-ExtWallTree_ColmLevD.xls

WTC Drawing Book 2: Tower A Exterior Wall Tree EL 363' to Floor 9 - Exterior Wall Tree Schedule at Level D

WTCA-Bk2-ExtWallTree_ColmLevE.xls

WTC Drawing Book 2: Tower A Exterior Wall Tree EL 363' to Floor 9 - Exterior Wall Tree Schedule at Level E

WTCA-Bk2-ExtWallTree_ColmLevF.xls

WTC Drawing Book 2: Tower A Exterior Wall Tree EL 363' to Floor 9 - Exterior Wall Tree Schedule at Level $F$

WTCA-Bk2-ExtWallTree_CornerPanSched.xls * *

WTC Drawing Book 2: Tower A Exterior Wall Tree EL 363' to Floor 9 - Exterior Wall Tree Corner Panel Schedule

WTCA-Bk2-ExtWallTree_SpandLevB.xls

WTC Drawing Book 2: Tower A Exterior Wall Tree EL 363' to Floor 9 - Exterior Wall Tree Spandrel Schedule at Level $B$

WTCA-Bk2-ExtWallTree_SpandLevD.xls 
WTC Drawing Book 2: Tower A Exterior Wall Tree EL 363' to Floor 9 - Exterior Wall Tree Spandrel Schedule at Level $D$

WTCB-Bk2-ExtWallTree_ColmLevB.xls

WTC Drawing Book 2: Tower B Exterior Wall Tree EL 363' to Floor 9 - Exterior Wall Tree Schedule at Level $B$

WTCB-Bk2-ExtWallTree_ColmLevC.xls WTC Drowing Book 2: Tower B Exterior Wall Tree EL 363' to Floor 9 - Exterior Wall Tree Schedule at Level $C$

WTCB-Bk2-ExtWallTree_ColmLevD.xls WTC Drawing Book 2: Tower B Exterior Wall Tree EL 363' to Floor 9 - Exterior Wall Tree Schedule at Level D

WTCB-Bk2-ExtWallTree_ColmLevE.xls WTC Drawing Book 2: Tower B Exterior Wall Tree EL 363' to Floor 9 - Exterior Wall Tree Schedule at Level E

WTCB-Bk2-ExtWallTree_ColmLevF.xls WTC Drawing Book 2: Tower B Exterior Wall Tree EL 363' to Floor 9 - Exterior Wall Tree Schedule at Level F

WTCB-Bk2-ExtWallTree_CornerPanSched.xls * WTC Drawing Book 2: Tower B Exterior Wall Tree EL 363' to Floor 9 - Exterior Wall Tree Corner Panel Schedule

WTCB-Bk2-ExtWallTree_SpandLevB.xls WTC Drawing Book 2: Tower B Exterior Wall Tree EL 363' to Floor 9 - Exterior Wall Tree Spandrel Schedule at Level B

WTCB-Bk2-ExtWallTree_SpandLevD.xls WTC Drawing Book 2: Tower B Exterior Wall Tree EL 363' to Floor 9 - Exterior Wall Tree Spandrel Schedule at Level D

\section{Drawing Book 3}

WTCA-Bk3-CoreColmAdata.xls * WTC Drawing Book 3: Tower A Core Columns Foundation to Floor 106 - Core Column Schedule

WTCA-Bk3-CoreColmAfloorelev.xls WTC Drawing Book 3: Tower A Core Columns Foundation to Floor 106 Reference Floor Elevation

WTCB-Bk3-CoreColmBdata.xls * WTC Drawing Book 3: Tower B Core Columns Foundation to Floor 106 - Core Column Schedule 
WTCB-Bk3-CoreColmBdataforTruss.xls *

WTC Drawing Book 3: Tower B Core Columns Foundation to Floor 106 - Core Column Truss Schedule

WTCB-Bk3-CoreColmBfloorelev.xls

WTC Drawing Book 3: Tower B Core Columns Foundation to Floor 106 Reference Floor Elevation

\section{Drawing Book 4}

WTCAB-Bk4-ColumnTypedata.xls *

WTC Drawing Book 4: Tower A and B Exterior Wall above $9^{\text {th }}$ Floor (To $106^{\text {th }}$ Floor) Column Type

WTCAB-Bk4-PanelTypedata.xls

WTC Drawing Book 4: Tower A and B Exterior Wall above $9^{\text {th }}$ Floor (To $106^{\text {th }}$ Floor) Panel Type

WTCAB-Bk4-SeatDetailsdata.xls

WTC Drawing Book 4: Tower A and B Exterior Wall above $9^{\text {th }}$ Floor (To $106^{\text {th }}$ Floor) Seat Details

WTCAB-Bk4-SpandrelConnectiondata.xls

WTC Drawing Book 4: Tower A and B Exterior Wall above $9^{\text {th }}$ Floor (To $106^{\text {th }}$ Floor) Spandrel Connection

WTCAB-Bk4-WeldElectrodesdata.xls

WTC Drawing Book 4: Tower A and B Exterior Wall above $9^{\text {th }}$ Floor (To $106^{\text {th }}$ Floor) Weld Electrodes

WTCAB-Bk4-ColumnSplicedata.xls

WTC Drawing Book 4: Tower A and B Exterior Wall above $9^{\text {th }}$ Floor (To $106^{\text {th }}$ Floor) Column Spice

WTCA-Bk4-ExtWallPanAdata.xls

WTC Drawing Book 4: Tower A Exterior Wall above $9^{\text {th }}$ Floor (To $106^{\text {th }}$ Floor) Panel Schedule

WTCA-Bk4-SpandrelPlateAdata_part1.xls

WTC Drawing Book 4: Tower A Exterior Wall above $9^{\text {th }}$ Floor $\left(\right.$ To $106^{\text {th }}$ Floor) Spandrel Schedule Part 1

WTCA-Bk4-SpandrelPlateAdata_part2.xls

WTC Drawing Book 4: Tower A Exterior Wall above $9^{\text {th }}$ Floor (To $106^{\text {th }}$ Floor) Spandrel Schedule Part 2

WTCB-Bk4-ExtWallPanBdata.xls

WTC Drawing Book 4: Tower B Exterior Wall above $9^{\text {th }}$ Floor $\left(\right.$ To $106^{\text {th }}$ Floor) Panel Schedule

WTCB-Bk4-SpandrelPlateBdata_partl.xls

WTC Drawing Book 4: Tower B Exterior Wall above $9^{\text {th }}$ Floor (To $106^{\text {th }}$ Floor) Spandrel Schedule Part 1 
WTCB-Bk4-SpandrelPlateBdata_part2.xls

WTC Drawing Book 4: Tower B Exterior Wall above $9^{\text {th }}$ Floor (To $106^{\text {th }}$ Floor) Spandrel

Schedule Part 2

WTCAB-Bk4-ExtWall_107to110_TH-ColmTypes.xls*

WTC Drawing Book 4: Tower A and B Exterior Wall Floors 107 to 110 Column Type

WTCAB-Bk4-ExtWall_107tol10_TH-SpandTypes.xls*

WTC Drawing Book 4: Tower A and B Exterior Wall Floors 107 to 110 Spandrel Type

WTCA-Bk4-ExtWall 107-110ColSpanSched.xls

WTC Drawing Book 4: Tower A Exterior Wall Floors 107 to 110 Column and Spandrel Schedule

WTCB-Bk4-ExtWall 107-1 10ColSpanSched.xls

WTC Drawing Book 4: Tower B Exterior Wall Floors 107 to 110 Column and Spandrel Schedule

\section{Drawing Book 5}

WTCAB-Bk5-BeamSched.xls

WTC Drawing Book 5: Tower A and B Beam Schedule

\section{Drawing Book 6}

WTCAB-Bk6-CoreBracingMember.xls *

WTC Drawing Book 6: Tower A and B Core Bracing Members

WTCAB-Bk6-CoreBracingScheduleData.xls

WTC Drawing Book 6: Tower A and B Core Bracing Schedule

\section{Drawing Book 9}

WTCAB-Bk9-BeamFL107-PH.xls -

WTC Drawing Book 9: Tower A and B Floors 107 to Penthouse Beam Member Types

\section{Included outside of the Drawing Book folders:}

Shape Property Table.xls

Shape Property Table 
This page intentionally left blank. 


\section{Appendix $E$ \\ RELATIONAL DATABASE FILE LIST AND DESCRIPTION}

(Files with $(*)$ include section property calculations)

(Files with (A) include multiple section properties calculations for some members)

WTCA_DBk $1 . \mathrm{mdb} \div$ a

WTC Drawing Book 1: Tower A Exterior Wall to EL. 363

WTCB_DBk1.mdb $*$ ^

WTC Drawing Book 1: Tower B Exterior Wall to EL. 363'

WTCA DBk2.mdb * a

WTC Drawing Book 2: Tower A Exterior Wall Tree EL. 363' to Floor 9

WTCB_DBk2.mdb $\bullet$

WTC Drawing Book 2: Tower B Exterior Wall Tree EL. 363' to Floor 9

WTCA_DBk3_col_foundation.mdb *

WTC Drawing Book 3: Tower A Core Columns Foundations to Floor 106

WTCB_DBk3_col_foundation.mdb *

WTC Drawing Book 3: Tow'er B Core Columns Foundations to Floor 106

WTCB_DBk3_col_truss.mdb *

WTC Drawing Book 3: Tower B Core Column Trusses

WTCA DBk4 9-106.mdb * a

WTC Drawing Book 4: Tower A Exterior Wall above $9^{\text {th }}$ Floor $\left(\right.$ To $106^{\text {th }}$ Flr)

WTCB_DBk4_9-106.mdb 2 ^

WTC Drawing Book 4: Tower B Exterior Wall above $9^{\text {th }}$ Floor $\left(\right.$ To $106^{\text {th }}$ Flr $)$

WTCA_DBk4_107-110.mdb 2

WTC Drawing Book 4: Tower A Exterior Wall Floor 107 to Floor 110

WTCB_DBk4 107-110.mdb *

WTC Drawing Book 4: Tower B Exterior Wall Floor 107 to Floor 110

WTCAB_DBk5.mdb

WTC Drawing Book 5: Tower A and B Beam Schedules and Types

WTCAB_DBk6.mdb $\%$

WTC Drawing Book 6: Tower A and B Core Bracing Schedules and Types 
WTCAB DBk9.mdb*

WTC Drawing Book 9: Tower A and B Floor 107 to Penthouse Beam Schedules 


\section{Appendix F \\ RELATIONAL DATABASE TUTORIAL}

\section{Database Structure:}

The relational database was developed using Microsoft Access 2002. Each database was set up based on the WTC Drawing Book flowcharts (refer to Appendix C). Each flowchart has a separate database for WTC 1 and WTC 2. The arrows in the flowcharts depict the links or common threads between tables. The relational database allows the data to be viewed and exported based on the user's preferences and communicated to the database via a query (a type of filter). Note: All screen views and examples below are based on the Drawing Book 2, WTC 1 database (WTC_DBk2_TWRA.mdb).

\section{Viewing Tables:}

To view a database table, first make sure that the tables are listed in the database window. To do this, click on "Tables" under Objects in the upper left box. The list of database tables should appear in the right hand box. (Fig. F-1) Note that the table names are listed in the flowcharts of Appendix C.

Double-click on the desired table to open it. The table will look similar to an Excel spreadsheet with columns and rows of data.

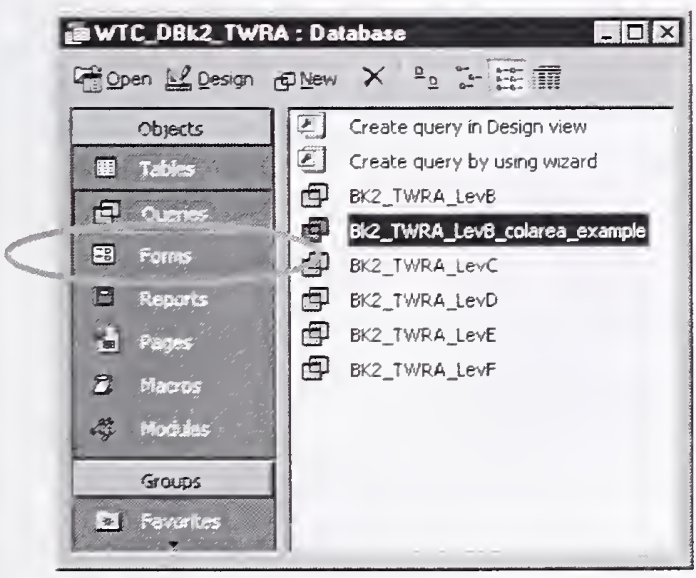

Figure F-2. List of database queries.

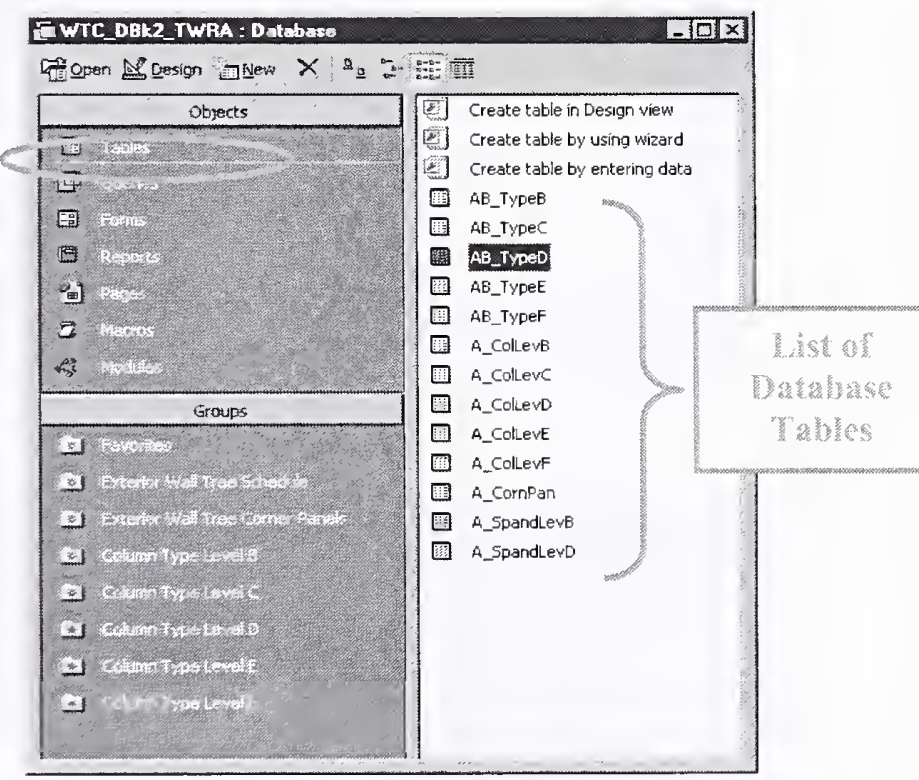

Figure F-1. List of database tables.

\section{Running Queries:}

To run a query, open up the query view from the main Database window by clicking on "Queries" under the Objects title in the upper left corner of the window. (Fig. F-2) A list of queries will be displayed in the box on the right.

Double-click on the dcsired query to run the query. 
Note: All of the resident queries contain the established links between different tables. These queries list all data from all linked tables. To include only desired data in a query, see "Creating Custom Queries" below.

\section{Creating Custom Queries:}

Note: All custom queries must be created from one of the original queries as the links between tables have already been established in these queries. Any new query would not contain these links and would require these links to be created manually.

Start by saving a new version of the query to be edited. Right-click on the query to be edited and select "Save As..." from the sub-menu that appears. (Fig, F-3)

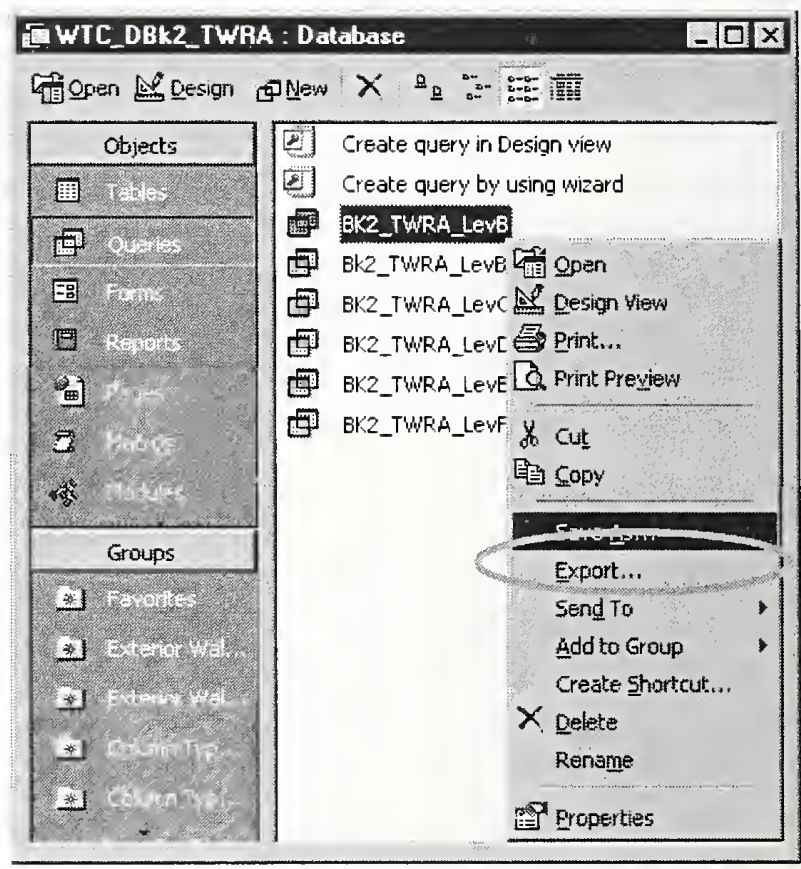

Figure F-3. Copying a query.

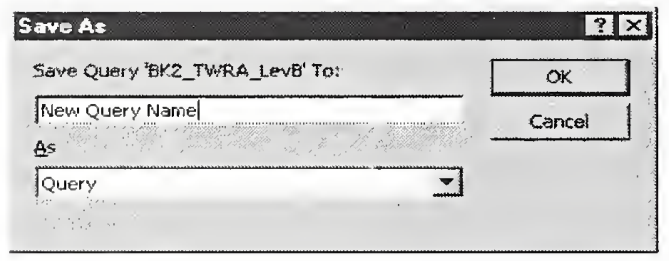

Figure F-4. Naming new query.
To edit the query, select the newly copied query and click on the "Design" button on the upper left corner of the database window (Fig. F-5). The query will appear in design (edit) view.
In the pop-up window, type in a name for the new query. Make sure that "Query" is selected in the "As" select-box. (Fig. F-4)

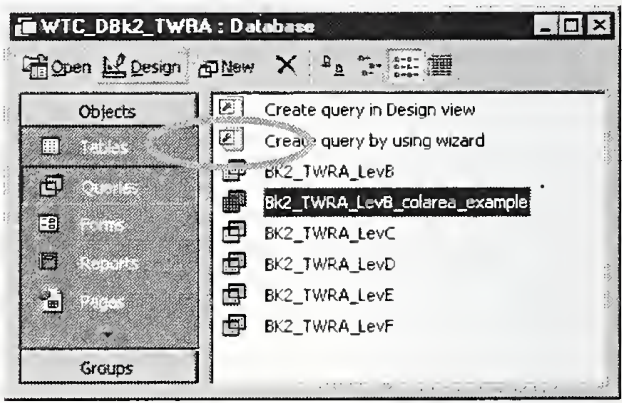

Figure F-5. Selecting design view for a query. 
The design view shows all table associations (depicted by arrows) for this query. The first box (from left) shows the main table. The tables to the right are the ones that are linked from the main table. The arrows show where the association is made. For example, "CollType" in the main table (table A_ColLevB) links to "Column" in the AB_CollTypeB table. The lower part of the view shows the query selections that will be displayed when the query is run. (Fig. F-6)

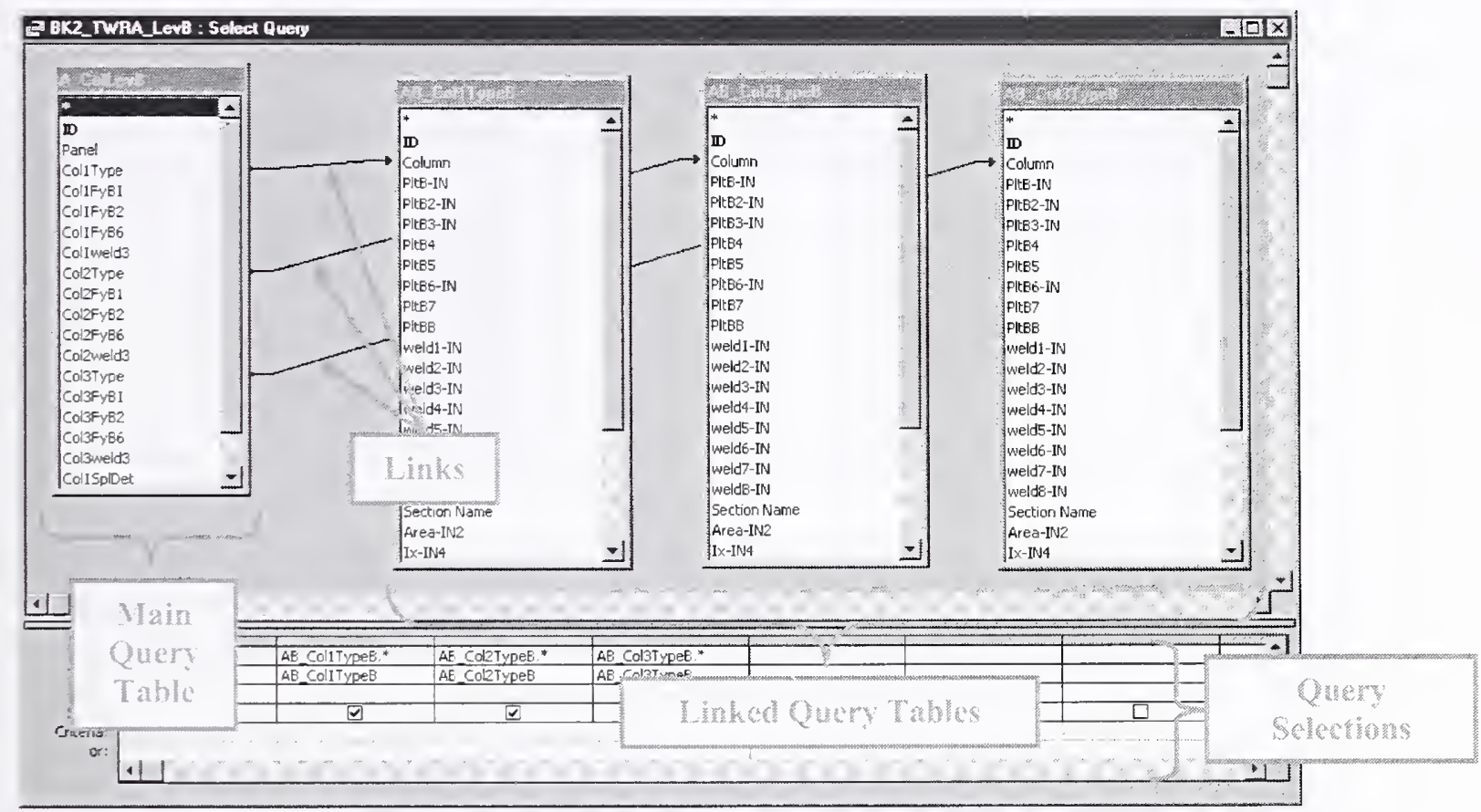

Figure F-6. Query design view.

First delete all the present query selections by clicking on the top row of each query selection (Fig. F-7) and pressing the delete key on the keyboard. Do this until all text is deleted from the query selections (the boxes themselves will not disappear)

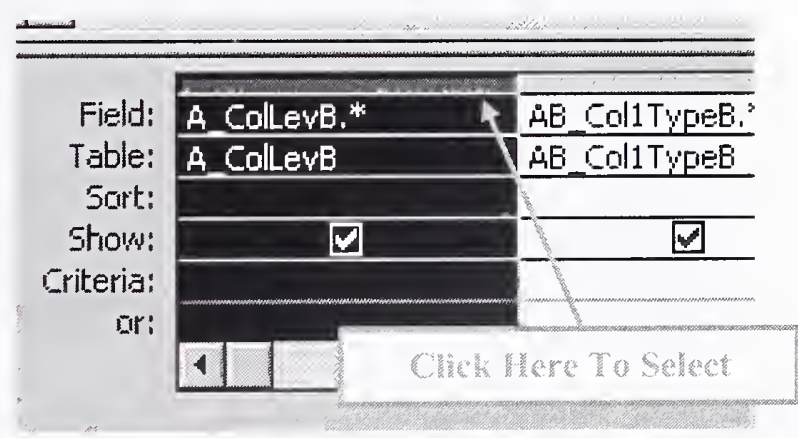

Figure F-7. Selecting query selection. 
Double-click on the data to be included in your query (see example below).

Note: Selecting the asterisk $\left(^{*}\right)$ at the top of each table will list all fields in that table.

Example: How to include the panel, the three column types, as well as their associated areas in one table.

Note: This example is an example query called "Bk2_TWRA_LevB_colarea_example" in the WTC Book 2 Tower A database.

Once the original query selections are deleted, select the "Panel" field from the main table (table A_ColLevB) by double-clicking on it. It should appear as a query selection below (Fig. F-8).

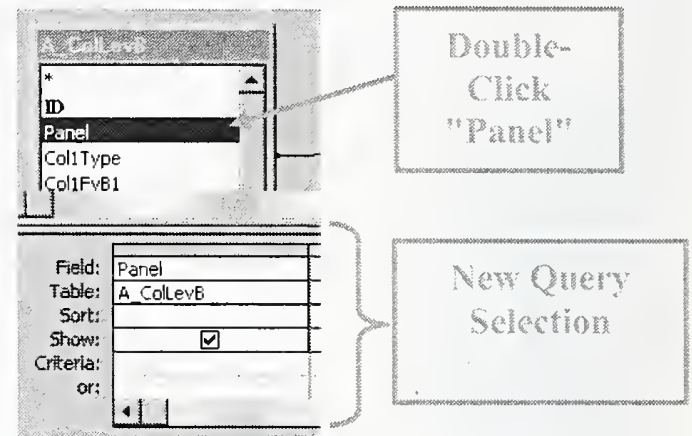

Figure F-8. Select panel field.

Select "Col1Type" from the main table. Then, select the "Area-IN2" field from the AB_Col1TypeB table. For the second column, select "Col2Type" from the main table and "Area-IN2" from the AB_Col2TypeB table. Repeat this for the third column, choosing the last table for the area of the column. There should now be 7 fields displaying in the Query Selection.

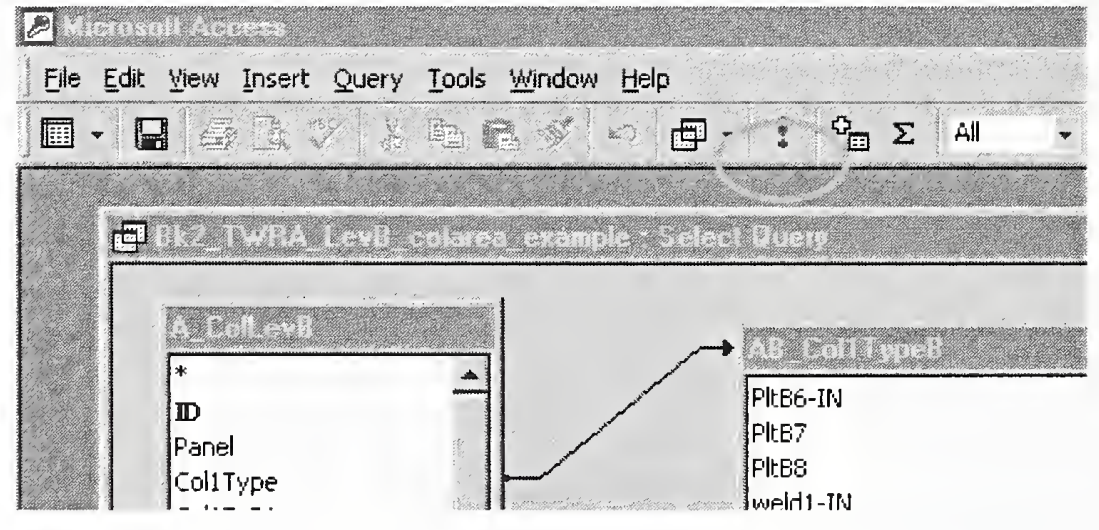

To run this query, click on the exclamation mark Run button - on the middle top bar of the MS Access window. (Fig. F-9).

Note: To save the query, either click on the save button, or go to File Menu - Save.

Figure F-9. Run query button.

\section{Exporting Data:}

Data can be exported from any query or table into a number of formats, including text and Excel formats. To export a query, open the query and select File Menu - Export. Select the location, name, and the type to save as (from the drop-down menu) and click "Save All". 


\section{Appendix G \\ CATEGORIZATION OF FLOOR CONSTRUCTION TYPES FOR AREAS OUTSIDE OF CORE}

The structural drawings for the floors in both towers were reviewed to identify structural similarities within the areas outside the core. Table G-1 summarizes the construction types and space usage for each floor for both towers. Information regarding the categorization and description of floor construction types are provided in Figs. G-1 through $\mathrm{G}-4$. Based on this review, the typical truss-framed and beam-framed floors were selected for modeling. 
Table G-1. Representative categorizations of floor construction types outside of core.

Tower A Floor Framing

\begin{tabular}{|c|c|c|}
\hline Ftoor & Space Usage & Const. Type \\
\hline PHRoof & Roof & Type 12 \\
\hline 110 & TVIStorage & Type 12 \\
\hline 109 & Upper Mech FI & Type 13 \\
\hline 108 & Lower Mech FI & Type 12 \\
\hline 107 & Restaurant & Type 12 \\
\hline 106 & Tenant & Type 10 \\
\hline 105 & Tenant & Type 1 \\
\hline 104 & Tenant & Type 1 \\
\hline 103 & Tenant & Type 1 \\
\hline 102 & Tenant & Type 1 \\
\hline 101 & Tenant & Type 1 \\
\hline 100 & Tenant & Type 1 \\
\hline 99 & Tenant & Type 1 \\
\hline 98 & Tenant & Type 1 \\
\hline 97 & Tenant & Type 1 \\
\hline 96 & Tenant & Type 1 \\
\hline 95 & Tenant & Type 1 \\
\hline 94 & Tenant & Type 1 \\
\hline 93 & Tenant & Type 1 \\
\hline 92 & Tenant & Type 2 \\
\hline 91 & Tenant & Type 1 \\
\hline 90 & Tenant & Type 1 \\
\hline 89 & Tenant & Type 1 \\
\hline 88 & Tenant & Type 1 \\
\hline 87 & Tenant & Type 1 \\
\hline 86 & Tenant & Type 1 \\
\hline 85 & Tenant & Type 1 \\
\hline 84 & Tenant & Type 1 \\
\hline 83 & Tenant & Type 9 \\
\hline 82 & Tenant & Type 9 \\
\hline 81 & Tenant & Type 9 \\
\hline 80 & Tenant & Type 9 \\
\hline 79 & Upper Escalator & Type 8 \\
\hline 78 & Sky Lobby & Type 7 \\
\hline 77 & Lower Escalator & Type 12 \\
\hline 76 & Upper Mech FI & Type 13 \\
\hline 75 & Lower Mech FI & Type 12 \\
\hline 74 & Tenant & Type 1 \\
\hline 73 & Tenant & Type 1 \\
\hline 72 & Tenant & Type 1 \\
\hline 71 & Tenant & Type 1 \\
\hline 70 & Tenant & Type 1 \\
\hline 69 & Tenant & Type 1 \\
\hline 68 & Tenant & Type 1 \\
\hline 67 & Tenant & Type 6 \\
\hline $60-66$ & Tenant & Type 1 \\
\hline 59 & Tenant & Type 2 \\
\hline $50-58$ & Tenant & Type 1 \\
\hline 49 & Tenant & Type 3 \\
\hline 48 & Tenant & Type 3 \\
\hline 47 & Tenant & Type 3 \\
\hline 46 & Tenant & Type 3 \\
\hline 45 & Upoer Escalator & Type 5 \\
\hline 44 & Sky Lobby & Type 4 \\
\hline 43 & Lower Escalator & Type 12 \\
\hline 42 & Upper Mech & Type 13 \\
\hline 41 & Lower Mech & Type 12 \\
\hline $27-40$ & Tenant & Type 1 \\
\hline 26 & Tenant & Type 1 \\
\hline 25 & Tenant & Type 2 \\
\hline $14-24$ & Tenant & Type 1 \\
\hline 13 & Tenant & Type 1 \\
\hline 12 & Tenant & Type 1 \\
\hline 11 & Tenant & Type 1 \\
\hline 10 & Tenant & Type 1 \\
\hline 9 & Tenant & Type 12 \\
\hline 8 & Upper Mech & Type 13 \\
\hline 7 & Lower Mech & Type 12 \\
\hline $3-6$ & Core Only (Storage) & NA \\
\hline 2 & Plaza - Lobby & Type 15 \\
\hline 1 & Concourse & Type 14 \\
\hline B1 & EL.294 & Type 14 \\
\hline
\end{tabular}

Tower B Floor Framing

\begin{tabular}{|c|c|c|}
\hline Floor & Space Usage & Const. Type \\
\hline PHRoof & Observation & Type 12 \\
\hline 110 & Storage & Type 12 \\
\hline 109 & Upper Mech FI & Type 13 \\
\hline 108 & Lower Mech FI & Type 12 \\
\hline 107 & Observation & Type 12 \\
\hline 106 & Tenant & Type 1 \\
\hline 105 & Tenant & Type 1 \\
\hline 104 & Tenant & Type 1 \\
\hline 103 & Tenant & Type 1 \\
\hline 102 & Tenant & Type 1 \\
\hline 101 & Tenant & Type 1 \\
\hline 100 & Tenant & Type 1 \\
\hline 99 & Tenant & Type 1 \\
\hline 98 & Tenant & Type 1 \\
\hline 97 & Tenant & Type 1 \\
\hline 96 & Tenant & Type 1 \\
\hline 95 & Tenant & Type 1 \\
\hline 94 & Tenant & Type 1 \\
\hline 93 & Tenant & Type 1 \\
\hline 92 & Tenant & Type 2 \\
\hline 91 & Tenant & Type 1 \\
\hline 90 & Tenant & Type 1 \\
\hline 89 & Tenant & Type 1 \\
\hline 88 & Tenant & Type 1 \\
\hline 87 & Tenant & Type 1 \\
\hline 86 & Tenant & Type 1 \\
\hline 85 & Tenant & Type 1 \\
\hline 84 & Tenant & Type 1 \\
\hline 83 & Tenant & Type 9 \\
\hline 82 & Tenant & Type 9 \\
\hline 81 & Tenant & Type 9 \\
\hline 80 & Tenant & Type 9 \\
\hline 79 & Upper Escalator & Type 8 \\
\hline 78 & Sky Lobby & Type 7 \\
\hline 77 & Lower Escalator & Type 12 \\
\hline 76 & Upper Mech FI & Type 13 \\
\hline 75 & Lower Mech FI & Type 12 \\
\hline 74 & Tenant & Type 1 \\
\hline 73 & Tenant & Type 1 \\
\hline 72 & Tenant & Type 1 \\
\hline 71 & Tenant & Type 1 \\
\hline 70 & Tenant & Type 1 \\
\hline 69 & Tenant & Type 1 \\
\hline 68 & Tenant & Type 1 \\
\hline 67 & Tenant & Type 1 \\
\hline $60-66$ & Tenant & Type 1 \\
\hline 59 & Tenant & Type 2 \\
\hline $50-58$ & Tenant & Type 1 \\
\hline 49 & Tenant & Type 3 \\
\hline 48 & Tenant & Type 3 \\
\hline 47 & Tenant & Type 3 \\
\hline 46 & Tenant & Type 3 \\
\hline 45 & Upper Escatator & Type 5 \\
\hline 44 & Sky Lobby & Type 4 \\
\hline 43 & Lower Escatator & Type 12 \\
\hline 42 & Upper Mech & Type 13 \\
\hline 41 & Lower Mech & Type 12 \\
\hline $27-40$ & Tenant & Type 1 \\
\hline 26 & Tenant & Type 1 \\
\hline 25 & Tenant & Type 2 \\
\hline $14 \cdot 24$ & Tenant & Type 1 \\
\hline 13 & Tenant & Type 11 \\
\hline 12 & Tenant & Type 11 \\
\hline 11 & Tenant & Type 11 \\
\hline 10 & Tenant & Type 11 \\
\hline 9 & Tenant & Type 12 \\
\hline 8 & Upper Mech & Type 13 \\
\hline 7 & Lower Mech & Type 12 \\
\hline $3-6$ & Core Only (Storage) & NA \\
\hline 2 & Plaza - Lobby & Type 15 \\
\hline 1 & Concourse & Type 14 \\
\hline B1 & EL. 294 & Type 14 \\
\hline
\end{tabular}

Expanded Zone

Impact Zone

$\square$ Combined Zones

Refer to Fig. G-1

through $\mathrm{G}-4$ for description of floor system categories 
Type 1 - WTC Typical Truss Floor Panel Plan

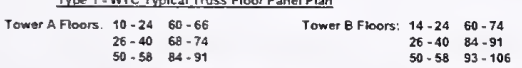

$\begin{array}{ll}26-40 & 68-74 \\ 50.58 & 84.91 \\ 93.105\end{array}$

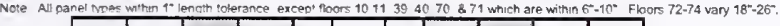

\begin{tabular}{llll|l|l|l|l|l|l|l} 
FR1 & ER1 & DR1 & CR1 & BR1 & A1 & B1 & $C_{1}$ & D1 & E1 & F1
\end{tabular}
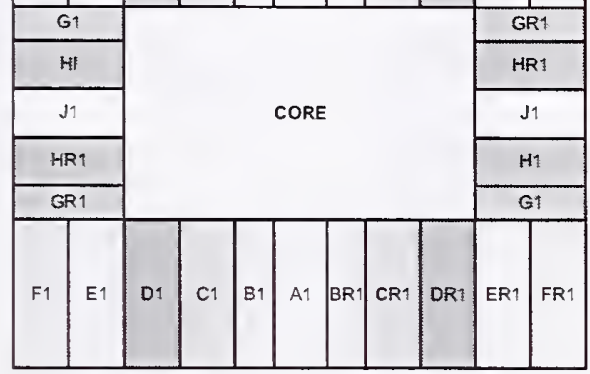

Type 2 -WTC Non-Typical Truss Floor Panel Plan

Note: Floois

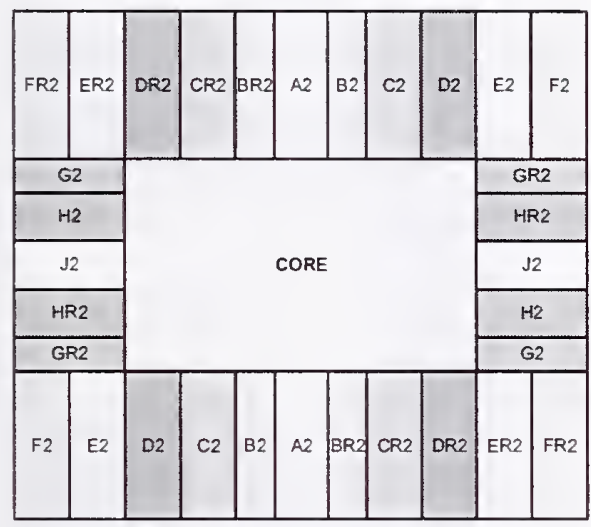

Iype 3-WTC Beam/Truss Floor Panel Plan

Note: $\mathrm{J} 1=\mathrm{K} 1=\mathrm{KR} 1$

Note: $H 1=M 1=M R 1$

(all C32T5 Trusses)

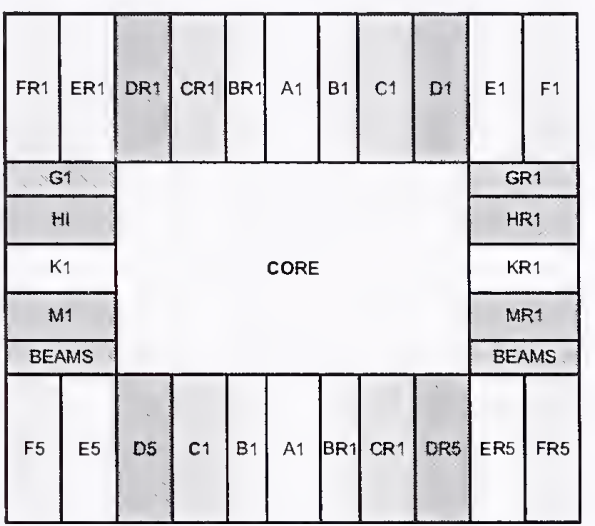

Type 4 - WTC Beam/Truss Sky Lobby Floor Panel Plan

Towers A \& B Floor: 44

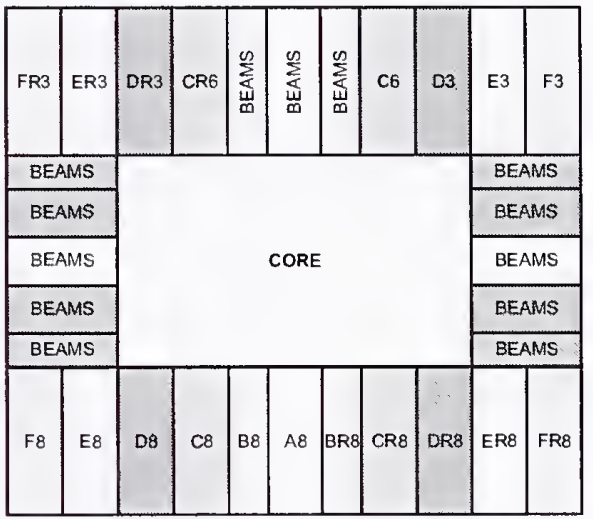

Figure G-1. Floor construction types 1 through 4 . 


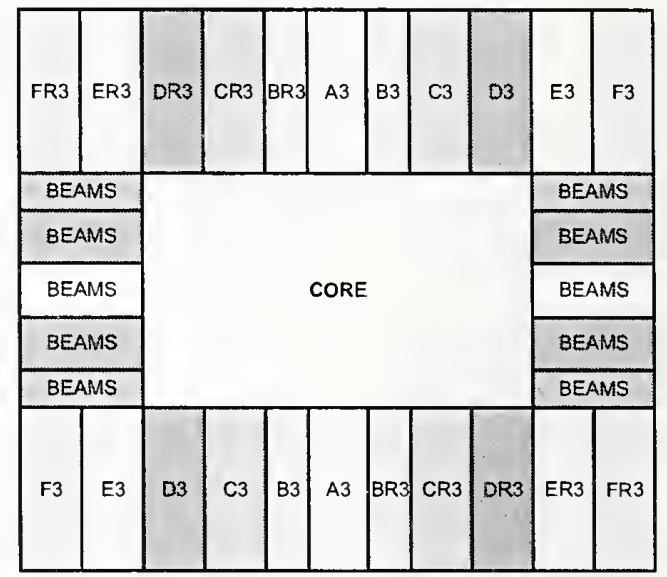

Iype 6. WTC Non-Typlcal Truss Floor Panel Plan Tower A Floor: 67

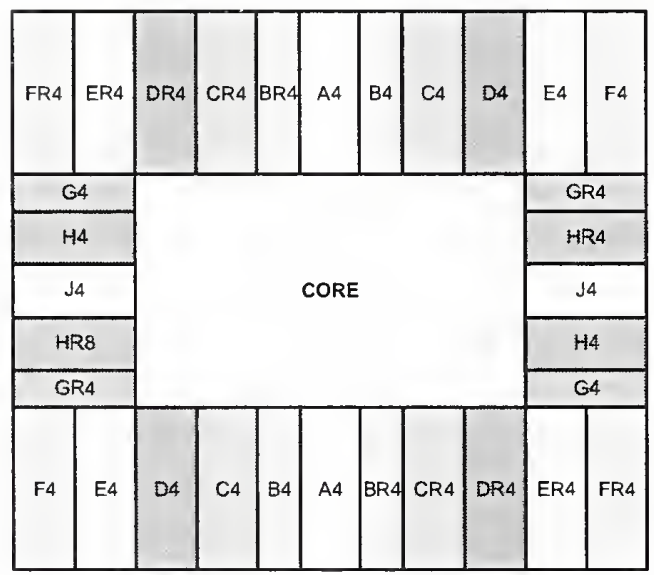

Iype 8. WTC Beam/Truss Upper Escatator Floor Panel Plan

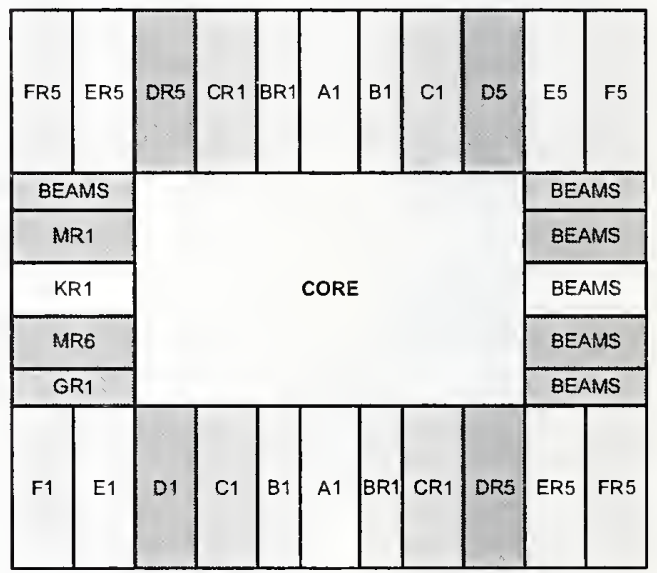

Figure G-2. Floor construction types 5 through 8. 
Iype 9-WTC Beam Floor Above MER Floor Panel Plan Note: Same as Type 3, with opposite orientation.

Towers A \& B Floors: 80 - 83

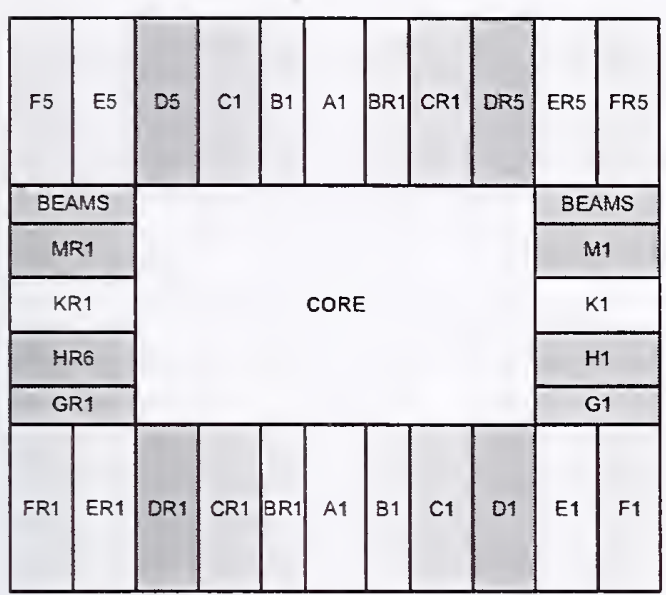

Iype 10-WTC Reinforced Type 1 Floor Panel Plan Tower A Floor: 106

Note: Same panel plan as typical fioor (Type 1) but with renforced trusses.

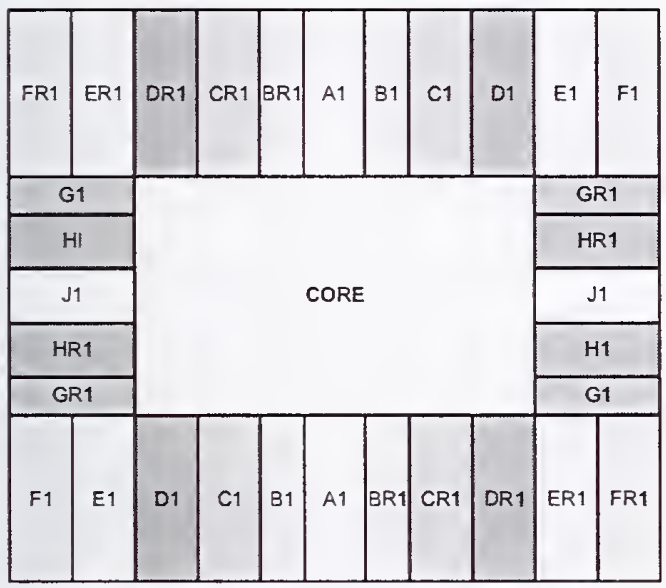

Type 11 - WTC Heavy Angle Truss Floor Panel Plan

Towers B Floors: 10-13

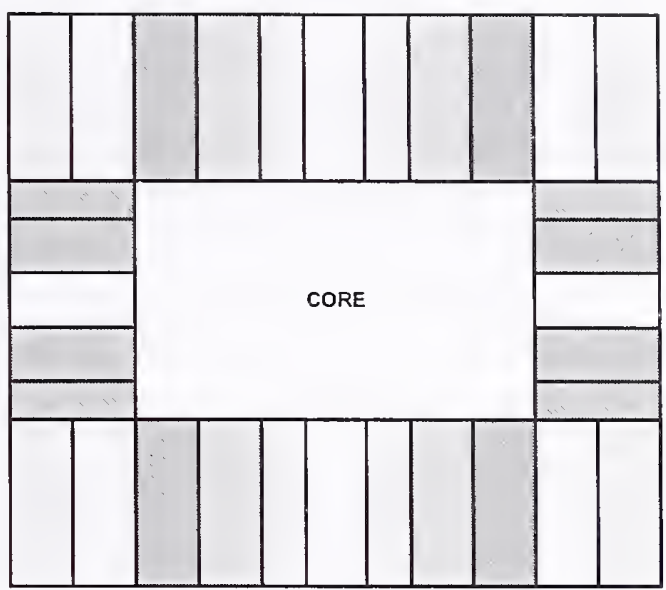

Figure G-3. Floor construction types 9 through 11 . 
Iype 12. WTC Beam Framed Floor Floor Plan

Towers A \& B MER Floors: 7,41,75,108 Towers A \& B Near MER Floors: $9,43,77,107,110$, Roof

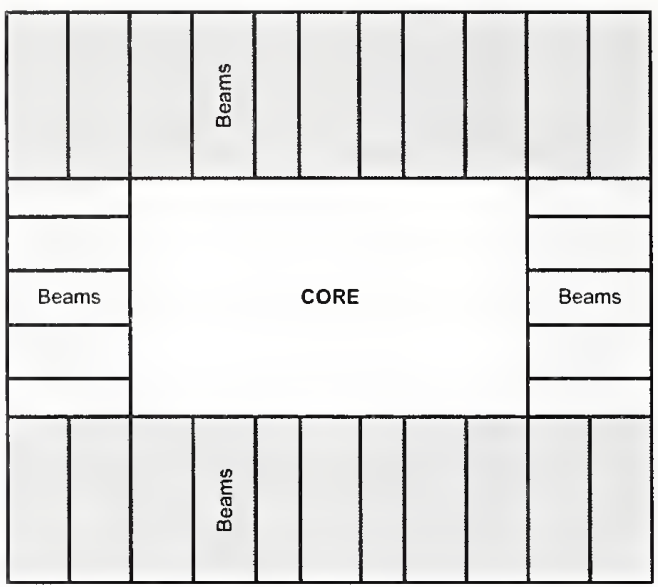

Type 13-WTC MER Mezz Floor Plan

Towers A \& B Floors: 8, 42,76, 109

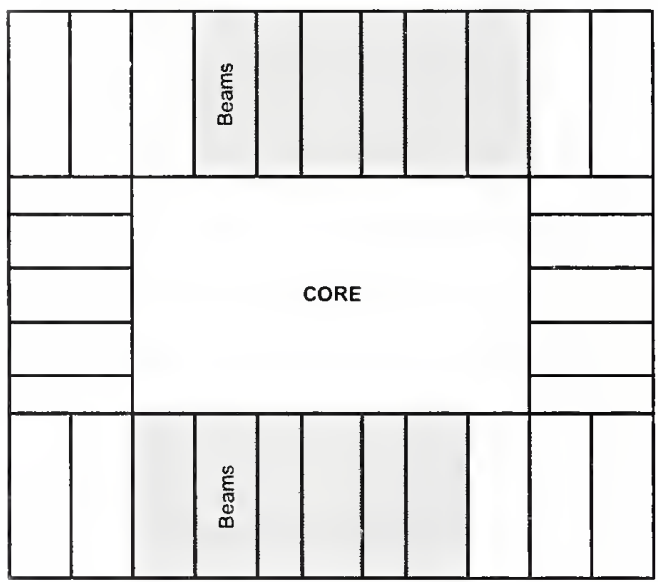

Type 14 - WTC Short Beam Framed Floor Floar Plan

Towers A \& B Floors: Conc, B1,B2,B3,B4,B5

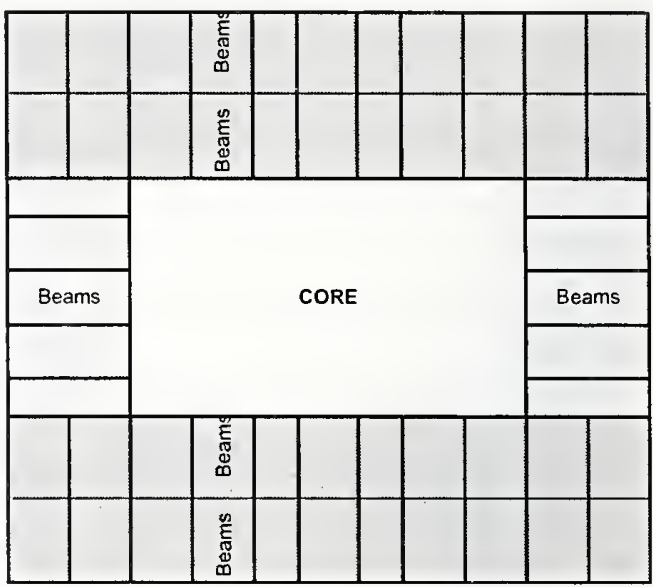

Iype 15- WTC Lobby Floor Plan

Towers A \& B Floors: 2

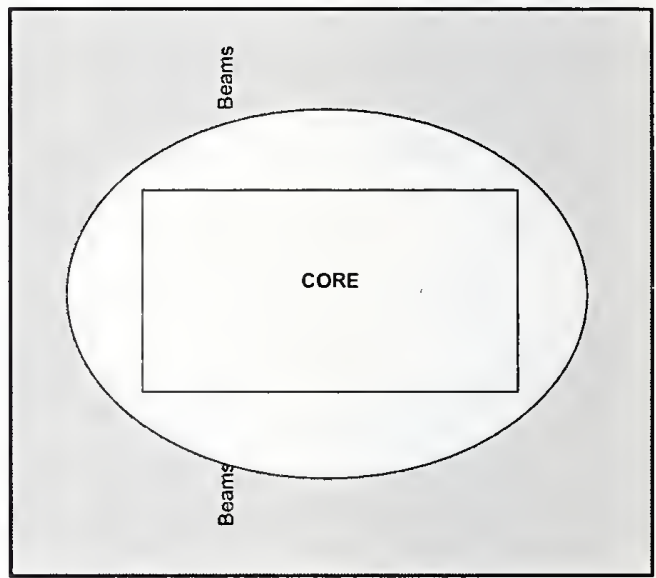

Figure G-4. Floor construction types 12 through 15. 

